\title{
Differential cognitive development : a neuropsychological approach
}

Citation for published version (APA):

Wassenberg, R. (2007). Differential cognitive development : a neuropsychological approach. [Doctoral Thesis, Maastricht University]. NeuroPsych Publishers. https://doi.org/10.26481/dis.20070706rw

Document status and date:

Published: 01/01/2007

DOI:

10.26481/dis.20070706rw

Document Version:

Publisher's PDF, also known as Version of record

\section{Please check the document version of this publication:}

- A submitted manuscript is the version of the article upon submission and before peer-review. There can be important differences between the submitted version and the official published version of record.

People interested in the research are advised to contact the author for the final version of the publication, or visit the DOI to the publisher's website.

- The final author version and the galley proof are versions of the publication after peer review.

- The final published version features the final layout of the paper including the volume, issue and page numbers.

Link to publication

\footnotetext{
General rights rights.

- You may freely distribute the URL identifying the publication in the public portal. please follow below link for the End User Agreement:

www.umlib.nl/taverne-license

Take down policy

If you believe that this document breaches copyright please contact us at:

repository@maastrichtuniversity.nl

providing details and we will investigate your claim.
}

Copyright and moral rights for the publications made accessible in the public portal are retained by the authors and/or other copyright owners and it is a condition of accessing publications that users recognise and abide by the legal requirements associated with these

- Users may download and print one copy of any publication from the public portal for the purpose of private study or research.

- You may not further distribute the material or use it for any profit-making activity or commercial gain

If the publication is distributed under the terms of Article $25 \mathrm{fa}$ of the Dutch Copyright Act, indicated by the "Taverne" license above, 


\section{DIFFERENTIAL COGNITIVE DEVELOPMENT:}

\section{A NEUROPSYCHOLOGICAL APPROACH}

Neuropsych Publishers Maastricht, the Netherlands 
(c) R. Wassenberg, Riemst/Maastricht, 2007

\author{
Cover design $\quad$ R. Wassenberg and Datawyse BV, Maastricht \\ Production \\ Datawyse BV, Maastricht \\ ISBN \\ 978-90-75579-33-8
}

Neuropsych Publishers is a non-profit organisation, which aims at promoting the science of 'Brain and Behavior' and imporving the application of the products of this science in health care and education. Neuropsych Publishers accomplishes these aims by publishing books, dissertations and other products of scientific activity, by disseminating educational materials and publication of tests, assessment scales and other psychometric instruments in the field of Neuropsychology, Neuropsychiatry and other areas within the domain of Brain and Behavior.

Postal address: $\quad$ Neuropsych Publishers

Department of Psychiatry and Neuropsychology

Maastricht University

P.O. Box 616

6200 MD Maastricht

The Netherlands

www.np.unimaas.nl

Financial support for the publication of this dissertation has been kindly provided by Animo Agribusiness BV and Eli Lilly. 


\section{DIFFERENTIAL COGNITIVE DEVELOPMENT:}

\section{A NEUROPSYCHOLOGICAL APPROACH}

\section{Proefschrift}

ter verkrijging van de graad van doctor aan de Universiteit Maastricht, op gezag van de Rector Magnificus, Prof. mr. G. P. M. F. Mols, volgens het besluit van het College van Decanen, in het openbaar te verdedigen op vrijdag 6 juli 2007 om 16.00 uur

door

Renske Wassenberg 


\section{Promotores}

Prof. dr. J. Jolles

Prof. dr. J. S. H. Vles

\section{Copromotores}

Dr. J. G. M. Hendriksen

Dr. P. P. M. Hurks

\section{Beoordelingscommissie}

Prof. dr. A. P. Aldenkamp (Voorzitter)

Prof. dr. J. M. Bouma (UMC Groningen)

Prof. dr. C. Kemner

Dr. P. Stiers

Prof. dr. H. Swaab-Barneveld (Universiteit Leiden)

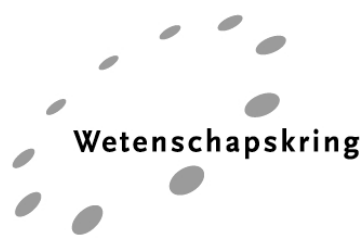

Mondriaan Zorggroep • Vijverdal • RIAGC Maastrich - RGC Westelijke Mijnstreek • RIBW Heuvelland en Maasvalle

Academisch Ziekenhuis Maastricht - Atrium Medisch Centrum

- Universiteit Maastricht • Onderzoeksschool Experimentele Psychopathologic - Onderzoeksschool Hersenen en Gedrag

The research described in this dissertation was performed in the Maastricht Brain and Behaviour Institute, Department of Psychiatry and Neuropsychology, Maastricht University and the University Hospital Maastricht. 
Toutes les grandes personnes ont d'abord été des enfants

(Mais peu d'entre elles s'en souviennent) Antoine de Saint-Exupéry - Le petit prince 



\section{CONTENTS}

$\begin{array}{lll}\text { Chapter } 1 & \text { Introduction } 9\end{array}$

Chapter 2 Relationship between cognitive and motor performance in children aged five to six

Chapter 3 Development of inattention, impulsivity, and processing speed as measured by the d2 Test

Chapter $4 \quad$ Attention in kindergarten and the first grade predicts academic outcome in the sixth grade

Chapter 5 Development of different aspects of sense of time

Chapter $6 \quad$ Complex language comprehension in school aged children

p. 89

Chapter $7 \quad$ Complex language comprehension continues to improve into secondary school

Chapter $8 \quad$ Speed of language comprehension is impaired in children and adolescents with ADHD - combined subtype

Chapter $9 \quad$ Concluding remarks

Summary

p. 161

Samenvatting

p. 169

Dankwoord

p. 177

Curriculum vitae

p. 187

Publications

p. 189 

CHAPTER 1

Introduction 
In the Netherlands, the education system has often been the subject of ongoing debate. Recently, the debate has become even livelier. On a weekly basis, national newspapers address important issues in the field of education. Some of the questions that have been posed include: a) should children's language skills be tested before they start kindergarten so that remedial teaching can be implemented at an early age? (NRC Handelsblad, 30-09-2006, 14-10-2006; Trouw, 24-11-2006); b) should all elementary schools use a standardized test at the end of the sixth grade and, if so, should it be this test or the teacher that determines the type of secondary education the child should enroll in? (NRC Handelsblad, 25a-11-2006; Trouw, 09-02-2006, 10-10-2006); c) should children with developmental disorders be integrated in regular elementary education and, if so, why are many children sitting at home because no school will accept them? (NRC Handelsblad, 28-12-2002, 21/28-10-2006); d) are new methods of learning and teaching a positive development that will lead to more independent and confident adolescents or will new methods generate children that cannot think for themselves because everything can be 'googled'? (NRC Handelsblad, 20/25b-11-2006; Trouw, 31-7-2006). These and similar questions about the practice of education can be summarized in one major question, namely "How can we help children to develop up to their full potential?". This is a complex question as many factors can influence a child's development. We do know that age-related differences in cognitive functioning are influenced by inter-individual variables and factors that can be both child and context related. Child-related inter-individual variables that have been found to influence development include attention (e.g. being inattentive or highly attentive) and sex (e.g. differences between boys and girls) (Baron, 2004). An example of a context-related inter-individual difference is socioeconomic background (e.g. differences between children from low, moderate, or highly educated families) (Kalff et al., 2001a). Given that cognitive development has implications for academic functioning, understanding how normal cognitive development, with all its variability, occurs is imperative. It is also important to know which factors contribute to this development. With this knowledge, we will likely be able to detect cognitive weaknesses earlier and more optimally. We may then be able to reduce these weaknesses using cognitive strengths. Evidently, scientific research that takes these factors into consideration is necessary if we are to find answers to the questions posed by the media. The studies described in this dissertation were conducted in an attempt to contribute to the scientific knowledge base on differential cognitive development and the inter-individual variability related to this aspect of development. Before describing the specific objectives of this dissertation, the provision of some background information on the various topics is in order.

\section{Higher-order brain and cognitive development}

New imaging techniques, such as functional magnetic resonance imaging (fMRI), have made it possible to study, in detail, the development of children's and adolescents' brains. Studies have shown that certain areas of the human brain, especially parts of the prefrontal cortex, continue to develop into late adolescence or early adulthood (Alvarez \& Emory, 2006; Casey, Giedd, \& Thomas, 2000; Castellanos et al., 2002; Crone, 2004; Gogtay et al., 2004; Klingberg, Vaidya, Gabrieli, Moseley, \& Hedehus, 1999; Paus, 2005; Shaw et al., 2006; Sowell et al., 2003; Thatcher, 1991). This prolonged neural development has been explained by referring to maturational processes such as progressive myelination and regressive pruning (De Bellis et al., 2001). In parallel to the prolonged 
differentiation and maturation of the prefrontal cortex, complex cognitive functions also continue to develop into adolescence or even adulthood. Some of these complex cognitive functions are cognitive flexibility, behavioral planning, impulse control, and working memory (V. A. Anderson, Anderson, Northam, Jacobs, \& Catroppa, 2001; Brocki \& Bohlin, 2004; Casey, Tottenham, Liston, \& Durston, 2005; Eslinger, Flaherty-Craig, \& Benton, 2004; Fuster, 2000; Hooper, Luciana, Conklin, \& Yarger, 2004; Luna, Garver, Urban, Lazar, \& Sweeney, 2004; Paus, 2005; Steinberg, 2005). These cognitive processes have been described as being 'executive functions'. Although there are many definitions of this term, most researchers agree that the term 'executive function' is an umbrella term for various self-regulatory processes that are responsible for purposeful, goal-directed behavior (Alvarez \& Emory, 2006; P. Anderson, 2002; Brocki \& Bohlin, 2004; Lehto, Juujarvi, Kooistra, \& Pulkinnen, 2003; Lezak, Howieson, \& Loring, 2004; Odhuba, van den Broek, \& Johns, 2005; Pennington \& Ozonoff, 1996; Zelazo, Craik, \& Booth, 2004). In box 1 , some definitions of executive functioning posed by influential researchers are listed. These definitions differ with respect to the extent to which executive functions are thought to be behavioral functions (Alexander \& Stuss, 2000; Lezak et al., 2004) or cognitive processes (Luria, 1966, 1980; Pennington \& Ozonoff, 1996).

\section{Box 1: Some definitions of executive functioning by influential researchers}

- Luria $(1966,1980)$ defined executive functions as higher order cognitive capabilities necessary for the synthesis of external stimuli, formation of goals and strategies, preparation for action, and use of feedback.

- Pennington and Ozonoff (1996) described several cognitive domains under the term executive functioning, namely set shifting, planning, working memory, contextual memory, inhibition, and fluency.

- Alexander and Stuss (2000) focused on the behavioral problems resulting from frontal brain damage and thus emphasized the social aspects of executive function, including self-awareness, consciousness, and humor.

- Lezak and colleagues (2004) considered executive functions to be non-cognitive functions and therefore placed an emphasis on behavior. They listed four components of executive functions, namely volition, planning, purposive action, and effective performance. Volition is described as intention, motivation, and awareness of oneself psychologically, physically, and in relation to one's surroundings. Planning is defined as looking ahead, developing a conceptual framework, conceiving alternatives, good impulse control, and memory. Purposive action is demonstrated by initiating, maintaining, switching, and stopping behavior. Lastly, effective performance is described as being able to monitor, self-correct, and regulate one-self.

From a child neuropsychological perspective, Peter Anderson's (2002) model is especially informative when executive functioning is concerned because it takes the developmental aspect of cognitive functions into account. According to this model, the principle elements associated with executive functioning are anticipation, goal selection, planning, inhibition of activity, self-regulation, mental flexibility, deployment of attention, and utilization of feedback. This model was used as the theoretical foundation of the studies described in this dissertation. Anderson (2002) based his model on an extensive litera- 
ture review of experimental cognitive studies in children and adolescents. The model conceptualizes executive functioning as four discrete cognitive domains that operate in an integrative manner (see Figure 1).

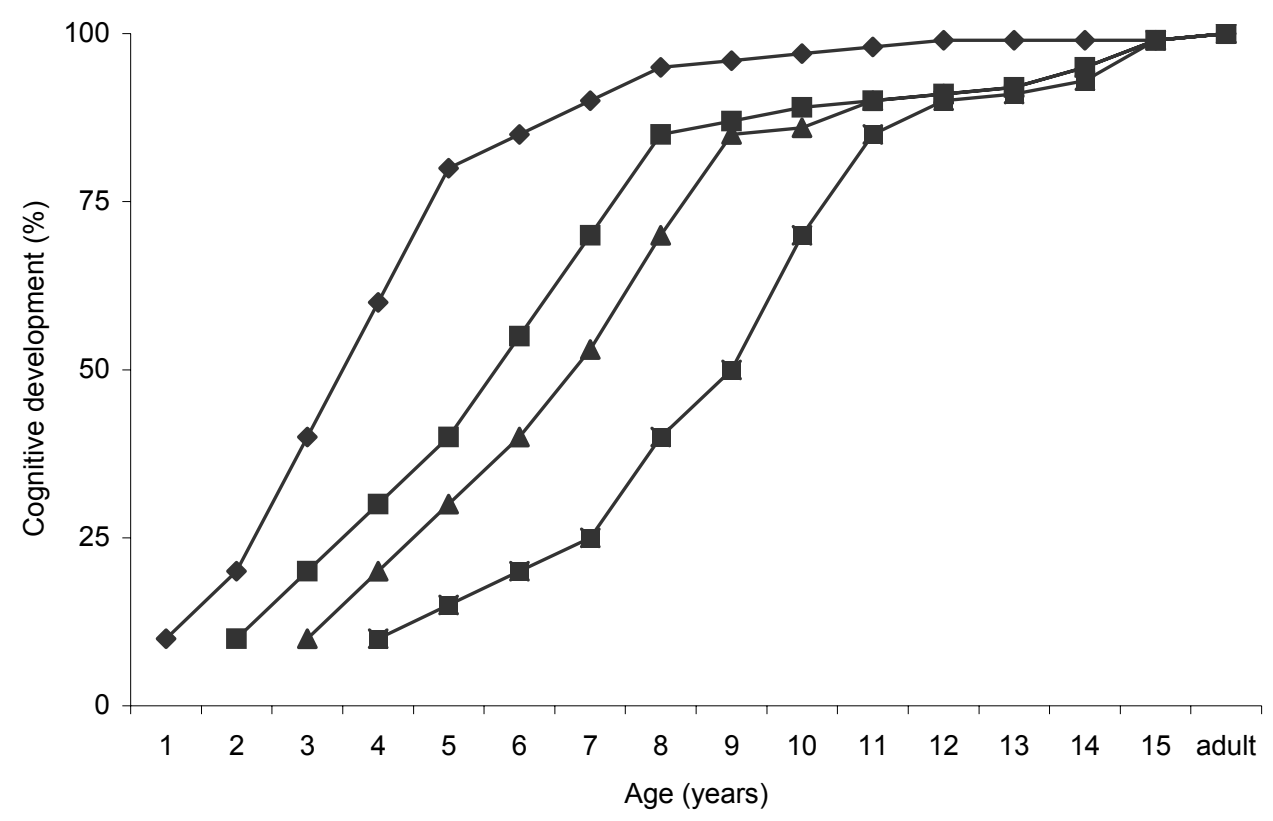

$\neg$ attentional control $\rightarrow$ - information processing $\rightarrow \leftarrow$ cognitive flexibility $\rightarrow$ goal setting

Figure 1: Protracted developmental trajectories of the executive domains Note: By Peter Anderson (2002), Child Neuropsychology, 8, p. 78.

The first domain of Peter Anderson's model (2002), namely attentional control, includes the capacity to a) attend selectively to specific stimuli; b) inhibit prepotent responses; and c) focus attention for an extended period of time. Deficits in this domain manifest as impulsive behavior, failure to complete tasks, failure to correct errors, and inappropriate responses. Anderson hypothesized this domain to reach full maturity somewhere between the ages of 9 and 11. The second domain, information processing, refers to the fluency, efficiency and speed with which one can respond. Difficulties with this domain include reduced output, delayed responses, hesitancy, and slowed reaction times. Performance in this domain is thought to improve until approximately the age of 15. The third domain, cognitive flexibility, includes shifting between response sets, learning from mistakes, devising alternative strategies, working memory, and dividing attention. Impairments in this domain include notably rigid and perseverative behavior and a failure to adapt to new demands. Cognitive flexibility continues to improve until midadolescence (approximately age 15). The fourth and final domain, goal setting, is described as the ability to develop new initiatives and concepts, plan actions in advance, and develop new strategies to approach tasks. Deficits in this domain are reflected as in 
poor problem solving abilities, disorganization, and reliance on previously learned strategies. This domain is thought to improve slower than the other domains. Full development is expected to occur by the age of 15. In summary, Anderson (2002) concluded that simple aspects of cognitive functioning mature before more abstract aspects.

In conclusion, higher-order processes in cognition display a differential development that continues into adolescence. This conclusion corresponds with results from fMRI studies demonstrating that prefrontal brain structures are not fully mature until late adolescence or even early adulthood. However, there is a significant amount of variability in the cognitive development of children (Baron, 2004) that may potentially be explained by inter-individual differences. We focus on the influence of three important inter-individual variables in the following sections.

\section{Inter-individual differences in development}

\section{Attention}

Attention is a higher-order cognitive function that is inherent to all other cognitive and academic processes (Baron, 2004; Cooley \& Morris, 1990; Tannock, 2003). It is not a unitary function as it involves various processes such as arousal, orientation, concentration, and vigilance (Van Zomeren \& Brouwer, 1994). Sub-domains of attention that are currently distinguished in clinical practice include selective attention, sustained attention, attention switching, and divided attention (Baron, 2004). Attention is necessary to select incoming sensory information, encode that information in memory, retain it and then manipulate that information into working memory. Additionally, attention is needed to successfully execute goal-directed behavior (Smith \& Jonides, 1999). Evidently, attention is necessary for all other cogntive processes. Without attention, a child cannot learn (Baron, 2004). According to Peter Anderson's (2002) executive functioning model, attentional control is the first domain to mature. Consequently, the intact functional of this domain is thought to significantly influence the functioning of the other three executive domains. Therefore, when differential cognitive development is investigated, it is important to evaluate a child's basic attention functions.

Attentional functioning in children can be viewed as a continuum that ranges from normal attention to clinical attention deficits, with sub-clinical attention deficits in between (Baron, 2004). Children on the extreme inattentive end of the continuum are thought to suffer from a pathological process. When certain conditions are met, the diagnosis of Attention Deficit Hyperactivity Disorder (ADHD) is made (American Psychiatric Association, 1994). This is a serious developmental disorder that occurs in three to five percent of all children, whereby boys are affected more often than girls (American Academy of Pediatrics, 2000; Kroes et al., 2001). Besides inattention, children with ADHD can suffer from impulsivity and hyperactivity. They can also have comorbid problems, such as learning disorders, disruptive behavior disorders, and internalizing disorders (Biederman, 2005; Crawford, Kaplan, \& Dewey, 2006). These deficits interfere with social, behavioral, academic, and cognitive development which underscores the need for adequate treatment. Recent studies have indicated that children with ADHD generally have smaller brain volumes than age-matched and sex-matched control children, especially with respect to the prefrontal areas and the caudate nucleus (Castellanos et al., 2002; Krain \& Castellanos, 2006; Kroes et al., 2001; Mostofsky, Cooper, Kates, Denckla, \& Kaufmann, 2002; Russell, 2002). Based on this information, it is not surprising that children with ADHD have difficulties with executive functioning (Willcutt, Doyle, Nigg, Faraone, \& Pen- 
nington, 2005). Although several neuropsychological models attempt to explain these difficulties experienced by children with ADHD, to date, there is no consensus on what the core problem is (Barkley, 1997; Pennington \& Ozonoff, 1996; Quay, 1997; Sergeant, Geurts, Huijbregts, Scheres, \& Oosterlaan, 2003; Sonuga-Barke, Dalen, \& Remington, 2003). It remains unclear whether the cognitive deficits of children with ADHD are permanent or whether ADHD is a developmental delay that is equalized at a later age (Barkley, 1997; Kipp, 2005).

In summary, attentional functioning can be viewed as a continuum. The influence of attention performance and attention deficits on cognitive development is not yet understood. The studies described in this dissertation aimed to increase our insight on this issue.

\section{Parental level of education}

A child's development is affected strongly by the family environment he or she is reared. For example, growing up in a single-parent home or living in a deprived neighborhood can significantly impact on the mental health of the children (Kalff et al., 2001a; Kalff et al., 2001b). This kind of background information is often summarized by the term socioeconomic status (SES). SES proxies can include the family income, parental level of education, and the parent's occupational status (Bradley \& Corwyn, 2002). With respect to cognition, parental level of education, as a proxy for SES, has been found to be an important factor that is associated with the academic performance as well as the general level of cognition in children (Greenberg, Lengua, Coie, \& Pinderhughes, 1999; Hoff, 2003; Huda, Grantham-McGregor, Rahman, \& Tomkins, 1999; Jackson, 2003; Landry, Smith, \& Swank, 2002; Roberts, Bornstein, Slater, \& Barrett, 1999). Explanations for the relationship between SES and child cognition include genetics, differences in access to material and social resources, and reactions to stressful conditions (Bradley \& Corwyn, 2002; Turkheimer, Haley, Waldron, D'Onofrio, \& Gottesman, 2003). Surprisingly, little is known about the relationship between SES and complex cognitive development.

In short, SES appears to be an important factor to consider when studying cognitive development in children. Therefore, the studies described in this dissertation either controlled for the influence of parental level of education, as a proxy of SES, on cognitive development or investigated this effect directly.

\section{Sex}

Another factor that should be considered in studies concerned with cognitive development is the child's sex. Boys and girls do not only differ physically, they also differ in their brain development. For example, a cross-sectional study indicated significant sex by age interactions for cerebral grey and white matter volumes and corpus callosal areas. Boys showed more prominent age-related grey matter volume decreases and white matter volume and corpus callosal area increases than girls (De Bellis et al., 2001; Overman, 2004). In addition, girls generally reach peak grey matter thickness one to two years earlier than boys (Giedd et al., 2006). Furthermore, 6- to 15-year-old boys tend to have a larger left inferior frontal gyrus than girls of the same age, even after correcting for total cerebral volume (Blanton et al., 2004). With respect to cognitive development, differences between boys and girls can be observed in specific areas. For example, girls tend to perform better on verbal tasks whereas boys tend to perform a better on spatial tasks (Dodd, Holm, Hua, \& Crosbie, 2003; Holm, Greaker, \& Stromberg, 2002; Lowe, Mayfield, 
\& Reynolds, 2003; Overman, 2004; Roulstone, Loader, Northstone, \& Beveridge, 2002; Tse, Kwong, Chan, \& Hui, 2002). However, these differences are not consistently found (P. Anderson, 2002). Academic differences between boys and girls also seem to be smaller than expected. Boys' literacy skills are on average poorer than those of girls, but this effect fades when the quality of teaching and learning provision is taken into account (Rowe, 2000).

In conclusion, the extent to which sex differences impact cognitive development is, at present, still unclear. Because of their potential influence, the effect of sex differences was either controlled for or investigated directly in the studies described in this dissertation.

\section{Objectives and outline of the dissertation}

In summary, cognitive development is a complex process characterized by variability that continues into late adolescence or even early adulthood. The specific pattern by which many cognitive functions develop rmains unclear. Additionally, the extent to which interindividual differences impact this development is also unclear. Therefore, the central goal of this dissertation was to extend Peter Anderson's (2002) model by describing agerelated improvement on several complex cognitive functions in relation to inter-individual differences. Although many cognitive functions can be studied, the complex cognitive functions described in this dissertation were chosen because of their importance for children's daily functioning. These functions included subcomponents of sense of time, complex language comprehension, and selective attention. The relationship between general cognitive and motor development in young children was also studied. This relationship was anticipated because both complex cognitive and motor performance continue to mature into early adulthood (Diamond, 2000) and because growth spurts in both domains appear to occur at similar ages (P. Anderson, 2002; V. A. Anderson et al., 2001; Ferrel-Chapus, Hay, Olivier, Bard, \& Fleury, 2002).

In the context of this central goal, several large-scale cross-sectional studies (see chapters 2, 3, 5, 6, 7, and 8) and one longitudinal study (see chapter 4) were conducted. Each of these studies focused on a distinct cognitive function. With respect to the study samples, the number of participants varied from several tens to several hundreds of children. The age range in the studies conducted was 5 to 16 years. The large sample populations and broad age-range made it possible to investigate inter-individual differences in attention, sex, and parental level of education. A short overview of the chapters included in this dissertation is provided below.

Chapter 2: $\quad$ Relationship between cognitive and motor performance in children aged five to six

This chapter describes a cross-sectional study in which the relationship between cognitive and motor performance in young children was investigated. This study examined the relationship between overall cognitive and motor performance was studied and more specific relationships between quality and quantity of motor performance and several domains of cognition, e.g. language, visuoperception, construction, attention, and executive functioning. The large sample tested $(\mathrm{N}=378)$ included children with externalizing behavior problems, internalizing behavior problems, and children without behavior problems, as deter- 
Chapter 3: Development of inattention, impulsivity, and processing speed as measured by the $\mathrm{d} 2$ Test

This chapter describes a large cross-sectional study that investigated the development of three subcomponents of selective attention. The subcomponents studied were processing speed, inattention, and impulsivity. Selective attention was measured using the d2 Test of attention (Brickenkamp \& Zillmer, 1998). Participants included 451 school aged children attending the second through sixth grade of regular elementary schools. Inter-individual differences (sex, behavior ratings of attention problems, verbal ability, and parental level of education) in the development of selective attention were studied as well.

Chapter 4: Attention in kindergarten and the first grade predicts academic outcome in the sixth grade.

Children who succeed in school tend to also succeed in other aspects of life (Durlak, 2001). This chapter describes a longitudinal study that investigated the predictive value of attention in kindergarten and the first grade for academic outcome in the sixth grade. Attention was measured using tests and behavioral ratings of attention problems. Several aspects of academic outcome were investigated, namely total academic performance, language, mathematics, study skills, and world orientation. Inter-individual differences, such as sex and parental level of education, were controlled for in the analyses of academic outcome.

\section{Chapter 5: Development of different aspects of sense of time}

This chapter describes a large cross-sectional study that explored the development of sense of time in school aged children. A questionnaire that aimed to measure different aspects of sense of time was developed and tested in a large group of children attending the second through the sixth grade $(\mathrm{N}=454)$. A control group of adults $(\mathrm{N}=248)$ was also used. Inter-individual differences in the development of sense of time, namely sex and parental level of education, were studied as well.

\section{Chapter 6: $\quad$ Complex language comprehension in school aged children}

This chapter describes a cross-sectional study that investigated complex language comprehension in school aged children. The aim of this study was to determine whether comprehension of logical grammatical structures is fully developed by the end of elementary school in a sample of children from high SES backgrounds. An example of the sentences studied is: "Who is fairest if Olga is fairer than Kate, but darker than Sonia?". The sample was comprised of 83 children assigned to 
one of three age-groups, namely children attending kindergarten and the first grade, children attending the second or third grade, and children attending the fourth, fifth or sixth grade. Language comprehension was measured according to the neuropsychological procedure proposed by Luria. Because of the relatively small number of participants, inter-individual differences were not investigated in this chapter.

Chapter 7: Complex language comprehension continues to improve into secondary school

As a continuation of the study described in chapter 6 , this chapter describes a second cross-sectional study on the development of complex language comprehension. Both accuracy and speed of language comprehension were investigated. The sample included 361 children aged five to fifteen. Complex language comprehension was measured using the neuropsychological procedure proposed by Luria, as described in chapter 6, and an adapted version of the Token Test. Inter-individual differences in the development of complex language comprehension, namley sex and parental level of education, were studied as well.

Chapter 8: $\quad$ Speed of language comprehension is impaired in children and adolescents with ADHD - combined subtype

This chapter describes a cross-sectional study in which complex language comprehension in was investigated in children and adolescents with ADHD. To determine whether possible language problems in persons with ADHD would be transient, both a child $(\mathrm{N}=15)$ and an adolescent $(N=15)$ ADHD group were included. Accuracy and speed of language comprehension were investigated using the same instruments described in chapter 7. Inter-individual differences in complex language comprehension were controlled for by matching children and adolescents with ADHD to participants from a control group for age, sex, and parental level of education.

\section{Chapter 9: $\quad$ Concluding remarks.}

In this chapter, the findings of the studies are discussed in the context of the central goal of the dissertation. In addition, theoretical implications as well as recommendations for clinical practice and education are discussed. 


\section{References}

Achenbach, T. M. (1991). Manual for the Child Behavior Checklist/4-18 and 1991 Profile. Burlington: University of Vermont, Department of Psychiatry.

Alexander, M. P., \& Stuss, D. T. (2000). Disorders of frontal lobe functioning. Seminars in Neurology, 20, 427-437.

American Academy of Pediatrics (2000). Clinical practice guideline: diagnosis and evaluation of the child with attention-deficit/hyperactivity disorder. Pediatrics, 105, 1158-1170.

American Psychiatric Association. (1994). Diagnostic and statistical manual of mental disorders (4th ed.). Washington, DC: American Psychiatric Association.

Alvarez, J. A., \& Emory, E. (2006). Executive function and the frontal lobes: a meta-analytic review. Neuropsychology Review, 16, 17-42.

Anderson, P. (2002). Assessment and development of executive function (EF) during childhood. Child Neuropsychology, 8, 71-82.

Anderson, V. A., Anderson, P., Northam, E., Jacobs, R., \& Catroppa, C. (2001). Development of executive functions through late childhood and adolescence in an Australian sample. Developmental Neuropsychology, 20, 385-406.

Barkley, R. A. (1997). Behavioral inhibition, sustained attention, and executive functions: constructing a unifying theory of ADHD. Psychological Bulletin, 121, 65-94.

Baron, I. S. (2004). Neuropsychological evaluation of the child. Oxford: University Press.

Biederman, J. (2005). Attention-deficit/hyperactivity disorder: a selective overview. Biological Psychiatry, 57, 1215-1220.

Blanton, R. E., Levitt, J. G., Peterson, J. R., Fadale, D., Sporty, M. L., Lee, M., To, D., Mormino, E. C., Thompson, P. M. McCracken J. T., \& Toga, A. W. (2004). Gender differences in the left inferior frontal gyrus in normal children. Neuroimage, 22, 626-636.

Bradley, R. H., \& Corwyn, R. F. (2002). Socioeconomic status and child development. Annual Review of Psychology, 53, 371-399.

Brickenkamp, R., \& Zillmer, E. (1998). The d2 Test of attention. First US Edition. Göttingen: Hogrefe \& Huber Publishers.

Brocki, K. C., \& Bohlin, G. (2004). Executive functions in children aged 6 to 13: a dimensional and developmental study. Developmental Neuropsychology, 26, 571-593.

Casey, B. J., Giedd, J. N., \& Thomas, K. M. (2000). Structural and functional brain development and its relation to cognitive development. Biological Psychology, 54, 241-257.

Casey, B. J., Tottenham, N., Liston, C., \& Durston, S. (2005). Imaging the developing brain: what have we learned about cognitive development? Trends in Cognitive Science, 9, 104-110.

Castellanos, F. X., Lee, P. P., Sharp, W., Jeffries, N. O., Greenstein, D. K., Clasen, L. S., Blumenthal, J. D., James, R. S., Ebens, C. L., Walter, J. M., Zijdenbos, A., Evans, A. C., Giedd, J. N., \& Rapoport, J. L. (2002). Developmental trajectories of brain volume abnormalities in children and adolescents with attention-deficit/hyperactivity disorder. Journal of the American Medical Association, 288, 1740-1748.

Cooley, E. L., \& Morris, R. D. (1990). Attention in children: A neuropsychologically based model for assessment. Developmental Neuropsychology, 6, 239-274.

Crawford, S. G., Kaplan, B. J., \& Dewey, D. (2006). Effects of coexisting disorders on cognition and behavior in children with ADHD. Journal of Attention Disorders, 10, 192-199.

Crone, E. (2004). Het brein in ontwikkeling: consequenties voor zelfregulatie [Brain in development: consequences for self regulation]. Neuropraxis, 5, 131-137.

De Bellis, M. D., Keshevan, M. S., Beers, S. R., Hall, J., Frustaci, K., Maselehdan, A., Noll, J. \& Boring, A. M. (2001). Sex differences in brain maturation during childhood and adolescence. Cerebral Cortex, 11, 552-557.

Diamond, A. (2000). Close interrelation of motor development and cognitive development and of the cerebellum and prefrontal cortex. Child Development, 71, 44-56.

Dodd, B., Holm, A., Hua, Z., \& Crosbie, S. (2003). Phonological development: a normative study of British English-speaking children. Clinical Linguistics and Phonetics, 17, 617-643. 
Durlak, J. (2001). School problems in children. In: M. C. Roberts (Ed.), Handbook of clinical child psychology (3rd ed.). New York: John Wiley \& Sons, Inc.

Eslinger, P. J., Flaherty-Craig, C. V., \& Benton, A. L. (2004). Developmental outcomes after early prefrontal cortex damage. Brain and Cognition, 55, 84-103.

Ferrel-Chapus, C., Hay, L., Olivier, I., Bard, C., \& Fleury, M. (2002). Visuomanual coordination in childhood: adaptation to visual distortion. Experimental Brain Research, 144, 506-517.

Fuster, J. M. (2000). Executive frontal functions. Experimental Brain Research, 133, 66-70.

Geurts, S. (1997). Motoriek. In: B. Deelman, P. Eling, E. de Haan, A. Jennekens-Schinkel \& E. van Zomeren (Eds.), Klinische neuropsychologie. Amsterdam: Uitgeverij Boom.

Giedd, J. N., Clasen, L. S., Lenroot, R., Greenstein, D., Wallace, G. L., Ordaz, S., Molloy, E. A., Blumenthal, J. D., Tossell, J. W, Stayer, C., Samango-Sprouse, C. A., Dinggang, S., Davatzikos, C., Merke, D., \& Chrousos, G. P. (2006). Puberty-related influences on brain development. Molecular and Cellular Endocrinology, 254-255, 154-162.

Gogtay, N., Giedd, J. N., Lusk, L., Hayaski, K. M., Greenstein, D., Vaituzis, A. C., Nugent, T. F. 3rd, Herman, D. H., Clasen, L. S., Toga, A. W., Rapoport, J. L., \& Thompson, P. M. (2004). Dynamic mapping of human cortical development during childhood through early adulthood. Proceedings of the National Academy of the Sciences, 101, 8174-8179.

Greenberg, M. T., Lengua, L. J., Coie, J. D., \& Pinderhughes, E. E. (1999). Predicting developmental outcomes at school entry using a multiple-risk model: four American communities. The Conduct Problems Prevention Research Group. Developmental Psychology, 35, 403-417.

Hoff, E. (2003). The specificity of environmental influence: socioeconomic status affects early vocabulary development via maternal speech. Child Development, 74, 1368-1378.

Holm, O., Greaker, E., \& Stromberg, A. (2002). Experiences of longing in Norwegian and Swedish 4- and 5-year-old children. Journal of Psychology, 136, 608-612.

Hooper, C. J., Luciana, M., Conklin, H. M., \& Yarger, R. S. (2004). Adolescents' performance on the lowa Gambling Task: implications for the development of decision making and ventromedial prefrontal cortex. Developmental Psychology, 40, 1148-1158.

Huda, S. N., Grantham-McGregor, S. M., Rahman, K. M., \& Tomkins, A. (1999). Biochemical hypothyroidism secondary to iodine deficiency is associated with poor school achievement and cognition in Bangladeshi children. Journal of Nutrition, 129, 980-987.

Jackson, A. P. (2003). The effects of family and neighborhood characteristics on the behavioral and cognitive development of poor Black children: a longitudinal study. American Journal of Community Psychology, 32, 175-186.

Kalff, A. C., Kroes, M., Vles, J. S. H., Bosma, H., Feron, F. J. M., Hendriksen, J. G. M., Steyaert, J., van Zeben, T. M. C. B., Crolla, I. F. A. M., \& Jolles, J. (2001a). Factors affecting the relation between parental education as well as occupation and problem behavior in Dutch 5- to 6- yearold children. Social Psychiatry and Psychiatric Epidemiology, 36, 324-331.

Kalff, A. C., Kroes, M., Vles, J. S. H., Hendriksen, J. G. M., Feron, F. J. M., Steyaert, J., van Zeben, T. M. C. B., Jolles, J., \& van Os, J. (2001b). Neighborhood-level and individual-level SES effects on child problem behavior: a multilevel analysis. Journal of Epidemiology and Community Health, 55, 246-250.

Kipp, K. (2005). A developmental perspective on the measurement of cognitive deficits in attentiondeficit/hyperactivity disorder. Biological Psychiatry, 57, 1256-1260.

Klingberg, T., Vaidya, C. J., Gabrieli, J. D., Moseley, M. E., \& Hedehus, M. (1999). Myelination and organization of the frontal white matter in children: a diffusion tensor MRI study. NeuroReport, 10, 2817-2821.

Krain, A. L., \& Castellanos, F. X. (2006). Brain development and ADHD. Clinical Psychology Review, 26, 433-444.

Kroes, M., Kalff, A. C., Kessels, A. G., Steyaert, J., Feron, F. J., van Someren, A. J., Hurks, P. P., Hendriksen, J. G., van Zeben, T. M., Rozendaal, N., Crolla, I. F., Troost, J., Jolles, J., \& Vles, J. S. (2001). Child psychiatric diagnoses in a population of Dutch schoolchildren aged 6 to 8 years. Journal of the American Academy of Child and Adolescent Psychiatry, 40, 1401-1409.

Landry, S. H., Smith, K. E., \& Swank, P. R. (2002). Environmental effects on language development in normal and high-risk child populations. Seminars in Pediatric Neurology, 9, 192-200. 
Lehto, J. E., Juujarvi, P., Kooistra, L., \& Pulkinnen, L. (2003). Dimensions of executive functioning: Evidence from children. British Journal of Developmental Psychology, 21, 59-80.

Lezak, M. D., Howieson, D. B., \& Loring, D. W. (2004). Neuropsychological assessment (4th ed.). New York: Oxford University press.

Lowe, P. A., Mayfield, J. W., \& Reynolds, C. R. (2003). Gender differences in memory test performance among children and adolescents. Archives of Clinical Neuropsychology, 18, 865-878.

Luna, B., Garver, K. E., Urban, T. A., Lazar, N. A., \& Sweeney, J. A. (2004). Maturation of cognitive processes from late childhood to adulthood. Child Development, 75, 1357-1372.

Luria, A. R. (1966). Higher cortical functions in man. New York: Basic Books

Luria, A. R. (1980). Higher cortical functions in man. New York: Basic Books.

Mostofsky, S. H., Cooper, K. L., Kates, W. R., Denckla, M. B., \& Kaufmann, W. E. (2002). Smaller prefrontal and premotor volumes in boys with attention-deficit/hyperactivitydisorder. Biological Psychiatry, 52, 785-794.

Odhuba, R. A., van den Broek, M. D., \& Johns, L. C. (2005). Ecological validity of measures of executive functioning. British Journal of Clinical Psychology, 44, 269-278.

Overman, W. H. (2004). Sex differences in early childhood, adolescence, and adulthood on cognitive tasks that rely on orbital prefrontal cortex. Brain and Cognition, 55, 134-147.

Paus, T. (2005). Mapping brain maturation and cognitive development during adolescence. Trends in Cognitive Science, 9, 60-68.

Pennington, B. F., \& Ozonoff, S. (1996). Executive functions and developmental psychopathology. Journal of Child Psychology and Psychiatry, 37, 51-87.

Quay, H. C. (1997). Inhibition and attention deficit hyperactivity disorder. Journal of Abnormal Child Psychology, 25, 7-13.

Roberts, E., Bornstein, M. H., Slater, A. M., \& Barrett, J. (1999). Early cognitive development and parental education. Infant and Child Development, 8, 49-62.

Roulstone, S., Loader, S., Northstone, K., \& Beveridge, M. (2002). The speech and language of children aged 25 months: Descriptive data from the Avon Longitudinal Study of Parents and Children. Early Child Development and Care, 172, 259-268.

Rowe, K. J. (2000). 'Problems' in the education of boys and exploring 'real' effects from evidencebased research: Useful findings in teaching and learning for boys and girls. Paper presented at the Teaching boys developing fine men conference, Carlton Crest Hotel, Brisbane.

Russell, V. A. (2002). Hypodopaminergic and hypernoradrenergic activity in prefrontal cortex slices of an animal model for attention-deficit hyperactivity disorder--the spontaneously hypertensive rat. Behavioural Brain Research, 130, 191-196.

Sergeant, J. A., Geurts, H., Huijbregts, S., Scheres, A., \& Oosterlaan, J. (2003). The top and the bottom of ADHD: a neuropsychological perspective. Neuroscience and Biobehavioral Review, 27, 583-592.

Shaw, P., Greenstein, D., Lerch, J., Clasen, L., Lenroot, R., Gogtay, N., Evans, A., Rapoport, J., \& Giedd, J. (2006). Intellectual ability and cortical development in children and adolescents. Nature, 440, 676-679.

Smith, E. E., \& Jonides, J. (1999). Storage and executive processes in the frontal lobes. Science, 283, 1657-1661.

Sonuga-Barke, E. J., Dalen, L., \& Remington, B. (2003). Do executive deficits and delay aversion make independent contributions to preschool attention-deficit/hyperactivity disorder symptoms? Journal of the American Academy of Child and Adolescent Psychiatry, 42, 1335-1342.

Sowell, E. R., Peterson, B. S., Thompson, P. M., Welcome, S. E., Henkenius, A. L., \& Toga, A. W. (2003). Mapping cortical change across the human life span. Nature Neuroscience, 6, 309315.

Steinberg, L. (2005). Cognitive and affective development in adolescence. Trends in Cognitive Science, 9, 69-74.

Tannock, R. (2003). Neuropsychology of attention disorders. In: S. J. Segalowitz. \& I. Rapin. (Eds.), Handbook of neuropsychology (2nd ed., pp. 753-784). Amsterdam: Elsevier Science B.V.

Thatcher, R. W. (1991). Maturation of the human frontal lobes: Physiological evidence for staging. Developmental Neuropsychology, 7, 397-419. 
Tse, S. K., Kwong, S. M., Chan, C., \& Hui, L. (2002). Sex differences in syntactic development: evidence from Cantonese-speaking preschoolers in Hong Kong. International Journal of Behavioral Development, 26, 509-517.

Turkheimer, E., Haley, A., Waldron, M., D'Onofrio, B., \& Gottesman, II. (2003). Socioeconomic status modifies heritability of IQ in young children. Psychological Science, 14, 623-628.

Van Zomeren, A. H., \& Brouwer, W. J. (1994). Clinical neuropsychology of attention. New York: Oxford University Press.

Willcutt, E. G., Doyle, A. E., Nigg, J. T., Faraone, S. V., \& Pennington, B. F. (2005). Validity of the executive function theory of attention-deficit/hyperactivity disorder: a meta-analytic review. Biological Psychiatry, 57, 1336-1346.

Zelazo, P. D., Craik, F. I., \& Booth, L. (2004). Executive function across the life span. Acta Psychologica, 115, 167-183.

Dutch newspapers articles

NRC Handelsblad:

28-12-2002. Thuiszitters. Wachtlijst voor toelating tot het speciaal onderwijs groeit [Sitting at home.

Waiting lists for special needs schools are growing]

30-09-2006. Hoe betrouwbaar is het toetsen van een peuter [How reliable is testing toddlers].

14-10-2006. Geef ze een klimrek in plaats van een toets [Give them a climbing frame instead of an exam].

21-10-2006. Meer over de rugzak [More about the 'backpack'].

28-10-2006. Onzichtbaar problem [Invisible problem].

20-11-2006. Het slechte leren [Bad teaching].

25a-11-2006. De scholen de maat; CITO: eindtoets niet bedoeld voor vergelijking scholen [Measuring schools; CITO: final exam not intended to compare schools].

25b-11-2006. Dat eeuwige wachten [Waiting endlessly].

Trouw:

9-02-2006. Inspectie: leder kind toetsen [Inspection: Test every child].

31-07-2006. Alle schoolkinderen hebben straks een eigen programma [Soon all pupils will have an individual schooling program].

10-10-2006. Schooltoets moet verplicht [Schoolexam should be obligatory].

24-11-2006. 'Het stigma is: jij voldoet niet aan de eisen' [The stigma is: You do not measure up]. 



\title{
CHAPTER 2
}

\section{Relationship between cognitive and motor performance in children aged five to six}

\begin{abstract}
The relationship between cognitive and motor performance was studied in a sample of 378 children aged five to six. Half of these children had no behavior problems; the others were selected for externalizing (38\%) or internalizing problems (12\%). Quantitative and qualitative aspects of motor performance were related to several aspects of cognition, after controlling for the influence of attention. No relationship between global aspects of cognitive and motor performance was found. Specific positive relations were found between both aspects of motor performance, visual motor integration and working memory, and between quantitative aspects of motor performance and fluency. These findings reveal interesting parallels between normal cognitive and motor development in children aged five to six that cannot be attributed to attentional processes.
\end{abstract}

Renske Wassenberg, Frans J. M. Feron, Alfons G. H. Kessels, Jos G. M. Hendriksen, Ariane C. Kalff, Marielle Kroes, Petra P. M. Hurks, Miranda Beeren, Jelle Jolles, \& Johan S. H. Vles. Published in Child Development (2005), volume 76, pp. 1092-1103. 
Over the years, there has been a stable interest in the relationship between cognitive and motor performance in children. Most research that has focused on this topic assumed a relationship between global aspects of cognitive behavior to global aspects of motor behavior. However, little experimental evidence exists that supports this assumption. In this study, we investigated both the global relationships and the more specific links between cognitive and motor behavior.

A global to global relationship between cognitive and motor behavior was assumed by Bushnell and Boudreau (1993), who stated that motor development might determine the sequence in which certain perceptual and cognitive abilities unfold. This notion is experimentally supported by the finding that the development of spatial search skills in children is facilitated by locomotion experience; however, this facilitation does not appear to provide any long lasting benefits to children who achieve locomotor milestones early (Kermoian \& Campos, 1988; Lehnung et al., 2003; Yan, Thomas, \& Downing, 1998).

The effect of delayed or deviant motor development early in life has been investigated by a number of researchers. For example, idiopathic toe walking, a motor abnormality without a known cause is considered to be a precursor of developmental language and learning problems (Sala, Shulman, Kennedy, Grant, \& Chu, 1999; Shulman, Sala, Chu, McCaul, \& Sandler, 1997). Also, impaired motor function early in life is a precursor of problems with language acquisition and attention skills later on (Amiel-Tison et al., 1996; Cantell, Smyth, \& Ahonen, 1994; Hadders-Algra \& Groothuis, 1999; Hamilton, 2002). For instance, in a 10-year follow-up study, the academic, social, and emotional problems associated with 'clumsiness' (Losse et al., 1991), later referred to as Developmental Coordination Disorder (American Psychiatric Association, 1994), at age six were still present at the age of sixteen (Losse et al., 1991). In other studies, motor performance at pre-kindergarten age has been found to be related to reading and language achievement in first grade (Solan \& Mozlin, 1986; Wolff, Gunnoe, \& Cohen, 1985).

The discussion on the relationship between global aspects of cognitive and motor performance was started, many centuries ago, by Descartes (1596-1650), who stated that cognitive processes are entirely different from motor processes (Hatfield, 2003). More recently, Piaget argued that cognitive and motor processes cannot be seen as separate entities because cognitive development relies totally on motor functioning (Piaget \& Inhelder, 1966). One of the major criticisms on Piaget's theory of cognitive development is that he took too little consideration of the motor possibilities and impossibilities of the young child (Berger, 1988). Moreover, little experimental evidence exists that supports his assumption of a global-to-global relationship. Churchland $(1986,2002)$ formulated the relationship between cognitive and motor performance more subtly, stating that if we want to understand cognition, we may need to understand its emergence in evolution, and, as a result, we may need to understand its origins in sensorimotor control. In other words, Churchland hypothesized the existence of a continuum of motor and cognitive functions, with lower (sensorimotor) functions (e.g. grasping and visual perception) at the one end, and higher cognitive functions (e.g. planning and regulating of behavior) at the other end (Churchland, 1986).

Neurobiological evidence for specific relationships between cognitive and motor development is derived from recent work in which it was shown that both complex cognitive and motor development continues into early adulthood (Diamond, 2000). Evidence exists that aspects of cognitive performance related to abstraction, behavioral planning, and executive functioning develop between five and ten years (P. Anderson, 2002; V. A. 
Anderson, Anderson, Northam, Jacobs, \& Catroppa, 2001), an age when motor processes, such as movement control and visuomotor coordination develop rapidly (FerrelChapus, Hay, Olivier, Bard, \& Fleury, 2002). Historically, the prefrontal cortex has been thought to be critical for the most complex cognitive abilities, whereas the cerebellum would fulfill this role for motor skills. Conversely, recent research using functional brain imaging techniques showed the cerebellum to be active during new, complex cognitive operations as well (Diamond, 2000). Other structures, such as the basal ganglia and the frontal cortex, and certain neurotransmitters, such as dopamine, are also believed to be involved in particular higher-order aspects of both cognitive and motor performance (Kandel, Schwartz, \& Jessell, 2000; Diamond, 2000; Geurts, 1997).

Interestingly, research focusing on developmental disorders, such as Attention Deficit Hyperactivity Disorder (ADHD), Developmental Coordination Disorder (DCD), and Developmental Apraxia of Speech (DAS), has suggested that cognitive and motor performance are associated. These developmental disorders co-occur with both cognitive and motor function deficits (ADHD: Klimkeit, Sheppard, Lee, \& Bradshaw, 2004; Pitcher, Piek, \& Hay, 2003; DCD: Dewey, Kaplan, Crawford, \& Wilson, 2002; Hamilton, 2002; Mandich, Buckolz, \& Polotajko, 2003; Visser, 2003; DAS: Nijland, 2003). Children who are at risk of dyslexia, because of a family history, often show delayed motor development in the first year of life (Viholainen, Ahonen, Cantell, Lyytinen \& Lyytinen, 2002).

Overall, little experimental evidence exists to support a global-to-global relationship between cognitive and motor behavior. Past research suggests a more specific association between aspects of cognitive and motor performance. However, it is hard to establish whether this relationship is direct, or whether the link is mediated by some other factor. A factor that is known to mediate both cognitive and motor performance is attention (Baron, 2004; Lezak, Howieson, \& Loring, 2004). The study of Lehnung and colleagues (2003), mentioned above, controlled for this by including only children who performed within normal limits on attention tasks. In most studies examining the link between cognitive and motor performance, attention was not controlled for (Yan et al., 1998; Sala et al., 1999). Furthermore, most studies in which the relationship between cognitive and motor performance in children was investigated, were performed with children already at risk of cognitive problems because of their motor problems or vice versa, and attention is often impaired in such groups (Tannock, 2003). Therefore, the aim of this study was to investigate the attention-controlled relationship between cognitive and motor performance in a sample including both normally and sub-normally performing children. The Child Behavior Checklist, a questionnaire that measures general pathology and is completed by parents (CBCL, Achenbach, 1991; translated into Dutch by Verhulst, van der Ende, \& Koot, 1996) was used as a selection criterion.

A large sample of children aged five to six was included to control for the influence of specific tasks and sex. Five- to six-year-olds were chosen because little is known about the development of so-called 'higher' cognitive processes in this age-group. Previous research has focused for the most part either on very young children (Diamond, 1985; Diamond, 2002) or on children aged seven years and older (P. Anderson, 2002; V. A. Anderson et al., 2001; Schonfeld, Shaffer, \& Barmack, 1989). Additionally, it has been suggested that adequate motor performance at the age of five and six is a prerequisite for learning. Inadequate motor performance is thought to be a marker of possible academic problems (Losse et al., 1991). However, the direct link between early motor difficulties and later academic performance has not been explicitly established. 
With respect to the influence of sex on motor performance, it is well known that motor problems generally occur more in boys than in girls (APA, 1994; Dewey et al., 2002). Therefore, it could be expected that the relationship between cognitive and motor performance would be more pronounced in boys than in girls. For this reason, analyses were performed both for the total group and for boys and girls separately.

In our study, several aspects of both cognitive and motor performance were measured. With respect to cognition, we measured aspects of verbal and perceptual abilities, working memory, and executive functioning (as advised by Lezak et al., 2004). Results were analyzed both separately and in combination, as an estimate of general cognitive performance. With respect to motor performance, both quantitative and qualitative aspects were measured (Kroes, 2002; Kroes et al., 2002a; Kroes et al., 2004; Largo et al., 2001; Largo, Fischer, \& Rousson, 2003; Prechtl et al., 1997). The quantitative aspects of movement reflect the acquisition of motor milestones, whereas qualitative aspects capture the acquisition of fundamental movement patterns (Boyce et al., 1995). Children with developmental disorders often display impaired qualitative motor performance, such as deviant gracefulness and lack of precision (Farber \& Njiokiktjien, 1993), while motor milestones are achieved at the appropriate age. Qualitative aspects of movement in particular are considered to reflect the maturity and integrity of the brain (Hadders-Algra \& Groothuis, 1999; Prechtl et al., 1997). Qualitative aspects may, therefore, be more relevant than quantitative aspects in predicting overall developmental cognitive problems. In an earlier study, qualitative but not quantitative aspects of motor performance were found to be related to ADHD (Kroes et al., 2002a). Thus, it was expected that qualitative aspects would be better related to cognitive performance than quantitative aspects. We investigated both aspects of motor performance and how these aspects were associated with cognitive performance.

In sum, this study focused on the attention-controlled relationship between cognitive and motor performance in children aged five to six, while the effect of sex was studied as well. Moreover, cognition was measured with several tests that are analyzed separately and in combination, and the difference between quantitative and qualitative aspects of motor performance was addressed as well.

\section{Method}

\section{Participants and procedure}

This study is part of 'the Study of Attention disorders Maastricht (SAM)', which is a multidisciplinary research program carried out by the Brain and Behaviour Institute, University of Maastricht (Departments of Neuropsychology \& Biological Psychology), the University Hospital of Maastricht (Departments of Neurology, Pediatrics, and Psychiatry \& Neuropsychology), the Youth Health Care (YHC) Division of the Regional Public Health Institute of Maastricht, and the Child Rehabilitation Center Franciscusoord. A prospective four-stage longitudinal research design was used, of which only the first two stages are relevant for this study (for a full description of the SAM-study see Kalff et al., 2002; Kroes et al., 2001).

First stage: In the Netherlands, all children are periodically invited for a health examination by the YHC. About $98 \%$ of parents respond to this invitation. In the school year 1996-1997, all children (as a rule aged five to six) attending the second grade of normal kindergarten in Maastricht, the Netherlands and immediate surroundings $(\mathrm{N}=$ 2290) were invited to participate in the study during the periodic health examination 
performed by the YHC organization. The parents of 1317 children (699 boys and 618 girls, mean age 5.87 years, SD $=.40$ ) decided to participate in the SAM study and filled out the Child Behavior Checklist (CBCL; Achenbach, 1991; translated into Dutch by Verhulst, van der Ende, \& Koot, 1996). Not all parent pairs were Dutch natives; about ten percent were born in a country outside the Netherlands $(\mathrm{N}=141)$. However, it was ensured that all participants (parents and their child) had an adequate command of the Dutch language so they would be able to complete the questionnaires and examinations. Socioeconomic status was as follows: $35.8 \%$ low, $29.4 \%$ middle, $33.9 \%$ high, and $0.9 \%$ missing. Parental level of education was distributed as follows: $36.1 \%$ high (higher vocational education to university), $40.4 \%$ middle (lower general secondary education to preuniversity education), $14.0 \%$ low (primary education to lower vocational education), and $9.4 \%$ missing. Most children lived with both parents (88\%), whereas $10.7 \%$ lived with one parent.

Responders and non-responders were compared by randomly sampling 200 children from both groups. Information concerning non-responders was obtained anonymously from YHC records, which is permitted by law. No significant differences were found with respect to age, sex, and demographic factors and, therefore, the responders can be considered a fair sample of the original population (Kroes et al., 2001).

To select not only normally developing children, but also children at risk of behavior problems, the CBCL score was used. Two groups were created: an Externalizing group $(E)$, which included children with $C B C L$ externalizing-scale scores above the 90th percentile and/or CBCL attention problem scores above the 95th percentile $(\mathrm{N}=173)$, and an Internalizing group (I), which included children with $\mathrm{CBCL}$ internalizing-scale scores above the 90th percentile and who did not fulfil the criteria for group $E(N=59)$. A control group was formed, existing of children who were matched to the children from groups $E$ and I on basis of age ( \pm 3 months), sex, and school area, and whose CBCL total problem scale scores fell within the normal range $(\mathrm{N}=220)$.

Four to nine months later, the 452 selected children were invited to participate in the second stage, which consisted of a neuropsychological evaluation $(N=400$; see for a previous report on this population Kalff et al., 2002) and a semi-quantified evaluation of motor behavior ( $N=438$; Kroes et al., 2004; Vles, Kroes \& Feron, 2004). A total of 378 children (224 boys, 172 girls, mean age 6.18 years $(S D=.45$ ) completed both the motor and the cognitive evaluation. Of these children, 187 fell in the control group (49.5\%), 145 fell in the externalizing group (38.3\%), and 46 fell in the internalizing group (12.2\%).

\section{Instruments}

Cognitive instruments: The neuropsychological test protocol investigated language, visuoperception, construction, attention, and executive functioning, as suggested by Lezak (2004). The protocol included for all cognitive aspects one or more tests suitable for the assessment of children in elementary school with satisfactory reliability and validity. All outcome variables were transformed to standard scores according to age norms.

The Beery Developmental Test of Visual Motor Integration (VMI Beery; Armstrong \& Knopf, 1982; Beery, 1997) was used to measure the integration of visual perceptual and fine motor abilities. In this test, the child is asked to copy 24 increasingly difficult geometric forms and is not allowed to use an eraser. Outcome is the number of correctly copied forms according to both quantitative and qualitative standards. Standard scores range from 1 to $19($ mean $=10, S D=3)$. 
The Picture Vocabulary test of the Revised Amsterdam Child Intelligence Test (RAKIT; Bleichrodt, Drenth, Zaal, \& Resing, 1987; Evers, van Vliet-Mulder, \& Groot, 2000) measures passive vocabulary ability. It closely resembles the Peabody Picture Vocabulary test (Dunn, Dunn, Robertson, \& Eisenberg, 1979), a commonly used instrument to estimate verbal intelligence (Marakovitz \& Campbell, 1998). Also, the Picture Vocabulary test is related to the verbal tasks of the WISC-R: the correlation between the Picture Vocabulary and the WISC-R Vocabulary tests has been established as $r=.30$. In a study investigating the relationship between the RAKIT and the WISC-R, the Picture Vocabulary subtest loaded together with the verbal WISC-R tasks Information, Similarities, Mathematics, Vocabulary and Comprehension on one factor when using a factor analysis (Bleichrodt, Resing, Drenth, \& Zaal, 1987). During the Vocabulary subtest, the child must choose one of four pictures shown that matches the word the psychologist reads aloud. These words increase in complexity. Outcome is the number of correctly chosen pictures. Standard scores range from 1 to 29 (mean $=15, S D=5$ ).

The Verbal Fluency test of the RAKIT (Bleichrodt et al., 1987; Evers et al., 2000) was used to measure the ability to retrieve information from semantic memory as well as verbal organization, as a measure of attention capacity and executive functioning. The child is asked five questions (including concrete and more abstract questions, e.g. 'What can you drink?', 'What can you do on the street?') and must generate as many answers as possible within 1 minute (per question). Outcome is the number of correct answers for all five questions combined. Standard scores range from 1 to 29 (mean =15, SD =5).

The Embedded Figures test of the RAKIT (Bleichrodt et al., 1987; Evers et al., 2000) is a test of perceptual functioning that measures visual analysis, pattern recognition, and matching. Also, selective attention is important for resisting the distracting stimuli. The child is shown a complex picture with intersecting lines and six simple drawings beneath it. The task is to recognize from the simple drawings the one that is completely presented in the complex picture. The drawings increase in complexity. Outcome is the total number of correctly recognized drawings. Standard scores range from 1 to 29 (mean $=15$, $\mathrm{SD}=5)$.

The Gestalt Closure test of the Kaufman Assessment Battery for Children (K-ABC; Kaufman \& Kaufman, 1983) was used to measure perceptual closure. The child is asked to name a series of drawings, which are only partially completed. These drawings increase in complexity. Outcome is the total number of correctly identified drawings. Standard scores range from 1 to 19 (mean $=10, \mathrm{SD}=3$ ).

The Number Recall test and the Word Order test of the K-ABC (Kaufman \& Kaufman, 1983) were used to measure attention span and auditory working memory. The Number Recall test consists of a series of strings of digits that are presented verbally to the child. The child is subsequently asked to repeat these digits in the same order. The digit strings are progressively longer. Outcome is the number of correctly repeated strings. In the more complex Word Order test, which also measures inhibition, the child must point to a sequence of pictures in the same order as the test assistant reads aloud the names of the objects. For children older than 5 years, there is a second, interfering part, in which the child has to name colored dots before pointing out the sequence of pictures. Outcome is the number of correctly pointed sequences over both parts. Standard scores for both tests range from 1 to 19 (mean $=10, S D=3$ ).

The Progressive Figures Test (Reitan \& Wolfson, 1985) is part of the original Halstead-Reitan neuropsychological battery and was used in this study to measure working 
memory, mental control, and attention switching. The child is presented a sheet of small figures within larger figures and is asked to connect each small figure with the identical larger figure using a pencil. Each pair of figures is unique. The small figures within the larger figures point out the sequence of connecting. To do this, the child constantly has to switch between small and larger figures. Outcome is the amount of time the child needs to complete the task successfully.

The Sustained Attention and Focused Attention tasks of the computerized test battery, Amsterdam Neuropsychological Tasks (ANT; De Sonneville, 1999), were used to measure attention. During both tasks, the child is required to respond as rapidly and accurately as possible to visual stimuli presented on a laptop screen. Trials with response times falling outside a predefined valid response window (200-8000 ms poststimulus onset) were automatically replaced by similar trials. The Sustained Attention task is a variant of a continuous performance task. During this task, a house is continuously depicted on the screen. In each of the trials, an animal is randomly placed in one of the three windows. The child is instructed to press the 'yes' key with the preferred hand when the animal is a bee (target signal) and the 'no' key with the non-preferred hand when the animal is a cat or mouse (non-target signals). In total, there are 20 series with 12 trials, each containing 6 targets and 6 non-targets. Visual feedback on error responses is given by a red square that appears in the center of the house. In the Focused Attention task, a fruit basket is continuously depicted on the screen. Each of the 56 trials consists of the simultaneous presentation of four pieces of fruit in the basket. These pieces are aligned on a vertical (top and bottom) and on horizontal axis (left and right). The child is instructed to attend to the vertical axis and to ignore the horizontal axis. Whenever there are cherries on the vertical axis (target signal), the child has to press the 'yes' key. In all other conditions (cherries on the horizontal axis (irrelevant target signal) or no cherries (non-target signals), the child has to press the 'no' key. These three types of signals are randomly presented (28 target signals, 14 irrelevant target signals, and 14 non-target signals). For both ANT tasks, two outcome variables were used, namely mean median of speed (in $\mathrm{ms}$ ) as an index for speed of information processing and the mean within-subject standard deviation of reaction times as measure of speed variability.

Motor performance instrument: The Maastricht Motor Test (MMT: Kroes et al., 2004; Vles et al., 2004) was developed to score the quality and quantity of movement in an objective way in children in the second year of kindergarten (age 5-6 years). The MMT measures motor function in four areas: static balance (14 items), dynamic balance (20 items), ball skills (8 items), and diadochokinesis and manual dexterity (28 items). In the diadochokinesis tasks, the children are shown sequences of movements, such as tapping the hand on the table, and were told to repeat these sequences as fast as they could. Of the total of 70 items, 36 deal with qualitative and 34 with quantitative aspects of motor function. For example, one of the ball skills items requests the child to bounce the ball five times while standing still. The qualitative aspect of this item involves whether the child can maintain balance and catches the ball with both hands in front of the body. The quantitative aspect involves how many times the child is able to bounce the ball. The scores of the four areas are combined in a total score, a quality score and a quantity score. The inter-observer and intra-observer reliability of the MMT total, quality, and quantity scores ranges from .92 to .96 (Kroes et al., 2004). The test re-test reliability of the MMT ranges from .61 to .74 (Kroes et al., 2004), but because motor control and 
visuomanual coordination develop rapidly in children of this age (Ferrel-Chapus et al., 2002), scores are not expected to be constant (Kroes et al., 2004). Validity was calculated by using a Receiver Operating Characteristic Curve with the school doctor's judgment being used as final outcome. Areas under the curve were relatively high: .81 for the quantitative score, .86 for the qualitative score, and .87 for the total score of the MMT (Kroes et al., 2004).

\section{Statistical analyses}

A compound score was calculated as an overall measure of cognitive performance, using the mean of the z-scores of all tests administered, except the Focused and Sustained attention tasks (cf. Van Boxtel et al., 1998; De Groot et al., 2000, 2001). The between this overall measure of cognitive performance and motor performance was investigated by linear regression analyses with the three motor performance measures (total, quality and quantity of motor performance) as independent variables and the overall measure of cognitive performance as dependent variable. Linear regression analysis was also used to investigate the relationship between cognitive performance (dependent variable) and motor performance (independent variable) for each cognitive variable.

Logistic regression analysis was used to investigate the nature of the specific relations between cognitive and motor performance. Compared to the test means, cognitive scores were divided more or less normally, and were trichotomized: 'Cognition below average' (a score of one or more standard deviation(s) below the test mean), 'Cognition average' (a score between one standard deviation below and one above the test mean), and 'Cognition above average' (a score of one or more standard deviation(s) above the test mean). This classification left about $23 \%$ of all participants in each of the 'Cognition below average' groups, about 59\% in each of the 'Cognition average' groups, and about $18 \%$ in each of the 'Cognition above average' groups.

On the other hand, MMT scores were skewed to the left in our sample compared to the test mean, i.e. there were more children who obtained high scores than children with low scores. Therefore, motor scores were dichotomized as follows: Motor below average' (a score of one or more standard deviation(s) below the test mean) and 'Motor average' (score higher than one standard deviation below the test mean). This classification left about $5 \%$ of all participants in the motor below average-groups, and $95 \%$ in the motor average-group. Then separate logistic regression analyses were performed for the 'Cognition below average' versus the 'Cognition average' condition (dependent variable) and the dichotomized motor scores and for the 'Cognition above average' versus the 'Cognition average' condition (dependent variable) and the dichotomized motor scores.

All analyses described above were first executed without statistically controlling for attention. Second, a compound score of the four attention variables was calculated, and this compound score was included in all analyses to control for the influence of attention.

Sex was included in all analyses to control for a possible confounding effect. The significance level was set at .05 . Because the study population was selected on the basis of the CBCL score, the group was not a random sample of the total population. To control for possible sample bias, all analyses were weighted for selection characteristics (sex, age, and rural or city environment), using the 'sampling weight option' of STATA 8 (Statacorp, 2003). The weights were calculated as the inverse of the probability of selection (Kroes et al., 2002b). 


\section{Results}

Linear regression analyses

Pearson's bivariate correlation between the quantity total score and the quality total score of the MMT was calculated to ensure that analysis of the two aspects of motor performance separately was justified. A correlation coefficient of .545 was found ( $p$ $<.001)$.

The estimate of general cognitive performance was found to be significantly related to all three motor performance measures, i.e. total, quality and quantity of motor performance. After we statistically controlled for attention, however, the relationship with quantity of motor performance disappeared (see Table 1). To filter out the influence of those cognitive tasks with a substantial motor component (Visual Motor Integration and Progressive Figures), the estimate of cognitive performance was recalculated without these two measures. The relationship of this new compound score with motor performance did not reach significance, when attention was controlled. This argues against a global relationship between cognitive and motor performance.

Initial analyses using separate linear regression analyses indicated that four aspects of cognitive performance (Visual Motor Integration, Word Order, Embedded Figures and Verbal Fluency) were related to several aspects of motor performance. After statistically controlling for attention, however, only the relationships between all aspects of motor performance and Visual Motor Integration and Word Order remained significant, as well as the relationship between quantity of motor performance and Verbal Fluency (see Table 1).

Table 1: Linear regression analyses, statistically controlled for attention

\begin{tabular}{lllllll}
\hline & \multicolumn{2}{c}{ Total motor score } & \multicolumn{2}{c}{ Quality motor score } & \multicolumn{2}{c}{ Quantity motor score } \\
& coef. $95 \% \mathrm{Cl}$ & coef. & $95 \% \mathrm{Cl}$ & \multicolumn{2}{c}{ coef. $95 \% \mathrm{Cl}$} \\
\hline General estimate $^{1}$ & .01 & $(-.001-.01)$ & .01 & $(-.001-.01)^{*}$ & .01 & $(-.01-.03)$ \\
Visual motor integration $^{2}$ & .05 & $(.03-.07)^{\star * *}$ & .07 & $(.04-.10)^{\star * *}$ & .09 & $(.02-.15)^{\star *}$ \\
Picture vocabulary $^{3}$ & .02 & $(-.03-.06)$ & .02 & $(-.04-.08)$ & .04 & $(-.11-.18)$ \\
Verbal fluency $^{3}$ & .03 & $(-.02-.07)$ & .01 & $(-.05-.08)$ & .16 & $(.03-.28)^{*}$ \\
Embedded figures $^{3}$ & .03 & $(-.02-.08)$ & .06 & $(-.01-.12)$ & .002 & $(-.15-.15)$ \\
Gestalt closure $^{4}$ & .01 & $(-.02-.04)$ & .01 & $(-.03-.05)$ & .03 & $(-.05-.11)$ \\
Word order $^{4}$ & .04 & $(.01-.07)^{\star *}$ & .04 & $(.01-.08)^{*}$ & .10 & $(.01-.19)^{*}$ \\
Number recall $^{4}$ & .002 & $(-.02-.03)$ & .003 & $(-.03-.04)$ & .001 & $(-.08-.08)$ \\
Progressive figures $^{5}$ & .04 & $(-.07-.14)$ & .07 & $(-.07-.21)$ & -.02 & $(-.28-.23)$
\end{tabular}

Note: ${ }^{1}$ The general estimate of cognitive performance was calculated by averaging the $z$-scores of all eight cognitive tests administered. In case of missing variables, the total number was divided by the number of tests administered. Displayed here is the general estimate of cognitive performance without tasks with a motor compoment; ${ }^{2}$ (Beery, 1997); ${ }^{3}$ (Bleichrodt et al., 1987); ${ }^{4}$ (Kaufman \& Kaufman, 1983); ${ }^{5}$ Reitan \& Wolfson, 1985); coef= coefficient; $\mathrm{Cl}=$ confidence interval; ${ }^{*} p<.05$; ** $p$ $<.01 ;{ }^{* *} p<.001$. 


\section{Logistic regression analyses}

Logistic regression analyses, corrected for attention (see Tables $2 \mathrm{~A}$ and $2 \mathrm{~B}$ ), showed that motor performance had a significant effect on three cognitive variables in the cognition below average/ cognition average condition: Visual Motor Integration (quality of motor performance), Verbal Fluency (quantity of motor performance), and Word Order (all three motor performance measures). The odds ratios (OR's) were higher than 1, which implies that the children with a score below average on the motor measure also performed below average on the cognitive measures. In the cognition average/ cognition above average condition, no cognitive variable was significantly associated with motor performance measures, although the relationship between Embedded Figures and quality of motor performance approached significance $(p=.073)$.

Table 2: Logistic regression analyses, statistically controlled for attention

A. Low/average cognitive performance versus low/average motor performance

\begin{tabular}{lllllll}
\hline & \multicolumn{2}{c}{ Total motor score } & \multicolumn{3}{c}{ Quality motor score } & \multicolumn{2}{c}{ Quantity motor score } \\
Dependent: low/average & OR & $95 \% \mathrm{Cl}$ & OR & $95 \% \mathrm{Cl}$ & OR & $95 \% \mathrm{Cl}$ \\
\hline Visual motor integration $^{1}$ & 2.59 & $(.61-11.00)$ & 4.93 & $(1.18-20.60)^{*}$ & .39 & $(.37-9.62)$ \\
Picture vocabulary $^{2}$ & 1.47 & $(.64-3.39)$ & .90 & $(.38-2.15)$ & 1.61 & $(.74-3.47)$ \\
Verbal fluency $^{2}$ & 2.12 & $(.87-5.20)$ & 1.76 & $(.79-3.95)$ & 3.03 & $(1.23-7.49)^{*}$ \\
Embedded figures $^{2}$ & .85 & $(.34-2.15)$ & .67 & $(.26-1.76)$ & 1.45 & $(.62-3.41)$ \\
Gestalt closure $^{3}$ & .85 & $(.34-2.08)$ & .67 & $(.25-1.79)$ & 1.28 & $(.57-2.87)$ \\
Word order $^{3}$ & 2.50 & $(1.05-5.95)^{*}$ & 2.91 & $(1.31-6.45)^{*}$ & 2.27 & $(.90-5.67)$ \\
Number recall $^{3}$ & 1.08 & $(.49-2.35)$ & 1.01 & $(.44-2.30)$ & 1.13 & $(.52-2.44)$ \\
Progressive figures $^{4}$ & 1.46 & $(.50-4.28)$ & .44 & $(.11-1.74)$ & 1.47 & $(.53-4.07)$ \\
\hline
\end{tabular}

B. Average/high cognitive performance versus low/average motor performance

\begin{tabular}{lllllll}
\hline & \multicolumn{2}{c}{ Total motor score } & \multicolumn{3}{c}{ Quality motor score } & \multicolumn{2}{c}{ Quantity motor score } \\
Dependent: high/average & OR & $95 \% \mathrm{Cl}$ & OR & $95 \% \mathrm{Cl}$ & OR & $95 \% \mathrm{Cl}$ \\
\hline Visual motor integration $^{1}$ & .33 & $(.10-1.08)$ & .38 & $(.12-1.21)$ & .37 & $(.13-1.08)$ \\
Picture vocabulary $^{2}$ & .51 & $(.16-1.60)$ & .52 & $(.17-1.56)$ & .37 & $(.11-1.21)$ \\
Verbal fluency $^{2}$ & .52 & $(.12-2.21)$ & .53 & $(.13-2.22)$ & .57 & $(.15-2.13)$ \\
Embedded figures $^{2}$ & .49 & $(.14-1.66)$ & .34 & $(.11-1.10)$ & .64 & $(.16-2.28)$ \\
Gestalt closure $^{3}$ & .34 & $(.12-1.01)$ & .48 & $(.17-1.33)$ & .46 & $(.16-1.34)$ \\
Word order $^{3}$ & .48 & $(.06-3.66)$ & .55 & $(.08-3.70)$ & .74 & $(.20-2.73)$ \\
Number recall $^{3}$ & .56 & $(.09-3.38)$ & 1.38 & $(.34-5.50)$ & .46 & $(.08-2.74)$ \\
Progressive figures $^{4}$ & .58 & $(.25-1.32)$ & .47 & $(.20-1.09)$ & .61 & $(.28-1.32)$ \\
\hline
\end{tabular}

Note: ${ }^{1}$ (Beery, 1997); ${ }^{2}$ (Bleichrodt et al., 1987); ${ }^{3}$ Kaufman \& Kaufman, 1983); ${ }^{4}$ (Reitan \& Wolfson, 1985); OR= odds ratio; $\mathrm{Cl}=$ confidence interval; ${ }^{*} p<.05$. 
Sex

The influence of sex was addressed by repeating the analyses separately for boys and girls. The relationship between general cognitive performance and quantitative and total motor performance remained significant in both boys and girls. However, the relationship between general cognitive performance and qualitative motor performance was significant only in boys. After controlling for attention, only the relations in girls remained significant.

When attention-controlled linear regression analyses between specific cognitive measures and motor measures were performed separately for boys and girls, it was found that the relationship between Visual Motor Integration and motor performance was of equal strength in boys and girls. The relation between Verbal Fluency and quantity of motor performance occurred solely in boys, while the relation between Word Order and motor performance was significant only in girls.

When attention-controlled logistic regression analyses were performed separately for boys and girls, it was found that the relation between Visual Motor Integration and motor performance was significant in both sexes. However, different relations were significant in boys and girls: in boys only, lower performance on the Verbal Fluency test related to lower quantity of movement, and in girls only, lower performance on the Word Order test related to lower quantity, quality, and total motor performance.

\section{Psychopathology}

It is likely that some of the children studied here might have displayed signs of psychopathology, which could have influenced the results. To evaluate whether the group of children with increased $\mathrm{CBCL}$ scores (including children at risk of psychopathology) influenced the relationship between cognitive and motor performance, the same analyses were repeated in the control group of 220 children only. Results were highly comparable. Thus, the relationship we found between aspects of cognitive and motor behavior was not caused by psychopathology in some children and can therefore be seen as a global relation in healthy children aged five to six.

\section{Discussion}

The aim of this study was to investigate the relationship between cognitive and motor performance, statistically corrected for attention, in a large cross-sectional sample drawn from a population of children aged five to six attending normal kindergarten. The relationship between both quantitative and qualitative motor performance on the one hand, and an estimate of general cognitive performance as well as specific cognitive functions on the other hand were studied. Although findings became less strong after controlling for attention, positive linear relations remained between an estimate of general cognitive performance and total and qualitative aspects of motor performance. However, the relations found were rather small and when only cognitive tasks without a motor component were included in the estimate of cognitive performance, no significant association with motor performance was found. This finding argues against a global relationship between cognitive and motor performance. Thus, we could not support the theoretical assumption, raised by influential researchers such as Piaget, of a direct linkage between global aspects of cognitive and motor behavior.

In addition to a global-to-global relationship between cognitive and motor behavior, more specific relationships were investigated between aspects of both. It was shown that 
performance on several specific cognitive tests, i.e. of working memory, verbal fluency, and visual motor integration, was related to motor performance, independently of attention. All relationships were positive, i.e. lower performance on the above-mentioned cognitive tests indicated lower performance on the motor test. These relationships were not more pronounced in children who performed below average than in children with average performance. Thus, several aspects of cognitive and motor performance in 5- to 6 -year-old children seems to be on a continuum, ranging from children who perform well on both cognitive and motor tasks, those who perform at an average level, and those who perform poorly on both types of tasks. These findings and those of previous studies are determined by a large extent by the tasks used to assess both cognitive and motor performance. We have taken care to minimize the effects of this limitation, underlying all studies using tests, by including only tasks known to be sensitive to the function they are intended to measure in children aged five to six.

This is the first study to show that specific aspects of cognitive and motor performance are related, independently of attention, in a large sample of healthy children aged five to six. Interestingly, earlier studies showed these two processes to be related in children with clinical problems such as Attention Deficit Hyperactivity Disorder, Developmental Apraxia of Speech, Developmental Coordination Disorder, and dyslexia (Pitcher et al., 2003; Hamilton, 2002; Nijland, 2003; Viholainen et al., 2002).

The relationship found between visual motor integration and qualitative and quantitative aspects of motor performance is not surprising, considering the role of fine motor performance in the visual motor integration test. Both quantitative and qualitative aspects of motor performance as well as visual perception are important in this task (Beery, 1997). Although it is difficult to exclude the visual perception aspects from the motor aspects of this test, evidence against a relationship between visual perception and motor performance stems from the negative finding of a relationship between motor performance and the other test of visual perception, the embedded figures test. Thus, visual perception as assessed by the tasks used in this study seems not to be related to motor performance.

Performance on a working memory test and a verbal fluency test, two measures of executive functioning (Baron, 2004), was related to motor performance. It has been suggested that certain brain structures, such as the basal ganglia or frontal cortex, and dopamine transmission are common to both cognitive and motor performance (Kandel et al., 2000; Diamond, 2000; Geurts, 1997; Nieoullon, 1997). However, performance on the Progressive Figures test, a third measure of executive functioning, was not related to motor performance. Thus, there seems to be a relationship especially between certain aspects of executive functioning and motor performance. Future research should specify this relationship further by relating performance on different measures of aspects of executive functioning to motor performance.

The expectation that the relationship between cognitive and motor performance would be more pronounced in boys than in girls (APA, 1994; Dewey et al., 2002), was not confirmed. After controlling for attention, it was found that the relationship between general cognitive performance and motor performance was still present in girls, but not in boys. In addition, the relationship between verbal fluency and quantity of motor performance occurred solely in boys, while the relationship between Word Order and motor performance occurred solely in girls. Thus, the relationship between cognitive and motor performance in children aged five to six is of similar strength in boys and girls, but there 
is a difference regarding the specific cognitive functions that are associated with motor performance.

We did not confirm our expectation, based on the literature (Prechtl et al., 1997; Kroes et al., 2002a), that qualitative aspects of motor performance would be more relevant than quantitative aspects in predicting general cognitive performance. Although general cognitive performance was related only to qualitative aspects of motor performance, no consistent pattern was seen in the relationships between four specific cognitive functions and motor performance. This contrasts with the findings of Kroes and colleagues (2002a), who reported that qualitative aspects of motor performance could predict disorders in the attention spectrum whereas quantitative aspects could not. Apparently, there is a more general relationship between cognitive performance and motor performance in healthy children aged five to six in which both quantitative and qualitative aspects are important. However, we did not include specific measures of impulsiveness, a function hypothesized to be especially impaired in children with ADHD (Barkley, 1997). It is possible that performance on such a measure would be related only to qualitative aspects of motor performance. Future research should focus on this question.

In summary, in this cohort of children aged five to six, no consistent relationships were found between an estimate of general cognitive performance and motor performance. Conversely, it was found that motor performance was related to performance on several specific cognitive measures, which involved attention and other aspects of executive functioning. This could indicate that attention, executive functioning, and motor performance are related in children aged five to six. These findings show the parallel development of specific cognitive and motor functions in children, during both normal and delayed development. Future research should extend these findings to other developmental periods, in order to more comprehensively investigate the parallels between cognitive and motor development of children. 


\section{References}

Achenbach, T. M. (1991). Manual for the Child Behavior Checklist/4-18 and 1991 Profile. Burlington: University of Vermont Department of Psychiatry.

American Psychiatric Association (1994). Diagnostic and statistical manual of mental disorders (4th ed.). Washington DC: American Psychiatric Association.

Amiel-Tison, C., Njiokiktjien, C., Vaivre-Douret, L., Verschoor, C. A., Chavanne, E., \& Garel, M. (1996). Relation of early neuromotor and cranial signs with neuropsychological outcome at 4 years. Brain and Development, 18, 180-286.

Anderson, P. (2002). Assessment and development of executive function (EF) during childhood. Child Neuropsychology, 8, 71-82.

Anderson, V. A., Anderson, P., Northam, E., Jacobs, R., \& Catroppa, C. (2001). Development of executive functions through late childhood and adolescence: an Australian sample. Developmental Neuropsychology, 20, 385-406.

Armstrong, B.B., \& Knopf, K.F. (1982). Comparison of the Bender-gestalt and revised developmental test of visual-motor integration. Perceptual and Motor skills, 56, 164-166.

Barkley, R. A. (1997). Behavioral inhibition, sustained attention, and executive functions: constructing a unifying theory of ADHD. Psychological Bulletin, 121, 65-94.

Baron, I. S. (2004). Neuropsychological evaluation of the child. Oxford: University Press.

Beery, K.E. (1997). The Beery-Buktenica developmental test of visual-motor integration (VMI). Parsipanny, New Jersey: Modern Curriculum Press.

Berger, K. S. (1988). The developing person through the life span (2nd ed.). New York: Worth Publishers Lts.

Bleichrodt, N., Drenth, P.J.D., Zaal, J.N., \& Resing, W.C.M. (1987). Rakit: Handleiding bij de Revisie Amsterdamse Kinder Intelligentie Test [RAKIT: Manual of the revised Amsterdam intelligence test for children]. Lisse: Swets \& Zeitlinger B.V.

Bleichrodt, N., Resing, W. C. M., Drenth, P. J. D., \& Zaal, J. N. (1987). Intelligentie-meting bij kinderen [Measurement of intelligence in children]. Lisse: Swets \& Zeitlinger B.V.

Boyce, W. F., Gowland, C., Rosenbaum, P. L., Lane, M., Plews, N., Goldsmith, C. H., Russell, D. J., Wright, V., Potter, S., \& Harding, D. (1995). The Gross Motor Performance Measure: validity and responsiveness of a measure of quality of movement. Physical Therapy, 75, 603-613.

Bushnell, E.W., \& Boudreau, J.P. (1993). Motor development and the mind: the potential role of motor abilities as a determinant of aspects of perceptual development. Child Development, 64, 1005-1021.

Cantell, M. H., Smyth, M. M., \& Ahonen, T. P. (1994). Clumsiness in adolescence: educational, motor, and social outcomes of motor delay detected at 5 years. Adapted Physical Activity Quarterly, 11, 115-129.

Churchland, P.S. (1986). Neurophilosophy: toward a unified science of the mind-brain. Boston: MIT Press.

Churchland, P.S. (2002). Brain-wise. Studies in neurophilosophy. Cambridge, Massachusett: MIT Press.

De Groot, J. C., de Leeuw, F. -E., Oudkerk, M., van Gijn, J., Hofman, A, Jolles, J., \& Breteler, M. B. (2000). Cerebral white matter lesions and cognitive function: the Rotterdam scan study. Annals of Neurology, 47, 145-151.

De Groot, J. C., de Leeuw, F. -E., Oudkerk, M., van Gijn, J., Hofman, A, Jolles, J., \& Breteler, M. B. (2001). Cerebral white matter lesions and subjective cognitive dysfunction: the Rotterdam scan study. Neurology, 56, 1539-1545.

De Sonneville, L. M. J. (1999). Amsterdam Neuropsychological Tasks : A computer-aided assessment program. In: B. P. L. M. Den Brinker, P. J., Beek, A. N. Brands, S. J. Maarse, \& L. J. M. Mulder (Eds). Cognitive ergonomics, clinicial assessment and computer-assisted learning: Computers in Psychology (pp. 187-203). Lisse, the Netherlands: Swets \& Zeitlinger.

Dewey, D., Kaplan, B. J., Crawford, S. G., \& Wilson, B. N. (2002). Developmental coordination disorder: associated problems in attention, learning, and psychosocial adjustment. Human Movement Science, 21, 905-918. 
Diamond, A. (1985). Development of the ability to use recall to guide action, as indicated by infant's performance on AB. Child Development, 56, 868-883.

Diamond, A. (2000). Close interrelation of motor development and cognitive development and of the cerebellum and prefrontal cortex. Child Development, 71, 44-56.

Diamond, A. (2002). Normal development of prefrontal cortex from birth to young adulthood: Cognitive functions, anatomy, and biochemistry. In: D.T. Stuss \& R. T. Knight (Eds.), The frontal lobes (pp.466-503). London, UK: Oxford University Press.

Dunn, L, M., Dunn, L. M., Robertson, G. J., \& Eisenberg, J. L. (1979). Peabody Picture Vocabulary Test- Revised. Circle Pines (MN): American Guidance Service.

Evers, A., van Vliet-Mulder, J. C., \& Groot, C. J. (2000). Documentatie van tests en testresearch in Nederland. Deel I: Testbeschrijvingen [Documentation of tests and testresearch in the Netherlands. Part I: Test descriptions]. Assen: van Gorcum.

Farber, D., \& Njiokiktjien, C. (1993). Developing brain and cognition. Amsterdam: Suyi Publications.

Ferrel-Chapus, C., Hay, L., Olivier, I., Bard, C., \& Fleury, M. (2002). Visuomanual coordination in childhood: adaptation to visual distortion. Experimental Brain Research, 144, 506-517.

Geurts, S. (1997). Motoriek. In: B. Deelman \& P. Eling \& E. de Haan \& A. Jennekens- Schinkel \& E. van Zomeren. Klinische neuropsychologie [Clinical neuropsychology] (pp. 249-268). Amsterdam: Uitgeverij Boom.

Hadders-Algra, M., \& Groothuis, A.M.C. (1999). Quality of general movements in infancy is related to neurological dysfunction, ADHD, and aggressive behaviour. Developmental Medicine and Child Neurology, 41, 381-391.

Hamilton, S.S. (2002). Evaluation of clumsiness in children. American Family Physician, 66, 14351440.

Hatfield, G. (2003). Routledge philosophy guidebook to Descartes and the 'Mediations'. London: Routledge.

Kalff, A. C., Hendriksen, J. G. M., Kroes, M., Vles, J. S. H., Steyeart, J., Feron, F. J. M., van Zeben, T. M. C. B., \& Jolles, J. (2002). Neurocognitive performance of 5- and 6- year old children who met diagnosis for Attention Deficit/Hyperactivity Disorder at 18 months follow-up: results from a prospective population study. Journal of Abnormal Child Psychology, 30, 589-598.

Kandel, E. R., Schwartz, J. H., \& Jessell, T. M. (2000). Principles of neural science. New York: McGraw-Hill.

Kaufman, A.S., \& Kaufman, N.L. (1983). K-ABC. Kaufman Assessment Battery for Children. Circle Pines, Minnesota: American Guidance Services.

Kermoian, R., \& Campos, J. J. (1988). Locomotor experience: a facilitator of spatial cognitive development. Child Development, 59, 908-917.

Klimkeit, E. I., Sheppard, D. M., Lee, P., \& Bradshaw, J. L. (2004). Bimanual coordination deficits in Attention Deficit/Hyperactivity Disorder (ADHD). Journal of Clinical and Experimental Neuropsychology, 26, 999-1010.

Kroes, M., Kessels., A. G., Kalff, A. C., Feron, F. J., Vissers, Y. L., Jolles, J., \& Vles, J. S. (2002a). Quality of movement as predictor of ADHD: results from a prospective population study in 5and 6-year old children. Developmental Medicine and Child Neurology, 44, 753-760.

Kroes, M., Kalff, A. C., Kessels, A. G. H., Hendriksen, J. G. M., Van Zeben, T. M. C. B., Rozendaal, N., Crolla, I. F. A. M., Troost, J., Jolles, J., \& Vles, J. S. H. (2001). Child psychiatric diagnoses in a population of Dutch schoolchildren aged 6 to 8 years. Journal of the American Academy of Child and Adolescent Psychiatry, 40, 1401-1409.

Kroes, M., Kalff, A. C., Steyaert, J., Kessels, A. G., Feron, F. J., Hendriksen, J. G., van Zeben, T. M., Troost, J., Jolles, J., \& Vles, J. S. (2002b). A longitudinal community study: do psychosocial risk factors and child behavior checklist scores at 5 years of age predict psychiatric diagnoses at a later age? Journal of the American Academy of Child and Adolescent Psychiatry, 41, 955963 
Kroes, M., Vissers, Y. L. J., Sleijpen, F. A. M., Feron, F. J. M., Kessels, A. G. H., Bakker, E., Kalff, A. C., Hendriksen, J. G. M., Troost, J., Jolles, J., Vles, J. S. H. (2004). Reliability and validity of a qualitative and quantitative motor test for 5- to 6- year old children. European Journal of Paediatric Neurology, 8, 135-143.

Largo, R. H., Caflisch, J. A., Hug, F., Muggli, K., Molnar, A. A., \& Molinari, L. (2001). Neuromotor development from 5 to 18 years. Part 2: associated movements. Developmental Medicine and Child Neurology, 43, 444-453.

Largo, R. H., Fischer, J. E., \& Rousson, V. (2003). Neuromotor development from kindergarten age to adolescence: developmental course and variability. Swiss Medical Weekly, 133, 193-199.

Lehnung, M., Leplow, B., Ekroll, V., Herzog, A., Mehdorn, M., \& Ferstl, R. (2003). The role of locomotion in the acquisition and transfer of spatial knowledge in children. Scandinavian Journal of Psychology, 44, 79-86.

Lezak, M. D., Howieson, D. B., \& Loring, D. W. (2004). Neuropsychological assessment (4th ed.). New York: Oxford University press.

Losse, A., Henderson, S.E., Elliman, D., Hall, D., Knight, E., \& Jongmans, M. (1991). Clumsiness in children: do they grow out of it? A 10-year follow-up study. Developmental Medicine and Child Neurology, 33, 55-68.

Mandich, A., Buckolz, E., \& Polatajko, H. (2003). Children with developmental coordination disorder (DCD) and their ability to disengage ongoing attentional focus: More on inhibitory function. Brain and Cognition, 51, 346-356.

Marokovitz, S. E., \& Campbell., S. B. (1998). Inattention, impulsivity, and hyperactivity from preschool to school age: performance of hard to manage boys on laboratory measures. Journal of Child Psychology and Psychiatry, 39, 841-851.

Nieoullon, A. (2002). Dopamine and the regulation of cognition and attention. Progress in Neurobiology, $67,53-83$.

Nijland, L. (2003). Developmental apraxia of speech: deficits in phonetic planning and motor programming. Thesis. Wageningen: Ponsen \& Looijen BV.

Piaget, J., \& Inhelder, B. (1966). La psychologie de l'enfant [The psychology of the child]. Paris: Presses Universitaires de France.

Pitcher, T. M., Piek, J. P., \& Hay, D. A. (2003). Fine and gross motor ability in males with ADHD. Developmental Medicine and Child Neurology, 45, 525-535.

Prechtl., H.F.F., Einspieler, C., Cioni, G., Bos, A.F., Ferrari, F., \& Sontheimer, D. (1997). An early marker for neurological deficits after perinatal brain lesions. The Lancet, 349, 1361-1363.

Reitan, R.M., \& Wolfson, D. (1985). The Halstead-Reitan neuropsychology test battery. Tucson, Arizona: Neuropsychology Press.

Sala, D. A., Shulman, L. H., Kennedy, R. F., Grant, A. D., \& Chu, M. L. (1999). Idiopathic toewalking: a review. Developmental Medicine and Child Neurology, 41, 846-848.

Schonfeld, I. S., Shaffer, D., \& Barmack, J. E. (1989). Neurological soft signs and school achievement: the mediating effects of sustained attention. Journal of Abnormal Child Psychology, 17, 575-596.

Shulman, L. H., Sala, D. A., Chu, M. L., McCaul, P. R., \& Sandler, B. J. (1997). Developmental implications of idiopathic toe walking. Journal of Pediatrics, 130, 541-546.

Solan, H. A., \& Mozlin, R. (1986). The correlations of perceptual-motor maturation to readiness and reading in kindergarten and the primary grades. Journal of the American Optometric Association, 57, 28-35.

Statacorp (2003). STATA 8 Base reference manual. College Station, Texas: Stata Press.

Tannock, R. (2003). Neuropsychology of attention disorders. In: S. J. Segalowitz. \& I. Rapin. (Eds.), Handbook of neuropsychology (2nd ed., pp. 753-784). Amsterdam: Elsevier Science B.V.

Van Boxtel, M. P., Buntinx, F., Houx, P. J., Metsemakers, J. F. M., Knottnerus, A., \& Jolles, J. (1998). The relation between morbidity and cognitive performance in a normal aging population. Journal of Gerontology: Series A: Biological Sciences and Medical Sciences, 53A, M147M154. 
Verhulst, F. C., van der Ende J., \& Koot, H.M. (1996). Handleiding voor de CBCL (Child Behavior Checklist) 4-18 [Manual for the CBCL]. Rotterdam: Afdeling Kinder en jeugdpsychiatrie, Sophia Kinderziekenhuis/Academisch Ziekenhuis Rotterdam/ Erasmus Universiteit Rotterdam, the Netherlands.

Visser, J. (2003). Developmental coordination disorder: a review of research on subtypes and comorbidities. Human Movement Science, 22, 479-493.

Vles, J. H. S., Kroes, M., \& Feron, F. J. M. (2004). MMT: Maastricht Motoriek Test [MMT: Maastricht Motor Test]. Leiden: PITS.

Viholainen, H., Ahonen, T., Cantell, M., Lyytinen, P., \& Lyytinen, H. (2002). Development of early motor skills and language in children at risk for familial dyslexia. Developmental Medicine and Child Neurology, 44, 761-769.

Wolff, P. H., Gunnoe, C., \& Cohen, C. (1985). Neuromotor maturation and psychological performance: a developmental study. Developmental Medicine and Child Neurology, 27, 344-354.

Yan, J.H., Thomas, J.R., \& Downing, J.H. (1998). Locomotion improves children's spatial search: a meta-analytic review. Perceptual and Motor Skills, 87, 67-82. 



\title{
CHAPTER 3
}

\section{Development of inattention, impulsivity, and processing speed as measured by the $\mathrm{d} 2$ Test}

\begin{abstract}
The development of three aspects of selective attention was studied in 451 Dutch school children attending the second to sixth grade. Selective attention was measured with the d2 Test of attention. The largest age differences were found for processing speed, that continued to improve until the sixth grade. Impulsivity, as measured by the percentage of errors of commission, decreased until the fourth grade. Inattention, measured by the percentage of errors of omission, was stable in all grades. Processing speed and impulsivity were correlated with the score on the Attention Problems subscale of the Child Behavior Checklist. These results imply that selective attention continues to develop, at least, until the end of elementary school. The findings are support for a stepwise model of cognitive development (P. Anderson, 2002).
\end{abstract}


Attentional processes are important for normal functioning in daily life. An adequate attention is a prerequisite for normal performance on the majority of neuropsychological tests (Cooley \& Morris, 1990). Recently, investigators became interested in how different aspects of attention develop in children, both in normally developing children (Klenberg, Korkman, \& Lahti-Nuuttila, 2001; Klimkeit, Mattingley, Sheppard, Farrow, \& Bradshaw, 2004; Lin, Hsiao, \& Chen, 1999; McKay, Halperin, Schwartz, \& Sharma, 1994; Rebok et al., 1997; Ruff \& Lawson, 1990; Stahl \& Pry, 2005), and in children with developmental disorders, such as Attention Deficit Hyperactivity Disorder (ADHD) (Brodeur \& Pond, 2001; Drechsler, Brandeis, Földényi, Imhof, \& Steinhausen, 2005; Marakovitz \& Campbell, 1998). The main conclusion of these studies was that attentional functioning develops in spurts throughout childhood and adolescence. This development seems to parallel the growth spurts in the maturation of the brain, particulary of specific areas in the prefrontal cortex (Gogtay et al., 2004; Klingberg, Vaidya, Gabrieli, Moseley, \& Hedehus, 1999; Sowell \& Jernigan, 1998; Thatcher, 1991). A recent model placed this differential cognitive development in a theoretical framework (P. Anderson, 2002). The present study focused on selective attention, the ability to attend to relevant stimuli and to ignore irrelevant stimuli (Baron, 2004; R. A. Cohen, 1993; Tannock, 2003). It is critical for the majority of other cognitive processes because it is needed for selecting incoming sensory information, encoding information in memory, retaining and manipulating information into working memory, and successfully executing goal-directed behavior (Smith \& Jonides, 1999). Based on the model named above (P. Anderson, 2002), we investigated the differential development of subprocesses within selective attention.

Previous studies of the development of selective attention across childhood yielded inconsistent results as to the age until most improvement occurs. McKay and colleagues (1994) did not find differences in performance between children aged seven to eleven ( $\mathrm{N}$ = 62) and adults ( $N=16$, aged 21 to 48 years), whereas Brodeur and Pond (2001) reported better performance in children aged nine to eleven $(N=18)$ than in children aged six to eight ( $N=14)$. Rebok and colleagues (1997) found a significant improvement from eight to ten years $(N=289)$. Klimkeit and colleagues (2004) found the largest improvement between the ages of eight and ten years, with a plateau in performance between ten and twelve years of age $(N=40)$. Klenberg and colleagues (2001) also reported that development was complete by ten years $(N=400)$. In summary, selective attention appears to be fully developed by about ten years of age.

However, selective attention encompasses different processes, such as speed and accuracy (Manly et al., 2001). These processes may have distinct developmental patterns and they have not been examined by all of the abovementioned studies. Interestingly, McKay and colleagues (1994), who failed to detect group differences in selective attention, used speed as the sole outcome measure. Brodeur and Pond (2001) and Rebok and colleagues (1997) reported on both speed and accuracy, whereas Klenberg and colleagues (2001) used a speed-accuracy trade-off as the dependent measure. In contrast, Klimkeit and colleagues (2004) used four types of errors besides speed, among others misses and premature responses. In the present study of how selective attention develops with age in school children in the second to sixth grades of regular primary school, we adopted a similar approach. Three aspects of selective attention were studied, namely processing speed (number of items processed), impulsivity (percentage of errors of commission), and inattention (percentage of errors of omission). We expected performance on these aspects to be optimal by the fourth grade, 
when children are about ten years, based on the results of the above described studies (Brodeur \& Pond, 2001; Klenberg et al., 2001; Klimkeit et al., 2004; McKay et al., 1994; Rebok et al., 1997).

We used the d2 Test of attention to measure the different aspects of selective attention (Baron, 2004; Brickenkamp \& Zillmer, 1998; Culbertson \& Sari, 1997). Mental concentration, visual perception, visual scanning ability, and perceptual speed are thought to be involved in this well-known test that takes 6 minutes to administer (Baron, 2004; Brickenkamp \& Zillmer, 1998). Although the d2 Test has been described as a test of both selective and sustained attention (Baron, 2004), the duration of 4 minutes and 40 seconds required for the test after practice and instruction does not approach that of classic vigilance or sustained attention tasks. For example, continuous performance tests usually last about 14 minutes (Baron, 2004; Lezak, Howieson, \& Loring, 2004; Spreen \& Strauss, 1998). Also, the prompt that is given every 20 seconds makes this test dissimilar to classic tests of sustained attention, in which performance is selfmonitored (Brickenkamp \& Zillmer, 1998). For these reasons, the d2 Test should be considered primarily a test of selective attention.

The d2 Test has the advantage over other tests of selective attention that it is short, does not require extensive instruction, can be administred to a large age-range and to groups or individuals alike, and has high reliability and validity (Brickenkamp \& Zillmer, 1998; Culbertson \& Sari, 1997; Culbertson \& Zillmer, 1998; Eser, 1987). It has been used in various European and North American studies (Lufi, 2001; Muller et al., 2003; Olvera, Semrud-Clikeman, Pliszka, \& O'Donnell, 2005; Reimann et al., 2000; Seidl, Peyrl, Nicham, \& Hauser, 2000). We do not know of previous studies that investigated the development of selective attention using the d2 Test. However, the d2 Test is commonly used in neuropsychological studies of children, among others in studies of the effect of neurofeedback treatment for ADHD (Fuchs, Birbaumer, Lutzenberger, Gruzelier, \& Kaiser, 2003), the neuropsychological markers of schizophrenia in adolescents (Klemm, Schmidt, Knappe, \& Blanz, 2006; Schreiber, Stolz-Born, Heinrich, Kornhuber, \& Born, 1992), the neuropsychological effects of irradiation for childhood leukemia (Langer et al., 2002), the remediation of attention deficits (Penkman, 2004), the neuropsychological profiles of children and adolescents with temporal lobe epilepsy (Lendt, Helmstaedter, \& Elger, 1999), the neuropsychological profiles of early treated children with phenylketonuria (Weglage et al., 1999; Weglage, Pietsch, Funders, Koch, \& Ullrich, 1996), and the influence of methylphenidate on cortical processing of children with ADHD (Wienbruch, Paul, Bauer, \& Kivelitz, 2005). Because children who have not learned the difference between the characters ' $d$ ' and ' $p$ ' cannot be tested with the $d 2$ Test (Brickenkamp \& Zillmer, 1998), we chose to study children in the second (age 7) and higher grades of school in order to be certain that they had sufficient knowledge of the characters used.

A child's development is affected by several age-extrinsic factors. For example, parental education and occupation have a large impact on problem behavior and attention problems in children aged five to six (Kalff et al., 2001a), as does living in a deprived environment (Kalff et al., 2001b). Factors such as parental level of education have received little attention in previous studies of selective attention in children (Brodeur \& Pond, 2001; Drechsler et al., 2005; Klimkeit et al., 2004; McKay et al., 1994), but could be confounders (Bradley \& Corwyn, 2002; Jackson, 2003). We therefore included three age-extrinsic factors: parental level of education, verbal intelligence, and attention prob- 
lems in daily life. The selection of this last factor allowed us to study the practical implications and ecological validity of the $\mathrm{d} 2$ Test. Attention problems in daily life were measured with the Attention Problems scale of the Child Behavior Checklist (Achenbach, 1991; translated into Dutch by Verhulst, van der Ende, \& Koot, 1996).

In summary, the aims of this study were to investigate age differences in processing speed, inattention, and impulsivity in a large sample of healthy Dutch school children attending the second to the sixth grade, and to study the influence of parental level of education, verbal ability, and attention problems in daily life on this development. We expected to find no further improvement for the different aspects of selective attention after the age of ten years.

\section{Method}

\section{Procedure and participants}

The sampling frame consisted of all children attending the second through the sixth grades of two regular elementary schools in south Limburg, an area in the south of the Netherlands (250,000 inhabitants). These schools were selected in cooperation with the Youth Health Care (YHC) Division of the Regional Public Health Institute Maastricht, The Netherlands. All parents $(\mathrm{N}=561)$ were sent a letter describing the purpose of the study and were asked to cooperate. Four hundred and eighty-eight parent-pairs $(87.0 \%)$ replied: 465 of them gave permission for the investigation and signed an informed consent (82.9\%) and 23 did not (4.1\%); 73 did not reply (13.0\%).

Information about the parents who did not give permission or did not respond was obtained anonymously from YHC records, which is permitted by law. There were no significant differences with respect to age and sex between the parents who did not wish to cooperate, those that did not reply, and randomly selected parents whose child participated in the study. However, the non-responding parents had a lower level of educational attainment than the other parents (mean $=1.49$ vs. $1.70, t=2.53, p=.013$ ).

Nine children were ill on the day the investigation was scheduled, so 456 children participated in the study (81.3\%). Parents who agreed to cooperate completed a short questionnaire on their education and occupation, the presence of learning and/or behavior problems in their child, and the attention problems subscale of the CBCL (Achenbach, 1991; Verhulst et al., 1996). The CBCL is a screening instrument for behavior problems in children, and is completed by parents. The attention subscale includes 11 items. Each item can be scored as 0 (this problem is not present), 1 (this problem is sometimes present), or 2 (this problem is always present). The attention problems raw score was used as the outcome variable (maximum possible $=22$ ). The presence of attention problems did not differ between the grades $\left(F_{(4,436)}=.94, p=.441\right)$.

The data of two children who were previously diagnosed with ADHD by health care professionals (not based on this investigation) were excluded from the analyses. This low number of children with ADHD is not representative of the normal Dutch population as the prevalence is estimated to be $3.8 \%$ (Kroes et al., 2001). This distinction is probably due to the fact that we told the schools and parents we wanted to recruit normally developing children for the study. This may have led parents of children with ADHD to give no permission or to refrain from responding at all. Secondly, and possibly more importantly, Dutch children with ADHD are often placed at a school for children with special needs. Thus, the prevalence of ADHD at regular elementary schools may be lower than in the total population, as children with ADHD aged seven and older may 
have already been placed at a special needs school. Two children had been diagnosed with dyslexia. Because the results of the study did not change when these children were excluded, their data was retained. The data of three other children were not analyzed because these children had completed the d2 Test with the sheet upside down, and as a result had marked the wrong targets (all p's with two dashes). The remaining 451 children (243 boys (54\%) and 208 girls (46\%) were aged 7.42 to 13.00 years.

Level of parental education was based on the partner with the highest level of education (Kalff et al., 2001a). The majority of participants came from middle to highly educated families: 12 parent-pairs (2.7\%) had a low level of parental education, 139 parentpairs $(30.8 \%)$ a middle level, and 286 parent-pairs $(63.4 \%)$ a high level; relevant data for 14 parent-pairs were missing (Directoraat-Generaal voor de Arbeidsvoorziening, 1989). Because only a few parent-pairs had a low level of education, level of parental education was scored on a 2-point scale low/middle (1 point, primary school to vocational education degree) vs. high (general secondary education to doctoral degree). Level of parental education did not differ between the grades $\left(F_{(4,432)}=.92, p=.452\right)$. Table 1 shows the characteristics of the participants and their parents.

\section{Table 1: Demographic characteristics of the participants}

\begin{tabular}{llcccccl}
\hline & & \multicolumn{5}{c}{ Grade } & \\
\cline { 3 - 6 } & & 2 & 3 & 4 & 5 & 6 & \\
Characteristic & $(\mathrm{N}=82)$ & $(\mathrm{N}=86)$ & $(\mathrm{N}=102)$ & $(\mathrm{N}=92)$ & $(\mathrm{N}=89)$ & Dif $^{1}$ \\
\hline $\mathrm{N}$ & Boys & $41(50 \%)$ & $51(59.3 \%)$ & $58(56.9 \%)$ & $44(47.8 \%)$ & $49(55.1 \%)$ & \multirow{2}{*}{$\mathrm{NS}$} \\
& Girls & $41(50 \%)$ & $35(40.7 \%)$ & $44(43.1 \%)$ & $48(52.2 \%)$ & $40(44.9 \%)$ & \\
Age & Mean & 8.06 & 8.99 & 10.13 & 11.07 & 12.09 & $2<3<4$ \\
& $(\mathrm{SD})$ & $(.36)$ & $(.43)$ & $(.41)$ & $(.41)$ & $(.40)$ & $<5<6$ \\
EVA & Mean & 39.89 & 44.72 & 47.64 & 51.52 & 52.88 & $2<3<4$ \\
& (SD) & $(4.25)$ & $(4.03)$ & $(4.05)$ & $(3.25)$ & $(3.83)$ & $<5<6$ \\
LPE & L/M3 & $25(30.5 \%)$ & $33(38.4 \%)$ & $39(38.2 \%)$ & $29(31.5 \%)$ & $25(28.1 \%)$ & \\
& High & $56(68.3 \%)$ & $52(60.5 \%)$ & $58(56.9 \%)$ & $60(65.2 \%)$ & $60(67.4 \%)$ & NS \\
& Mis & $1(1.2 \%)$ & $1(1.2 \%)$ & $5(4.9 \%)$ & $3(3.3 \%)$ & $4(4.5 \%)$ & \\
AT & Mean & 1.54 & 1.86 & 2.15 & 1.76 & 1.73 & NS \\
& (SD) & $(1.55)$ & $(2.23)$ & $(2.41)$ & $(2.38)$ & $(2.29)$ & \\
\hline
\end{tabular}

Note: $E V A=$ Estimate of Verbal Ability, mean and $S D$ of the raw score on the Vocabulary subtest of the RAKIT, maximum possible = 60 (Bleichrodt et al., 1987; Evers et al., 2000); LPE = Level of Parental Education (Directoraat-Generaal voor de Arbeidsvoorziening, 1989), number of children in each category, $L / M=$ Low/Middle level of parental education; High = High level of parental education, Mis = Missing data; $A T=$ mean and $S D$ of the raw score on the attention problems subscale of the CBCL, maximum possible = 22 (Achenbach, 1991; Verhulst et al., 1996); 2 = second grade; $3=$ third grade; 4 = fourth grade; 5 = fifth grade; 6 = sixth grade; ${ }^{1}$ Differences between grades, calculated by one-way ANOVA with post hoc Bonferroni multiple comparisons

Children took tests of selective attention, verbal ability, and sense of time (reported on in chapter 5) in their classroom. Testing took 30-45 minutes; all tests were administered in the same order to all children. The d2 Test was administered first to minimize effects of fatigue. Children whose parents had not agreed to their participation in the 
study were either present in the classroom during the study (working on their own) or left the room with their teacher or a teaching assistant. The tests were administered by a psychologist and psychology graduate who had been trained in test administration. They were not aware of the specific hypotheses of the study. The ethics commission of the Faculty of Psychology, University of Maastricht, approved the study.

\section{Instruments}

Selective attention was measured with the d2 Test of attention (Brickenkamp \& Zillmer, 1998; Culbertson \& Sari, 1997). The d2 Test consists of 14 lines, each containing 47 characters; in total there are 658 items. The test items are composed of the characters ' $p$ ' and ' $d$ ' with one to four dashes, arranged either individually or in pairs above and below the character. The subject is required to scan across the line to identify and mark all 'd's with two dashes, which can be either above or below the letter. Twenty seconds per line are allowed, after which the subject is told to continue to the next line by the words "stop, next line". The subject is asked to work as quickly as possible without making mistakes. The d2 Test can be administered individually or in group format; in the present study the latter format was chosen. Total administration time for the d2 Test is 6 minutes. The reliability and validity of the d2 Test are reported to be good. More specifically, internal consistency of the total number of items processed ranged from .84 to .98 in different studies, test-retest reliability was .87 in a group of students that were retested after 6 months, and construct validity was supported in a factor analytic study in which the d2 Test loaded with other tests of selective attention such as the Stroop Color Word Test and the Symbol Digit Modalities Test (Brickenkamp \& Zillmer, 1998). Reliability and validity have also been established in studies with children: internal consistency of the total number of items processed was .93 in a study of children aged nine to sixteen with deviant behavior (Eser, 1987); test-retest reliability was .75 in 18 adolescents with behavior problems when they were retested after 4 months (Eser, 1987), and significant correlations of medium to high effect size were found between d2 Test and Tower of London performance in a study of American children with ADHD (Culbertson \& Zillmer, 1998).

The three outcome measures used in this study were (1) the total number of items processed, as a measure of processing; (2) the number of misses (errors of omission: d's with two dashes that were not marked) divided by processing speed as a measure of inattention, and (3) the number of false alarms (errors of commission: marked d's with less or more than 2 dashes or p's) divided by processing speed as a measure of impulsivity speed (see d2 Test manual; Brickenkamp \& Zillmer, 1998) .

Verbal ability (EVA) was estimated with the Picture Vocabulary subtest of the Revised Amsterdam Child Intelligence Test for children aged 4 years and 2 months to 11 years and 1 month (Bleichrodt, Drenth, Zaal, \& Resing, 1987; Evers, van Vliet-Mulder, \& Groot, 2000). The Picture Vocabulary test closely resembles the Peabody Picture Vocabulary test (Dunn, Dunn, Robertson, \& Eisenberg, 1979), a commonly used instrument to estimate verbal intelligence (Marakovitz \& Campbell, 1998). During the Picture Vocabulary test, the child has to choose one of four pictures that matches the word the experimenter reads aloud. These words increase in complexity. For the present study, the booklet version of the Picture Vocabulary test was adapted for use in class, by copying the pictures on sheets and projecting them onto a white screen. Every child marked his/her 
answers on an answer form showing small versions of the same pictures projected on the white screen. Because some subjects were older than the available norms for the test, the outcome variable was the total number of correctly chosen pictures (maximum possible $=60$ ). As can be expected, performance improved linearly with school grade (see Table 1).

\section{Statistical analyses}

The statistical package SPSS 11.5 was used for all analyses. Specific group differences on d2 Test processing speed were analyzed with four separate linear regression analyses. In these analyses, one of the grades was systematically compared with the others. This was done by including one of four sets of dummy variables. For example, with the dummy variables of the second grade, the following comparisons were made: second with third grade, second with fourth grade, second with fifth grade, and second with sixth grade. No set of dummy variables was needed for the highest grade, because all comparisons had been made already. The second block of linear regression analyses included the same grade differences as in block 1 but also parental level of education (coded as: low $/$ middle $=1$, high $=2$ ), estimate of verbal ability (continuous), $\mathrm{CBCL}$ attention problems scale raw score (continuous), and sex (to control for possible differences, coded as: boy $=1$, girl $=2$ ).

To analyze impulsivity and inattention, we first visually inspected the distribution of these variables, to check for normality (see Figures $1 \mathrm{~A}$ and $\mathrm{B}$ ). As can be seen in Figure 1 , relatively few impulsive errors were made, whereas inattentive errors were more common. Neither of the two measures was distributed normally. Thus, the two variables could not be analyzed continuously. The cut-off points between 'normal' and 'weak' was placed at $3.0 \%$ for inattention, and at $1.0 \%$ for impulsivity, because at these points the curves started to bend (see arrows in Figures $1 \mathrm{~A}$ and $\mathrm{B}$ ).

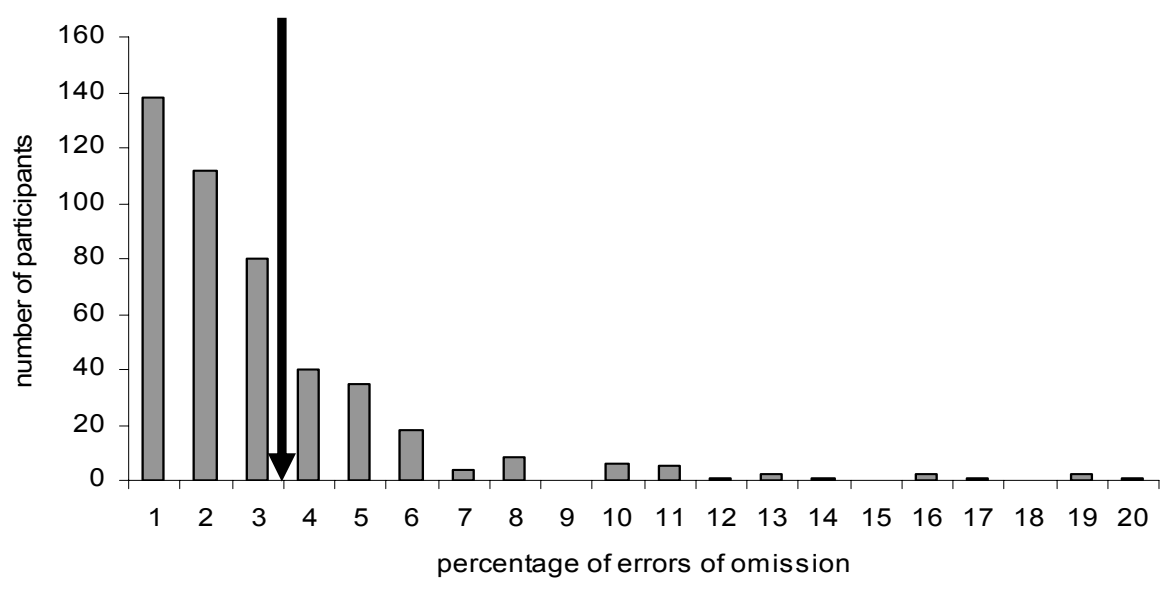

Figure 1A: Distribution of Inattention

Note: Number of errors of omission divided by total number of items processed.

The arrow indicates the borderline (3\%) between normal and weak performance. 


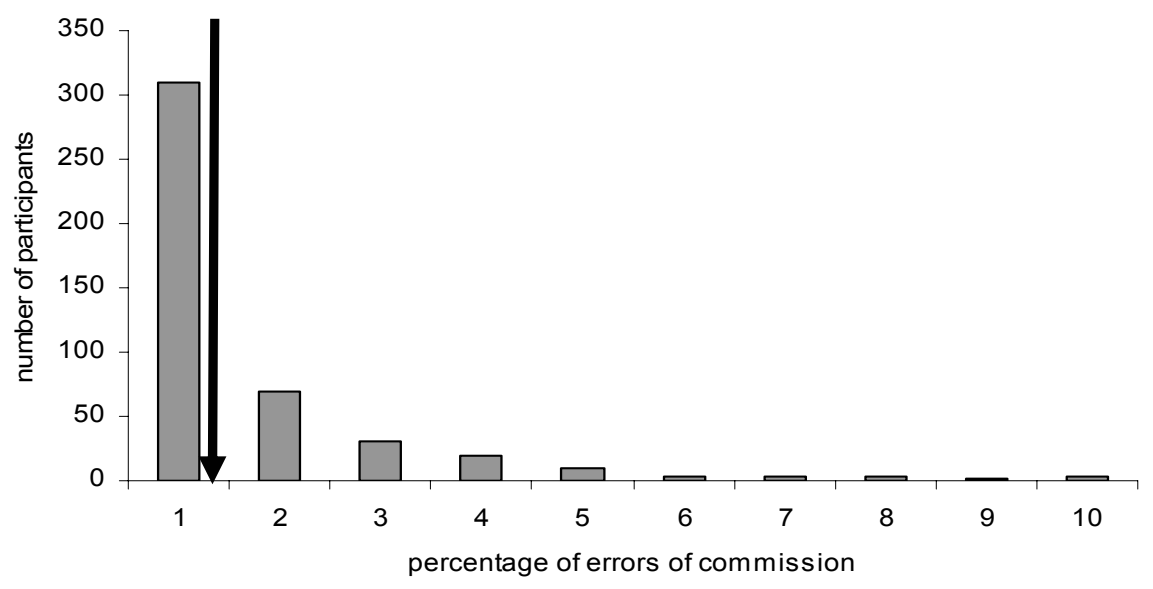

Figure 1B: Distribution of Impulsivity

Note: Number of errors of commission divided by total number of items processed.

The arrow indicates the borderline (1\%) between normal and weak performance.

Using these cut-off points, $27.1 \%$ of the participants showed weak inattention and $31.3 \%$ showed weak impulsivity. More conservative cut-off points were considered, but these made the groups of children who were characterized by weak performance too small to enable meaningful prediction. For example, when the cut-off points were placed at $6.0 \%$ for inattention and $4.0 \%$ for impulsivity, only $6.2 \%$ respectively $4.7 \%$ of participants showed weak performance. Inattention and impulsivity were then analyzed by logistic regression analysis (normal $=0$, weak $=1$ ), using the same approach as described above. Alpha value was set at .05 for all analyses.

\section{Results}

\section{Processing speed}

Figure $2 \mathrm{~A}$ shows the processing speed of children in the different grades. The linear regression model for processing speed was significant $(F(8,418)=38.20, p<.001 ; R 2=$ $42.20 \%)$. The total number of items processed increased significantly and linearly over the grades, with each grade performing better than the previous grade. Of the ageextrinsic variables studied, only one was significantly correlated with processing speed: "having more attention problems in daily life" was correlated with a slower performance. Specific grade differences and other statistics are reported in Table 2.

\section{Inattention}

Figure $2 \mathrm{~B}$ shows the proportion of children per grade who made more inattentive errors than the $3.0 \%$ cut-off point. The logistic regression model for inattention was not significant (Chi-square $(4)=8.80, p=.066)$. To control whether the relation between grade and inattention was underestimated because inattention was dichotomized, we conducted a Spearman correlation analysis (non-parametric). Results showed a significant association with a small effect size $(\rho=-.11, p=.002)$, that did not change the implications of the above described results (J. Cohen, 1992). 


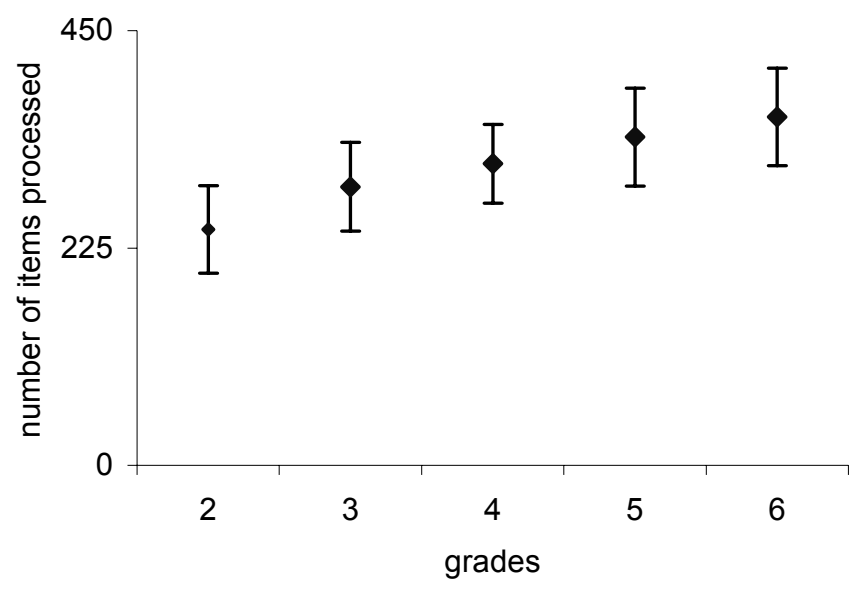

Figure 2A: Processing speed over the grades

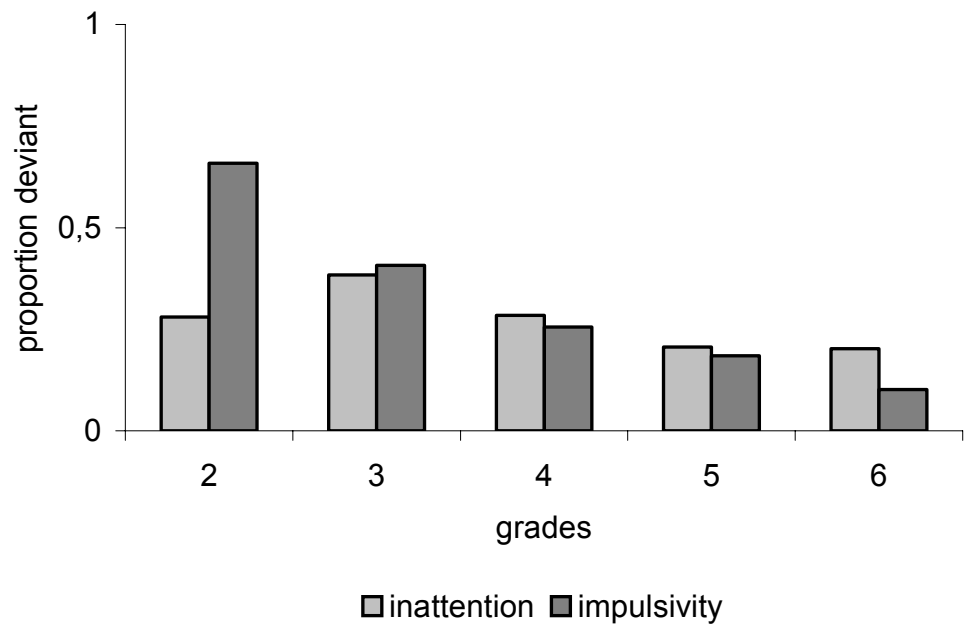

Figure 2B: Inattention and impulsivity over the grades

Impulsivity

Figure $2 \mathrm{~B}$ also shows the proportion of children per grade who made more impulsive errors than the $1 \%$ cut-off point. The logistic regression models for impulsivity were significant (Chi-square $=74.38, p<.001)$. All group differences were found to be significant, except those between grades 4,5 , and 6 (see Table 2). In other words, impulsivity appeared to be optimal in the fourth grade. Of the age-extrinsic variables studied, only the level of attention problems in daily life was correlated with impulsivity: children who were 
highly impulsive had more attention problems in daily life. To control whether the relation between grade and inattention was underestimated because impulsivity was dichotomized, we conducted a Spearman correlation analysis (non-parametric). Results showed a significant association with a medium effect size $(\rho=-.44, p<.001)$, that did not change the implications of the above described results (J. Cohen, 1992).

Table 2: Regression models for processing speed and inhibitory control

\begin{tabular}{|c|c|c|c|c|c|c|c|c|}
\hline \multirow[b]{2}{*}{ Differences: } & \multicolumn{4}{|c|}{ Processing speed } & \multicolumn{4}{|c|}{ Inhibitory control } \\
\hline & B & SE & $\beta$ & $p$-value & B & SE & OR & $p$-value \\
\hline $2 \mathrm{nd}<3$ rd grade & 45.56 & 7.92 & .30 & .000 & -.99 & .36 & .37 & .006 \\
\hline 2 nd $<4$ th grade & 70.85 & 8.58 & .48 & .000 & -1.70 & .42 & .18 & .000 \\
\hline $2 \mathrm{nd}<5$ th grade & 95.82 & 10.04 & .64 & .000 & -1.82 & .51 & .16 & .000 \\
\hline 2 nd $<6$ th grade & 117.84 & 10.80 & .76 & .000 & -2.52 & .59 & .08 & .000 \\
\hline $3 r d<4$ th grade & 25.29 & 7.24 & .17 & .001 & -.71 & .35 & .49 & .040 \\
\hline $3 \mathrm{rd}<5$ th grade & 50.26 & 8.20 & .33 & .000 & -.83 & .41 & .44 & .045 \\
\hline $3 \mathrm{rd}<6$ th grade & 72.28 & 8.78 & .47 & .000 & -1.53 & .50 & .22 & .002 \\
\hline 4 th $<5$ th grade & 24.97 & 7.31 & .17 & .000 & -.12 & .40 & .89 & .766 \\
\hline 4 th $<6$ th grade & 46.99 & 7.77 & .30 & .001 & -.82 & .48 & .44 & .087 \\
\hline 5 th $<6$ th grade & 22.02 & 7.24 & .14 & .002 & -.70 & .47 & .20 & .138 \\
\hline Sex & 6.36 & 4.61 & .05 & .168 & .35 & .24 & 1.41 & .154 \\
\hline EVA & -.21 & .60 & -.02 & .726 & -.04 & .03 & .96 & .194 \\
\hline LPE & -5.31 & 4.82 & -.04 & .271 & .39 & .25 & 1.48 & .109 \\
\hline AT & -2.82 & 1.05 & -.10 & .008 & .13 & .05 & 1.14 & .009 \\
\hline
\end{tabular}

Note: $B=$ Unstandardized regression coefficient, $S E=$ Standard error, $\beta=$ Standardized regression coefficient, $O R=$ Odds ratio, EVA = Estimate of Verbal Ability, raw score on the Vocabulary subtest of the RAKIT (Bleichrodt et al., 1987; Evers et al., 2000); LPE = Level of Parental Education, scored on a 3-point scale ranging from 1 (low) to 3 (high) (Directoraat-Generaal voor de Arbeidsvoorziening, 1989); $A T$ = raw score on the attention problems subscale of the CBCL (Achenbach, 1991; Verhulst et al., 1996).

\section{Discussion}

We investigated processing speed, inattention, and impulsivity in a large population of Dutch school children in second through sixth grades, using the d2Test of Attention. These three processes are regarded as aspects of selective attention (Brickenkamp \& Zillmer, 1998; Klimkeit et al., 2004; Manly et al., 2001). In addition, we controlled for several variables that may alter the development of selective attention, namely attention problems in daily life as reported by the parents, parental level of education, and verbal ability, as an estimate of intelligence. Most importantly, the results of this study indicated a differential development of the three aspects of selective attention. More specifically, no age-related improvement was found for level of inattention, indicating complete development in or before the second grade, level of impulsivity had stabilized in the fourth grade, and processing speed continued to improve into the sixth grade. These findings could be interpreted in light of Peter Anderson's model (2002) on the development of 
executive functioning. Executive function is an umbrella term for various processes that are responsible for purposeful, goal-directed behavior (P. Anderson, 2002; Lezak et al., 2004). In his model, based on cognitive and neuroimaging studies, Anderson proposes four executive domains that follow different developmental trajectories. Simple aspects of executive functioning develop before more complex ones. Inattention and impulsivity are regarded as part of the Attentional Control domain that develops fastest and is relatively mature by nine years. Processing speed, on the other hand, is part of the Information Processing domain that is relatively mature by twelve years of age, but not completely established until mid-adolescence or early adulthood (P. Anderson, 2002). Based on this model, one would expect that processing speeds develops longer than inattention and impulsivity, consistent with our results. Thus, our findings are strong support for a stepwise model of cognitive development (V. A. Anderson, Anderson, Northam, Jacobs, \& Catroppa, 2001; Casey, Tottenham, Liston, \& Durston, 2005; De Bellis et al., 2001; Eslinger, Flaherty-Craig, \& Benton, 2004; Gogtay, Giedd, \& Rapoport, 2002; Gogtay et al., 2004; Klingberg et al., 1999; Paus, 2005; Sowell \& Jernigan, 1998; Steinberg, 2005; Thatcher, 1991).

With respect to processing speed, we found an improvement into the sixth grade (age twelve). Differences in processing speed decreased gradually over the grades, but remained significant. In other words, we did not find a plateau in performance after the fourth grade (age ten), as was expected. This finding is interesting in light of previous studies reporting that processing speed is already optimal by the age of seven (McKay et al., 1994) or ten years (Brodeur \& Pond, 2001; Klimkeit et al., 2004). This discrepancy could be due to the use of different selective attention tasks in which the number and nature of the distracters and the duration of the task varied from study to study, and to differences in sample size. Most importantly, the abovementioned studies all used experimental computerized paradigms whereas we employed a neuropsychological paperand-pencil approach. Our results are more consistent with those of Hale (1990) and Kail (1991, 1996, 2000), who investigated processing speed not within a selective attention paradigm but as a separate cognitive function using reaction time tests. They showed that the reaction times of children and adolescents continued to decrease until the age of about 15, when adult levels were reached. This prolonged development of processing speed has been explained by neural processes such as myelination and synaptogenesis (Kail, 1996; Travis, 1998). We conclude that processing speed of selective attention continues to develop for longer than previously thought to be the case.

Age-extrinsic variables are of importance when studying cognitive development because they can explain inter-individual variance. We controlled for three such factors in our analyses of age differences in selective attention, namely, attention problems in daily life, parental level of education, and level of verbal ability. Attention problems in daily life, as reported by the parents on the CBCL (Achenbach, 1991; Verhulst et al., 1996), were correlated with processing speed and impulsivity. This confirms the ecological validity of the d2 Test of Attention. The results clearly showed that children with more attention problems in daily life performed slower and made more impulsive errors. Although these results may seem intuitive, they are contradictory to findings in children with ADHD. These children show clinical levels of attention problems in daily life, but have been found to perform normally on tasks of selective attention (Booth et al., 2005; Hooks, Milich, \& Lorch, 1994; Huang-Pollock, Nigg, \& Carr, 2005; Manly et al., 2001). The sustained attention component of the task used might be associated with this contradiction: 
longer tasks have a stronger sustained attention component, and sustained attention is known to be compromised in ADHD (Manly et al., 2001). However, this appears not to be the case, because the duration of the d2 Test (4 minutes and 40 seconds) falls between Manly and colleagues' tasks (2001; 1 minute to 84 seconds) and Huang-Pollock and colleagues' task (2005; 20 minutes).

As Baron (2004) stated, "the minimal length required for a test to elicit failure to sustain attention is still debated" (pp. 223). Although selective attention tasks are always shorter than classic vigilance tests, they are not consistently shorter than sustained attention tasks. Rather, their duration overlaps considerably in the child ADHD literature: sustained attention tests take as little as 3 minutes to as long as 30 minutes, whereas selective attention tasks last somewhere between 1 and 20 minutes (Brodeur \& Pond, 2001; Corkum \& Siegel, 1993; Hooks et al., 1994; Manly et al., 2001). Thus, test duration is not the most important variable when it comes to distinguishing children with and without ADHD using a sustained attention task (Corkum \& Siegel, 1993). Rather, children with and without ADHD can be best differentiated with a task that the child must attend to consistently because of short stimulus exposure duration, relatively short inter stimulus interval, and higher percentage of targets (Corkum \& Siegel, 1993; Hooks et al., 1994). The d2 Test of attention requires constant attending and responding to and has a high percentage of targets. This may explain the association we found between selective attention as measured by the $\mathrm{d} 2$ Test and sub-clinical attention problems in daily life in children attending regular education.

Parental level of education is a recognized mediator of cognitive development in general (Bradley \& Corwyn, 2002; Kalff et al., 2001a) but we did not find it to be correlated with selective attention. Although our sample size was more than large enough to find subtle influences, we may not have found an effect because the mean level of parental education was relatively high in our sample. In other words, there may have been too few children in our sample whose parents had a low level of educational attainment. With respect to verbal ability, we did not find an association to any aspect of selective attention measured with the d2 Test. In a previous study of 435 first- and second-grade children, it was found that children with higher verbal intelligence performed better on tasks of selective attention with high, but not low, processing demands (Pascualvaca et al., 1997). More specifically, verbal intelligence did not influence performance on the standard version of a digit cancellation test but it was related to performance on the distracted version of this test. Thus, we can conclude that $\mathrm{d} 2$ Test performance is not related to verbal intelligence, possibly because of low processing demands.

Cultural factors are known to be of influence on the measurement of attention. For example, a recent review found great variations among the prevalence rates of ADHD in countries worldwide, ranging from $2.2 \%$ to $17.8 \%$ (Skounti, Philalithis, \& Galanakis, 2007). This indicates that there could be a difference in the extent to which inattentive behavior is accepted in Dutch relative to, for example, American classrooms, which would reduce the generalisability of our results. However, we believe the influence of cultural factors was minimized because the the $\mathrm{d} 2$ Test and the CBCL attention problems subscale we employed to measure attention are standardized and frequently used in several nationalities (Achenbach, 1991; Baron, 2004; Brickenkamp \& Zillmer, 1998; Culbertson \& Sari, 1997; Spreen \& Strauss, 1998).

The results of this study have to be considered in light of several limitations. First, inattention and impulsivity were dichotomized in normal and weak performance. The 
choice of these cut-off points was, to a certain extent, arbitrary. Second, the total number of items processed may be a less valid way to measure processing speed than, for example, reaction times. Both these limitations are related to the use of the d2 Test for selective attention. However, we felt that these limitations were outweighed by the advantages of the d2 Test compared to other selective attention tests, such as high reliability and validity, short administration time, and suitability for group based approaches. Third, cross-sectional samples are obviously less suitable for developmental research than longitudinal samples. This underscores the need for large scale longitudinal investigations in selective attention and other aspects of cognitive development. Fourth, the group-based investigation took place in the classroom. Such a typically noisy context might be problematic for the assessment of attention. We minimized these distractions by administering the $\mathrm{d} 2$ Test first so concentration was optimal and fatigue minimal, and by providing detailed explanation and practice before administering the test. In addition, two investigators were present in each classroom during administration; one focused on reporting the 20 seconds interval and the other walked around to help with potential problems. Fifth, considering the association between attention and learning challenges, it is unfortunate that we do not know whether any of the participants of this study had retained in a grade because of poor scholastic progress or had been provided with remedial tutoorial assistance (Baron, 2004; Cooley \& Morris, 1990; Tannock, 2003).

In summary, in a large cross-sectional study we found that inattention did not change between the second and the sixth grade, impulsivity had stabilized by the fourth grade, and processing speed continued to improve into the sixth grade. These findings support a step-wise model of cognitive development (P. Anderson, 2002), by which simple aspects of a cognitive function develop before more abstract aspects. Our data emphasizes it is important to break attention down into its subcomponents so subtype differences can be identified. This will enable early and more optimal detection and remediation of attention weaknesses and deficits. 


\section{References}

Achenbach, T. M. (1991). Manual for the Child Behavior Checklist/4-18 and 1991 Profile. Burlington: University of Vermont Department of Psychiatry.

Anderson, P. (2002). Assessment and development of executive function (EF) during childhood. Child Neuropsychology, 8, 71-82.

Anderson, V. A., Anderson, P., Northam, E., Jacobs, R., \& Catroppa, C. (2001). Development of executive functions through late childhood and adolescence in an Australian sample. Developmental Neuropsychology, 20, 385-406.

Baron, I. S. (2004). Neuropsychological evaluation of the child. Oxford: University Press.

Bleichrodt, N., Drenth, P. J. D., Zaal, J. N., \& Resing, W. C. M. (1987). Handleiding bij de Revisie Amsterdamse Kinder Intelligentie Test [Revised Amsterdam Child Intelligence Test manual]. Lisse: Swets \& Zeitlinger BV.

Booth, J. R., Burman, D. D., Meyer, J. R., Lei, Z., Trommer, B. L., Davenport, N. D., Li, W., Parrish, T. B., Gitelman, D. R., \& Mesulam, M. M. (2005). Larger deficits in brain networks for response inhibition than for visual selective attention in attention deficit hyperactivity disorder (ADHD). Journal of Child Psychology and Psychiatry, 46, 94-111.

Bradley, R. H., \& Corwyn, R. F. (2002). Socioeconomic status and child development. Annual Review of Psychology, 53, 371-399.

Brickenkamp, R., \& Zillmer, E. (1998). The d2 Test of attention. First US Edition. Göttingen: Hogrefe \& Huber Publishers.

Brodeur, D. A., \& Pond, M. (2001). The development of selective attention in children with attention deficit hyperactivity disorder. Journal of Abnormal Child Psychology, 29, 229-239.

Casey, B. J., Tottenham, N., Liston, C., \& Durston, S. (2005). Imaging the developing brain: what have we learned about cognitive development? Trends in Cognitive Sciences, 9, 104-110.

Cohen, J. (1992). A power primer. Psychological Bulletin, 112, 155-159.

Cohen, R. A. (1993). The neuropsychology of attention. New York: Plenum Press.

Corkum, P. V., \& Siegel, L. S. (1993). Is the Continuous Performance Task a valuable research tool for use with children with Attention-Deficit-Hyperactivity Disorder? Journal of Child Psychology and Psychiatry, 34, 1217-1239.

Cooley, E. L., \& Morris, R. D. (1990). Attention in children: A neuropsychologically based model for assessment. Developmental Neuropsychology, 6, 239-274.

Culbertson, W. C., \& Sari, D. (1997). A preliminary normative study of the d2 Test with American children. Archives of Clinical Neuropsychology, 4, 303-304.

Culbertson, W. C., \& Zillmer, E. A. (1998). The construct validity of the Tower of London DX as a measure of the executive functioning of ADHD children. Assessment, 5, 215-226.

De Bellis, M. D., Keshevan, M. S., Beers, S. R., Hall, J., Frustaci, K., Maselehdan, A., Noll, J., \& Boring, A. M. (2001). Sex differences in brain maturation during childhood and adolescence. Cerebral Cortex, 11, 552-557.

Directoraat-Generaal voor de Arbeidsvoorziening (1989). Handleiding voor de functieanalyse [Function analysis manual]. Den Haag: SDU uitgeverij.

Drechsler, R., Brandeis, D., Földényi, M., Imhof, K., \& Steinhausen, H-C. (2005). The course of neuropsychological functions in children with attention deficit hyperactivity disorder from late childhood to early adolescence. Journal of Child Psychology and Psychiatry, 46, 824-836.

Dunn, L. M., Dunn, L. M., Robertson, G. J., \& Eisenberg, J. L. (1979). Peabody Picture Vocabulary Test- Revised. Cirle Pines (MN): American Guidance Service.

Eser, K. H. (1987). Reliabilitäts- und Validitätsaspekte des Aufmerksamkeits-Belastungs-Tests (Test d2) bei verhaltensgestörten Kindern und Jugendlichten. [Reliability and validity aspects of the d2 Test of Attention among children and adolescents with behavior problems.]. Diagnostica, $33,74-80$.

Eslinger, P. J., Flaherty-Craig, C. V., \& Benton, A. L. (2004). Developmental outcomes after early prefrontal cortex damage. Brain and Cognition, 55, 84-103. 
Evers, A., van Vliet-Mulder, J. C., \& Groot, C. J. (2000). Documentatie van tests en testresearch in Nederland. Deel I: Testbeschrijvingen [Documentation of tests and testresearch in the Netherlands. Part I: Test descriptions]. Assen: van Gorcum.

Fuchs, T., Birbaumer, N., Lutzenberger, W., Gruzelier, J. H., \& Kaiser, J. (2003). Neurofeedback treatment for attention-deficit/hyperactivity disorder in children: a comparison with methylphenidate. Applied Psychophysiology and Biofeedback, 28, 1-12.

Gogtay, N., Giedd, J., \& Rapoport, J. L. (2002). Brain development in healthy, hyperactive, and psychotic children. Archives of Neurology, 59, 1244-1248.

Gogtay, N., Giedd, J. N., Lusk, L., Hayaski, K. M., Greenstein, D., Vaituzis, A. C., Nugent, T. F. 3rd, Herman, D. H., Clasen, L. S., Toga, A. W., Rapoport, J. L., \& Thompson, P. M. (2004). Dynamic mapping of human cortical development during childhood through early adulthood. Proceedings of the National Academy of the Sciences, 101, 8174-8179.

Hale, S. (1990). A global developmental trend in cognitive processing speed. Child Development, 61, 653- 663.

Hooks, K., Milich, R., \& Lorch, E. P. (1994). Sustained and selective attention in boys with Attention Deficit Hyperactivity Disorder. Journal of Clinical Child Psychology, 23, 69-77.

Huang-Pollock, C. L., Nigg, J. T., \& Carr, T. H. (2005). Deficient attention is hard to find: applying the perceptual load model of selective attention to attention deficit hyperactivity disorder subtypes. Journal of Child Psychology and Psychiatry, 46, 1211-1218.

Jackson, A. P. (2003). The effects of family and neighborhood characteristics on the behavioral and cognitive development of poor black children: a longitudinal study. American Journal of Community Psychology, 32, 175-186.

Kail, R. (1991). Developmental change in speed of processing during childhood and adolescence. Psychological Bulletin, 109, 490-501.

Kail, R. (1996). Nature and consequences of developmental change in speed of processing. Swiss Journal of Psychology, 55, 133-138.

Kail, R. (2000). Speed of information processing: Developmental change and links to intelligence. Journal of School Psychology, 38, 51-61.

Kalff, A. C., Kroes, M., Vles, J. S. H., Bosma, H., Feron, F. J. M., Hendriksen, J. G. M., Steyaert, J., van Zeben, T. M. C. B., Crolla, I. F. A. M., \& Jolles, J. (2001a). Factors affecting the relation between parental education as well as occupation and problem behavior in Dutch 5- to 6- yearold children. Social Psychiatry and Psychiatric Epidemiology, 36, 324-331.

Kalff, A. C., Kroes, M., Vles, J. S. H., Hendriksen, J. G. M., Feron, F. J. M., Steyaert, J., van Zeben, T. M. C. B., Jolles, J., \& van Os, J. (2001b). Neighborhood-level and individual-level SES effects on child problem behavior: a multilevel analysis. Journal of Epidemiology and Community Health, 55, 246-250.

Klemm, S., Schmidt, B., Knappe, S., \& Blanz, B. (2006). Impaired working speed and executive functions as frontal lobe dysfunctions in young first-degree relatives of schizophrenic patients. European Child \& Adolescent Psychiatry, 15, 400-408.

Klenberg, L., Korkman, M., \& Lahti-Nuuttila, P. (2001). Differential development of attention and executive functions in 3- to 12-year-old Finnish children. Developmental Neuropsychology, 20, 407-428.

Klimkeit, E., I., Mattingley, J. B., Sheppard, D. M., Farrow, M., \& Bradshaw, J. L. (2004). Examining the development of attention and executive functions in children with a novel paradigm. Child Neuropsychology, 10, 201-211.

Klingberg, T., Vaidya, C. J., Gabrieli, J. D. E., Moseley, M. E., \& Hedehus, M. (1999). Myelination and organization of the frontal white matter in children: a diffusion tensor MRI study. NeuroReport, 10, 2817-2821.

Kroes, M., Kalff, A. C., Kessels, A. G., Steyaert, J., Feron, F. J., van Someren, A. J., Hurks, P. P., Hendriksen, J. G., van Zeben, T. M., Rozendaal, N., Crolla, I. F., Troost, J., Jolles, J., \& Vles, J. S. (2001). Child psychiatric diagnoses in a population of Dutch schoolchildren aged 6 to 8 years. Journal of the American Academy of Child and Adolescent Psychiatry, 40, 1401-1409. 
Langer, T., Martus, P., Ottensmeier, H., Hertzberg, H., Beck, J. D., \& Meier, W. (2002). CNS lateeffects after ALL therapy in childhood. Part III: neuropsychological performance in long-term survivors of childhood ALL: impairments of concentration, attention, and memory. Medical and Pediatric Oncology, 38, 320-328.

Lendt, M., Helmstaedter, C., \& Elger, C. E. (1999). Pre- and postoperative neuropsychological profiles in children and adolescents with temporal lobe epilepsy. Epilepsia, 40, 1543-1550.

Lezak, M. D., Howieson, D. B., \& Loring, D. W. (2004). Neuropsychological assessment (4th ed.). New York: Oxford University press.

Lin, C. C., Hsiao, C. K., \& Chen, W. J. (1999). Development of sustained attention assessed using the continuous performance test among children 6-15 years of age. Journal of Abnormal Child Psychology, 27, 403-412.

Lufi, D. (2001). Double-coding test: a new paper-and-pencil measure of eye-hand coordination. Perceptual and Motor Skills, 92, 815-826.

Manly, T., Anderson, V., Nimmo-Smith, I., Turner, A., Watson, P., \& Robertson, I. H. (2001). The differential assessment of children's attention: the Test of Everyday Attention for Children (TEA-Ch), normative sample and ADHD performance. Journal of Child Psychology and Psychiatry, 42, 1065-1081

Marakovitz, S. E., \& Campbell, S. B. (1998). Inattention, impulsivity, and hyperactivity from preschool to school age : performance of hard-to-manage boys on laboratory measures. Journal of Child Psychology and Psychiatry, 39, 841-851.

McKay, K. E., Halperin, J. M., Schwartz, S. T., \& Sharma, V. (1994). Developmental analysis of three aspects of information processing: sustained attention, selective attention, and response organization. Developmental Neuropsychology, 10, 121-132.

Muller, S. V., Johannes, S., Wieringa, B., Weber, A., Muller-Vahl, K., Matzke, M., Kolbe, H., Dengler, R., \& Munte, T. F. (2003). Disturbed monitoring and response inhibition in patients with Gilles de la Tourette syndrome and co-morbid obsessive compulsive disorder. Behavioural Neurology, 14, 29-37.

Olvera, R. L., Semrud-Clikeman, M., Pliszka, S. R., \& O'Donnell, L. (2005). Neuropsychological deficits in adolescents with conduct disorder and comorbid bipolar disorder: a pilot study. Bipolar Disorders, 7, 57-67.

Pascualvaca, D. M., Anthony, B. J., Arnold, L. E., Rebok, G. W., Ahearn, M. B., Kellam, S. G., \& Mirsky, A. F. (1997). Attention performance in an epidemiological sample of urban children: The role of gender and verbal intelligence. Child Neuropsychology, 3, 13-12.

Paus, T. (2005). Mapping brain maturation and cognitive development during adolescence. Trends in Cognitive Sciences, 9, 60-67.

Penkman, L. (2004). Remediation of attention deficits in children: a focus on childhood cancer, traumatic brain injury and attention deficit disorder. Pediatric Rehabilitation, 7, 111-123.

Rebok, G. W., Smith, C. B., Pascualvaca, D. M., Mirsky, A. F., Anthony, B. J., \& Kellam, S. G. (1997). Developmental changes in attentional performance in urban children from eight to thirteen years. Child Neuropsychology, 3, 28-46.

Reimann, F. M., Samson, U., Derad, I., Fuchs, M., Schiefer, B., \& Stange, E. F. (2000). Synergistic sedation with low-dose midazolam and propofol for colonoscopies. Endoscopy, 32, 239-244.

Ruff, H. A., \& Lawson, K. R. (1990). Development of sustained, focussed attention in young children during free play. Developmental Psychology, 26, 85-93.

Schreiber, H., Stolz-Born, G., Heinrich, H., Kornhuber, H. H., \& Born, J. (1992). Attention, cognition, and motor perseveration in adolescents at genetic risk for schizophrenia and control subjects. Psychiatry Research, 44, 125-140.

Seidl, R., Peyrl, A., Nicham, R., \& Hauser, E. (2000). A taurine and caffeine-containing drink stimulates cognitive performance and well-being. Amino Acids, 19, 635-642.

Skounti, M., Philalithis, A., \& Galanakis, E. (2007). Variations in prevalence of attention deficit hyperactivity disorder worldwide. European Journal of Pediatrics, 166, 117-123.

Smith, E. E., \& Jonides, J. (1999). Storage and executive processes in the frontal lobes. Science, 283, 1657-1661. 
Sowell, E. R., \& Jernigan, T. L. (1998). Further MRI evidence of late brain maturation: Limbic volume increases and changing asymmetries during childhood and adolescence. Developmental Neuropsychology, 14, 599-617.

Spreen, O., \& Strauss, E. (1998). A compendium of neuropsychological tests. New York: Oxford University Press.

Stahl, L., \& Pry, R. (2005). Attentional flexibility and perseveration: developmental aspects in young children. Child Neuropsychology, 11, 175-189.

Steinberg, L. (2005). Cognitive and affective development in adolescence. Trends in Cognitive Sciences, 9, 69-74.

Tannock, R. (2003). Neuropsychology of attention disorders. In: S. J. Segalowitz. \& I. Rapin. (Eds.), Handbook of neuropsychology (2nd ed., pp. 753-784). Amsterdam: Elsevier Science B.V.

Thatcher, R. W. (1991). Maturation of the frontal lobes: physiological evidence for staging.Developmental Neuropsychology, 7, 397-419.

Travis, F. (1998). Cortical and cognitive development in 4th, 8th and 12th grade students. The contribution of speed of processing and executive functioning to cognitive development. Biological Psychology, 48, 37-56.

Verhulst, F. C., van der Ende, J., \& Koot, H. M. (1996). Handleiding voor de CBCL (Child Behavior Checklist) 4-18 [Manual for the CBCL]. Rotterdam: Afdeling Kinder en jeugdpsychiatrie, Sophia Kinderziekenhuis/Academisch Ziekenhuis Rotterdam/ Erasmus Universiteit Rotterdam, the Netherlands.

Weglage, J., Pietsch, M., Denecke, J., Sprinz, A., Feldmann, R., Grenzebach, M., \& Ullrich, K. (1999). Regression of neuropsychological deficits in early-treated phenylketonurics during adolescence. Journal of Inherited Metabolic Disease, 22, 693-705.

Weglage, J., Pietsch, M., Funders, B., Koch, H. G., \& Ullrich, K. (1996). Deficits in selective and sustained attention processes in early treated children with phenylketonuria--result of impaired frontal lobe functions? European Journal of Pediatrics, 155, 200-204.

Wienbruch, C., Paul, I., Bauer, S., \& Kivelitz, H. (2005). The influence of methylphenidate on the spectrum of ADHD children - an MEG study. BioMedCentral Psychiatry, 5, 29. 



\title{
CHAPTER 4
}

\section{Attention in kindergarten and the first grade predicts academic outcome in the sixth grade}

\begin{abstract}
The predictive value of attention measured in kindergarten and the first grade for academic outcome in the sixth grade was studied using a longitudinal design. Attention was measured with tests and behavioral ratings of attention problems. The following domains of academic outcome were investigated: total academic achievement $(\mathrm{N}=147)$, language, mathematics, study skills $(\mathrm{N}=133)$, and world orientation $(\mathrm{N}=117)$. The results showed that performance on working memory and selective attention tests correlated best with academic outcome. In addition, higher scores on an ADHD precursor questionnaire significantly predicted lower levels for study skills and mathematics. Thus, both cognitive tests and behavioral ratings of attention problems are important factors to consider when predicting the academic outcome of elementary school children.
\end{abstract}

Renske Wassenberg, Petra P. M. Hurks, Jos G. M. Hendriksen, Frans J. M. Feron, Alfons G. H. Kessels, Johan S. H. Vles, Jelle Jolles. Submitted for publication. 
Children who succeed in school tend to also succeed in other aspects of life. They generally have more positive relationships with peers, are less often delinquent, and have higher self-esteem than children who perform poorly at school (Durlak, 2001). In short, there is a relationship between academic achievement, behavior and social functioning. It is therefore important to understand which abilities and factors, at kindergarten age, contribute to later academic achievement so that children who may eventually need special help in school can be identified at an earlier age. This is important for the development and application of effective intervention programs (Sonuga-Barke, 2006).

In the past few decades, numerous studies have identified several factors that impact academic performance, including birth weight (Jefferis, Power, \& Hertzman, 2002), socioeconomic status (Greenberg, Lengua, Coie, \& Pinderhughes, 1999), parenting style (DeGarmo, Forgatch, \& Martinez, 1999), genetic factors (Bartels, Rietveld, Van Baal, \& Boomsma, 2002) and breastfeeding (Horwood \& Fergusson, 1998). With respect to psychological factors, externalizing and internalizing behavior have been found to be important (Masten et al., 2005). Additional factors such as early cognitive performance, as manifest by language production (Walker, Greenwood, Hart, \& Carta, 1994) and perceptual and motor abilities (Belka \& Williams, 1979; Bruininks \& Mayer, 1979) have also been identified. Evidently, previous research has focused mainly on biological, social, and psychological factors.

A factor that, to date, has not extensively been explored in normally developing children is attention. Its influence thus remains largely unknown. This is unfortunate since attention is necessary to learn (Baron, 2004; Cooley \& Morris, 1990; Tannock, 2003). Attentional functioning can be viewed as a continuum that ranges from children who are very inattentive to children who are very attentive (Baron, 2004). Since both kinds of children are present in regular classrooms, knowledge about the relationship between attention and academic outcome could have important implications for the practice of education. As a result, we investigated the predictive value of attention at the beginning of elementary school for academic outcome in the sixth grade.

The relationship between attention and academic performance in school children has mainly been studied within the context of Attention Deficit Hyperactivity Disorder (ADHD) (Biederman, 2005; Hinshaw, 1992). This developmental disorder is characterized by inattention, impulsivity, and hyperactivity (American Psychiatric Association, 1994). Children with ADHD tend to underachieve at school. Additionally, a negative relationship between symptom severity and academic performance has been established (DeShazo Barry, Lyman, \& Grofer Kinger, 2002). Further research has shown that adults who continued to manifest symptoms of ADHD beyond elementary school often failed to complete high school (Barkley, Fischer, Smallih, \& Fletcher, 2006; Murphy, Barkley, \& Bush, 2002).

Very little research has been devoted to the relationship between attention and academic outcome in normally developing children. In one population study, the attention problems of 4-11 year old children, as reported by parents and teachers on standardized behavioral rating scales, were found to predict poorer general outcome six years later (Verhulst, Koot, \& van der Ende, 1994). Unfortunately, this study did not explore the specific relationship between the attention problems and academic achievement. Although a relationship between attention and academic outcome in normally developing children is expected, the nature and the extent of this relationship are not yet known. The present study thus investigated this relationship in a large sample of children who were 
followed from kindergarten (aged five to six) to the sixth grade (aged twelve). Different aspects of academic outcome, namely total academic achievement, arithmetic/mathematics, language, study skills, and world orientation, were included in order to establish the specificity of the relationship between academic performance and attention.

We used a dual approach to measure attention following guidelines for clinical practice (Baron, 2004). Firstly, cognitive tests intended to measure attention were included. These tests normally require children to focus, sustain, or shift their attention relative to a predefined target. Performance is measured in terms of speed or accuracy and, ultimately, these tests provide an indication of a cognitive skill of the child. Secondly, behavioral ratings of attention problems were employed. These standardized rating scales ask parents or teachers to provide observations about a child's attention functioning in daily life (e.g. Baron, 2004). In addition to behavioral ratings of attention problems, we included measures of impulsivity and hyperactivity because these three characteristics are often concurrent (Barkley, 1997). This approach allowed us to determine whether characteristics of ADHD in general or attention problems specifically are related to academic outcome. In summary, we studied the predictive value of performance on attention tests and behavioral ratings of attention problems in kindergarten and the first grade for different domains of academic outcome in the sixth grade. This relationship was studied both with and without a step that controls for four general predictors of academic outcome, namely sex, parental level of education, verbal intelligence, and having repeated a grade or not (Greenberg et al., 1999; Rabiner \& Coie, 2000; Resnick et al., 1999).

\section{Method}

\section{Participants and procedure}

The study reported here is a component of 'the Study of Attention disorders Maastricht (SAM)'. SAM is a multidisciplinary research program carried out by the Brain and Behavior Institute at the Maastricht University and Maastricht University Hospital of Maastricht in the Netherlands. This is a large cross-sectional, longitudinal research program that endeavors to explore the determinants of healthy cognitive development and the incidence of learning problems and psychopathology. A prospective five-stage longitudinal research design was used (for previous reports on this population, see Hurks et al., 2006; Kalff et al., 2005; Kroes et al., 2001, 2002; Wassenberg et al., 2005). The process of the study was follows: In Stage 1, parents of a large sample of children aged five to six $(\mathrm{N}=1317)$ provided information on their child via standardized behavioral questionnaires. Approximately six months later, in Stage 2, a cognitive and motor assessment was performed on 452 of the children that were included in the first stage. One year later, in Stage 3, the parents and teachers of the 452 children from the previous stage submitted, to the researchers, behavioral and psychiatric observations. Two years after Stage 3, a longitudinal follow-up of the cognitive assessment of the selected children occurred (Stage 4). Stage 5 took place three to four years after Stage 4. In this stage, the school performance of the children in the sixth grade was assessed. A more in-depth description of the stages in which relevant data was obtained for the present study is presented below. Additionally, an overview of the study design is shown in Figure 1.

In the first stage (September 1996 - June 1997), the parents of all children attending kindergarten in Maastricht, the Netherlands and the surrounding area $(N=2290)$ were invited to include their child in the SAM during a periodic health examination performed by the Youth Health Care Organization. The parents of 1317 children (699 boys and 618 
girls, mean age 5.9 years) provided informed consent and completed the Child Behavior Checklist (CBCL) (Achenbach, 1991; Verhulst et al., 1996) and the Precursors ADHD Questionnaire (see Hendriksen et al., 2002). No significant differences with respect to age, sex, and demographic factors were found between those who participated and those who chose not to (see Kroes et al., 2001). The parental level of education was high for $36.1 \%$, moderate for $40.4 \%$, low for $14.0 \%$, and missing for $9.4 \%$ of the participating children.

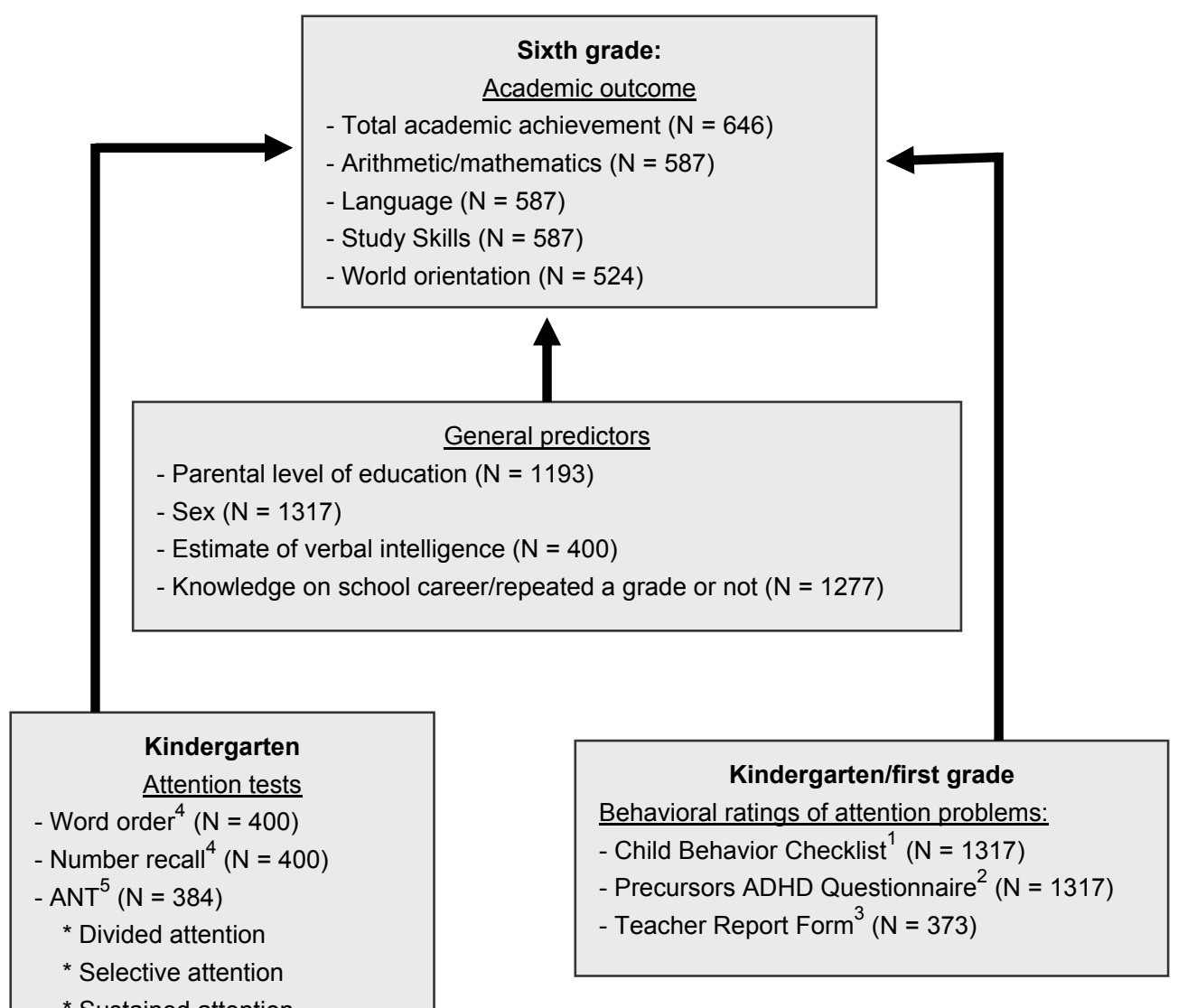

\section{Figure 1: Study design}

Note: ${ }^{1}$ Attention Problems scale, raw score (Achenbach, 1991); ${ }^{2}$ Subcales Attention/language problems, Impulsivity, and Hyperactivity, raw scores (Hendriksen et al., 202); ${ }^{3}$ Attention Problems scale, raw score (Achenbach, 1991); ${ }^{4}$ Kaufman Assessment Battery for Children, scaled scores (Kaufman \& Kaufman, 1983); ${ }^{5}$ Amsterdam Neuropsychological Tasks (De Sonneville, 1996), mean reaction time.

In the second stage (January 1997 - September 1997), 452 selected children were invited to participate in a cognitive evaluation, which included the attention tests used in 
the present study. The children were selected based on their $\mathrm{CBCL}$ scores. Three groups were established: an externalizing group $(\mathrm{N}=173$ : $\mathrm{CBCL}$ externalizing-scale score above the 90th percentile and/or $\mathrm{CBCL}$ attention problem score above the 95th percentile); an internalizing group ( $N=59$ : $C B C L$ internalizing-scale score above the 90th percentile and no fulfillment of the criteria for E); and a control group consisting of children who were matched to the children from the other two groups for age, sex, and school area ( $N=220$, normal CBCL scores). In the third stage (January 1998 - September 1998), the teachers of the selected children were asked to complete the Teacher Report Form (TRF) (Achenbach, 1991; Verhulst et al., 1996). The neuropsychological data collected in the fourth stage (January 2000 - October 2000) was not used in the present study.

In the fifth stage (May 2003 - March 2006), the researchers approached the parents that had completed the CBCL when their child was in kindergarten and asked if they would allow the researchers to view and use the academic scores of their children. The parents of 1279 of the original 1317 children (97\%) were contacted. The other 38 children had moved out of the region and their addresses were not known. These children who were in kindergarten during Stage One were, during Stage Five, in the sixth grade of elementary school. In that grade, almost all elementary schools in the Netherlands administer a standardized test of academic achievement. For the purpose of this study, we collected the data of one such test, namely the CITO elementary education final test (hereafter abbreviated as the CITO). The CITO is used at $85 \%$ of the elementary schools in the Netherlands. We collected the data derived from the CITO to assess the academic performance of these children.

Parents who did not respond within six months were reminded with a second request letter. The response rate was $75.8 \%$. The parents of 858 children provided their permission to release their child's academic scores. The parents of 112 children did not consent. Of the 858 children whose parents did consent, 646 had completed a CITO $(84 \%)$. The remaining $16 \%$ of the children completed other tests, such as an intelligence test $(\mathrm{N}=18)$ or less common academic tests like the Basis Niveau Test (Basic Level Test, $N=72$, Swets \& Zeitlinger, 1998). The results of these tests could not be compared directly to the CITO.

Of the 858 participating children, 40 had attended a school for children with special needs. Because special needs schools generally do not administer the CITO, we do not report on this group here, meaning that the sample included only children enrolled in regular elementary school education.

\section{Instruments}

Previous studies have shown that all of the measures used in this study can validly and reliably be administered to children of the age-group we studied (Bleichrodt, Drenth, Zaal, \& Resing, 1987; De Sonneville, 1999; Evers, van Vliet-Mulder, \& Goot, 2000; Hendriksen, Steyaert, Kroes, \& Vles, 2002; Kalff et al., 2005; Kaufman \& Kaufman, 1983; Verhulst, van der Ende, \& Koot, 1996).

Academic outcome (measured in the sixth grade): Educational achievement was assessed using a standardized test of academic performance. We were interested both in total academic achievement and in performance on specific domains, such as language and mathematics. For this purpose, the data from the CITO were gathered (see 
www.citogroep.nl/com_edu/menu_fr.htm and Bartels et al., 2002 for more information). The CITO is a standardized test of academic performance in the Netherlands that is administered, by the classroom teacher, to all children in the sixth grade on three consecutive February mornings. The CITO is an assessment tool independent of the teacher that can guide parents and professionals in choosing the most appropriate secondary school academic program for their children. According to a study conducted by the CITO publishers, the CITO results agree with the teachers' assessment for $80 \%$ of the children assessed. For $10 \%$ of the children, the teacher thinks the CITO results underestimate the capabilities of the child and, for the other $10 \%$, the teacher believes that the CITO results overestimate the capabilities of the child. The results of this study can be found on the following website: www.citogroep.nl/share/eb/Verslag_vragenlijst.pdf.

The CITO consists of 290 multiple-choice items assessing four different academic skills, namely arithmetic/mathematics (60 items on understanding figures, mental arithmetic, percentages and fractions, calculations for measures, weights, money, and periods of time), language (100 items on spelling, writing, reading comprehension, and vocabulary), study skills (40 items that deal with not only textbook material and other sources of information such as the telephone directory but also reading and understanding diagrams, schedules, tables and graphs), and world orientation (90 items on applying knowledge acquired in the fields of geography, history, biology, physics, civics and religious movements). This last scale is not obligatory, meaning that each school can choose to include or exclude this domain. Scores on these four academic domains result in a percentage score (ranging from 0 to 100\%). In addition, the CITO characterizes the child with a global standardized score (ranging from 501 to 550) which reflects overall academic achievement. These five CITO measures were used in the present study.

For 646 children, the CITO total score was available ( $49.1 \%$ of the original sample). For the academic domains arithmetic/mathematics, language, and study skills, we were able to acquire the scores of 587 children. Further, on the domain world orientation, the scores for 524 children were available. The mean CITO total score of our sample was 538.6 (SD = 8.3). This score was slightly, but significantly, higher than the overall Dutch mean on the CITO total score, which was 535.0 (one-sample T-test: 11.1, $p<.001$ ). Some of the participants $(N=106)$ had repeated a grade during regular elementary education. These children performed significantly poorer on the CITO than the children who passed through all grades successfully (CITO total score: mean $=533.5, \mathrm{SD}=9.0$ vs. mean $=539.4, \mathrm{SD}=8.0, p<.001$ ). To control for this difference, a dummy variable indicating the student type was included in all analyses. This was coded as follows: $1=$ successful school career; 2 = repeated a grade.

Estimate of verbal intelligence (completed in kindergarten): The Picture Vocabulary Test of the Revised Amsterdam Child Intelligence Test (RAKIT) (Bleichrodt et al., 1987; Evers et al., 2000) measures passive vocabulary ability and was used to estimate verbal intelligence. Age-adjusted standard scores were used as the outcome variable (range 1-29, mean $=15, S D=5$ ).

Attention tests (completed in kindergarten): The performance of children on five attention tests was analyzed in this study. The Number Recall test and the Word Order test of the Kaufman Assessment Battery for Children (K-ABC) (Kaufman \& Kaufman, 1983) were used to measure short-term memory and attention span/working memory, respectively. 
Age-adjusted standard scores that range from 1 to 19 (mean $=10, S D=3$ ) were used in the analyses. The Sustained Attention (part 1), Memory Search (part 2), and Focussed Attention tasks of a computerized test battery called the Amsterdam Neuropsychological Tasks (ANT) (De Sonneville, 1999; Kalff et al., 2005), were used to measure sustained, divided, and selective attention, respectively. During all three tasks, the child was required to respond as rapidly and accurately as possible to visual stimuli presented on a laptop screen. The outcome variable for each task was the mean reaction time of the hits in seconds (lower is better).

Behavioral ratings of attention problems (completed in kindergarten and the first grade): Five indices of attention and attention-related problems as judged by caregivers were used in this study. Higher scores on all six indices generally indicate more problems. The first is the CBCL Attention Problems scale (11 items, Achenbach, 1991; Verhulst et al., 1996), which was completed by the parent(s) in the first stage of the study. The outcome variable was the raw score (range 0-22). Secondly, the Teacher Report Form (TRF) Attention Problems scale (20 items) was used (Achenbach, 1991; Verhulst et al., 1996). This scale is comparable to that of the CBCL. The TRF was completed by the child's first grade classroom teacher. The outcome variable was the raw score (range 0-40). Thirdly, three scores of the Precursors ADHD Questionnaire were used (PAQ) (Hendriksen et al., 2002), namely the PAQ Attention/Language Problems Scale (5 items), the PAQ Impulsivity Scale (6 items), and the PAQ Hyperactivity Scale (5 items). These scales were completed by the parent(s) of all the children included in the First Stage. The raw scores were used as the outcome measures (range $=0-10$ for the attention/language problems and the hyperactivity scales and 0-12 for the impulsivity scale).

\section{Statistical analyses}

With respect to the sex of the child, the participants of the study, which were the children whose CITO scores were available ( $49.1 \%$ of the original sample), did not differ from the non-participants, which were the children whose CITO scores were not available. However, the participants did have higher Picture Vocabulary scores (mean $=14.6, \mathrm{SD}=4.7$ ) than the non-participants (mean $=12.9, \mathrm{SD}=5.1 ; p=.001$ ). They also came from higher educated families (participants: $8.0 \%$ low, 33.4\% middle, $58.6 \%$ high; non-participant: $23.4 \%$ low, $36.9 \%$ middle, $39.7 \%$ high; $p<.001$ ). These differences were corrected for using the "sampling weight option" of STATA 8 (Statacorp, 2003). In addition, the differences between the selected sample and the original population were corrected for with sampling weights as well (see Kroes et al., 2002).

After ensuring that no extreme values could influence the results, linear regression analyses were used to investigate the nature of the relationship between attention and academic performance. Separate analyses were conducted for each of the five domains of academic outcome (CITO Total, CITO Arithmetic/Mathematics, CITO Language, CITO Study Skills, and CITO World Orientation). A two-step method was used. First and foremost, in order to investigate the influence of attention on academic outcome, the five behavioral ratings of attention problems and the five attention test scores were entered in a linear regression analysis. Secondly, to investigate the influence of attention on academic outcome when controlling for general predictors of academic outcome, all ten attention measures were included in a stepwise linear regression analysis together with four general predictors of academic outcome, namely parental level of education, sex of 
the child, the estimate of verbal intelligence, and student type (having repeated a grade or not). The number of children for which we had complete data varied according to the academic outcome domains. These were CITO total score $(N=147)$, language, mathematics, and study skills $(\mathrm{N}=133)$, and world orientation $(\mathrm{N}=117)$. The significance level for all analyses was set at .05 .

\section{Results}

\section{Relationship between attention and academic outcome}

Table 1 displays the results of the linear regression analyses for the relationship between the ten attention measures and the five domains of academic outcome. One or more of the attention measures were significantly associated with all academic outcome domains. The amount of variance explained by the attention measures was smallest for world orientation (5\%) and largest for total academic achievement $(29 \%)$. In the arithmetic/ mathematics, language, and study skills models, the attention measures explained 20 to $26 \%$ of the variation. This suggests that attention is indeed strongly related to academic outcome.

Table 1: Relationship between attention and academic outcome

\begin{tabular}{|c|c|c|c|c|c|}
\hline & CITO Total $^{1}$ & CITO Maths ${ }^{2}$ & CITO Lang $^{3}$ & CITO Study ${ }^{4}$ & CITO WO \\
\hline \multicolumn{6}{|l|}{ Model } \\
\hline F value & $7.92^{* \star *}$ & $10.83^{\star * \star}$ & $18.73^{* * *}$ & $12.02^{* * *}$ & $4.50^{*}$ \\
\hline $\mathrm{df1}, \mathrm{df2}$ & 4,142 & 4,128 & 2,130 & 4,128 & 1,115 \\
\hline $\mathrm{R} 2$ & $28.74 \%$ & $25.85 \%$ & $24.91 \%$ & $20.04 \%$ & $5.21 \%$ \\
\hline \multicolumn{6}{|c|}{ Cognitive attention scores: coefficients (SE) } \\
\hline $\mathrm{WO}^{6}$ & $1.08(.24)$ & - & $3.90(.71)$ & $3.11(.82)$ & $2.05(.97)$ \\
\hline$N R^{6}$ & - & $3.60(1.02)$ & - & - & - \\
\hline $\mathrm{DA}^{7}$ & - & - & - & - & - \\
\hline SuA $^{7}$ & - & - & - & - & - \\
\hline $\operatorname{SeA}^{7}$ & $-5.39(1.78)$ & $-20.67(6.40)$ & $-11.98(5.51)$ & - & - \\
\hline \multicolumn{6}{|c|}{ Behavioral ratings of attention problems: coefficients (SE) } \\
\hline $\mathrm{CBCL}^{8}$ & - & - & - & - & - \\
\hline TRF $^{9}$ & $.57(.23)$ & $.91(.43)$ & - & - & - \\
\hline$P A Q A^{10}$ & $-1.87(.64)$ & $-6.38(1.88)$ & - & $-5.29(2.04)$ & - \\
\hline PAQ ${ }^{10}$ & - & - & - & - & - \\
\hline PAQ $H^{10}$ & - & - & - & - & - \\
\hline
\end{tabular}

Note: Only significant predictors $(p<.05)$ are shown; ${ }^{1}$ CITO Total score; ${ }^{2}$ CITO Arithmetic / mathematics score; ${ }^{3}$ CITO Language score; ${ }^{4}$ CITO Study Skills; ${ }^{5}$ ClTO World Orientation; ${ }^{6}$ Kaufman Assessment Battery for Children (Kaufman \& Kaufman, 1983), scaled scores (WO $=$ Word Order, $N R=$ Number Recall); ${ }^{7}$ Amsterdam Neuropsychological Tasks (De Sonneville, 1996), mean reaction time (SuA = Sustained attention, $D A=$ Divided attention, $\mathrm{SeA}=$ Selective attention); ${ }^{8}$ Child Behavior Checklist, Attention Problems scale, raw score (Achenbach, 1991); ${ }^{9}$ Teacher Report Form, Attention Problems scale, raw score (Achenbach, 1991); ${ }^{10}$ Precursors ADHD Questionnaire $(A=$ Attention/language problems subscale, $I=$ impulsivity subscale, $H=$ hyperactivity subscale), raw scores (Hendriksen et al., 202); ${ }^{* *} p<.001 ;{ }^{* *} p<.01 ;{ }^{*} p<.05$. 
With respect to the attention tests, three of the five performance scores were associated with academic outcome on one or more domains $(p<.05)$. Firstly, better performance on the word order task predicted higher academic outcome for all domains except arithmetic/mathematics. Secondly, the selective attention task predicted total academic achievement and outcome for the domains arithmetic/mathematics and language. Faster response speed on the selective attention task was associated with higher academic outcome. The third attention test that was associated with academic outcome was the number recall task. Higher performance on this test was associated with higher academic outcomes in arithmetic/mathematics.

With respect to the behavioral questionnaires for attention problems, two of the five ratings were associated with academic outcome. A higher score on the PAQ attention/language score, which is indicative of attention problems, was associated with lower total academic achievement and lower outcomes for arithmetic/mathematics and study skills. Contrary to our expectations, a higher score on the TRF attention problems scale, which also is indicative of attention problems, predicted a better total academic achievement and a higher outcome for the arithmetic/mathematics domain.

\section{Relationship between attention and academic outcome, after controlling for general predictors}

Table 2 displays the results of the linear regression analyses that aimed to investigate the relationship between the ten attention measures and the five domains of academic outcome, while controlling for four general predictors, namely parental level of education, sex, estimate of verbal intelligence, and student type. We found that higher parental level of education predicted better outcomes on all domains. In addition, higher verbal intelligence predicted better outcomes on all domains except arithmetic/mathematics. Further, boys performed better than girls on arithmetic/mathematics but no gender differences were found for any of the other domains. Lastly, children who had repeated a grade performed poorer on arithmetic/mathematics but, with respect to the other domains, no differences were found between those who had repeated a grade and those who had not.

We found that, even after controlling for the four general predictors, one or more of the attention measures continued to significantly predict academic outcome in all domains except for world orientation. This means that the previously mentioned association between word order and outcomes on the world orientation domain lost its significance. For the other aspects of academic outcome, the same attention tests remained significant even when the four general predictors were included. The word order task predicted total academic achievement, language, and study skills. The selective attention task predicted total academic achievement, arithmetic/mathematics and language. Lastly, the number recall task predicted arithmetic/mathematics.

In contrast, the behavioral ratings of attention problems predicted academic outcome less often after we controlled for the general predictors. A higher PAQ attention/language problems score, which indicates more problems, predicted poorer outcomes in the domains of arithmetic/mathematics and study skills only. Thus, the association between $P A Q$ attention/language problems and total academic achievement was no longer significant. In addition, the TRF attention problems score also lost its significance. Clearly, cognitive performance on attention tests appears to be more important than behavioral 
ratings of attention problems with respect to predicting academic outcome, especially after controlling for general predictors of academic outcome.

Table 2: Relationship between attention and academic outcome, controlled for general predictors

\begin{tabular}{|c|c|c|c|c|c|}
\hline & CITO Total ${ }^{1}$ & CITO Maths $^{2}$ & CITO Lang $^{3}$ & CITO Study ${ }^{4}$ & CITO WO $^{5}$ \\
\hline \multicolumn{6}{|l|}{ Model } \\
\hline $\mathrm{F}$ value & $12.09^{* * *}$ & $16.10^{* * *}$ & $23.85^{\star * *}$ & $15.63^{* * *}$ & $19.66^{\star * *}$ \\
\hline df1, df2 & 4,142 & 6,126 & 4,128 & 4,128 & 2,114 \\
\hline R2 & $43.26 \%$ & $42.19 \%$ & $50.74 \%$ & $40.29 \%$ & $37.52 \%$ \\
\hline \multicolumn{6}{|c|}{ General predictors: coefficients (SE) } \\
\hline $\mathrm{PLE}^{6}$ & $1.67(.41)$ & $4.90(1.71)$ & $5.05(1.21)$ & $4.44(1.33)$ & $6.02(1.74)$ \\
\hline Sex $^{7}$ & - & $-15.67(5.77)$ & - & - & - \\
\hline$V I Q^{8}$ & $.50(.20)$ & - & $1.63(.50)$ & $1.57(.54)$ & $2.23(.64)$ \\
\hline S. Type ${ }^{9}$ & - & $-13.30(6.20)$ & - & - & - \\
\hline \multicolumn{6}{|c|}{ Cognitive attention scores: coefficients (SE) } \\
\hline WO $^{10}$ & $.69(.19)$ & - & $2.47(.59)$ & $1.85(.62)$ & - \\
\hline $\mathrm{NR}^{10}$ & - & $3.23(.096)$ & - & - & - \\
\hline $\mathrm{DA}^{11}$ & - & - & - & - & - \\
\hline $\operatorname{SuA}^{11}$ & - & - & - & - & - \\
\hline $\operatorname{Se} A^{11}$ & $-4.22(1.41)$ & $-13.82(5.76)$ & $-10.72(3.81)$ & - & - \\
\hline \multicolumn{6}{|c|}{ Behavioral ratings of attention problems: coefficients (SE) } \\
\hline $\mathrm{CBCL}^{12}$ & - & - & - & - & - \\
\hline $\mathrm{TRF}^{13}$ & - & - & - & - & - \\
\hline PAQ A ${ }^{14}$ & - & $-5.04(1.59)$ & - & $-4.02(1.72)$ & - \\
\hline PAQ I ${ }^{14}$ & - & - & - & - & - \\
\hline PAQ H ${ }^{14}$ & - & - & - & - & - \\
\hline
\end{tabular}

Note: Only significant predictors $(p<.05)$ are shown; ${ }^{1}$ CITO Total score; ${ }^{2}$ CITO Arithmetic / mathematics score; ${ }^{3}$ CITO Language score; ${ }^{4}$ CITO Study Skills; ${ }^{5}$ CITO World Orientation; ${ }^{6}$ Parental level of education; ${ }^{7}$ Coded as: 1 = boy, 2 = girl; ${ }^{8}$ (Bleichrodt et al., 1984); ${ }^{9}$ Student type, coded as $1=$ children who passed through elementary school successfully, 2 = children who repeated at least one grade; ${ }^{10}$ Kaufman Assessment Battery for Children (Kaufman \& Kaufman, 1983), scaled scores $\left(W O=\right.$ Word Order, NR = Number Recall); ${ }^{11}$ Amsterdam Neuropsychological Tasks (De Sonneville, 1996), mean reaction time (SuA $=$ Sustained attention, $D A=$ Divided attention, $S e A=$ Selective attention); ${ }^{12}$ Child Behavior Checklist, Attention Problems scale, raw score (Achenbach, 1991); ${ }^{13}$ Teacher Report Form, Attention Problems scale, raw score (Achenbach, 1991); ${ }^{14}$ Precursors $A D H D$ Questionnaire $(A=$ Attention/language problems subscale, $I=$ impulsivity subscale, $H=$ hyperactivity subscale), raw scores (Hendriksen et al., 202); ${ }^{* *} p<.001 ;{ }^{* *} p<.01 ;{ }^{*} p<.05$.

\section{Discussion}

Using a longitudinal design, we studied the influence of attention test scores and behavioral ratings of attention problems on children's academic achievement. Aspects of atten- 
tion were measured in kindergarten and the first grade and scores for academic outcome were obtained in the sixth grade. To our knowledge, no similar follow-up studies have been reported in the literature. Two main results were found. Firstly, the influence of attention on academic outcome was impressive. Attention test scores explained $29 \%$ of the variance of the total score on a standardized academic test, $26 \%$ of the variance in arithmetic/mathematics, and $25 \%$ of the variance in language. Evidently, attention is strongly related to academic outcome in children attending elementary schools.

Secondly, we looked at the predictive value of attention measures while taking four variables that are known to be associated with academic achievement in children into account. These variables were sex, parental level of education, verbal intelligence, and having repeated a grade or not (see Greenberg et al., 1999; Rabiner \& Coie, 2000; Resnick et al., 1999). After controlling for these factors, attention remained important for the prediction of academic outcome. One or more attention measures were significantly associated with total academic achievement, language, arithmetic/mathematics, and study skills. World orientation was the only academic domain that was not significantly predicted by attention measures after controlling for the general predictors. In other words, attention was strongly associated with total academic achievement and achievement on the core domains of academic performance.

We used two methods to measure attention, namely performance on attention tests and behavioral ratings of attention problems. The results show that performance on attention tests showed the strongest correlation with academic outcome. The cognitive aspect that was found to be related most often to academic outcome was attention span/working memory. This was measured using the Word Order subtest of the K-ABC (Kaufman \& Kaufman, 1983). Performance on this test was positively related to academic outcome in the following domains: total academic achievement, language, and study skills. Interestingly, another aspect of memory predicted arithmetic/mathematics, namely short-term memory. In studies on developmental disorders in children, memory functions have been demonstrated to be related to scholastic achievement (Gathercole \& Alloway, 2006; Papageorgiou et al., 2005). We know of only one previous study relating working memory to academic performance in normally developing school children (Aronen, Vuontela, Steenari, Salmi, \& Carlson, 2005). This recent cross-sectional study with 66 children aged six to thirteen found that good spatial working memory performance was associated with academic success at school (Aronen et al., 2005). The large sample and the longitudinal design of our study in addition to the subdivision of academic outcome in specific domains, increases the consistency of our conclusion that working and short-term memory are indeed important factors to consider when predicting academic outcome in children attending regular elementary school.

Selective attention was the second cognitive function found to be related to academic outcome. Performance on this test was associated with arithmetic/mathematics, language, and total academic achievement. Faster response speed was related to higher academic scores. In contrast, levels of sustained and divided attention at kindergarten age were not predictive of academic outcome in the sixth grade. This discrepancy could point to a specific relationship between selective attention and academic outcome. On the other hand, it could also be explained by the distinct developmental patterns of attention functions. Selective attention is thought to develop at a faster rate than sustained or divided attention (Anderson, 2002). At kindergarten age, selective attention is already well developed and, as a result, this form of attention is thought to result in a clear differ- 
entiation between weak and strong performance in children (Anderson, 2002). In contrast, sustained and divided attention continue to develop until a much older age. Consequently, even when valid and reliable tests are used, performance of children in kindergarten on tests of sustained and divided attention may not generate enough variation to distinguish between actual performance levels. If this claim is correct, we could expect to find the opposite results when predicting the academic outcome of older children (e.g. attention measured at twelve years for the prediction of academic outcome at eighteen years). In other words, at different ages, distinct cognitive aspects of attention may be important for the prediction of academic outcome. We thus recommend focusing future research on the differential relationship between selective, sustained, and divided attention and the academic outcome of young adolescents.

Behavioral ratings of attention problems were also found to be involved in the prediction of academic outcome, although not as strongly as the attention tests. More specifically, outcomes in arithmetic/mathematics and study skills could be predicted using the attention/language problems scale of a precursor questionnaire for ADHD. A higher rating on this questionnaire, which indicates more attention problems, was associated with lower academic achievement. Interestingly, after controlling for the previously mentioned general predictors, attention problems measured with broad-band behavioral scales like the CBCL and TRF did not contribute significantly to the prediction of academic achievement in the sixth grade. Our findings thus suggest that, to predict academic outcome, a specific questionnaire that screens for precursors of ADHD may be more suitable than general questionnaires.

The studied behavioral ratings of impulsivity and hyperactivity did not predict academic outcome in any domain. Thus, we can conclude that no general relationship between characteristics/precursors of ADHD in kindergarten and academic outcome in the sixth grade exists. Rather, there seems to be a more specific association between inattention and some aspects of academic outcome. Although this finding is beyond the scope of this paper, it could be interesting in light of the academic difficulties experienced by children with ADHD. Their performance in school may be related more to inattention than to impulsivity and hyperactivity. To date, consensus on this issue has not occurred and, consequently, these relationships are worthy of further investigation (Baeyens, Roeyers, \& Vande Walle, 2006; Weiss, Worling, \& Wasdell, 2003).

The results of this study have to be interpreted in the light of several limitations. Firstly, the sample included only children attending regular education. This reduces the extent to which the findings can be generalized to the whole population. However, we expect that the association we found between attention and academic outcome is at least equal but probably stronger in children with special needs because of the high percentage of developmental and attention disorders in this group (Winters, 1997). Secondly, children with developmental disorders were not excluded from the study as long as they attended regular education (for an overview of child psychiatric diagnoses in this population, see Kroes et al., 2001). It is thus possible that the relationships we found between attention and academic outcome were not present in the whole sample, but only, for example, in the subgroup of children with ADHD (3.8\%). However, post-hoc analyses indicated that the results were essentially the same when children with ADHD were excluded from the analyses. Consequently, our results do seem to reflect a population wide association between attention and academic outcome. Thirdly, our findings are determined for a large extent by the tasks used to assess attention and academic per- 
formance. Performance on these tests could have been influenced by factors such as motivation, dedication, nervousness, and background noise. We have taken care to minimize the effects of this limitation, underlying all studies using tests, by including only tasks known to be sensitive to the function they are intended to measure in children of the age-groups studied.

The results of the present study have important clinical and educational implications. It seems that, in general, cognitive performance on attention tests is a better predictor of a child's academic career than behavioral ratings of attention problems. The examination of working memory and selective attention proved to be of particular importance. In terms of the practical implications of this study, it appears that using a wide range of attention tests to evaluate all children is unnecessary and likely undesirable given that, for all the academic domains studied except world orientation, levels of short-term and working memory were found to be predictive. In addition, the scores on a parent questionnaire that screens for precursors of ADHD predicted later study skills and arithmetic/mathematics performance. We thus recommend using these tests to screen children whose preparatory reading and counting skills are below average. This method could help to identify children who are at risk for negative academic outcome and could thus allow for interventions at a young age (Sonuga-Barke, 2006; Wright \& Limond, 2004). However, before implementing this, future research is necessary to determine the cut-off scores that are indicative for adverse academic outcome on the tests used. 


\section{References}

Achenbach, T. M. (1991). Manual for the Child Behavior Checklist/4-18 and 1991 Profile. Burlington: University of Vermont Department of Psychiatry.

American Psychiatric Association (1994). Diagnostic and statistical manual of mental disorders (4th ed.). Washington DC: American Psychiatric Association.

Anderson, P. (2002). Assessment and development of executive function (EF) during childhood. Child Neuropsychology, 8, 71-82.

Aronen, E. T., Vuontela, V., Steenari, M. R., Salmi, J., \& Carlson, S. (2005). Working memory,psychiatric symptoms, and academic performance at school. Neurobiology of Learning and Memory, 83, 33-42.

Baeyens, D., Roeyers, H., \& Walle, J. V. (2006). Subtypes of attention-deficit/hyperactivity disorder (ADHD): distinct or related disorders across measurement levels? Child Psychiatry and Human Development, 36, 403-417.

Barkley, R. A., Fischer, M., Smallish, L., \& Fletcher, K. (2006). Young adult outcome of hyperactive children: adaptive functioning in major life activities. Journal of the American Academy of Child and Adolescent Psychiatry, 45, 192-202.

Baron, I. S. (2004). Neuropsychological evaluation of the child. Oxford: University Press.

Bartels, M., Rietveld, M. J., Van Baal, G. C., \& Boomsma, D. I. (2002). Heritability of educational achievement in 12-year-olds and the overlap with cognitive ability. Twin Research, 5, 544-553.

Belka, D. E., \& Williams, H. G. (1979). Prediction of later cognitive behavior from early school perceptual-motor, perceptual, and cognitive performances. Perceptual and Motor Skills, 49, 131141.

Biederman, J. (2005). Attention-deficit/hyperactivity disorder: a selective overview. Biological Psychiatry, 57, 1215-1220.

Bleichrodt, N., Drenth, P.J.D., Zaal, J.N., \& Resing, W.C.M. (1987). Rakit: Handleiding bij de Revisie Amsterdamse Kinder Intelligentie Test [RAKIT: Manual of the revised Amsterdam intelligence test for children]. Lisse: Swets \& Zeitlinger B.V.

Bruininks, V. L., \& Mayer, J. H. (1979). Longitudinal study of cognitive abilities and academic achievement. Perceptual and Motor Skills, 48, 1011-1021.

Cooley, E. L., \& Morris, R. D. (1990). Attention in children: A neuropsychologically based model for assessment. Developmental Neuropsychology, 6, 239-274.

De Sonneville, L. M. J. (1999). Amsterdam Neuropsychological Tasks: A computer-aided assessment program. In: B. P. L. M. Den Brinker, P. J., Beek, A. N. Brands, S. J. Maarse, \& L. J. M. Mulder (Eds). Cognitive ergonomics, clinical assessment and computer-assisted learning: Computers in Psychology (pp. 187-203). Lisse, the Netherlands: Swets \& Zeitlinger.

DeGarmo, D. S., Forgatch, M. S., \& Martinez, C. R., Jr. (1999). Parenting of divorced mothers as a link between social status and boys' academic outcomes: unpacking the effects of socioeconomic status. Child Development, 70, 1231-1245.

DeShazo Barry, T., Lyman, R. D., \& Grofer Klinger, L. (2002). Academic underachievement and Attention-Deficit/Hyperactivity Disorder: the negative impact of symptom severity on school performance. Journal of School Psychology, 40, 259-283.

Durlak, J. (2001). School problems in children. In: M. C. Roberts (Ed.), Handbook of clinical child psychology (3rd ed.). New York: John Wiley \& Sons, Inc.

Evers, A., van Vliet-Mulder, J. C., \& Groot, C. J. (2000). Documentatie van tests en testresearch in Nederland. Deel I: Testbeschrijvingen [Documentation of tests and testresearch in the Netherlands. Part I: Test descriptions]. Assen: van Gorcum.

Gathercole, S. E., \& Alloway, T. P. (2006). Practitioner review: short-term and working memory impairments in neurodevelopmental disorders: diagnosis and remedial support. Journal of Child Psychology and Psychiatry, 47, 4-15.

Greenberg, M. T., Lengua, L. J., Coie, J. D., \& Pinderhughes, E. E. (1999). Predicting developmental outcomes at school entry using a multiple-risk model: four American communities. The Conduct Problems Prevention Research Group. Developmental Psychology, 35, 403-417. 
Hendriksen, J. G. M., Steyaert, J., Kroes, M., \& Vles, J. S. H. (2002). VVA: Vragenlijst Voorlopers ADHD [PAQ: Precursors ADHD Questionnaire]. Leiden: PITS.

Hinshaw, S. P. (1992). Externalizing behavior problems and academic underachievement in childhood and adolescence: causal relationships and underlying mechanisms. Psychological Bulletin, 111, 127-155.

Horwood, L. J., \& Fergusson, D. M. (1998). Breastfeeding and later cognitive and academic outcomes. Pediatrics, 101, E9.

Hurks, P. P., Vles, J. S., Hendriksen, J. G., Kalff, A. C., Feron, F. J., Kroes, M., van Zeben, T. M., Steyaert, J., \& Jolles, J. (2006). Semantic category fluency versus initial letter fluency over 60 Seconds as a measure of automatic and controlled processing in healthy school aged children. Journal of Clinical and Experimental Neuropsychology, 28, 684-695.

Jefferis, B. J., Power, C., \& Hertzman, C. (2002). Birth weight, childhood socioeconomic environment, and cognitive development in the 1958 British birth cohort study. British Medical Journal, $325,305$.

Kaufman, A.S., \& Kaufman, N.L. (1983). K-ABC. Kaufman Assessment Battery for Children. Circle Pines, Minnesota: American Guidance Services.

Kalff, A. C., De Sonneville, L. M., Hurks, P. P., Hendriksen, J. G., Kroes, M., Feron, F. J., Steyaert, J., van Zeben, T. M., Vles, J. S., \& Jolles, J. (2005). Speed, speed variability, and accuracy of information processing in 5 to 6 -year-old children at risk of ADHD. Journal of the International Neuropsychological Society, 11, 173-183.

Kroes, M., Kalff, A. C., Kessels, A. G., Steyaert, J., Feron, F. J., van Someren, A. J., Hurks, P. P., Hendriksen, J. G., van Zeben, T. M., Rozendaal, N., Crolla, I. F., Troost, J., Jolles, J., \& Vles, J. S. (2001). Child psychiatric diagnoses in a population of Dutch schoolchildren aged 6 to 8 years. Journal of the American Academy of Child and Adolescent Psychiatry, 40, 1401-1409.

Kroes, M., Kalff, A. C., Steyaert, J., Kessels, A. G., Feron, F. J., Hendriksen, J. G., van Zeben, T. M., Troost, J., Jolles, J., \& Vles, J. S. (2002). A longitudinal community study: do psychosocial risk factors and child behavior checklist scores at 5 years of age predict psychiatric diagnoses at a later age? Journal of the American Academy of Child and Adolescent Psychiatry, 41, 955963.

Masten, A. S., Roisman, G. I., Long, J. D., Burt, K. B., Obradovic, J., Riley, J. R., Boelcke-Stennes, K., \& Tellegen, A. (2005). Developmental cascades: linking academic achievement and externalizing and internalizing symptoms over 20 years. Developmental Psychology, 41, 733-746.

Murphy, K. R., Barkley, R. A., \& Bush, T. (2002). Young adults with attention deficit hyperactivity disorder: subtype differences in comorbidity, educational, and clinical history. Journal of Nervous and Mental Disease, 190, 147-157.

Papageorgiou, C., Anagnostopoulos, D., Giannakakis, G. A., Sakelariou, K., Tsiaparas, N., Paraskevopoulou, P., Nikita, K. S., Rabavilas, A., \& Soldatos, C. (2005). Preattentive deficits in developmental disorders of scholastic skills. NeuroReport, 16, 1829-1832.

Rabiner, D., \& Coie, J. D. (2000). Early attention problems and children's reading achievement: a longitudinal investigation. The Conduct Problems Prevention Research Group. Journal of the American Academy of Child and Adolescent Psychiatry, 39, 859-867.

Resnick, M. B., Gueorguieva, R. V., Carter, R. L., Ariet, M., Sun, Y., Roth, J., Bucciarelli, R. L., Curran J. S., Mahan, C. S. (1999). The impact of low birth weight, perinatal conditions, and sociodemographic factors on educational outcome in kindergarten. Pediatrics, 104, e74.

Sonuga-Barke, E. (2006). Longitudinal analyses of risk-disorder pathways: the key to early identification and targeted intervention. Journal of Child Psychology and Psychiatry, 47, 757-758.

Statacorp (2003). STATA 8 Base reference manual. College Station, Texas: Stata Press.

Swets \& Zeitlinger (1998). Basis Niveau Test (BNT) [Basic Level Test]. Handleiding. Lisse: Swets \& Zeitlinger.

Tannock, R. (2003). Neuropsychology of attention disorders. In: S. J. Segalowitz. \& I. Rapin. (Eds.), Handbook of neuropsychology (2nd ed., pp. 753-784). Amsterdam: Elsevier Science B.V. 
Verhulst, F. C., van der Ende J., \& Koot, H.M. (1996). Handleiding voor de CBCL (Child Behavior Checklist) 4-18 [Manual for the CBCL]. Rotterdam: Afdeling Kinder en jeugdpsychiatrie, Sophia Kinderziekenhuis/Academisch Ziekenhuis Rotterdam/ Erasmus Universiteit Rotterdam, the Netherlands.

Verhulst, F. C., Koot, H. M., \& van der Ende, J. (1994). Differential predictive value of parents' and teachers' reports of children's problem behaviors: a longitudinal study. Journal of Abnormal Child Psychology, 22, 531-546.

Walker, D., Greenwood, C., Hart, B., \& Carta, J. (1994). Prediction of school outcomes based on early language production and socioeconomic factors. Child Development, 65, 606-621.

Wassenberg, R., Feron, F. J., Kessels, A. G., Hendriksen, J. G., Kalff, A. C., Kroes, M., Hurks, P. P., Beeren, M., Jolles, J., \& Vles, J. S. (2005). Relation between cognitive and motor performance in 5- to 6-year-old children: results from a large-scale cross-sectional study. Child Development, 76, 1092-1103.

Weiss, M., Worling, D., \& Wasdell, M. (2003). A chart review study of the inattentive and combined types of ADHD. Journal of Attention Disorders, 7, 1-9.

Winters, C. A. (1997). Learning disabilities, crime, delinquency, and special education placement. Adolescence, 32, 451-462.

Wright, I., \& Limond, J. (2004). A developmental framework for memory rehabilitation in children. Pediatric Rehabilitation, 7, 85-96.

Information about the CITO can be found at:

www.citogroep.nl/com_edu/menu_fr.htm

www.citogroep.nl/share/eb/Verslag_vragenlijst.pdf. 


\title{
CHAPTER 5
}

\section{Development of different aspects of sense of time}

\begin{abstract}
We investigated the development of sense of time in children, using a new questionnaire. Participants were 454 children (second - sixth grade) and 248 adults. Five aspects of sense of time could be distinguished: duration comparisons, sequential arrangement of months \& days, life expectancy, and events with and without a clear time component. The ability to estimate life expectancy and to arrange months \& days sequentially developed last, namely in the fourth grade. Verbal ability and sex influenced several aspects of sense of time, with girls performing better than boys. Thus, sense of time develops differentially in school children. These findings support a step-wise model of cognitive development.
\end{abstract}


'Sense of time' is a psychological construct that consists of different processes, among others the distinction between past, present, and future (Friedman, 2003); the relation between succession and duration (Piaget, 1946); knowledge of cyclic patterns of months and days (Friedman, 1989); the ability to estimate, produce, and reproduce certain time intervals (Block, Zakay, \& Hancock, 1999); and knowledge of time units and telling time (Friedman, 1978). Recently, investigators have become interested in the sense of time of individuals with Attention Deficit Hyperactivity Disorder (Barkley, 1997; Barkley, Edwards, Laneri, Fletcher, \& Metevia, 2001; Barkley, Koplowitz, Anderson, \& McMurray, 1997; Bauermeister et al., 2005; Meaux \& Chelonis, 2005; Rubia, Noorloos, Smith, Gunning, \& Sergeant, 2003; Smith, Taylor, Lidzba, \& Rubia, 2003; Sonuga-Barke, Saxton, \& Hall, 1998; Tannock, 2003). Although a sense of time is important for independent functioning (Piaget, 1946; Barkley, 1997), existing methods generally do not sufficiently take the multiple nature of the construct into account and may not be valid for daily life functioning. The aim of this study was to investigate development of different aspects of sense of time in school aged children in an ecologically valid way, by use of a short screening questionnaire.

The foundation for studies on sense of time was laid by Piaget (1946), in his experiments in which children had to judge the time and speed of two or more objects moving at different speed but arriving simultaneously. Fraisse (1964) continued the work on sense of time in children and stated that young children were better able to judge the duration of events than Piaget thought. Both Piaget and Fraisse agreed that an abstract representation of sense of time is not present before the age of sixteen. This is illustrated by the fact that until adolescence, children are likely to believe that their age is altered when clocks are set ahead or back for daylight saving time (by Michaud, described in Fraisse, 1964). Thus, concrete aspects of sense of time are acquired at an earlier age than more abstract aspects. This is in line with a stepwise model of cognitive development, as described by Anderson (2002). Recently, investigators have studied sense of time using the Biber Cognitive Estimation Test (BCET, Bullard et al., 2004; Liss, Fein, Bullard, \& Robins, 2000). In this test, children have to estimate the duration of several events, which they are expected to do at an adult level by the age of nine (Bullard et al., 2004). The BCET aims to measure cognitive estimation and uses questions for which it is unlikely that participants know the real answer to. Thus, general knowledge is filtered out as much as possible and the events of which the duration has to be estimated in the BCET are unfamiliar to children (the items concern building a house, writing a one-page letter, ironing a shirt, fresh milk going sour in the refrigerator, and the age of the oldest living person in the United States). In other words, the BCET does not measure aspects of sense of time that are useful in daily life, but rather time aspects of cognitive estimation. This means that the BCET is not a suitable measure for studying the sense of time in daily life.

Friedman $(1986,1990,2000,2003)$ performed a series of studies on the development of sense of time in children that seem to be more ecologically valid. One of the topics Friedman studied is the ability of children to make order judgments with respect to familiar sequences, namely days of the weeks and months (1986), and daily activities (1990). In these experiments, children had to judge, for example, whether Saturday or Monday comes next after Thursday [the order of days and months] (forward), and whether eating lunch or going to bed at night comes before eating breakfast [daily activities] (backward). Results showed that children can make forward judgments about days 
and months by ten years of age and backward judgments by the age of fifteen. Knowledge of the order of daily activities developed at a younger age: children aged seven performed accurately on both the forward and the backward conditions. Friedman explained this difference in development by the fact that young children's activities are not as clearly differentiated by days and months as they are by time of day.

Other studies in which sense of time was investigated using familiar events were based on four methods, by which children had to produce a particular interval, reproduce a specific interval that was shown previously, judge which of two or more intervals is shortest or longest, and verbally estimate how long an interval is. Studies using these computerized methods showed that normally developing children younger than 13 years generally make larger verbal estimates of time intervals, comparable productions, and shorter reproductions of duration than older children and adults (Block et al., 1999). Performance of these tasks requires cognitive functions other than a sense of time, namely attention, working memory, and inhibition (Block et al., 1999; McCormack, Brown, Smith, \& Brock, 2004; Van Scoy \& Fairchild, 1993; Zakay, 1992). Also, it is questionable to what extent the (very) small intervals used in these studies (generally ranging from milliseconds to a couple of minutes) are representative of a sense of time in daily life. Thus, the ecological validity of these methods to measure sense of time appears to be poor.

In summary, if we want to measure sense of time in an ecologically valid way, the task must concern events that are familiar to children. To this end, we developed a questionnaire that combined different aspects of sense of time, such as estimation (Bullard et al., 2004) and knowledge of the order of days and months (Friedman, 1986). We hypothesized that concrete aspects of sense of time would be developed at an earlier age than more abstract aspects.

\section{Method}

Procedure and participants

The sampling frame consisted of all children attending the second through the sixth grades of two elementary schools in south Limburg, an area in the south of the Netherlands (250,000 inhabitants). These schools were selected in cooperation with the Youth Health Care (YHC) Division of the Regional Public Health Institute Maastricht, The Netherlands. All parents $(N=561)$ were sent a letter describing the purpose of the study and asking them to cooperate. Four hundred sixty-five parents gave permission for the investigation and signed an informed consent (82.9\%), 23 replied but did not give permission (4.1\%), and 73 did not reply (13.0\%).

Information about the parents who did not give permission or did not respond was obtained anonymously from YHC records, which is permitted by law. There were no significant differences with respect to the child's age and sex between the participants and the non-participants. However, the non-responding parents had a lower level of educational attainment than the responding parents (mean $=1.49$ vs. $1.70, t=2.530, p=.013$ ).

Nine children were ill on the day the investigation was scheduled, so 456 children participated in the study (81.3\%). Parents who agreed to cooperate completed a short questionnaire on their education and occupation and the presence of learning and/or behavior problems in their child. The data of two children previously diagnosed with ADHD by health care professionals were excluded from the analyses. The remaining 454 children (245 boys [54\%] and 209 girls [46\%]) were aged 7.4 to 13.0 years. 
Level of parental education was based on the partner with the highest level of education (Kalff et al., 2001). The majority of participants came from middle to highly educated families: 12 parent-pairs (2.7\%) had a low level of parental education, 139 parentpairs $(30.8 \%)$ a middle level, and 286 parent-pairs $(63.4 \%)$ a high level; relevant data for 14 parent-pairs were missing (Directoraat-Generaal voor de Arbeidsvoorziening, 1989). Because only a few parent-pairs had a low level of education, level of parental education was scored on a 2-point scale low/middle (1 point, primary school to vocational education degree) vs. high (general secondary education to doctoral degree). Level of parental education did not differ between the grades $\left(F_{(4,432)}=.920, p=.452\right)$. All analyses were controlled for level of parental education. Table 1 shows the characteristics of the participants and their parents.

Children took tests of sense of time, verbal ability, and selective attention (reported on in chapter 3 ) in their classroom. Testing took 30-45 minutes; all tests were administered in the same order to all children. Children whose parents had not agreed to their participation in the study were either present in the classroom during the study (working on their own) or left the room with their teacher or a teaching assistant. The tests were administered by a psychologist and a psychology graduate who had been trained in test administration. The ethics commission of the Faculty of Psychology, Maastricht University, approved the study.

Table 1: Demographic characteristics of the participants

\begin{tabular}{llccccc}
\hline & & \multicolumn{5}{c}{ Grade } \\
\cline { 3 - 7 } & & 2 & 3 & 4 & 5 & 6 \\
\multicolumn{2}{l}{ Characteristic } & $(\mathrm{N}=83)$ & $(\mathrm{N}=86)$ & $(\mathrm{N}=102)$ & $(\mathrm{N}=94)$ & $(\mathrm{N}=89)$ \\
\hline $\mathrm{N}$ & Boys & $42(50.6 \%)$ & $51(59.3 \%)$ & $58(56.8 \%)$ & $45(47.8 \%)$ & $49(55.1 \%)$ \\
& Girls & $41(49.4 \%)$ & $35(40.7 \%)$ & $44(43.2 \%)$ & $49(52.2 \%)$ & $40(44.9 \%)$ \\
\multirow{2}{*}{ Age } & Mean & 8.05 & 8.99 & 10.13 & 11.07 & 12.09 \\
& $(\mathrm{SD})$ & $(.36)$ & $(.44)$ & $(.42)$ & $(.41)$ & $(.40)$ \\
$\mathrm{EVA}^{1}$ & Mean & 39.9 & 44.7 & 47.6 & 51.5 & 52.9 \\
& $(\mathrm{SD})$ & $(4.2)$ & $(4.0)$ & $(4.1)$ & $(3.3)$ & $(3.8)$ \\
$\mathrm{LPE}^{2}$ & $\mathrm{~L} / \mathrm{M}^{3}$ & $25(30.1 \%)$ & $31(36.0 \%)$ & $39(38.2 \%)$ & $30(31.9 \%)$ & $25(28.1 \%)$ \\
& $\mathrm{High}$ & $56(67.5 \%)$ & $53(61.6 \%)$ & $58(56.9 \%)$ & $60(63.8 \%)$ & $60(67.4 \%)$ \\
& Mis & $2(2.4 \%)$ & $2(2.3 \%)$ & $5(4.9 \%)$ & $4(4.3 \%)$ & $4(4.5 \%)$ \\
\hline
\end{tabular}

Note: ${ }^{1} E V A$, Estimate of Verbal Ability, maximum $=60$ (Bleichrodt et al., 1987; Evers et al., 2000);

${ }^{2}$ LPE, Level of Parental Education (Directoraat-Generaal voor de Arbeidsvoorziening, 1989);

${ }^{3}$ Low/Middle; ${ }^{4}$ Missing data.

\section{Instruments}

Sense of time was measured with the Children's Time Awareness Questionnaire (CTAQ). We developed this instrument to measure different aspects of sense of time and included questions on time concepts (namely time units, order of the months, order of the days of the week, order of parts of the day, and telling time) and time estimation (namely the ability to estimate several events in time, including the life of a dog, the time needed to blow up a balloon, and the time it takes to get dressed). Three of the estimation questions were derived from the Temporal Judgement Test (Gillespie, Evans, 
Gardener, \& Bowen, 2002; Wilson, Alderman, Burgess, Emslie, \& Evans, 1996). In this subtest of the Behavioural Assessment of the Dysexecutive Syndrome (BADS), adults are asked to estimate the duration of four events: a routine dental examination, the life of a dog, blowing up a party balloon, and a window cleaner cleaning the windows of an average-sized house. The last question was not included in the CTAQ because window cleaning was not judged to be a familiar event for children. The original CTAQ had 20 items.

The questions were read aloud by one of the experimenters, while the children read along on their own sheet. Children entered their answers on the sheet themselves. The other experimenter walked through the classroom to ensure that the children understood the test. Administration of the CTAQ took 5-10 minutes. The time concept questions were multiple choice (e.g. "What comes first in the week, Monday or Wednesday"), and were scored as 1 (correct) or 0 (incorrect). The time estimation questions were scored on a scale from -2 to +2 , based on answers given by an adult reference sample. We chose to use such a sample, because this gave us the opportunity to study sense of time in a developmental perspective. We hypothesized that sense of time would be fully developed in adults (Anderson, 2002). The adult reference sample consisted of 246 adults (students and employees of Maastricht University the Netherlands, $31.7 \%$ male, 18-72 years, mean age $=26.5$ years, $S D=11.0$, educational level: $0.6 \%$ low, $9.3 \%$ medium, $89.4 \%$ high). Answers that fell between the 25th and 75th percentile of the adult distribution were scored as 0 (mean); answers that fell between the 2.5th and 25th percentile were scored as -1 (small underestimation); answers that fell between the 75th and 97.5 th percentile were scored as +1 (small overestimation); answers that fell below the 2.5th percentile were scored as -2 (large underestimation); and answers that fell above the 97.5 th percentile were scored as +2 (large overestimation). This procedure is adapted from the scoring procedure of the B-CET (Bullard et al., 2004).

In adults, the total scores for the CTAQ questions of time units, order of the months, order of the days of the week, order of parts of the day, and telling the time were not influenced by age $(\rho=.003, p=.959)$, level of education $\left(F_{(6,240)}=.414, p=.865\right)$, or $\operatorname{sex}\left(t_{(238)}=.082, p=.935\right)$. The score for CTAQ time estimation was also not influenced by age $(\rho=-.020, p=.757)$, level of education $\left(F_{(6,240)}=2.090, p=.055\right)$, or $\operatorname{sex}\left(t_{(238)}=\right.$ $.576, p=.565)$.

In an unpublished pilot study, we found positive and significant correlations between the estimation questions of the CTAQ and the time estimation questions of the BCET (Bullard et al., 2004) in 150 healthy children (aged five to eleven, $\rho=.434, p<.001$ ) and in a group of 82 children with and without ADHD (both groups $N=41$, aged six to twelve, $\rho=.524, p<.001)$. Also, we found a significant association between score on the estimation questions of the CTAQ and performance on a computerized task of time estimation (sample with $41 \mathrm{ADHD}$ and 41 normally developing children, $\rho=-.494, p<.001$ ).

Verbal ability was measured to control for overall verbal abilities in sense of time. It was estimated with the Picture Vocabulary subtest of the Revised Amsterdam Child Intelligence Test for children aged 4 years and 2 months to 11 years and 1 month (Bleichrodt, Drenth, Zaal, \& Resing, 1987; Evers, van Vliet-Mulder, \& Groot, 2000). The Picture Vocabulary test closely resembles the Peabody Picture Vocabulary test (Dunn, Dunn, Robertson, \& Eisenberg, 1979) and is related to the verbal tasks of the WISC-R (Bleichrodt et al., 1987), two commonly used instruments to estimate verbal intelligence 
(Marakovitz \& Campbell, 1998). In the Picture Vocabulary test, the child must choose one of four pictures shown that matches the word the experimenter reads aloud. These words increase in complexity. For the present study, the booklet version of the Picture Vocabulary test was adapted for use in class, by copying the pictures on sheets and projecting them onto a white screen. Each child marked his/her answers on an answer form showing small versions of the same pictures projected on the white screen. Because some subjects were older than the available norms for the test, the outcome variable was the total number of correctly chosen pictures (maximum $=60$ ).

\section{Statistical analyses}

As a first step, the 20 items of the CTAQ were entered in a principal component factor analysis with varimax rotation. Factors with eigenvalues above 1 were inspected. Interindividual differences on each of the extracted factors of sense of time were investigated by separate linear regression analyses with the total score on each of the factors as the dependent measure, grade (second grade $=2$, third grade $=3$, fourth grade $=4$, fifth grade $=5$, sixth grade $=6$ ), sex (boy $=1$, girl $=2$ ), parental level of education (low/middle $=1$, high $=2$ ), and verbal ability (continuous) as the independent measures. Alpha value was set at .05 for all analyses.

\section{Results}

\section{Test characteristics}

The factor analysis of the 20 CTAQ items resulted in 9 factors with an eigenvalue higher than 1 , with relatively low factor loadings on each factor. Because we felt that this large number of factors reduced the interpretability of the CTAQ, we excluded the six items that did not load on the first six factors and the analysis was repeated with the 14 remaining items. The two excluded estimation items concerned the duration of the summer holidays and the duration of brushing one's teeth. The four excluded concept questions asked what takes longer, a movie or Sesame Street (a television program for children), and what comes first, now or tomorrow, one o'clock or four o'clock, and soon or immediately.

This second analysis resulted in five factors with an eigenvalue higher than 1 . These five factors, which together explained $55.2 \%$ of the variance, were interpreted and used in further analyses. The factors were calculated by adding the scores for the separate items of each factor and dividing this figure by the number of items included. Thus, scores on the factors ranged, as for the items, from -2 to +2 , with 0 being the mean. Factor 1 (eigenvalue $=2.1$, explained variance $=14.9 \%$ ) consisted of three items asking which of two time units takes longer (a quarter of an hour or half an hour, an afternoon or a week, and a month or a weekend). This factor was named Duration Comparison. Factor 2 (eigenvalue $=1.9$, explained variance $=13.2 \%$ ) consisted of three items reflecting events of which the duration is regularly talked about in daily life, namely the time it takes to go to the dentist for a control visit, to get dressed, and to get a haircut. This factor was named Events with a clear Time Component. Factor 3 (eigenvalue $=1.3$, explained variance $=9.6 \%$ ) consisted of three items reflecting events that, contrary to those in the previous factor, are probably not talked about in daily life, namely the time it takes to drink a glass of lemonade, to blow up a balloon, and the duration of a commercial. This factor was named Events without a clear Time Component. Factor 4 (eigenvalue $=1.3$, explained variance $=9.2 \%$ ) concerned three questions about the 
mean age of humans, dogs, and flowers in a vase. It was named Life Expectancy. Lastly, factor 5 (eigenvalue $=1.2$, explained variance $=8.3 \%$ ) consisted of two questions, one asking whether March or September comes first in the year, the other whether Monday or Wednesday comes first in the week. This factor was named Sequential Arrangement of Months \& Days. Thus, two factors consisted of time concept items, and three factors of time estimation items.

\section{Improvement over grades}

With respect to the factor Duration Comparison $\left(F_{(7,428)}=3.590, p=.001\right)$, mean performance in the second grade was significantly lower than that in the higher grades (see Table 2). There were no differences in mean performance between the other grades. Performance on the factor Duration Comparison was not influenced by sex ( $p=$ $.868)$ or parental level of education $(p=.295)$. There was a trend for the positive influence of verbal ability $(p=.067)$.

\section{Table 2: Performance on the five sense of time factors}

\begin{tabular}{|c|c|c|c|c|c|c|}
\hline \multirow[b]{2}{*}{ Grade } & \multirow[b]{2}{*}{ Stat. } & \multicolumn{5}{|c|}{ Factors } \\
\hline & & $\begin{array}{c}\text { Duration } \\
\text { comparison }{ }^{1}\end{array}$ & $\begin{array}{l}\text { Events with a } \\
\text { clear time } \\
\text { component }^{2}\end{array}$ & $\begin{array}{c}\text { Events without } \\
\text { a clear time } \\
\text { Component }^{2}\end{array}$ & $\begin{array}{l}\text { Life ex- } \\
\text { pec- } \\
\text { tancy }^{2}\end{array}$ & $\begin{array}{c}\text { Sequential } \\
\text { arrangement } \\
\text { of months \& } \\
\text { days }^{1}\end{array}$ \\
\hline \multirow[t]{3}{*}{2} & Mean $^{3}$ & $74.89 \mathrm{a}$ & $-.83 \mathrm{a}$ & $-.52 \mathrm{a}$ & $.55 \mathrm{a}$ & $91.36 \mathrm{a}$ \\
\hline & SD & 30.06 & .87 & .87 & .75 & 19.02 \\
\hline & Median & 100 & -.67 & -.33 & .67 & 100 \\
\hline \multirow[t]{3}{*}{3} & Mean & $90.70 \mathrm{~b}$ & $-.43 b$ & $-.13 b$ & $.52 \mathrm{a}$ & $95.35 a, b$ \\
\hline & SD & 22.08 & .77 & .67 & .69 & 14.61 \\
\hline & Median & 100 & -.33 & 0 & .33 & 100 \\
\hline \multirow[t]{3}{*}{4} & Mean & $89.87 \mathrm{~b}$ & $-.53 a, b$ & $-.05 b$ & $.16 \mathrm{~b}$ & $99.01 \mathrm{~b}$ \\
\hline & SD & 26.45 & .76 & .57 & .62 & 7.00 \\
\hline & Median & 100 & -.67 & 0 & .33 & 100 \\
\hline \multirow[t]{3}{*}{5} & Mean & $88.04 \mathrm{~b}$ & $-.51 \mathrm{a}, \mathrm{b}$ & $.09 \mathrm{~b}$ & $.09 \mathrm{~b}$ & $98.91 \mathrm{a}, \mathrm{b}$ \\
\hline & SD & 24.00 & .53 & .59 & .59 & 10.42 \\
\hline & Median & 100 & -.67 & 0 & 0 & 100 \\
\hline \multirow[t]{3}{*}{6} & Mean & $85.77 \mathrm{~b}$ & $-.40 \mathrm{a}, \mathrm{b}$ & $.01 \mathrm{a}, \mathrm{b}$ & $.08 \mathrm{~b}$ & $100 \mathrm{~b}$ \\
\hline & SD & 28.38 & .64 & .63 & .60 & 0 \\
\hline & Median & 100 & -.33 & 0 & 0 & 100 \\
\hline
\end{tabular}

Note: Stat $=$ Statistic; ${ }^{1}$ Scores are in percentages, $100 \%$ is maximum; ${ }^{2}$ Scores are on a scale ranging from -2 (underestimation) to +2 (overestimation) with 0 as the mean adult score; ${ }^{3}$ Scores in the same column with the same letter are not significantly different from each other.

On the factor Events with a clear Time Component $\left(F_{(7,424)}=4.060, p<.001\right)$, significant differences in mean performance were only found between the second and third grades $(p=.006)$ (see Table 2 and Figure 1). There was a difference between girls and boys on this factor, with girls underestimating Events with a clear Time Component 
less than boys (mean difference $=.504, p=.016$ ), and a trend for the influence of verbal ability (mean difference $=.048, p=.081)$. No influence of parental level of education $(p=$ .159) was found.

On the factor Events without a clear Time Component $\left(F_{(7,422)}=7.247, p<.001\right)$, significant differences in mean performance were found between the second and third grades $(p=.013)$, second and fourth grades $(p=.014)$, and second and fifth grades $(p=$ .014) (see Table 2 and Figure 1). The difference in performance between the second and sixth grades was not significant $(p=.141)$, nor was the difference in performance between the other grades. Verbal ability influenced performance positively (mean difference $=.069, p=.007)$. No influence of parental level of education $(p=.983)$ and $\operatorname{sex}(p=.697)$ was found.

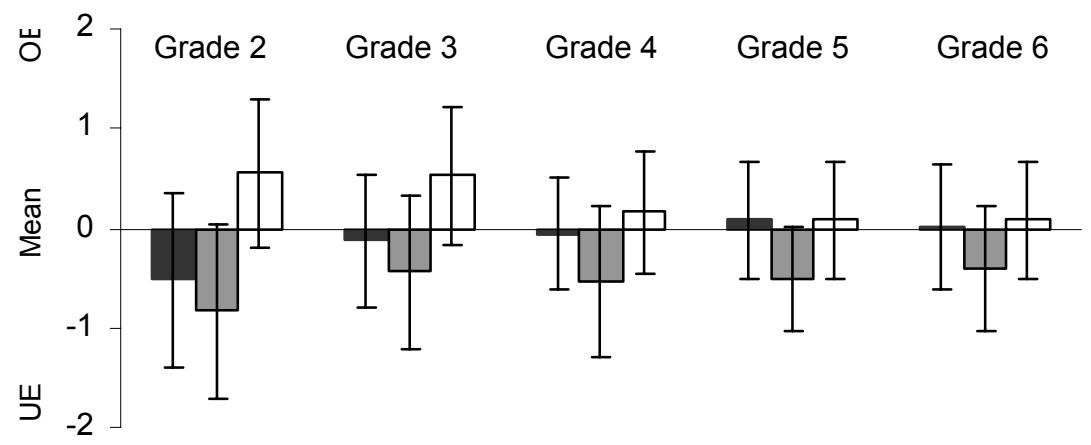

Events with a clear time component

$\square$ Events without a clear time component

$\square$ Life expectancy

\section{Figure 1: Performance on the three estimation factors}

Note: UE = Underestimation (score between -1 and -2 ) compared to adults; Mean = Moderate estimation (score between -1 and 1) compared to adults; $O E=$ Overestimation (score between 1 and 2) compared to adults.

On the factor Life Expectancy $\left(F_{(7,420)}=8.467, p<.001\right)$, significant differences in mean performance were found between the second and fourth grades $(p=.004)$, second and fifth grades $(p=.011)$, second and sixth grades $(p=.017)$, third and fourth grades $(p$ $=.001)$, third and fifth grades $(p=.002)$, and third and sixth grades $(p=.003)$ (see Table 2 and Figure 1). There was a difference between girls and boys on this factor, with girls overestimating Life Expectancy less than boys (mean difference $=-.550, p=.004$ ). No influence of parental level of education $(p=.120)$ and verbal ability $(p=.241)$ was found.

On the factor Sequential Arrangement of Months \& Days $\left(F_{(7,427)}=5.450, p<.001\right)$, significant differences in mean performance were found between the second and fourth grades $(p=.008)$, and second and sixth grades $(p=.038)$. There was a trend for the 
difference between the second and fifth grades $(p=.063)$. No influence of parental level of education $(p=.198)$ and verbal ability $(p=.115)$ was found. Girls performed better than boys (mean difference $=2.4 \%, p=.035$ ).

\section{Discussion}

We investigated the development of five different aspects of sense of time in children, using the newly developed Children's Time Awareness Questionnaire. The questionnaire evaluates whether children can estimate low long familiar events last. Factor analysis clearly showed five distinct factors, namely, duration comparisons, estimation of events with and without a clear time component, sequential arrangement of months \& days, and life expectancy.

Duration Comparison concerns questions regarding which of two time units takes longer (e.g. an afternoon or a week). We found that performance on this factor improved substantially from the second grade to the higher grades and stabilized in the third grade (at the age of nine). These findings are in line with previous research (Friedman, 2003). Thus, this factor, which exists of three items, seems suitable to screen for problems with knowledge of Duration Comparison.

Events with a clear Time Component, the second aspect of sense of time found in our questionnaire, concerns the duration of events talked about in daily life, e.g. the time a control visit to the dentists takes. We found that children, compared with adults, underestimated the duration of these events. Age differences on this factor were only found between the second and third grades. The performance of children in second, fourth, fifth, and sixth grades did not differ. Thus, performance had probably already stabilized at or before the age of eight. This result should be considered in light of work on children's representations of the pattern of daily activities, such as eating lunch and going to bed, which are thought to be fully developed at the age of seven (Friedman, 1990). One of the Events with a clear Time Component concerns a daily activity (getting dressed), whereas the other two concerned monthly to half-yearly activities (visit to the dentist and hairdresser). Post-hoc analyses indicated that children were slower (up to the fourth to sixth grade) in developing a sense of time regarding events that occurred irregularly than for events that occurred regularly (up to the second grade). Thus, children learn to estimate the duration of activities that occur on a daily basis before they can estimate how long monthly activities take. This difference can probably be explained by children's experience with the activities (see also Friedman, 1990) and supports the notion that there is a step-wise development of sense of time, with the concrete aspects developing before the more abstract ones.

The third aspects of sense of time identified here, Events without a clear Time Component, concerns the duration of three familiar events that are probably not regularly talked about, e.g. the time it takes to drink a glass of lemonade. In other words, events such as these do not have a clear time component in daily life. Age differences on this factor were found between the second and the higher grades, with the exception of the sixth grade. Thus, performance appeared to stabilize in the second to third grade. This is about a year earlier than reported previously for an adult level of estimation of unfamiliar events in time (Baron, 2004; Bullard et al., 2004). These results are again consistent with a step-wise development of aspects of time, starting with familiar, or concrete, aspects of sense of time and continuing to more abstract aspects. 
Life Expectancy, the fourth aspect, concerns how long dogs and humans live. Performance improved until the fourth grade (age ten years), which means that this aspect of time was the slowest to develop. To our knowledge, not much research has been done with respect to knowledge of age and duration of life. The work of Montangero (1996) and Fraisse (1964) perhaps comes closest because it also concerned knowledge of natural concepts: Montangero (1996) studied children's diachronic thinking (e.g. the growth and decay of trees), and Fraisse (1964) concluded that children younger than seven years cannot separate age and size and, thus, believe that all adults are the same age because they are the same size. However, experiences in daily life may be especially relevant for performance on the factor Life Expectancy. For example, whether or not children grow up in an environment with dogs will probably influence their knowledge of the average life expectancy of a dog. Thus, this sense of time factor may measure general knowledge instead of estimation. More research on this issue is necessary.

The final aspect of sense of time we identified, Sequential Arrangement of Months \& Days, concerns knowledge of the order of days and months. Performance on this factor differed between the second and fourth grades, and between the second and sixth grades. There was a trend for the difference between the second and fifth grades. Thus, performance appeared to stabilize in the fourth grade, at the age of ten. This is in line with research of Friedman $(1986 ; 2003)$, who concluded that children in fourth grade know the order of the days of the weeks and the months of the year and can use this knowledge in a forward paradigm, by judging which of two days comes first in the week.

Age-extrinsic variables are of importance when studying cognitive development, because they can explain inter-individual variance. We controlled for three such factors, namely parental level of education, level of verbal ability, and sex. Parental level of education, a well-known mediator of cognitive development (Bradley \& Corwyn, 2002; Campbell, 1995; Kalff et al., 2001), did not influence performance on the five aspects of sense of time. This may be because the parents in our sample had a relatively high level of educational achievement. In other words, there were too few children whose parents had a low level of educational attainment. Future research should investigate this issue. Verbal ability was found to be positively associated with performance on one factor, namely Events without a clear Time Component, and a trend for significance was observed for two other factors, namely Duration Comparison and Events with a clear Time Component. All three relationships were positive, i.e. children with a better verbal ability performed better on the three aspects of sense of time. Given the verbal nature of the test, this could be expected but does not explain why verbal ability was not associated with the other two aspects of sense of time. The results could suggest that general ability develops in parallel with aspects of sense of time. More research is needed to clarify this issue. Finally, girls performed better than boys on Sequential Arrangement of Months \& Days, Events with a clear Time Component, and Life Expectancy, i.e. their performance was closer to the mean performance of the group of adults. To the best of our knowledge, this is the first study to show an advantage for girls over boys in sense of time.

In conclusion, the CTAQ seems to be a promising instrument and can be administered in a short time to groups and individuals alike. Because the instrument is based on events familiar to children, results have ecological validity. Because an adequate sense of time is important for performance of many activities of daily life, such as social skills (Meaux \& Chelonis, 2003) and mathematics (Butterworth, 2005), the 
CTAQ provides information that can be used in clinical and research settings. Our results showed that performance on three of the five aspects of sense of time stabilized in or before the third grade, whereas improvement on the factors Sequential Arrangement of Months \& Days and Life Expectancy continued until the fourth grade. Thus, sense of time in children consists of different processes with separate developmental patterns. These findings support a step-wise model of cognitive development (Anderson, 2002), by which simple aspects of a cognitive function develop before more abstract aspects. An understanding of the normal development of sense of time makes it possible to identify developmental deviations at an earlier age and improve treatment interventions. Thus, this knowledge is essential for educational and health care professionals working with children and adolescents. 


\section{References}

Anderson, P. (2002). Assessment and development of executive function (EF) during childhood. Child Neuropsychology, 8, 71-82.

Barkley, R. A. (1997). Behavioral inhibition, sustained attention, and executive functions: constructing a unifying theory of ADHD. Psychological Bulletin, 121, 65-94.

Barkley, R. A., Edwards, G., Laneri, M., Fletcher, K., \& Metevia, L. (2001). Executive functioning, temporal discounting, and sense of time in adolescents with attention deficit hyperactivity disorder (ADHD) and oppositional defiant disorder (ODD). Journal of Abnormal Child Psychology, 29, 541-556.

Barkley, R. A., Koplowitz, S., Anderson, T., \& McMurray, M. B. (1997). Sense of time in children with ADHD: effects of duration, distraction, and stimulant medication. Journal of the International Neuropsychological Society, 3, 359-369.

Baron, I. S. (2004). Neuropsychological evaluation of the child. Oxford: University Press.

Bauermeister, J. J., Barkley, R. A., Martinez, J. V., Cumba, E., Ramirez, R. R., Reina, G.,Matos, M., \& Salas, C. C. (2005). Time estimation and performance on reproduction tasks in subtypes of children with attention deficit hyperactivity disorder. Journal of Clinical Child and Adolescent Psychology, 34, 151-162.

Bleichrodt, N., Drenth, P. J. D., Zaal, J. N., \& Resing, W. C. M. (1987). Handleiding bij de Revisie Amsterdamse Kinder Intelligentie Test [Revised Amsterdam Child Intelligence Test manual]. Lisse: Swets \& Zeitlinger BV.

Block, R. A., Zakay, D., \& Hancock, P. A. (1999). Developmental changes in human duration judgements: A meta-analytic review. Developmental Review, 19, 183-211.

Bradley, R. H., \& Corwyn, R. F. (2002). Socioeconomic status and child development. Annual Review of Psychology, 53, 371-399.

Bullard, S. E., Fein, D., Gleeson, M. K., Tischer, N., Mapou, R. L., \& Kaplan, E. (2004). The Biber Cognitive Estimation Test. Archives of Clinical Neuropsychology, 19, 835-846.

Butterworth, B. (2005). The development of arithmetical abilities. Journal of Child Psychology and Psychiatry, 46, 3-18.

Campbell, S. B. (1995). Behavior problems in preschool children: a review of recent research. Journal of Child Psychology and Psychiatry, 36, 113-149.

Directoraat-Generaal voor de Arbeidsvoorziening (1989). Handleiding voor de functieanalyse [Function analysis manual]. Den Haag: SDU uitgeverij.

Dunn, L. M., Dunn, L. M., Robertson, G. J., \& Eisenberg, J. L. (1979). Peabody Picture Vocabulary Test - Revised. Circle Pines (MN): American Guidance Service.

Evers, A., van Vliet-Mulder, J. C., \& Groot, C. J. (2000). Documentatie van tests en testresearch in Nederland. Deel I: Testbeschrijvingen [Documentation of tests and testresearch in the Netherlands. Part I: Test descriptions]. Assen: van Gorcum.

Fraisse, P. (1964). The psychology of time. London: Lowe \& Brydone.

Friedman, W. J. (1978). Development of time concepts in children. In: H. W. Reese \& L. P. Lipsitt (Eds.), Advances in child development and behavior (Vol. 12, pp. 267-298). New York: Academic Press.

Friedman, W. J. (1986). The development of children's knowledge of temporal structure. Child Development, 57, 1386-1400.

Friedman, W. J. (1989). The representation of temporal structure in children, adolescents and adults. In: I. Levin \& D. Zakay (Eds.), Time and human cognition: A life-span approach. Amsterdam: Elsevier Science Publishers B. V.

Friedman, W. J. (1990). Children's representations of the pattern of daily activities. Child Development, 61, 1399-1412.

Friedman, W. J. (2000). The development of children's knowledge of the times of future events. Child Development, 71, 913-932.

Friedman, W. J. (2003). The development of a differentiated sense of the past and the future. Advances in Child Development and Behaviour, 31, 229-269. 
Gillespie, D. C., Evans, R. I., Gardener, E. A., \& Bowen, A. (2002). Performance of older adults on tests of cognitive estimation. Journal of Clinical and Experimental Neuropsychology, 24, 286293.

Kalff, A. C., Kroes, M., Vles, J. S., Bosma, H., Feron, F. J., Hendriksen, J. G., Steyaert, J., van Zeben, T. M., Crolla, I. F., \& Jolles, J. (2001). Factors affecting the relation between parental education as well as occupation and problem behavior in Dutch 5- to 6-year-old children. Social Psychiatry and Psychiatric Epidemiology, 36, 324-331.

Liss, M., Fein, D., Bullard, S., \& Robins, D. (2000). Brief report: cognitive estimation in individuals with pervasive developmental disorders. Journal of Autism and Developmental Disorders, 30, 613-618.

Marakovitz, S. E., \& Campbell, S. B. (1998). Inattention, impulsivity, and hyperactivity from preschool to school age: performance of hard-to-manage boys on laboratory measures. Journal of Child Psychology and Psychiatry, 39, 841-851.

McCormack, T., Brown, G. D., Smith, M. C., \& Brock, J. (2004). A timing-specific memory distortion effect in young children. Journal of Experimental Child Psychology, 87, 33-56.

Meaux, J. B., \& Chelonis, J. J. (2005). The relationship between behavioral inhibition and time perception in children. Journal of Child and Adolescent Psychiatric Nursing, 18, 148-160.

Meaux, J. B., \& Chelonis, J. J. (2003). Time perception differences in children with and without ADHD. Journal of Pediatric Health Care, 17, 64-71.

Montangero, J. (1996). Understanding changes in time. London: Taylor \& Francis Ltd.

Piaget, J. (1946). Le développement de la notion de temps chez l'enfant. Paris: Presses universitaires de France.

Rubia, K., Noorloos, J., Smith, A., Gunning, B., \& Sergeant, J. (2003). Motor timing deficits in community and clinical boys with hyperactive behavior: the effect of methylphenidate on motor timing. Journal of Abnormal Child Psychology, 31, 301-313.

Smith, A., Taylor, E., Lidzba, K., \& Rubia, K. (2003). A right hemispheric frontocerebellar network for time discrimination of several hundreds of milliseconds. Neuroimage, 20, 344-350.

Sonuga-Barke, E. J., Saxton, T., \& Hall, M. (1998). The role of interval underestimation in hyperactive children's failure to suppress responses over time. Behavioural Brain Research, 94, 45-50.

Tannock, R. (2003). Neuropsychology of attention disorders. In: S. J. Segalowitz. \& I. Rapin. (Eds.), Handbook of neuropsychology (2nd ed., pp. 753-784). Amsterdam: Elsevier Science B.V.

Van Scoy, I. J., \& Fairchild, S. H. (1993). It's about time! Helping preschool and primary children understand time concepts. Young Children, 1, 21-24.

Wilson, B. A., Alderman, N., Burgess, P. W., Emslie, H., \& Evans, J. J. (1996). Behavioral assessment of the dysexecutive syndrome. Bury St. Edmunds: Thames Valley Test Company.

Zakay, D. (1992). The role of attention in children's time perception. Journal of Experimental Child Psychology, 54, 355-371. 



\title{
CHAPTER 6
}

\section{Complex language comprehension in school aged children}

\begin{abstract}
We investigated the comprehension of simple and complex language structures in three age-groups of primary school children. Participants were 83 children attending kindergarten and first grade (group I), second to third grades (group II) and fourth to sixth grades (group II). Language comprehension was measured according to the neuropsychological procedure proposed by Luria. An $85 \%$ cut-off score was used as a criterion for mastery of language comprehension. Levels of short-term and working memory were controlled in the evaluation of language comprehension. Comprehension of simple instructions was mastered in group I, whereas some logical grammatical structures were only mastered in group III. Other logical grammatical structures were too difficult to comprehend, even for children in group III. Short-term memory and working memory were related to language comprehension but did not account for the age differences found. In conclusion, language comprehension develops differentially. The more complex logical grammatical structures are not mastered at the end of primary school. Thus, children at secondary school may be less able than expected to deal with multifaceted questions and tasks, a finding which could have implications for educational practice.
\end{abstract}

Renske Wassenberg, Petra P. M. Hurks, Jos G. M. Hendriksen, Ariane C. Kalff, Dorine I. E. SlaatsWillemse, Frans J. M. Feron, Johan S. H. Vles \& Jelle Jolles. Submitted for publication. 
In recent decades evidence has accumulated that certain regions of the human brain, especially parts of the prefrontal cortex, are not mature until early adulthood (De Bellis et al., 2001; Gogtay et al., 2004; Klingberg, Vaidya, Gabrieli, Moseley, \& Hedehus, 1999). Parallel to the maturation of the prefrontal cortex, complex cognitive functions, such as flexibility and behavioral planning, continue to develop into early adulthood as well ( $P$. Anderson, 2002; V. A. Anderson, Anderson, Northam, Jacobs, \& Catroppa, 2001; Casey, Tottenham, Liston, \& Durston, 2005; Eslinger, Flaherty-Craig, \& Benton, 2004; Fuster, 2002; Paus, 2005; Steinberg, 2005). Less is known about the developmental pattern of other cognitive functions (Ohta, 2002). In this context, the aim of this study was to investigate whether comprehension of logical grammatical structures is complete at the end of primary school. This complex language function relates to the ability to understand relationships between objects, actions, and qualities in complex sentences (Luria, 1966, 1980). For example, the focus in the expression 'the father's brother' is on a person not directly mentioned, namely 'the uncle'. Comprehension of such logical grammatical structures is assumed to be essential for the integration of various cognitive processes with intentions, emotions and actions into purposeful behavior (Johnson \& Munakata, 2005; Lezak, Howieson, \& Loring, 2004; Nigg, 2000; Stuss, 1992). This is important in our language-oriented society and schooling system (Cook, Murdoch, Cahill, Whelan, 2004). We hypothesized that comprehension of logical grammatical structures would not be fully developed by the age of 12 . Finding this would have implications for the practice of education, as many instructions are of a verbal nature, and the efficiency of information-transfer can be expected to be dependent upon the extent to which the child can understand the intention of the teacher.

Functions that are indispensable for understanding complex language are short-term and working memory (Baddely, 2003; Booth, MacWhinney, \& Harasaki, 2000; Carpenter, Miyake, \& Just, 1994; Deevy \& Leonard, 2004; Dick, Wulfreck, Krupa-Kwiatkowski, \& Bates, 2004; Hahne, Eckstein, \& Friederici, 2004; Helland \& Asbjornsen, 2004; Marton \& Schwartz, 2003; Montgomery, 2003). A sentence cannot be comprehended when children are not able to keep the sentence active long enough in their short-term memory so that its content can be processed in their working memory. Currently, there are two prominent memory models that are pertinent to language processing. First, according to the phonological loop model (Baddeley, 2003) the ability to remember a phonological trace of words (short-term memory) is critical to language comprehension. Secondly, the capacity theory (Just \& Carpenter, 1992) states that storage and processing functions of working memory have to share the same limited amount of resources during comprehension. When the task demands exceed the storage capacity, comprehension will be compromised. It is known from previous studies that short-term memory and working memory continue to improve after the age of twelve (Brocki \& Bohlin, 2004; Kemps, De Rammelaere, \& Desmet, 2000; Luciana, Conklin, Hooper, \& Yarger, 2005; Luna, Garver, Urban, Lazar, \& Sweeney, 2004). If language comprehension is as dependent on memory as is hypothesized by the theories described above, it can be expected that comprehension of complex language continues to improve into adolescence as well. In summary, working memory and/or short-term memory should always be included in studies of logical grammatical structures.

Previous studies of complex language comprehension in children used two different paradigms. The first is the multiple choice paradigm, in which children have to indicate, for example, the agent in presented sentences by either choosing the corresponding 
picture (Dick et al., 2004) or by answering yes/no questions (Booth et al., 2000). In their study of children aged between five and seventeen, Dick and colleagues (2004) found that the accuracy of choosing the agent in sentences increased up to the age of nine. Booth and colleagues (2000) also found significant improvement of accuracy from a young (third and fourth graders) to an older group (fifth and sixth graders). However, the ecological validity of the multiple-choice paradigm seems to be low. In the real world, children rarely get two or more options to choose from when confronted with complex language.

The second paradigm previously used in language comprehension research requires children to respond to Wh-questions (what, where, who etc.) about presented sentences (Deevy \& Leonard, 2004; Marton \& Schwartz, 2003). This method seems to be more ecologically valid because this type of questioning concerns content instead of structure, which is more prevalent in daily life. Previous studies using Wh-questions compared the performance of children with Specific Language Impairment (SLI) with that of age-matched healthy children without focusing on the effect of age (Deevy \& Leonard, 2004; Marton \& Schwartz, 2003). So far, development of complex language comprehension in normally developing children has not been studied using this technique. The present study attempted to fill this gap. In addition, this study attempted to control for two factors that are of importance when studying the development of logical grammatical structures. First, the basic language level children are expected to have obtained before logical grammatical structures can be comprehended was tested by including a number of relatively simple sentences. These sentences were phrased as instructions and required the children to perform an action (e.g. 'Take this pen, put it on the windowsill and give me the pencil you find there'). Performance with respect to these sentences was expected to be close to perfect for all children included in this study, regardless of their age (Bates, Thal, Finlay, \& Clancy, 2003; Luria, 1966, 1980). Second, the influence of short-term and working memory cannot be ruled out in comprehension of (especially) complex language, so measures of these cognitive functions were included to control for their influence.

In summary, the aim of this cross-sectional study was to investigate whether language comprehension is completed at the end of primary school, around the age of twelve. To test this, comprehension of direct instructions and logical grammatical structures was investigated in three age-groups of primary school children. Care was taken to only include children in the study who were characterized by normal psychosocial circumstances.

\section{Method}

\section{Procedure}

To reduce the risk that environmental variables, such as school environment, teaching method, and teacher attitude, would influence language comprehension, we used a captive sample. The sampling frame consisted of all children frequenting kindergarten through sixth grades at a regular elementary school in Maastricht, a city in the south of the Netherlands. Most children came from a high socioeconomic background. All parents were sent a letter about the purpose of the study and a request to participate. Parents who agreed to participate completed an extensive sociodemographic questionnaire, of which only information about parental level of education was used in this study. To 
screen for developmental disabilities, parents were asked to complete a questionnaire about their child's medical history and milestone development. Only children with a normal developmental and medical history were considered eligible for participation in the study. All children were tested individually in a test room that was stimulus free and situated near the school. All tests were given in the same order for each child. If necessary, a break halfway was included for the younger children. The language comprehension screening was administered after about 45 minutes.

\section{Participants}

The majority of parents who gave consent for the study were highly educated. Of the 87 children eligible for participation, four were excluded from analyses because parental education was missing $(\mathrm{N}=2)$, or parental education was not of a high level, i.e. parents had not completed secondary school or did not have a university degree $(\mathrm{N}=2)$. This was done because many studies have shown that lower parental educational level and lower social economic status is a risk factor in regard to lower language and cognitive development (Dolloghan et al., 1999; Hoff, 2003; Jackson, 2003; Landry, Smith, \& Swank, 2002; Mackner, Black, \& Starr, 2003; Quay \& Blaney, 1992). The present study was too small to investigate the influence of parental educational level on language comprehension, thus we chose to select only children from families with the same level of education.

The ages of the 83 remaining children ranged from 6.3 to 12.4 years. All children were healthy. The medical history of these children was regarded as normal and developmental milestones were reached at appropriate ages. For example, the mean duration of pregnancy was 39.8 weeks ( $S D=1.5$ weeks), the mean age at which the children could walk without assistance was 13.7 months (SD $=2.4$ months), and no child had sustained a serious brain injury in the past. Seventy-three of the children (88\%) were right-handed.

The number of children in individual classes was too small for reliable separate analyses and so we created three groups: children frequenting (I) Kindergarten and first grade $(\mathrm{N}=25,10$ boys, mean age $=6.9$ years, $S D=.41)$; (II) Second and third grades $(\mathrm{N}=25,11$ boys, mean age $=8.6$ years, $\mathrm{SD}=.60)$; and (III) Fourth through sixth grades $(\mathrm{N}=33,20$ boys, mean age $=10.9$ years, $\mathrm{SD}=.71)$. The groups did not differ in sex distribution $\left(F_{(2,80)}=1.414, p=.249\right)$.

\section{Instruments}

Complex language comprehension: Both the ability to understand simple, direct instructions and the ability to comprehend logical grammatical structures were investigated. The task employed in this study is part of a more extensive language comprehension battery developed by Luria $(1966 ; 1980)$ and adapted by Christensen (1993). Fifteen of the 24 items in the original battery were administered. Items that would have been too easy for school age children were not used in the present study (they were developed by Luria for the assessment of patients with brain injuries; an example is 'pointing to objects'). Two categories of direct instructions were tested in the present study, namely verbal and conflicting instructions. Five categories of logical grammatical structures were tested, i.e. constructions using the attributive genitive case, prepositional constructions using spatial relationships, comparative constructions, inverted grammatical constructions, and complex grammatical structures. Table 1 defines the categories and their items. In the rest of 
this text the battery is referred to as the Abbreviated Battery of Comprehension of Language or ABC-L for short.

Table 1: ABC-L items, characteristics and percentages correct per group

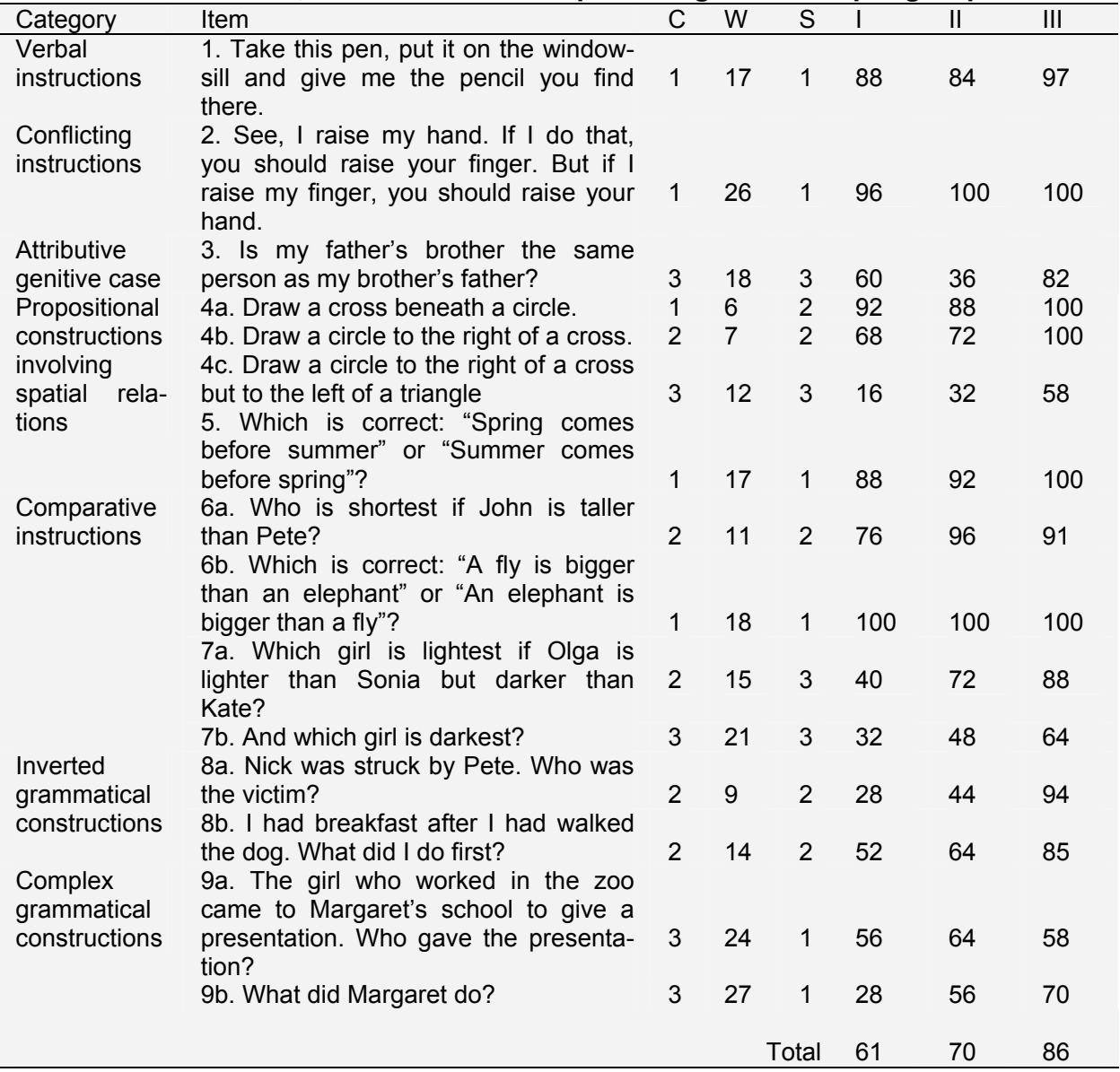

Note: $C=$ complexity levels: 1 = Low complexity items (mastered in group I), $2=$ Medium complexity items (mastered in group II or III), and $3=$ High complexity items (not mastered in group III). W= number of words in the original Dutch items, $S=$ umber of mental steps needed to understand the item, I= youngest group: kindergarten-first grade, $I I=$ middle group: second-third grades, $I I I=$ odest group: fourth-sixth grades.

Table 1 also includes the number of words (in Dutch) that each item consisted of, because of the obvious relevance of this number to short-term and working memory capacities. Furthermore, the number of mental steps that are needed to understand the item is shown in Table 1. This refers to the process of changing the word order so that the question can be answered with sequentially ordered information. For example, only one step needs to be taken to understand the item "Take this pen, put it on the window- 
sill and give me the pencil you find there"; it can be understood and executed in the presented order. Two mental steps are needed for items such as "Draw a circle to the right of a cross", because both 'left' and 'right' have to be considered in order to perform the item correctly. Finally, three mental steps need to be taken to understand items such as "Draw a circle to the right of a cross but to the left of a triangle", because 'left', 'right', and 'middle' need to be considered.

The ABC-L took about 10 minutes to administer. Each correct answer was awarded one point (instruction items $=2$ points, logical grammatical structures $=13$ points, maximum score possible $=15$ points). The total $A B C-L$ score and the scores on each of the five categories were analyzed and related to the number of words and mental steps. Language comprehension scores were analyzed in terms of percentages.

Memory: To control for the influence of memory on comprehension of complex language, we used the Digit Span Forwards (short-term memory) and Backwards (working memory) subtests of the WISC (De Bruyn et al., 1986; Wechsler, 1974). According to Baddeley (2003), pseudo-word repetition is a better measure of phonological short-term memory than digit span. However, as Booth and colleagues argued (2000), digit span forwards may be a better measure of sentence processing in the real word because this requires, in part, remembering a series of familiar words. Pseudo-word repetition, on the other hand, could be more related to vocabulary acquisition and forming persistent phonological traces. The Digit Span Forwards requires children to repeat a series of digits (range 3-8) in the same order as the experimenter presented them. The maximum number of digits a child could repeat at once, corrected for age, was used as the outcome variable.

The Digit Span Backwards task asks children to repeat a series of digits (range 2-7) in the opposite order to that in which they were presented by the experimenter. The maximum string of digits a child could repeat at once, corrected for age, was used as the outcome variable. This test has been described as a sensitive measure of working memory by Montgomery (2003).

Vocabulary: The ABC-L score was correlated to the Vocabulary subtest of the Wechsler Intelligence Scale for Children Revised (WISC, De Bruyn et al., 1986; Wechsler, 1974). The WISC-R rather than the WISC-III was used because the latter was not available in the Netherlands at the time of the study. As the Vocabulary subtest requires the subject to describe the meaning of words read aloud by the experimenter, language production is the primary outcome measure in that test. However, language comprehension of the words that need be defined is a basic requirement in order to achieve a good outcome. The words that need to be defined in the Vocabulary subtest are arranged from more concrete to more abstract. Children are awarded one point if they give a correct but incomplete, or too concrete definition. They are given two points for a completely correct, and sufficiently abstract, answer. Relationships between standard score (mean $=10$, SD = 3) performance on the Vocabulary subtest (range 0-64) and ABC-L were calculated to investigate the language component in the latter.

Performance Intelligence: An estimate of performance intelligence (PIQ) was included in this study to check the level of overall visuospatial abilities. PIQ was estimated with the Block Design subtest of the WISC-R (De Bruyn et al., 1986; Wechsler, 1974) The reli- 
ability and validity of this Dutch WISC-R subtest is believed to be good (De Bruyn et al., 1986). Age corrected standard scores were used with a mean of 10 and a standard deviation of 3 .

\section{Results}

The total score on the ABC-L ranged from 33\% correct (minimum in group I) to $100 \%$ correct (maximum in group III). As a general rule, an aspect of language comprehension was considered to be 'mastered' if at least $85 \%$ of the children within a certain group answered it correctly. As can be seen in Table 1, children in group I answered on average $61 \%$ of the items correctly, children in group II answered on average $70 \%$ of the items correctly, and children in group III answered on average $86 \%$ of the items correctly. Thus, in general, subjects in group III had 'mastered' the tested aspects of complex language comprehension.

When we look at the direct instructions and the logical grammatical structures separately, we see different patterns. Comprehension of direct instructions was, as expected, relatively easy for all groups. As can be seen in Table 1, performance in all groups was higher than $85 \%$ on the two items of verbal and conflicting instructions. On the logical grammatical structures, however, large differences in complexity were observed within a certain category. For example, in the category 'spatial relationships', item 4a ('Draw a cross beneath a circle') was mastered by all groups whereas most children answered item 4c ('Draw a circle to the right of a cross but to the left of a triangle') incorrectly. Based on these findings, we classified each item in one of three degrees of complexity, based on the proportion of correct answers per group, irrespective of their original category. The degrees of complexity were items that were already mastered in group I (Level 1: Low complexity), items that were not mastered until group II or III (Level 2: Medium complexity), and those that were not mastered in group III (Level 3: High complexity). All three levels consisted of five items (Low complexity: items 1, 2, 4a, 5, and 6b; Medium complexity: 2: items 4b, 6a, 7a, 8a, and 8b; High complexity: 3, 4c, 7b, 9a, and 9b).

Mean word length of the three levels of complexity was as follows: Low complexity: mean $=16.8(\mathrm{SD}=7.1)$, Medium complexity: mean = 11.2 $(\mathrm{SD}=3.3)$, High Complexity: mean $=20.4(S D=5.8)$. The differences in word length per category were not significant $\left(F_{(2,12)}=3.387, p=.068\right)$. Mental steps needed to perform the different items per category were evaluated as well. Performance on the Low complexity level required one (four items, $1,2,5$, and $6 \mathrm{~b}$ ) or two (item 4a) steps (mean = 1.2, SD = .45). Performance on items belonging to the Medium complexity level required two (items $4 b, 6 a, 8 a$, and $8 b$ ) or three (item $7 \mathrm{a}$ ) steps (mean $=2.2, \mathrm{SD}=.45$ ). Items belonging to the High complexity level, finally, required one (items $9 a$ and $9 b$ ) or three (items $3,4 c$, and $7 b$ ) steps (mean = $2.2, S D=1.10)$. The differences in mean number of mental steps per category were not significant $\left(F_{(2,12)}=3.125, p=.081\right)$.

\section{Specificity of the findings}

The age-corrected relationships between ABC-L and Vocabulary performance were calculated with Pearson's correlation coefficients and were found to differentiate between the levels of complexity: Total ABC-L X Vocabulary: $r=.202, p=.069$, Low complexity $\times$ Vocabulary: $r=.217, p=.050$, Medium complexity $x$ Vocabulary: $r=.273, p=.013$, High complexity $\times$ Vocabulary: $r=.015, p=.892$. These findings confirm the language component in the ABC-L, but also show that our findings with this battery are not limited to gen- 
eral verbal intelligence, especially not when the more complex language structures have to be comprehended.

Table 2: Linear regression analyses for the total $A B C-L$ score and the three levels of complexity

\begin{tabular}{|c|c|c|c|c|c|}
\hline Language comprehension component & Variable & $\mathrm{B}$ & SE & $\beta$ & p-value \\
\hline Total ABC-L score & $\mathrm{I}<\mathrm{II}$ & 5.98 & 3.83 & .17 & .123 \\
\hline $\begin{array}{l}F_{(6,75)}=10.88, p<.001 \\
R^{2}=46.50 \%\end{array}$ & $\begin{array}{l}I<I I I \\
\text { II }<\text { III } \\
\text { PIQ } \\
\text { VOC } \\
\text { DF } \\
\text { DB }\end{array}$ & $\begin{array}{l}17.81 \\
11.83 \\
.39 \\
.26 \\
2.56 \\
2.13\end{array}$ & $\begin{array}{l}4.15 \\
3.65 \\
.48 \\
.56 \\
1.47 \\
1.50\end{array}$ & $\begin{array}{l}.55 \\
.34 \\
.07 \\
.04 \\
.18 \\
.15\end{array}$ & $\begin{array}{l}.000 \\
.002 \\
.415 \\
.644 \\
.086 \\
.159\end{array}$ \\
\hline $\begin{array}{l}\text { Low complexity } \\
F_{(6,75)}=2.23, p=.051 \\
\mathrm{R}^{2}=38.72 \%\end{array}$ & $\begin{array}{l}I<I I \\
I<I I I \\
\text { II }<\text { III } \\
\text { PIQ } \\
\text { VOC } \\
\text { DF } \\
\text { DB }\end{array}$ & $\begin{array}{l}-.55 \\
4.05 \\
4.60 \\
.05 \\
.56 \\
.69 \\
1.08\end{array}$ & $\begin{array}{l}3.03 \\
3.28 \\
2.88 \\
.38 \\
.45 \\
1.16 \\
1.18\end{array}$ & $\begin{array}{l}-.03 \\
.20 \\
.21 \\
.02 \\
.14 \\
.08 \\
.12\end{array}$ & $\begin{array}{l}.858 \\
.220 \\
.115 \\
.891 \\
.213 \\
.553 \\
.365\end{array}$ \\
\hline $\begin{array}{l}\text { Medium complexity } \\
F_{(6,75)}=10.91, p<.001 \\
\mathrm{R}^{2}=46.63 \%\end{array}$ & $\begin{array}{l}I<\text { II } \\
I<I I I \\
\text { II }<\text { III } \\
\text { PIQ } \\
\text { VOC } \\
\text { DF } \\
\text { DB }\end{array}$ & $\begin{array}{l}14.49 \\
34.62 \\
20.13 \\
.64 \\
1.22 \\
5.17 \\
-2.34\end{array}$ & $\begin{array}{l}6.22 \\
6.73 \\
5.92 \\
.78 \\
.91 \\
2.39 \\
2.43\end{array}$ & $\begin{array}{l}.26 \\
.65 \\
.36 \\
.07 \\
.12 \\
.22 \\
-.10\end{array}$ & $\begin{array}{l}.023 \\
.000 \\
.001 \\
.415 \\
.184 \\
.034 \\
.339\end{array}$ \\
\hline $\begin{array}{l}\text { High complexity } \\
F_{(6,75)}=4.25, p=.001 \\
\mathrm{R}^{2}=25.22 \%\end{array}$ & $\begin{array}{l}I<\text { II } \\
I<I I I \\
\text { II }<\text { III } \\
\text { PIQ } \\
\text { VOC } \\
\text { DF } \\
\text { DB }\end{array}$ & $\begin{array}{l}4.00 \\
14.75 \\
10.75 \\
.49 \\
-1.00 \\
1.81 \\
7.65\end{array}$ & $\begin{array}{l}7.75 \\
8.39 \\
7.37 \\
.97 \\
1.14 \\
2.97 \\
3.03\end{array}$ & $\begin{array}{l}.07 \\
.29 \\
.18 \\
.05 \\
-.09 \\
.07 \\
.31\end{array}$ & $\begin{array}{l}.608 \\
.083 \\
.149 \\
.616 \\
.383 \\
.544 \\
.014\end{array}$ \\
\hline
\end{tabular}

Note: $B=$ Unstandardized coefficient, $S E=$ Standard error, $\beta=$ Standardized coefficient, $P I Q=$ Performance $I Q, V O C=$ Vocabulary,$D F=$ Digit span Forwards, $D B=$ Digit span Backwards .

Group differences and the influence of memory, Vocabulary and PIQ

Performance on the measures of memory was as follows: short term memory (Digit Span Forwards): mean $=5.1$ (SD = 1.1); working memory (Digit Span Backwards): mean = 3.6 $(S D=1.1)$. The correlation between performance on the Digit Span Forwards and Backwards was not significant $(r=.127, p=.263)$. Group differences and the influence of memory on language comprehension were investigated by separate stepwise linear regression analyses with the Total $A B C-L$ score and the scores on the three complexity levels as the dependent variables and group, PIQ, Vocabulary, short-term memory and working memory as the predictors. Table 2 shows the results of these analyses. As can be seen in Table 2, there were no differences between groups in regard to items of Low complexity, whereas linear improvement could be seen on items of Medium complexity. On items of High complexity, finally, a global trend of improvement from group I to group III could be seen without further group differences. Age-corrected level of short-term 
memory had an effect on the items of Medium complexity only, whereas age-corrected level of working memory only was related to performance on items of High complexity.

\section{The influence of sex}

All the above described results were essentially the same when sex was included in the analyses. Thus, a subject's sex did not influence Total, Low complexity, Medium complexity, and High complexity language comprehension performance.

\section{Discussion}

This cross-sectional study involving 83 children focused on the question whether complex language comprehension was fully developed at the end of primary school. Our expectation with respect to comprehension of basic instructions was confirmed. Children in kindergarten and all older children through sixth grade performed close to perfect on these items. Thus, the children participating in this study had the baseline language comprehension level we expected them to have. Children's overall language comprehension abilities improved gradually and significantly between the ages of 6 and 12 year, from an average of $61 \%$ correct in the youngest group to $86 \%$ correct in the oldest group. In contrast to this, we found that not all logical grammatical structures were mastered at the end of primary school. We divided 'language comprehension' into three levels of complexity, using $85 \%$ correct as the cut-off point to consider an ability to have been mastered. Some items, among them the direct instructions, were easy for all children - performance on these items was above $85 \%$ correct for all groups. There were no group differences on these items. Secondly, there was a group of medium complexity logical grammatical structures that became mastered over the age period studied. On these items, group I performed worse than group II, and group II performed worse than group III. The youngest $(53 \%$ correct) and middle (70\% correct) groups had difficulty with these items, but performance in the oldest children was well above the cut-off point of $85 \%$ (92\% correct). Finally, results with the most complex items improved from the youngest (38\% correct) to the oldest $(66 \%$ correct) group, but performance remained well below the $85 \%$ cut-off point.

Thus, some aspects of logical grammatical structures were already mastered by the beginning of primary school, some became mastered during primary school, and some had not been mastered by the end of primary school. In conclusion, it appears that comprehension of some logical grammatical structures continues to develop into at least early adolescence. This has important implications for educational practice, because children at secondary school may be less able than expected to deal with multifaceted questions and tasks. Future studies with longitudinal designs are needed to investigate the age at which comprehension of logical grammatical structures is completed. Our findings are consistent with those of Peter Anderson (2002), who described how aspects of executive functioning, such as conceptual reasoning, working memory, and speed of processing, continue to develop into adolescence.

To explain the differential development of language comprehension, we looked at the characteristics of the items included in each of the three complexity levels. The mean number of words and the mean number of mental steps needed to perform the items were investigated. For both characteristics, comparisons between the three levels of complexity were not significant. Thus, items that were easy for all children did not differ from more difficult items in word length and number of mental steps. A third possible explanation for 
the differential development of language comprehension is the grammatical complexity or ambiguity of the items. Items in the easiest category were grammatically straightforward, whereas the medium and most complex levels included grammatically difficult items that could be misunderstood. The process of interpreting the most difficult items could be ambiguous for children, leading to impaired comprehension (Clifton \& Duffy, 2001; Dennis \& Barnes, 1990). For example, one of the most difficult items is "The girl who worked at the zoo came to Margaret's school to give a presentation. Who gave the presentation?". To understand this item, children have to be aware that the agent of the sentence is 'the girl who worked at the zoo', instead of simply 'the girl'. Thus, in the comprehension process of such sentences, both content and structure have to be incorporated. Future research combining linguistic and neuropsychological approaches should systematically investigate this issue in a developmental perspective.

Comprehension of logical grammatical structures, especially of medium complexity, was found to be related to level of vocabulary. This confirms the language component of the ABC-L. However, the relationships found were not large and were absent when the more complex logical grammatical structures were related to Vocabulary. This suggests that comprehension of logical grammatical structures is not the same as 'verbal knowledge'. Higher-order language and verbal reasoning, in particular, are more important in this respect than knowledge of the meaning of words per se. This interpretation is in line with the notions formulated by Luria some years ago (Luria, 1966, 1980) and underscores the possible relevance of the more complex -higher- aspects of language. Future research is necessary to determine how well comprehension of logical grammatical structures relates to other aspects of language than the one studied here and to evaluate verbal reasoning in more detail, especially in relation to comprehensive language in applied settings such as school.

Age-corrected levels of short-term and working memory were controlled in respect of language comprehension in this study, based on the large literature in this area (Baddely, 2003; Booth et al., 2000; Carpenter et al., 1994; Deevy \& Leonard, 2004; Dick et al., 2004; Hahne et al., 2004; Helland \& Asbjornsen, 2004; Marton \& Schwartz, 2003; Montgomery, 2003). If the demands of a sentence exceed the working or short-term memory capacity of a child, comprehension is not possible (Just \& Carpenter, 1992). This is especially important in combined sentences that require computations of the type we used in this study.

We found that level of short-term memory was positively related to performance on medium complex items, whereas working memory was positively related to the most difficult items. Thus, working memory played a smaller role in understanding logical grammatical structures that required concrete operations, such as arranging hair color (e.g. 'Which girl is lightest if Olga is lighter than Sonia but darker than Kate?'), than it did in structures with more abstract operations, such as left-right distinctions (e.g. 'Draw a circle to the right of a cross but to the left of a triangle'). In concrete sentences, only short-term memory appeared to be significantly involved. Our findings show clearly that the ability to remember and compare is not only dependent on the number of items and operations in the sentence, but mostly of the content.

The influence of short-term memory and working memory on the comprehension of logical grammatical structures was rather small. Each series of digits a child could repeat more on the Digit Span task was associated with a 5 to $8 \%$ better performance on the comprehension of logical grammatical structures. Short-term memory and working mem- 
ory did not explain the age-differences in the comprehension of logical grammatical structures described above. Thus, although language comprehension and memory are obviously linked, the improvement over the grades in understanding logical grammatical sentences is not purely caused by an increase in memory capacities.

Girls and boys performed equally with respect to the comprehension of logical grammatical structures. This strengthens the notion that the 'language comprehension' investigated here is dissimilar from the more basic aspects of language. This is because there is substantial literature that girls outperform boys in more basic aspects of language (Bauer, Goldfield, \& Reznick, 2002; Dodd, Holm, Hua, \& Crosbie, 2003; Holm, Greaker, \& Stroemberg, 2002; Roulstone, Loader, Northstone, \& Beveridge, 2002; Tse, Kwon, Chan, \& $\mathrm{Li}, 2002)$. Our findings seem to be in line with those for verbal memory and verbal learning in children, in which no effect of sex has been reliably and consistently established (Van den Burg \& Kingma, 1999; Kramer, Delis, Kaplan, O'Donnell, \& Prifitera, 1997; Lowe, Mayfield, \& Reynolds, 2003). On the other hand, the relatively small sample size may have prevented findings in this area.

Because the majority of parents that gave consent for the study were highly educated, we limited the sample to this group. This may reduce the generalizability of our results, but has the advantage that the findings give a conservative estimation and therefore underscore the possible implications of our findings for applied settings. Accordingly, if comprehension of logical grammatical structures is not fully developed at the end of primary school, even in children from high level socioeconomic backgrounds and with educated parents, this function will be less well-developed in children from middle and poorly educated families. This expectation is based on previous research establishing a firm influence of parental education and other social economic measures on cognitive development in children (Dolloghan et al., 1999; Hoff, 2003; Jackson, 2003; Landry et al., 2002; Mackner et al., 2003; Quay \& Blaney, 1992).

In summary, comprehension of logical grammatical structures is a complex cognitive function that appears to continue developing into the period of early adolescence. A language comprehension battery such as used in the present study seems promising for investigating the development of this function. Besides investigating large groups of healthy children and adolescents according to a longitudinal design, future research should investigate children with developmental disabilities. Children with Attention Deficit Hyperactivity Disorder and Pervasive Development Disorder are especially relevant in this respect, because these children have executive problems as well as deficits in understanding certain aspects of complex language (Geurts et al., 2004; Pennington \& Ozonoff, 1996). Such research could eventually lead to a better understanding of these disorders but also of the management of these children and optimal didactic approaches. Finally, the present findings may have implications for educational practice as they suggest that the complexity of a verbal instruction given by a teacher may determine the comprehension of the pupil, even in children at the end of primary or the beginning of secondary school. 


\section{References}

Anderson, P. (2002). Assessment and development of executive function (EF) during childhood. Child Neuropsychology, 8, 71-82

Anderson, V., Anderson, P., Northam, E., Jacobs, R., \& Catroppa, C. (2001). Development of executive functions through late childhood and adolescence in an Australian sample. Developmental Neuropsychology, 20, 385-406.

Baddeley, A. (2003). Working memory and language: an overview. Journal of Communication Disorders, 36, 189-208.

Bates, E., Thal, D., Finlay, B., \& Clancy, B. (2003). Early language development and its neural correlates. In: S.J. Segalowitz \& I. Rapin (Eds.), Handbook of Neuropsychology (2nd ed., pp. 525-592). Amsterdam: Elsevier Science B.V.

Bauer, D. J., Goldfield, B. A., \& Reznick, J. S. (2002). Alternative approaches to analysing individual differences in the rate of early vocabulary development. Applied Psycholinguistics, 23, 313336.

Booth, J. R., MacWhinney, B., \& Harasaki, Y. (2000). Developmental differences in visual and auditory processing of complex sentences. Child Development, 71, 981-1003.

Brocki, K. C., \& Bohlin, G. (2004). Executive functions in children aged 6 to 13: a dimensional and developmental study. Developmental Neuropsychology, 26, 571-593.

Carpenter, P. A., Miyake, A., \& Just, M. A. (1994). Working memory constraints in comprehension. Evidence from individual differences, aphasia, and aging. In: M. A. Gernsbacher. (Ed.), Handbook of Psycholinguistics (pp. 1075-1122). San Diego, California, Academic Press, Inc.

Casey, B. J., Tottenham, N., Liston, C., \& Durston, S. (2005). Imaging the developing brain: what have we learned about cognitive development? Trends in Cognitive Sciences, 9, 104-110.

Christensen, A-L. (1993). Luria's neuropsychological investigation text. Risskov, Denmark: P. J. Schmidts Bogtrykkeri, Vojens.

Clifton, C., Jr., \& Duffy, S. A. (2001). Sentence and text comprehension: roles of linguistic structure. Annual Review of Psychology, 52, 167-196.

Cook, M., Murdoch, B., Cahill, L., \& Whelan, B-M. (2004). Higher-level language deficits resulting from primary cerebellar lesions. Aphasiology, 18, 771-784.

De Bellis, M. D., Keshevan, M. S., Beers, S. R., Hall, J., Frustaci, K., Maselehdan, A., Noll, J., \& Boring, A. M. (2001). Sex differences in brain maturation during childhood and adolescence. Cerebral Cortex, 11, 552-557.

De Bruyn, E.E.J., Van der Steene, G., Van Haasen, P.P., Coetsier, P., Pijl, Y.J., Spoelders-Claes, R., Poortinga, Y.H., Stinissen, J., \& Lutje Spelberg, H.C. (1986). Wechsler Intelligence Scale for Children - Revised (WISC-R). Lisse: Swets \& Zeitlinger.

Deevy, P., \& Leonard, L. B. (2004). The comprehension of wh-questions in children with specific language impairment. Journal of Speech, Language and Hearing Research, 47, 802-815.

Dennis, M., \& Barnes, M. A. (1990). Knowing the meaning, getting the point, bridging the gap, and carrying the message: aspects of discourse following closed head injury in childhood and adolescence. Brain and Language, 39, 428-446.

Dick, F., Wulfeck, B., Krupa-Kwiatkowski, M., \& Bates, E. (2004). The development of complex sentence interpretation in typically developing children compared with children with specific language impairments or early unilateral focal lesions. Developmental Science, 7, 360-377.

Dodd, B., Holm, A., Hua, Z., \& Crosbie, S. (2003). Phonological development: a normative study of British-English speaking children. Clinical Linguistics and Phonetics, 17, 617-643.

Dollaghan, C. A., Campbell, T. F., Paradise, J. L., Feldman, H. M., Janosky, J. F., Pitcairn, D. N., \& Kurs-Lasky, M. (1999). Maternal education and measures of early speech and language. Journal of Speech, Language and Hearing Research, 42, 1432-1443.

Eslinger, P. J., Flaherty-Craig, C. V., \& Benton, A. L. (2004). Developmental outcomes after early prefrontal cortex damage. Brain and Cognition, 55, 84-103.

Fuster, J. M. (2002). Frontal lobe and cognitive development. Journal of Neurocytology, 31(3-5), 375-385 
Geurts, H. M., Verté, S., Oosterlaan, J., Roeyers, H., Hartman, C. A., Mulder, E. J., van BerckelaerOnnes, I. A., \& Sergeant, J. A. (2004). Can the Children's Communication Checklist differentiate between children with autism, children with ADHD, and normal controls? Journal of Child Psychology and Psychiatry, 45, 1437-1453.

Gogtay, N., Giedd, J. N., Lusk, L., Hayaski, K. M., Greenstein, D., Vaituzis, A. C., Nugent, T. F. 3rd, Herman, D. H., Clasen, L. S., Toga, A. W., Rapoport, J. L., \& Thompson, P. M. (2004). Dynamic mapping of human cortical development during childhood through early adulthood. Proceedings of the National Academy of the Sciences, 101, 8174-8179.

Hahne, A., Eckstein, K., \& Friederici, A. D. (2004). Brain signatures of syntactic and semantic processes during children's language development. Journal of Cognitive Neuroscience, 16, $1302-$ 1318.

Helland, T., \& Asbjornsen, A. (2004). Digit span in dyslexia: variations according to language comprehension and mathematics skills. Journal of Clinical and Experimental Neuropsychology, 26, 31-42.

Hoff, E. (2003). The specificity of environmental influence: socioeconomic status affects early vocabulary development via maternal speech. Child Development, 74, 1368-1378.

Holm, O., Greaker, E., \& Stroemberg, A. (2002). Experiences of longing in Norwegian and Swedish 4- and 5- year-old children. Journal of Psychology, 136, 608-612.

Jackson, A. P. (2003). The effects of family and neighbourhood characteristics on the behavioural and cognitive development of poor black children: a longitudinal study. American Journal of Community Psychology, 32, 175-186.

Johnson, M. H, \& Munakata, Y. (2005). Processes of change in brain and cognitive development. Trends in Cognitive Sciences, 9, 152-158.

Just, M. A., \& Carpenter, P. A. (1992). A capacity theory of comprehension: individual differences in working memory. Psychological Review, 99, 122-149.

Kemps, E., De Rammelaere, S., \& Desmet, T. (2000). The development of working memory: exploring the complementarity of two models. Journal of Experimental Child Psychology, 77, 89-109.

Klingberg, T., Vaidya, C. J., Gabrieli, J. D. E., Moseley, M. E., \& Hedehus, M. (1999). Myelination and organization of the frontal white matter in children: a diffusion tensor MRI study. NeuroReport, 10, 2817-2821.

Kramer, J. H., Delis, D. C., Kaplan, E., O’Donnell, L., \& Prifitera, A. (1997). Developmental sex differences in verbal learning. Neuropsychology, 11, 577-584.

Landry, S. H., Smith, K. E., \& Swank, P. R. (2002). Environmental effects on language development in normal and high-risk child populations. Seminars in Pediatric Neurology, 9, 192-200.

Lezak, M. D., Howieson, D. B., \& Loring, D. W. (2004). Neuropsychological assessment (4th ed.). New York: Oxford University press.

Lowe, P. A., Mayfield, J. W., \& Reynolds, C. R. (2003). Gender differences in memory test performance among children and adolescents. Archives of Clinical Neuropsychology, 18, 865-878.

Luciana, M., Conklin, H. M., Hooper, C. J., \& Yarger, R. S. (2005). The development of nonverbal working memory and executive control processes in adolescents. Child Development, 76, 697712.

Luna, B., Garver, K. E., Urban, T. A., Lazar, N. A., \& Sweeney, J. A. (2004). Maturation of cognitive processes from late childhood to adulthood. Child Development, 75, 1357-1372.

Luria, A. R. (1966). Higher cortical functions in man. New York: Basic Books

Luria, A. R. (1980). Higher cortical functions in man. New York: Basic Books.

Mackner, L. M., Black, M. M., \& Starr Jr, R. H. (2003). Cognitive development of children in poverty with failure to thrive: a prospective study through age 6. Journal of Child Psychology and Psychiatry, 44, 743-751.

Marton, K., \& Schwartz, R. G. (2003). Working memory capacity and language processes in children with specific language impairment. Journal of Speech, Language and Hearing Research, 46, 1138-1153.

Montgomery, J. W. (2003). Working memory and comprehension in children with specific language impairment: what we know so far. Journal of Communication Disorders, 36, 221-231. 
Nigg, J. T. (2000). On inhibition/disinhibition in developmental psychopathology: views from cognitive and personality psychology and a working inhibition taxonomy. Psychological Bulletin, 126, 220-246.

Ohta, N. (2002). The need for a lifespan developmental approach within memory research is more urgent than ever. In: P. Graf \& N. Ohta. Lifespan development of human memory (pp. 3-12). Cambridge, Massachusetts: The MIT Press.

Paus, T. (2005). Mapping brain maturation and cognitive development during adolescence. Trends in Cognitive Sciences, 9, 60-67.

Pennington, B. F. \& Ozonoff, S. (1996). Executive functions and developmental disabilities. Journal of Child Psychology, 37, 51-87.

Quay, L. C., \& Blaney, R. L. (1992). Verbal communication, nonverbal communication, and private speech in lower and middle socioeconomic status preschool children. Journal of Genetic Psychology, 153, 129-138.

Roulstone, S., Loader, S., Northstone, K., \& Beveridge, M. (2002). The speech and language of children aged 25 months: descriptive data from the Avon Longitudinal Study of Parents and Children. Early Child Development and Care, 172, 259-268.

Steinberg, L. (2005). Cognitive and affective development in adolescence. Trends in Cognitive Sciences, 9, 69-74.

Stuss, D. T. (1992). Biological and psychological development of executive functions. Brain and Cognition, 20, 8-23.

Tse, S. K., Kwon, S. M., Chan, C., \& Li, H. (2002). Sex differences in syntactic development: evidence for Cantonese-speaking preschoolers in Hong Kong. International Journal of Behavioral Development, 26, 509-517.

Van den Burg, W., \& Kingma, A. (1999). Performance of 225 Dutch school children on Rey's auditory verbal learning test (AVLT). Archives of Clinical Neuropsychology, 14, 545-559.

Wechsler, D. (1974). Wechsler Intelligence Scale for Children - Revised. Manual. San Antonio: The Psychological Corporation. 


\title{
CHAPTER 7
}

\section{Complex language comprehension continues to improve into secondary school}

\begin{abstract}
We investigated age-related improvement in speed and accuracy of complex language comprehension in 361 children attending kindergarten and the second, fourth, sixth, seventh, and eighth grade. Language comprehension was measured using both the neuropsychological procedure proposed by Luria and an adapted version of the Token Test. Levels of short-term memory and verbal intelligence were controlled for in the evaluation of language comprehension. The findings show that the accuracy of language comprehension continued to develop until the sixth grade, whereas the speed of language comprehension continued to improve up until the seventh grade. We thus conclude that the complex language comprehension of children is not fully developed until early adolescence. We further contend that the speed of complex language comprehension appears to be more sensitive than accuracy with respect to measuring developmental differences.
\end{abstract}


Language comprehension, production, and use are fundamental to social and academic success (Bashir \& Scavuzzo, 1992; Cook, Murdoch, Cahill, \& Whelan, 2004). Although normal language development in children up to the age of five has been described extensively (Bates, Thal, Finlay, \& Clancy, 2003), little is known about the capacity of older children to understand complex language. Recent brain research has shown that certain regions of the human brain, especially parts of the prefrontal cortex, do not fully mature until early adulthood (De Bellis et al., 2001; Gogtay et al., 2004; Klingberg, Vaidya, Gabrieli, Moseley, \& Hedehus, 1999). Because of this, complex cognitive functions also continue to develop into adolescence or early adulthood (P. Anderson, 2002; V. A. Anderson, Anderson, Northam, Jacobs, \& Catroppa, 2001; Casey, Tottenham, Liston, \& Durston, 2005; Eslinger, Flaherty-Craig, \& Benton, 2004; Fuster, 2002; Paus, 2005; Steinberg, 2005). The comprehension of complex language may be one of the cognitive functions that continue to develop beyond childhood and into adolescence given that it is a) assumed to be essential for purposeful behavior; and b) dependent on the maturation of the prefrontal cortex (Johnson \& Munakata, 2005; Lezak, Howieson, \& Loring, 2004; Luria, 1966, 1980; Nigg, 2000; Stuss, 1992). If language comprehension does continue to develop into adolescence, large implications with respect to the practice of education can be expected. The efficiency of information-transfer can then be expected to be dependent upon the extent to which the child can understand the intention of the teacher. Given this possibility, the present study investigated the degree to which five to fifteen year old children can comprehend complex sentences.

Studies on the development of complex language comprehension are rather limited. However, Dick, Wulfeck, Krupa-Kwiatkowski, and Bates (2004), in their study with 102 children aged five to seventeen, demonstrated, using a multiple-choice paradigm, that the accuracy of and speed in choosing the agent in sentences improved up until the age of nine. Additionally, Booth, MacWhinney, \& Harasaki (2000) noted a significant improvement in accuracy as children moved from a younger grade (third and fourth graders) to an older grade (fifth and sixth graders). However, the ecological validity of a multiple-choice paradigm appears to be limited. In the real world, children are rarely provided with two or more options to choose from when confronted with complex language. Differences between children with and without Specific Language Impairment have been investigated using a second approach, namely the Wh-questions paradigm. In this paradigm, children are required to respond to what, where, when and who questions (Deevy \& Leonard, 2004; Marton \& Schwartz, 2003). In a previous study with 83 children aged six to twelve from relatively high socioeconomic backgrounds (see chapter 6), we used the Wh-paradigm to investigate the language comprehension in normally developing children. The accuracy of language comprehension was measured using the neuropsychological procedure proposed by Luria $(1966 ; 1980)$. The Luria approach was initially proposed for use with patients suffering from brain lesions. However, it was adapted by the research group for use in normally developing children. The results of this study indicated that some aspects of language comprehension were already mastered at the beginning of elementary school, while others became mastered sometime during elementary school, and still others were not yet mastered at the end of elementary school (age twelve). We thus concluded that accuracy of complex language comprehension was probably not fully developed at end of elementary school.

To extend these findings, we conducted a second cross-sectional study using a much larger sample of children. In contrast to our previous study, the present study in- 
cluded not only children attending elementary school but also children attending secondary school. Additionally, we aimed to include children from more diverse socioeconomic backgrounds. In the study presented here, the sample included 361 children, aged five to fifteen, who were attending kindergarten and the second, fourth, sixth, seventh, and eighth grade. This grade selection was chosen based on recent knowledge of the differential development of complex cognitive functions and the age at which these functions mature (Blakemore \& Choudhury, 2006; Crone, Bunge, van der Molen, \& Ridderinkhof, 2006; Luciana, Conklin, Hooper, \& Yarger, 2005; Shaw et al., 2006). In essence, we focused primarily on the age of twelve to fifteen years as this is the age at which complex language comprehension is expected to mature. In doing so, we expected to be able to determine at exactly which age complex language comprehension is fully developed. Additionally, in the present study, two adaptations were made with respect to how language comprehension was measured. Firstly, we included a larger sample so that we could effectively study both accuracy and speed of complex language comprehension. Studying both accuracy and speed of complex language comprehension was considered to improve the ecological validity of the study, given that, in real life, we rarely have time to reflect as we communicate (Dick et al., 2004). Secondly, we endeavored to acquire more knowledge on the processes within complex language comprehension so that more specific conclusions could be drawn about the maturation order of these different aspects. In other words, we were interested in uncovering which aspects of complex language comprehension mature at the earliest age and which continue to develop the longest. Therefore, we supplemented the Luria approach (ABC-L) that was used in the previous study by also using an adaptation of the Token Test (TT-A) in this study. The Token Test is a test in which children have to demonstrate that they understand increasingly complex commands by moving tokens accordingly (Lezak et al., 2004). Both approaches test the child's ability to understand sentences. The difference is related to the response output. In the ABC-L, mostly oral answers are required, whereas in the TT-A, motor answers are expected.

The second aim of the study was to investigate the influence of several age-extrinsic variables on language comprehension. These variables are mediating factors in a child's development. For example, parental education and occupation have a large impact on problem behavior and attention problems in five to six year old children (Kalff et al., 2001), as does living in a deprived environment (Kalff et al., 2001b). Additionally, with respect to early language development, previous research has demonstrated that girls have an advantage over boys (Bauer, Goldfield, \& Reznick, 2002; Dodd, Holm, Hua, \& Crosbie, 2003; Holm, Greaker, \& Stroemberg, 2002; Roulstone, Loader, Northstone, \& Beveridge, 2002; Tse, Kwon, Chan, \& Li, 2002), and that children from families with a high level of education generally develop faster than children with lower socioeconomic status (Dollaghan et al., 1999; Hoff, 2003; Jackson, 2003; Landry, Smith, \& Swank, 2002; Mackner, Black, \& Starr, 2003; Quay \& Blaney, 1992). Based on these results found with young children, we expected that complex language comprehension would mature at an earlier age in girls and in children whose parents are highly educated than it would in boys and in children from families with a lower level of education. These hypotheses were investigated in this study.

In summary, the aims of this study were, firstly, to investigate age differences in speed and accuracy of complex language comprehension in a large sample of healthy Dutch school children attending kindergarten through to the eighth grade, and, secondly, 
to study the influence of sex and parental level of education on this development. The strengths of the study include the wide age range tested (5-15 years), the sample size employed $(N=361)$, and our attempt to control for several variables that may alter the development of complex language comprehension (verbal intelligence and short-term memory).

\section{Method}

\section{Procedure}

This study is part of a large, ongoing research program that focuses on mechanisms underlying cognitive development in children. This program makes use of large scale cross-sectional and longitudinal experiments (e.g. Hurks et al., 2006; Kalff et al., 2005; Kroes et al., 2001). As the first step in the project, all schools for regular elementary education and three large schools for regular secondary education in Maastricht, a city in the southern region of the Netherlands, were approached. Schools that agreed to participate in the study received information packages for the parents of all children in the following grades: kindergarten, second, fourth, and sixth grade (elementary schools), seventh and eighth grade (secondary schools). The information packages for the parents contained a letter about the purpose of the study, a request to participate, and a stamped return envelope. Parents who agreed to participate also completed a questionnaire on sociodemographic characteristics and their child's medical history and milestone development.

Only children who had the Dutch nationality and who were in the appropriate grade were eligible for participation in the study (with the exception of children who remained in kindergarten an extra year because they were born in September and, as a result, were so called 'young' pupils). The exclusion criterion was current use of medications that could influence cognitive functioning, such as antihistamines (prescribed for hay fever), and psycho stimulants (prescribed for Attention Deficit Hyperactivity Disorder and Autism Spectrum Disorders, among others). Children with developmental disorders such as dyslexia were not excluded from the study because we did not want a 'supernormal' sample (the estimated prevalence of reading and spelling problems in Dutch elementary education is $8.8 \%$ and the prevalence of dyslexia is $3.6 \%$ [Blomert, 2002]). Rather, we reasoned that if children were attending a school for regular education and were in the appropriate grade, they could be considered as normally developing. We endeavored to include a reasonable equally number of boys and girls for each grade. We also aimed to include children from various socioeconomic backgrounds.

All children were tested individually in a stimulus free test room at their school. Testing was conducted by well-trained graduate students majoring in developmental psychology or neuropsychology. The tests took approximately 90 minutes and were all administered in the same order for each child. A break halfway was included if necessary, e.g. because of fatigue. The cognitive battery that was administered focused on language and several other domains, such as memory, sense of time, and estimation. The study was approved by the ethical committee of the psychology department at Maastricht University.

\section{Participants}

Of the approximately 3000 information packages that were sent out, 1089 were returned (of these, $81.9 \%$ agreed to participate, $18.1 \%$ refused). Of the 892 children whose par- 
ents provided consent for the study, 450 were selected using the inclusion and exclusion criteria described above. Of these 450 children, 19 were excluded from the data analyses after the data were collected because the testing demonstrated that the inclusion or exclusion criteria had not been met. Of the remaining 431 children, data for 70 children was missing on one or more of the tests. Reasons for missing data were as follows: time scheduling problems $(\mathrm{N}=31)$, technical problems $(\mathrm{N}=9)$, and refusal of the child to comply with the test instructions (mainly because of fatigue, $\mathrm{N}=30$ ). In the end, data was complete for 361 children and only these children were included in the analyses. Table 1 shows the characteristics of these children.

Table 1: Characteristics of the participants

\begin{tabular}{|c|c|c|c|c|c|c|c|c|}
\hline & & \multicolumn{6}{|c|}{ Grade } & \multirow[b]{2}{*}{ Statistic } \\
\hline & & $\begin{array}{c}\mathrm{K} \\
(\mathrm{N}=52)\end{array}$ & $\begin{array}{c}2 \\
(\mathrm{~N}=62)\end{array}$ & $\begin{array}{c}4 \\
(N=66)\end{array}$ & $\begin{array}{c}6 \\
(\mathrm{~N}=64)\end{array}$ & $\begin{array}{c}7 \\
(\mathrm{~N}=66)\end{array}$ & $\begin{array}{c}8 \\
(N=51)\end{array}$ & \\
\hline Age & $\begin{array}{l}M \\
\text { (SD) }\end{array}$ & $\begin{array}{c}6.35 \\
(0.36)\end{array}$ & $\begin{array}{c}8.36 \\
(0.37)\end{array}$ & $\begin{array}{l}10.40 \\
(0.33)\end{array}$ & $\begin{array}{l}12.39 \\
(0.31)\end{array}$ & $\begin{array}{l}13.41 \\
(0.38)\end{array}$ & $\begin{array}{l}14.49 \\
(0.33)\end{array}$ & $4491^{* 1}$ \\
\hline Sex & $\begin{array}{l}\text { boys } \\
\text { girls }\end{array}$ & $\begin{array}{l}44.2 \% \\
55.8 \%\end{array}$ & $\begin{array}{l}50.0 \% \\
50.0 \%\end{array}$ & $\begin{array}{l}42.4 \% \\
57.6 \%\end{array}$ & $\begin{array}{l}48.4 \% \\
516 \%\end{array}$ & $\begin{array}{l}56.1 \% \\
43.9 \%\end{array}$ & $\begin{array}{l}58.8 \% \\
42.2 \%\end{array}$ & $4.8^{2}$ \\
\hline LPE & L/M & $\begin{array}{l}46.2 \% \\
53.8 \%\end{array}$ & $\begin{array}{l}38.7 \% \\
61.3 \%\end{array}$ & $\begin{array}{l}47.0 \% \\
53.0 \%\end{array}$ & $\begin{array}{l}70.3 \% \\
29.7 \%\end{array}$ & $\begin{array}{l}36.4 \% \\
63.6 \%\end{array}$ & $\begin{array}{l}49.0 \% \\
51.0 \%\end{array}$ & $7.0^{2}$ \\
\hline VIQ & $\begin{array}{l}\mathrm{M} \\
\text { (SD) }\end{array}$ & $\begin{array}{l}11.08 \\
(2.98)\end{array}$ & $\begin{array}{l}10.71 \\
(2.88)\end{array}$ & $\begin{array}{l}10.53 \\
(2.62)\end{array}$ & $\begin{array}{l}10.03 \\
(1.88)\end{array}$ & $\begin{array}{l}10.02 \\
(2.09)\end{array}$ & $\begin{array}{c}9.75 \\
(2.24)\end{array}$ & $2.3^{*^{1}}$ \\
\hline MEM & $\begin{array}{l}M \\
\text { (SD) }\end{array}$ & $\begin{array}{c}4.94 \\
(1.42) \\
\end{array}$ & $\begin{array}{c}5.95 \\
(1.94) \\
\end{array}$ & $\begin{array}{c}6.55 \\
(1.86) \\
\end{array}$ & $\begin{array}{c}7.56 \\
(1.82) \\
\end{array}$ & $\begin{array}{r}7.82 \\
(1.93) \\
\end{array}$ & $\begin{array}{c}7.76 \\
(1.62) \\
\end{array}$ & $23.8^{* 1}$ \\
\hline
\end{tabular}

Note: $K=$ Kindergarten; 2 = second grade; $4=$ fourth grade; $6=$ sixth grade; $7=$ seventh grade; $8=$ eighth grade; $L P E=$ Level of Parental Education: $L / M=$ Low/Medium, $H=$ High (Generaal-Dictoraat voor de Arbeidsvoorziening; $V I Q=$ estimate of verbal intelligence, measured with the Vocabulary subtest of the WISC-R (De Bruyn et al., 1986); MEM = Short-term memory, measured with a version of the Word Learning Test (Lezak et al., 2004); ${ }^{1}$ One way analysis of variance (df1 $=5$, df2 = 355); ${ }^{2}$ Chi Square test $(d f=5) ;{ }^{*} p<.05$.

\section{Instruments}

Complex language comprehension was investigated using two tasks. The first was the Assessment Battery for Children - Language (ABC-L for short, see chapter 6), which is part of a more extensive language comprehension battery developed by Luria (1966; 1980) and adapted by Christensen (1993). Eleven of the 24 items in the original battery were administered. Items that would have been too easy for school age children were not used in the present study (they were developed by Luria for the assessment of patients with brain injuries; an example is 'pointing to objects'). The ABC-L items (shown in Table 2) were read aloud to the child by the experimenter and the experimenter noted the child's answer. The time each item took was noted as well. Items were repeated as often as requested, which was reflected in the notation of a longer duration in response. The ABC-L took about 10 minutes to administer. Each correct answer was awarded one point (maximum score possible $=13$ points). The ABC-L proportion correct ( $A B C-L$ accuracy) and the mean time per item ( $A B C-L$ speed) were used in the analyses. 
Table 2: $A B C-L$ and TT-A items

\begin{tabular}{|c|c|c|c|c|c|c|c|}
\hline \multirow[b]{2}{*}{ Nr. } & \multirow[b]{2}{*}{ ABC-L (number of words in Dutch item) } & \multicolumn{6}{|c|}{ Percentage correct } \\
\hline & & $\mathrm{K}$ & 2 & 4 & 6 & 7 & 8 \\
\hline 1. $M$ & Is my father's brother the same person as & 76 & 74 & 68 & 82 & 89 & 88 \\
\hline 2. $M$ & Draw a cross beneath a circle (6) & 73 & 94 & 93 & 97 & 99 & 98 \\
\hline 3. $M$ & Draw a circle to the right of a cross (7) & 48 & 73 & 97 & 95 & 97 & 97 \\
\hline 4. $\mathrm{H}$ & $\begin{array}{l}\text { Draw a circle to the right of a cross but to } \\
\text { the left of a triangle (12) }\end{array}$ & 10 & 25 & 49 & 83 & 81 & 78 \\
\hline 5. $M$ & $\begin{array}{l}\text { Which is correct: "Spring comes before } \\
\text { summer" or "Summer comes before } \\
\text { spring"? (18) } \\
\text { Who is shortest if John is taller than }\end{array}$ & 80 & 74 & 93 & 97 & 94 & 93 \\
\hline & $\begin{array}{l}\text { Who is shortest if Jonn is taller than } \\
\text { Pete? (11) }\end{array}$ & 72 & 84 & 97 & 97 & 94 & 93 \\
\hline 7. E & $\begin{array}{l}\text { Which is correct: "A fly is bigger than an } \\
\text { elephant" or "An elephant is bigger than a } \\
\text { fly"? (18) } \\
\text { Which qirl is lightest if Olga is lighter than }\end{array}$ & 98 & 100 & 100 & 100 & 100 & 98 \\
\hline & Sonia but darker than Kate? (15) & 33 & 56 & 69 & 82 & 83 & 78 \\
\hline 8b. H & And which girl is darkest? (6) & 27 & 53 & 56 & 74 & 73 & 62 \\
\hline 9. $\mathrm{M}$ & $\begin{array}{l}\text { Nick was struck by Pete. Who was the } \\
\text { victim? (9) }\end{array}$ & 35 & 62 & 89 & 97 & 94 & 92 \\
\hline 10. $M$ & $\begin{array}{l}\text { I had breakfast after I had walked the } \\
\text { dog. What did I do first? (13) }\end{array}$ & 45 & 67 & 78 & 86 & 90 & 95 \\
\hline 11a. $\mathrm{H}$ & $\begin{array}{l}\text { The girl who worked in the zoo came to } \\
\text { Margaret's school to give a presentation. }\end{array}$ & & & & & & 79 \\
\hline 11b. $\mathrm{H}$ & What did Margaret do? (3) & $\begin{array}{l}62 \\
27 \\
53\end{array}$ & $\begin{array}{l}19 \\
59 \\
69\end{array}$ & $\begin{array}{l}58 \\
50 \\
75\end{array}$ & $\begin{array}{l}16 \\
73 \\
87\end{array}$ & $\begin{array}{l}71 \\
75 \\
88\end{array}$ & $\begin{array}{l}79 \\
79 \\
87\end{array}$ \\
\hline
\end{tabular}

\begin{tabular}{|c|c|c|c|c|c|c|c|}
\hline \multirow[b]{2}{*}{ Nr. } & \multirow[b]{2}{*}{ TT-A (number of words in Dutch item) } & \multicolumn{6}{|c|}{ Percentage correct } \\
\hline & & $\mathrm{K}$ & 2 & 4 & 6 & 7 & 8 \\
\hline 1. M & $\begin{array}{l}\text { Put the red circle on the green rectangle } \\
\text { (8) }\end{array}$ & 92 & 84 & 93 & 89 & 90 & 95 \\
\hline 2. $\mathrm{H}$ & $\begin{array}{l}\text { Touch the blue circle with the red rectan- } \\
\text { gle (9) }\end{array}$ & 13 & 32 & 43 & 42 & 70 & 72 \\
\hline 3. M & $\begin{array}{l}\text { Touch, with the blue circle, the red rectan- } \\
\text { gle (9) } \\
\text { Pick up the blue circle or the red rectangle }\end{array}$ & 82 & 87 & 92 & 89 & 93 & 93 \\
\hline 4. IVI & & 71 & 88 & 94 & 99 & 97 & 97 \\
\hline 5. M & $\begin{array}{l}\text { Place the green rectangle away from the } \\
\text { yellow rectangle (9) }\end{array}$ & 63 & 77 & 90 & 96 & 94 & 97 \\
\hline 6. M & $\begin{array}{l}\text { If there is a black circle, pick up the red } \\
\text { rectangle (12) }\end{array}$ & 73 & 71 & 89 & 96 & 96 & 95 \\
\hline 7. E & $\begin{array}{l}\text { Pick up the rectangles, except the yellow } \\
\text { one (7) }\end{array}$ & 98 & 97 & 100 & 100 & 100 & 100 \\
\hline 8. $E$ & $\begin{array}{l}\text { When I touch the green circle, you pick up } \\
\text { the white rectangle }(12)\end{array}$ & 89 & 96 & 97 & 86 & 93 & 100 \\
\hline 9. $M$ & $\begin{array}{l}\text { Put the green rectangles beside the red } \\
\text { circle }(8)\end{array}$ & 77 & 93 & 93 & 100 & 99 & 97 \\
\hline 10. M & $\begin{array}{l}\text { Touch the rectangles, slowly, and the } \\
\text { circles, quickly (16) }\end{array}$ & 45 & 68 & 72 & 77 & 89 & 86 \\
\hline 11. E & $\begin{array}{l}\text { Put the red circle between the yellow } \\
\text { rectangle and the green rectangle }(12)\end{array}$ & 89 & 94 & 93 & 96 & 96 & 93 \\
\hline $12 . \mathrm{MI}$ & $\begin{array}{l}\text { Except for the green one, touch the circles } \\
\text { (7) }\end{array}$ & 74 & 99 & 99 & 99 & 100 & 100 \\
\hline & $\begin{array}{l}\text { Pick up the red circle -no!- the white } \\
\text { rectangle (9) }\end{array}$ & 95 & 93 & 96 & 96 & 99 & 97 \\
\hline 14. M & $\begin{array}{l}\text { Instead of the white rectangle, pick up the } \\
\text { yellow circle (10) }\end{array}$ & 82 & 94 & 97 & 94 & 99 & 100 \\
\hline
\end{tabular}


Table 2 continued:

\begin{tabular}{|c|c|c|c|c|c|c|c|}
\hline \multirow[b]{2}{*}{ Nr. } & \multirow[b]{2}{*}{ TT-A (number of words in Dutch item) } & \multicolumn{6}{|c|}{ Percentage correct } \\
\hline & & $\mathrm{K}$ & 2 & 4 & 6 & 7 & 8 \\
\hline 15. E & $\begin{array}{l}\text { Together with the yellow circle, pick up the } \\
\text { blue circle (9) }\end{array}$ & 94 & 100 & 97 & 99 & 99 & 100 \\
\hline 16. $M$ & After picking up the green rectangle, touch & 61 & 81 & 92 & Q? & 87 & 07 \\
\hline 17. E & Put the blue circle under the white rectan- & וע & 01 & $\sqrt{2}$ & J2 & 01 & (1) \\
\hline & gle (8) & 94 & 91 & 96 & 99 & 100 & 100 \\
\hline 18. $\mathrm{M}$ & $\begin{array}{l}\text { Before touching the yellow circle, pick up } \\
\text { the red rectangle (12) }\end{array}$ & 60 & 83 & 89 & 99 & 96 & 98 \\
\hline 19. $\mathrm{H}$ & $\begin{array}{l}\text { Touch the little yellow circle with the large } \\
\text { green rectangle (11) }\end{array}$ & 37 & 57 & 60 & 68 & 81 & 81 \\
\hline 20. $M$ & $\begin{array}{l}\text { Put the large green circle on the small } \\
\text { white rectangle (10) }\end{array}$ & 61 & 83 & 89 & 86 & 91 & 88 \\
\hline 21. $M$ & $\begin{array}{l}\text { Before touching the small white circle, pick } \\
\text { up the large green rectangle (14) }\end{array}$ & 57 & 78 & 90 & 89 & 96 & 93 \\
\hline 22. $M$ & $\begin{array}{l}\text { Pick up the rectangles, except the small } \\
\text { blue one (8) }\end{array}$ & 53 & 75 & 88 & 94 & 97 & 97 \\
\hline 23. $M$ & $\begin{array}{l}\text { Touch, with the large white circle, the } \\
\text { small blue rectangle (11) }\end{array}$ & 55 & 77 & 88 & 91 & 96 & 88 \\
\hline 24. $M$ & $\begin{array}{l}\text { Put the small red rectangle next to the } \\
\text { small blue circle }(10)\end{array}$ & 57 & 83 & 90 & 97 & 94 & 92 \\
\hline 25. $M$ & $\begin{array}{l}\text { After picking up the large red rectangle, } \\
\text { pick up the small yellow circle (15) }\end{array}$ & 29 & 57 & 64 & 74 & 77 & 90 \\
\hline 26. M & $\begin{array}{l}\text { Pick up the large green circle or the small } \\
\text { yellow rectangle (11) }\end{array}$ & 76 & 83 & 90 & 91 & 96 & 98 \\
\hline 27. M & $\begin{array}{l}\text { Touch the circles, except the large white } \\
\text { one (8) }\end{array}$ & $\begin{array}{l}48 \\
68\end{array}$ & $\begin{array}{l}67 \\
81\end{array}$ & $\begin{array}{l}87 \\
88\end{array}$ & $\begin{array}{l}96 \\
90\end{array}$ & $\begin{array}{l}96 \\
93\end{array}$ & $\begin{array}{l}88 \\
94\end{array}$ \\
\hline
\end{tabular}

Note: $K=$ Kindergarten; digit refers to grade, e.g. 2 = second grade; $E=$ Easy item: percentage correct $>85 \%$ in all grades; $M=$ Medium complex item: percentage correct $<85 \%$ in some grades but $>85 \%$ correct in other; $\mathrm{H}=$ Hard item: percentage correct $<85 \%$ correct in all grades.

The second measure used for language comprehension was an Adapted version of the Token Test (abbreviated as TT-A in the rest of the text). The original Token Test assesses verbal comprehension of increasing complex commands (De Renzi \& Faglioni, 1978 ) and is generally used to screen for aphasia. Non-aphasic persons who have completed the fourth grade are expected to perform with few, if any, errors (Lezak et al., 2004). The test requires participants to move tokens according to oral commands provided by the experimenter. There are 20 tokens in two shapes (circles and rectangles), two sizes (big and little), and five colors (red, blue, yellow, white, and green). The tokens are laid out horizontally in parallel rows with colors in fixed order per row (Lezak et al., $2004)^{1}$. The adapted version used in this study consisted of: (1) part $V$ of the original Token Test which involves relational concepts and is considered to be the most difficult part (Lezak et al., 2004); and (2) a 9-item self-developed part in which the same type of relational concepts as part $\mathrm{V}$ are tested. However, in this part, not only large rectangles and circles are used. Small rectangles and circles are also used. For example, for the following item of part $\mathrm{V}$ of the original Token Test "Pick up the rectangles, except the

\footnotetext{
${ }^{1}$ In English-speaking areas, rectangles have been substituted by squares, to reduce the number of syllables that must be processed. In Dutch, however, this has never been necessary because the Dutch words for rectangle ("rechthoek") and square ("vierkant") both contain two syllables.
} 
yellow one", the instruction was changed to "Pick up the rectangles, except the small yellow one". This adapted part of the TT-A was included to increase the complexity and, in doing so, make the test more suitable for children as well as adolescents (in contrast to the original Token Test for Children which is appropriate for children aged three to twelve [DiSimoni, 1978] and the Revised Token Test which is suitable from age 20 on [McNeil \& Prescott, 1978]). The TT-A consisted of 27 items in total (see Table 2). Administration of the TT-A was similar to the ABC-L in that the items were read aloud to the child by the experimenter. The child responded by moving the tokens and the experimenter noted not only whether the response was correct or false but also the time taken to respond to each item. Again, items could be repeated as often as requested and this was reflected in the notation of a longer duration in response on that item.

To make the 90 minute test session as diverse as possible, the TT-A was divided in half (14 items, 13 items). The first half was administered after approximately 20 minutes and the second was administered after approximately an hour. Total administration time of both halves was about 15 minutes. Each correct answer was awarded one point (maximum score possible $=27$ points). The TT-A proportion correct (TT-A accuracy) and the mean time per item (TT-A speed) were used in the analyses.

To control for the influence of short-term memory on comprehension of complex language (Baddely, 2003; Booth et al., 2000; Carpenter, Miyake, \& Just, 1994; Deevy \& Leonard, 2004; Dick et al., 2004; Hahne, Eckstein, \& Friederici, 2004; Helland \& Asbjornsen, 2004; Just \& Carpenter, 1992; Marton \& Schwartz, 2003; Montgomery, 2003), we used the first trial of a Word Learning Test (WLT) (Lezak et al., 2004, Meijs, Hurks, Wassenberg, Feron, \& Jolles, in preparation). In this test, children were shown fifteen unrelated pictures or were presented fifteen unrelated words on a laptop computer. Immediately after all pictures/words were presented, children were instructed to name as many as possible. The total number of correctly reproduced words was recorded and used in the analyses. The different modalities and versions of the test had no influence on the language comprehension scores and, as a result, were not be used in the analyses. Table 1 indicated that WLT scores improved significantly over the grades. Post-hoc Bonferroni-adjusted comparisons showed a stage-like linear improvement. Only the differences between second and fourth grades, and the sixth, seventh, and eighth grades were not significant. Because of these age-differences and the expected influence of short-term memory on complex language comprehension, the WLT raw score (range $=0-15$ ) was included in all analyses as a covariate.

Verbal intelligence was estimated using the Vocabulary subtest of the Dutch Wechsler Intelligence Scale for Children Revised (WISC-R, De Bruyn et al., 1986; Wechsler, 1974). The WISC-R, rather than the WISC-III, was used because the latter became available in the Netherlands only after the study had started. In the Vocabulary subtest, children were required to define a number of words as accurately and completely as they could. Scaled scores ranging from 1 to 19 (mean $=10, S D=3$ ) were used as the outcome variable. Although the Vocabulary scores appeared to differ between the grades (see Table 1), post-hoc Bonferroni-corrected comparisons were not significant. Because of the expected relationship between vocabulary and complex language comprehension, vocabulary was included in all analyses as a covariate. 
Level of parental education was based on the partner with the highest level of education (Kalff et al., 2001a). The majority of participants came from families with a moderate to high level of education. Twenty-eight parent-pairs $(7.7 \%)$ had a low level of parental education, 122 parent-pairs (33.5\%) had a moderate level, and 214 parent-pairs $(58.8 \%)$ had a high level of education (Directoraat-Generaal voor de Arbeidsvoorziening, 1989). Because only a few parent-pairs had a low level of education, the level of parental education was scored on a 2-point scale: low/middle (1 point, elementary school to vocational education degree) vs. high (2 points, general secondary education to doctoral degree). The level of parental education did not differ between the grades (see Table 1).

\section{Statistical analyses}

The statistical package SPSS 11.5 was used for all analyses. Because the ABC-L and TT-A speed scores were not normally divided, their logarithmic transformations were used in the analyses. Specific group differences for accuracy and speed for the ABC-L and the TT-A were each analyzed with five separate linear regression analyses. In these analyses, one of the grades was systematically compared with the others. This was done by including one of four sets of dummy variables. For example, with the dummy variables of Kindergarten, the following comparisons were made: Kindergarten with second grade, Kindergarten with fourth grade, Kindergarten with sixth grade, Kindergarten with seventh grade, and Kindergarten with eighth grade. No set of dummy variables was needed for the oldest grade because all comparisons had been made already. Additional variables included in the analyses were sex (coded as: boy = 1, girl = 2), parental level of education (coded as: low/middle $=1$, high $=2$ ), estimate of verbal intelligence (continuous), and estimate of short-term memory (continuous). The alpha value was set at .05 for all analyses.

\section{Results}

\section{Descriptives}

Internal consistency of the ABC-L and TT-A speed and accuracy scores were calculated using Cronbach's alpha. Results were as follows: Cronbach's alpha $=.80$ for $A B C-L$ speed, .73 for ABC-L accuracy, .92 for TT-A speed and .79 for TT-A accuracy.

Correlations between the scores on the ABC-L and TT-A, corrected for grade, were calculated with Pearson correlation coefficients. We found positive and significant correlations between the ABC-L and TT-A accuracy scores $(\rho=.382, p<.001)$ and between the ABC-L and TT-A speed scores $(\rho=.429, p<.001)$. Speed and accuracy scores of the TT-A were found to correlate negatively and significantly $(\rho=-.264, p<.001)$ whereas no significant correlation was found between the ABC-L speed and accuracy scores $(\rho=-.032, p=.553)$. With respect to the association of speed and accuracy over the tests, a small negative correlation was found between ABC-L accuracy and TT-A speed $(\rho=-.107, p=.049)$ and no significant correlation was found between ABC-L speed and TT-A accuracy ( $\rho=-.029, p=.597)$. This indicates that there is no strong relation between speed and accuracy of language comprehension, when the effect of grade is partialled out.

As a general rule, an aspect of language comprehension was considered to be 'mastered' if at least $85 \%$ of the children within a certain group answered it correctly. One ABC-L item could be classified as 'easy' according to this rule. The proportion of correct answers on this item was above $85 \%$ for all grades. For the TT-A, six items could 
be classified as 'easy' (see items marked with $E$ in Table 2). Items on which performance was below $85 \%$ in some grades but above $85 \%$ in the highest grades were classified as 'medium complex'. Seven ABC-L and 19 TT-A items fit this description (see items marked with $\mathrm{M}$ in Table 2). The most difficult items, on which the proportion correct was below $85 \%$ in all grades, were classified as 'hard'. Five ABC-L items and two TT-A items fit this description (see items marked with $\mathrm{H}$ in Table 3). These most difficult items were grammatically ambiguous and consisted of at least three concepts to compare (e.g. "Draw a circle to the right of a cross but to the left of a triangle"). A one-way analysis of variance indicated that the mean number of words per item differed significantly between the three complexity levels (Easy: mean $=10.7(S D=3.7)$, Medium: mean $=10.7(S D=$ $3.0)$, Hard: mean $\left.=17.0(\mathrm{SD}=7.0), F_{(2,37)}=7.15, p=.002\right)$. The mean logarithmic transformation of speed per item, however, did not differ significantly between the three complexity levels (Easy: mean $=.97$ seconds $(S D=.09)$, Medium: mean $=1.05$ seconds $(S D$ $=.13)$, Hard: mean $=1.03$ seconds, SD $\left.=.13), F_{(2,37)}=1.27, p=.293\right)$.

\section{Age-related differences: Accuracy}

Figure $1 \mathrm{~A}$ shows the developmental pattern for total accuracy of language comprehension on the TT-A and ABC-L. Not surprisingly, accuracy increased from the lower grades through to the older grades. Table 3 shows the results of the linear regression analyses for accuracy of language comprehension. TT-A and ABC-L accuracy both improved linearly from kindergarten to the sixth grade. The differences between performance in the sixth, seventh, and eighth grades were not significant, although a trend for significance could be observed for the difference between the sixth and eighth grades on the TT-A. It thus appears that accuracy of complex language comprehension reached full development in the sixth grade.

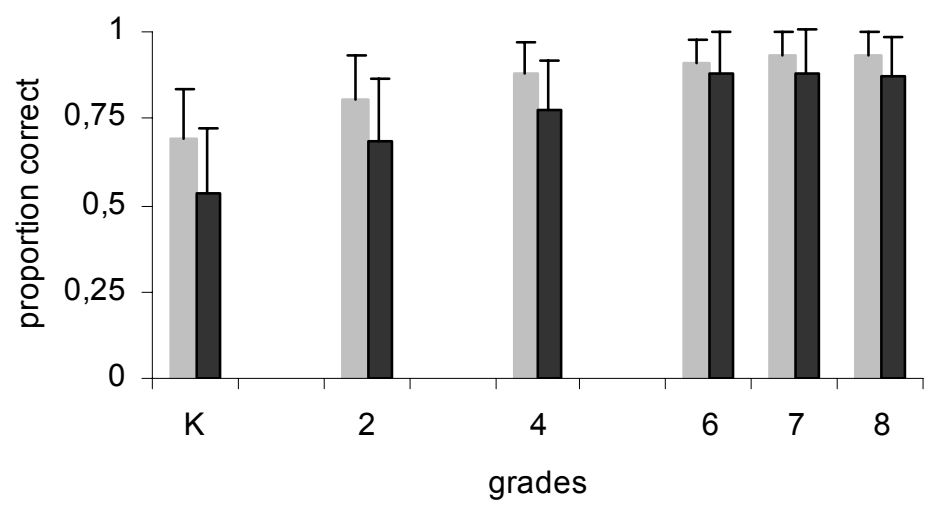

Token $\square \mathrm{ABC}-\mathrm{L}$

Figure 1A: Accuracy of complex language comprehension over the grades Note: Accuracy is defined as the percentage correct on the language comprehension measures over the grades 
Table 3: Linear regression models for accuracy of language comprehension

\begin{tabular}{|c|c|c|c|c|c|c|c|c|}
\hline \multirow[b]{2}{*}{ Differences: } & \multicolumn{4}{|c|}{$\begin{array}{c}\text { TT-A } \\
F_{(9,341)}=37.6, p<.001 \\
\mathrm{R}^{2}=49.8 \%\end{array}$} & \multicolumn{4}{|c|}{$\begin{array}{c}\text { ABC-L } \\
F_{(9,349)}=39.3, p<.001 \\
\mathrm{R}^{2}=50.3 \%\end{array}$} \\
\hline & B & SE & $\beta$ & p-value & B & $\mathrm{SE}$ & $\beta$ & $p$-value \\
\hline $\mathrm{K}<2$ nd grade & .12 & .02 & .36 & .000 & .16 & .03 & .32 & .000 \\
\hline $\mathrm{K}<4$ th grade & .19 & .02 & .59 & .000 & .24 & .03 & .50 & .000 \\
\hline$K<6$ th grade & .23 & .02 & .70 & .000 & .35 & .03 & .72 & .000 \\
\hline $\mathrm{K}<7$ th grade & .25 & .02 & .78 & .000 & .35 & .03 & .73 & .000 \\
\hline $\mathrm{K}<8$ th grade & .26 & .02 & .73 & .000 & .36 & .03 & .67 & .000 \\
\hline $2 \mathrm{nd}<4$ th grade & .07 & .02 & 22 & .000 & .08 & .02 & .17 & .001 \\
\hline 2 nd $<6$ th grade & 11 & .02 & .33 & .000 & 19 & .03 & .40 & .000 \\
\hline 2 nd $<7$ th grade & .13 & .02 & .41 & .000 & .20 & .03 & .40 & .000 \\
\hline 2 nd $<8$ th grade & 14 & .02 & .40 & .000 & .20 & .03 & .37 & .000 \\
\hline 4 th $<6$ th grade & .04 & .02 & .12 & .020 & .11 & .02 & .23 & .000 \\
\hline 4 th $<7$ th grade & .06 & .02 & .19 & .000 & .11 & .02 & .23 & .000 \\
\hline 4 th $<8$ th grade & .07 & .02 & .20 & .000 & .12 & .03 & .22 & .000 \\
\hline 6 th $<7$ th grade & .02 & .02 & .07 & .154 & .00 & .02 & .001 & .990 \\
\hline 6 th $<8$ th grade & .03 & .02 & .09 & .062 & .01 & .03 & .01 & .810 \\
\hline 7 th $<8$ th grade & .01 & .02 & .03 & .586 & .01 & .03 & .01 & 817 \\
\hline Sex & .004 & .01 & 01 & .721 & -.01 & .01 & -.02 & 659 \\
\hline LPE & -.01 & .01 & -.05 & .260 & .03 & .02 & .08 & .032 \\
\hline VIQ & .02 & .002 & .29 & .000 & .02 & .003 & .27 & .000 \\
\hline MEM & .002 & .003 & .04 & .389 & .002 & .004 & .03 & .538 \\
\hline
\end{tabular}

Note: Accuracy is defined as the proportion correct; $K=$ Kindergarten, $B=$ Unstandardized regression coefficient; $S E=$ Standard error; $\beta=$ Standardized regression coefficient; $L P E=$ Level of $P a-$ rental Education (Directoraat-Generaal voor de Arbeidsvoorziening, 1989); VIQ = estimate of verbal intelligence (Vocabulary subtest WISC-R [De Bruyn et al., 1986]); MEM = Short-term memory (Word Learn Test (Lezak et al., 2004).

With respect to the influence of age-extrinsic variables on the accuracy of complex language comprehension, we found that sex was not significantly related to performance on the TT-A and ABC-L accuracy scores. Boys and girls performed at equal levels. Level of parental education was, however, significantly associated with performance on the $A B C-L$. Children with highly educated parents scored, on average, $3 \%$ better than children from low/middle education backgrounds. The TT-A accuracy score did not differ between children from low/middle and highly educated families.

\section{Age-related differences: Speed}

Figure 1B shows the developmental pattern for speed of language comprehension on the TT-A and ABC-L. Not surprisingly, speed decreased over the grades tested. Table 4 shows the results of the linear regression analyses for the logarithmic transformation of speed of language comprehension. Speed of language comprehension appeared to improve a year longer than accuracy, thus until the seventh grade. TT-A speed improved linearly from kindergarten to the seventh grade, whereas the difference between performance in the seventh grade and performance in the eighth grade was not significant. For the ABC-L, a slightly different pattern was observed. The difference between performance in kindergarten and second grade was not significant, thus speed on this measure started to improve at a later age. In addition, the difference between speed of performance in the sixth and eighth grades on the ABC-L was such that only a statistical trend for significance could be demonstrated. 


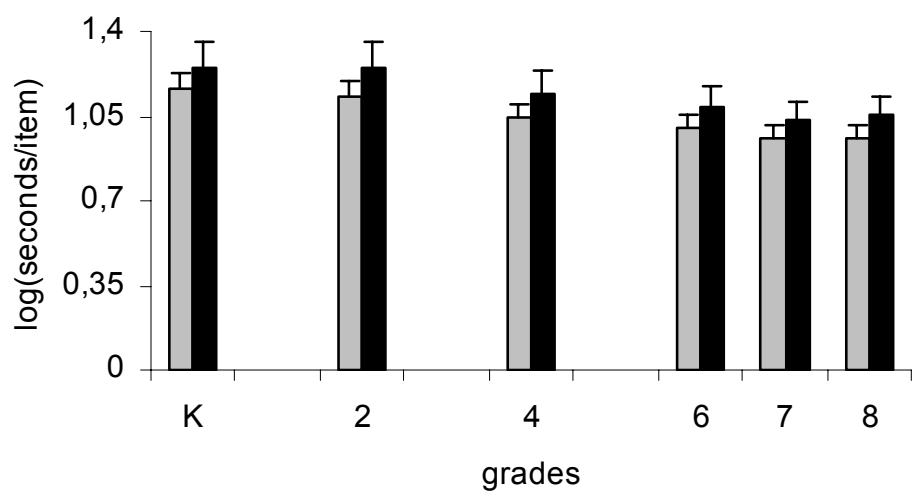

$\square$ Token $\square$ ABC-L

Figure 1B: Speed of complex language comprehension over the grades

Note: Speed is defined as the logarithmic transformation of mean seconds per item over the grades

Table 4: Linear regression models for speed of language comprehension

\begin{tabular}{|c|c|c|c|c|c|c|c|c|}
\hline \multirow[b]{2}{*}{ Differences: } & \multicolumn{4}{|c|}{$\begin{array}{c}\text { TT-A } \\
F_{(9,342)}=77.8, p<.001 \\
\mathrm{R}^{2}=67.2 \% .\end{array}$} & \multicolumn{4}{|c|}{$\begin{array}{c}\text { ABC-L } \\
F_{(9,349)}=34.1, p<.001 \\
\mathrm{R}^{2}=46.8 \%\end{array}$} \\
\hline & $B$ & SE & $\beta$ & $p$-value & $B$ & SE & $\beta$ & p-value \\
\hline $\mathrm{K}<2$ nd grade & -.04 & .01 & -.14 & .002 & .002 & .02 & .01 & .909 \\
\hline $\mathrm{K}<4$ th grade & -.12 & .01 & -.47 & .000 & -.11 & .02 & -.34 & .000 \\
\hline$K<6$ th grade & -.16 & .01 & -.65 & .000 & -.16 & .02 & -.50 & .000 \\
\hline $\mathrm{K}<7$ th grade & -.20 & .01 & -.81 & .000 & -.21 & .02 & -.65 & .000 \\
\hline $\mathrm{K}<8$ th grade & -.20 & .01 & -.74 & .000 & -.20 & .02 & -.55 & .000 \\
\hline 2 nd $<4$ th grade & -.08 & .01 & -.33 & .000 & -.11 & .02 & -.35 & .000 \\
\hline 2 nd $<6$ th grade & -.13 & .01 & -.51 & .000 & -.17 & .02 & -.51 & .000 \\
\hline 2 nd $<7$ th grade & -.17 & .01 & -.67 & .000 & -.22 & .02 & -.66 & .000 \\
\hline 2 nd $<8$ th grade & -.17 & .01 & -.62 & .000 & -.20 & .02 & -.55 & .000 \\
\hline 4 th $<6$ th grade & -.05 & .01 & -.18 & .000 & -.05 & .02 & -.16 & .001 \\
\hline 4 th $<7$ th grade & -.08 & .01 & -.34 & .000 & -.10 & .02 & -.31 & .000 \\
\hline 4 th $<8$ th grade & -.09 & .01 & -.31 & .000 & -.09 & .02 & -.24 & .000 \\
\hline 6 th $<7$ th grade & -.04 & .01 & -.16 & .000 & -.05 & .02 & -.15 & .002 \\
\hline 6 th $<8$ th grade & -.04 & .01 & -.15 & .000 & -.03 & .02 & -.09 & .051 \\
\hline 7 th $<8$ th grade & -.002 & .01 & -.01 & .848 & .02 & .02 & .05 & .337 \\
\hline Sex & -.02 & .01 & -.08 & .014 & -.01 & .01 & -.05 & .154 \\
\hline LPE & .001 & .01 & .004 & .901 & -.02 & .01 & -.06 & .128 \\
\hline VIQ & -.01 & .001 & -.13 & .000 & -.01 & .002 & -.14 & .000 \\
\hline MEM & -.004 & .002 & -.09 & .015 & -.01 & .003 & -.08 & .078 \\
\hline
\end{tabular}

Note: Speed is defined as the logarithmic transformation of the mean duration of items in seconds; other notes see Table 3.

With respect to the influence of age-extrinsic variables on speed of complex language comprehension, we found that sex was not significantly related to performance on the ABC-L. Boys and girls performed with almost equal speed. Performance on the TT- 
A, however, was faster for girls than for boys. Level of parental education was not significantly associated with TT-A and ABC-L speed of processing. Children from families with a low/middle education level and children from families with a high education level performed equally fast.

\section{Discussion}

We studied the age-related improvement of complex language comprehension and the influence of sex and parental level of education on this improvement in a sample of 361 normally developing children attending kindergarten and second, fourth, sixth, seventh, and eighth grades. Language comprehension was measured using an adaptation to the neuropsychological approach described by Luria (1960, 1980; Christensen, 1993) and by means of an adapted version of the Token Test (De Renzi \& Faglioni, 1978). The analyses were controlled for levels of verbal intelligence and short-term memory. Perfect language comprehension was not reached in the age period studied. The findings show that the most complex sentences were not mastered completely by the eighth grade and this suggests that the complex sentences were too difficult for 14 year old adolescents. This interpretation is supported by our finding that complex language comprehension appeared to plateau, for accuracy, in the sixth grade and, for speed, in the seventh grade. We can thus contend that complex language comprehension continues to mature until early adolescence. This finding corresponds with and extends Peter Anderson's (2002) executive function model. Peter Anderson (2002) concluded that the cognitive domains of cognitive flexibility, goal setting, and information processing are relatively mature by early adolescence (12 years of age). Other cognitive functions that have been found to continue developing into adolescence are working memory and control of impulsivity (Brocki \& Bohlin, 2004; Casey et al., 2005; Eslinger et al., 2004; Fuster, 2002; Paus, 2005; Steinberg, 2005). The findings of the present study add the construct 'complex language comprehension' to the existing list of cognitive functions that continue to develop beyond childhood and into adolescence. This could have significant implications for the practice of education. Children may, at the end of elementary school, be less able to comprehend multi-facetted tasks and instructions than we previously expected. Instructions containing several steps, such as "Take your workbook, open it to page 34, and start working on assignment B" should be divided in several short sentences as this would allow teachers to check whether children did indeed understand the instructions. Although this kind of practice is already common in early elementary education and in schools for children with special needs, this study indicates that normally developing children up to the eighth grade may also benefit from simpler instructions.

Using the $85 \%$ correct rule (an aspect of language comprehension was considered to be mastered when $85 \%$ of children in a certain age-group answered it correctly), the results showed that 7 of the 40 complex sentences tested here were already mastered in the earliest grades of elementary school while other sentences had not yet mastered in the eighth grade. However, most of the complex sentences (26) were mastered by students over the course of elementary and early secondary education. The most difficult items possessed strong grammatical complexity and ambiguity in contrast to the other items (Clifton \& Duffy, 2001; Dennis \& Barnes, 1990). For example, one of the most difficult items was "Touch the blue circle with the red rectangle". To understand this item, children have to be aware that the order of the words is not similar to the actions they are supposed to execute. First, they must pick up the red rectangle and then they have to 
use this token to touch the blue square. Thus, in the comprehension process of such sentences, both content and structure have to be incorporated.

Another potential explanation for this differential development of complex language comprehension can be derived from the length of the items in the three complexity levels. The most difficult items all contained at least three concepts to compare, whereas less difficult items contained two concepts at most. We found that the items that were not yet mastered in the highest grades were, on average, longer than the items that were mastered in the lower grades. This characteristic appears to point to the well-established relationship between memory and language comprehension (Baddely, 2003; Luria, 1966, 1980). When we looked at the total scores, we found that children with a larger memory span comprehended the complex sentences faster. However, no relationship between short-term memory and the accuracy of complex language comprehension was found. This distinction probably stems from the fact that, in this study, the language comprehension items could be repeated as often as requested which may have actually represented a slower speed of comprehension on that item. In essence, children with higher levels of short-term memory likely asked for repetition less often and, as a result, had higher levels of speed. However, because no strong relationship between accuracy and speed of language comprehension was found, we can contend that, when the effect of grade was not considered, a faster response did not automatically imply a correct response.

Speed of complex language comprehension continued to improve for a year longer than accuracy. This suggests that speed is more sensitive to developmental changes in language comprehension than accuracy is. A line of research that is related to this finding comes from Hale (1990) and Kail (1991, 1996, 2000). These researchers focused on the development of general processing speed measured by reaction time tests on different domains of cognitive functioning (e.g. mental rotation, letter matching, and abstract matching). They demonstrated that the reaction times of children and adolescents continued to decrease until about the age of 15, at which time adult levels were reached. According to Kail (1991), age differences in processing speed reflect a general component that changes rapidly during childhood and more slowly during adolescence. This prolonged development of processing speed has been explained by neural processes such as myelination and synaptogenesis (see Kail, 1996; Travis, 1998).

The second aim of this study was concerned with the influence of two age-extrinsic variables on the comprehension of complex language. These two variables were sex and parental level of education. Our expectation that girls would have an advantage over boys was confirmed for speed of language comprehension. Girls did indeed, on average, perform faster than boys on the TT-A. However, no influence of sex was found for the accuracy of language comprehension. In other words, boys and girls were equally able to understand complex sentences but girls were faster in giving the correct answer. Therefore, the advantage girls have over boys that has been demonstrated in young children (Bauer et al., 2002; Dodd et al., 2003; Holm et al., 2002; Roulstone et al., 2002; Tse et al., 2002) appears to be more specific in children and adolescents between the ages of 5 and 15 . Knowledge from adult cognitive psychology may be relevant in this context. In this field, research has shown that, on cognitive tasks, 40 year old individuals can perform with the same accuracy as 25 year olds. However, 40 year olds need considerably more time to do so (Van der Elst, van Boxtel, van Breukelen, \& Jolles, 2006). Hence, when speed is emphasized, 40 year olds perform much worse than 25 year olds. 
A similar mechanism may be present in 5 to 15 year old children with girls comprehending complex language faster than boys. This obviously results in better performance when speed is important, e.g. in the classroom situation. However, because we did not separately record the time children thought about a TT-A item and the time needed for the motor response on that item, we do not know whether we are dealing with a developmental difference in thinking speed or in motor speed. This warrants further research in this area of language comprehension whereby emphasis can be placed on separating the effect of thinking time from response speed.

With respect to the influence of parental level of education on language comprehension, we found that children of highly educated parents had an advantage over children from a low/middle education background with respect to accuracy on the ABC-L. No similar effect was found for the TT-A. The results thus suggest that children with highly educated parents perform more accurately on one of the complex comprehension tasks used in this study. A possible explanation for this distinction can be found in the content of the items. The amount of imagination and abstraction needed to respond correctly appears to be larger for the ABC-L than for the TT-A. After all, the TT-A response options can be easily considered given that the tokens are laid out in front of the participant. Different response strategies can be prepared and tested as the TT-A item is presented, whereas $A B C-L$ items and their possible responses can only be stored in working memory. Highly educated parents could be expected to use more abstract language in daily communication and thus train their children to respond orally in this way. In other words, children from highly educated families may have an advantage over children from lower educated families in understanding complex language that requires an oral response.

The results of this study have to be interpreted in the light of several limitations. First, although the sample size was large and care was taken to include children from various socioeconomic backgrounds, relatively few children whose parents had low levels of education could be included in the study. This reduced the extent to which the findings can be generalized to the whole population. Second, the number of times an item was repeated was not recorded during test administration. Because of this, we do not know whether slow performance was caused by problems with storing the information (which would be reflected in numerous requests to repeat the item) or by actual language comprehension problems (which would be reflected in no requests for repetition). Future research should separate these issues by recording the number of repetitions per item and measuring the time that passes between these repetitions. Third, although levels of short-term memory were controlled for, working memory abilities were not. Working memory may be of more importance in understanding the ABC-L items than short-term memory because of the previously described requirement for imagination and abstraction. Future research should include both types of memory and control for their influence in the comprehension of complex language. Fourth, cross-sectional samples are obviously less suitable for developmental research than longitudinal samples. This underscores the need for large scale longitudinal investigations in complex language comprehension and other aspects of cognitive development.

In conclusion, complex language comprehension is a higher-order cognitive function that continues to develop until early adolescence. The findings of this study have several implications for research and clinical practice. Firstly, the language comprehension batteries such as the ones used in this study appear to be promising measures for investi- 
gating the development of this function. The results of the present study can potentially be used as preliminary normative data for the use of these tests. In addition to investigating large groups of healthy children and adolescents according to a longitudinal design, future research should investigate children with developmental disabilities. Children with Attention Deficit Hyperactivity Disorder and with Pervasive Development Disorder are especially relevant in this respect because these children have executive problems as well as deficits in understanding certain aspects of complex language (Bruce, Thernlund, \& Nettelbladt, 2006; Camarata \& Gibson, 1999; Cohen et al., 2000; Geurts et al., 2004; Lorch, Milich, \& Sanchez, 1998; Mathers, 2006; Pennington \& Ozonoff, 1996; Purvis \& Tannock, 1997; Tirosh \& Cohen, 1998; Walker et al., 2004). This kind of research could eventually lead to not only a better understanding of these disorders but also better management of these children and more optimal didactic approaches. Lastly, the present findings may have implications for educational practice as they suggest that a) the complexity of a verbal instruction provided by a teacher; and b) the amount of time provided to understand this instruction may determine the comprehension of the pupil and that this may even be the case for older elementary school children and young adolescents enrolled in secondary school. 


\section{References}

Anderson, P. (2002). Assessment and development of executive function (EF) during childhood.Child Neuropsychology, 8, 71-82

Anderson, V. A., Anderson, P., Northam, E., Jacobs, R., \& Catroppa, C. (2001). Development ofexecutive functions through late childhood and adolescence in an Australian sample. Developmental Neuropsychology, 20, 385-406.

Baddeley, A. (2003). Working memory and language: an overview. Journal of Communication Disorders, 36, 189-208.

Bashir, A. S., \& Scavuzzo, A. (1992). Children with language disorders: natural history and academic success. Journal of Learning Disabilities, 25, 53-65.

Bates, E., Thal, D., Finlay, B., \& Clancy, B. (2003). Early language development and its neural correlates. In: S.J. Segalowitz \& I. Rapin (Eds.), Handbook of Neuropsychology (2nd ed., pp. 525-592). Amsterdam: Elsevier Science B.V.

Bauer, D. J., Goldfield, B. A., \& Reznick, J. S. (2002). Alternative approaches to analysing individual differences in the rate of early vocabulary development. Applied Psycholinguistics, 23, 313336.

Blakemore, S.-J., \& Choudhury, S. (2006). Development of the adolescent brain: implications for executive function and social cognition. Journal of Child Psychology and Psychiatry, 47, 296312.

Blomert, L. (2002). Stand van zaken dyslexie. In: Dyslexie; Naar een vergoedingsregeling [State of affairs dyslexia. In: Dyslexia; Towards a reimbursement of expenses]. Amstelveen: College voor Zorgverzekeringen, Rapport 03-144, pp. 28-139.

Booth, J. R., MacWhinney, B., \& Harasaki, Y. (2000). Developmental differences in visual and auditory processing of complex sentences. Child Development, 71, 981-1003.

Brocki, K. C., \& Bohlin, G. (2004). Executive functions in children aged 6 to 13: a dimensional and developmental study. Developmental Neuropsychology, 26, 571-593.

Bruce, B., Thernlund, G., \& Nettelbladt, U. (2006). ADHD and language impairment: A study of the parent questionnaire FTF (Five to Fifteen). European Child and Adolescent Psychiatry, 15, 5260.

Camarata, C. M., \& Gibson, T. (1999). Pragmatic language deficits in attention-deficit hyperactivity disorder (ADHD). Mental Retardation and Developmental Disabilities Research Review, 5, 207-214.

Carpenter, P. A., Miyake, A., \& Just, M. A. (1994). Working memory constraints in comprehension. Evidence from individual differences, aphasia, and aging. In: M. A. Gernsbacher. (Ed.), Handbook of Psycholinguistics (pp. 1075-1122). San Diego, California, Academic Press, Inc.

Casey, B. J., Tottenham, N., Liston, C., \& Durston, S. (2005). Imaging the developing brain: what have we learned about cognitive development? Trends in Cognitive Sciences, 9, 104-110.

Christensen, A-L. (1993). Luria's neuropsychological investigation text. Risskov, Denmark: P. J. Schmidts Bogtrykkeri, Vojens.

Clifton, C., Jr., \& Duffy, S. A. (2001). Sentence and text comprehension: roles of linguistic structure. Annual Review of Psychology, 52, 167-196.

Cohen, N. J., Vallance, D. D., Barwick, M., Im, N., Menna, R., Horodezky, N. B., \& Isaacson, L. (2000). The interface between ADHD and language impairment: an examination of language, achievement, and cognitive processing. Journal of Child Psychology and Psychiatry, 41, 353362.

Cook, M., Murdoch, B., Cahill, L., \& Whelan, B-M. (2004). Higher-level language deficits resulting from primary cerebellar lesions. Aphasiology, 18, 771-784.

Crone, E. A., Bunge, S. A., van der Molen, M. W., \& Ridderinkhof, K. R. (2006). Switching between tasks and responses: a developmental study. Developmental Science, 9, 278-287.

De Bellis, M. D., Keshevan, M. S., Beers, S. R., Hall, J., Frustaci, K., Maselehdan, A., Noll, J., \& Boring, A. M. (2001). Sex differences in brain maturation during childhood and adolescence. Cerebral Cortex, 11, 552-557. 
De Bruyn, E.E.J., Van der Steene, G., Van Haasen, P.P., Coetsier, P., Pijl, Y.J., Spoelders-Claes, R., Poortinga, Y.H., Stinissen, J., \& Lutje Spelberg, H.C. (1986). Wechsler Intelligence Scale for Children - Revised (WISC-R). Lisse: Swets \& Zeitlinger.

De Renzi, E., \& Faglioni, P. (1978). Normative data and screening power of a shortened version of the Token Test. Cortex, 14, 41-49.

Deevy, P., \& Leonard, L. B. (2004). The comprehension of wh-questions in children with specific language impairment. Journal of Speech, Language and Hearing Research, 47, 802-815.

Dennis, M., \& Barnes, M. A. (1990). Knowing the meaning, getting the point, bridging the gap, and carrying the message: aspects of discourse following closed head injury in childhood and adolescence. Brain and Language, 39, 428-446.

Dick, F., Wulfeck, B., Krupa-Kwiatkowski, M., \& Bates, E. (2004). The development of complex sentence interpretation in typically developing children compared with children with specific language impairments or early unilateral focal lesions. Developmental Science, 7, 360-377.

Directoraat-Generaal voor de Arbeidsvoorziening (1989). Handleiding voor de functieanalyse [Function analysis manual]. Den Haag: SDU uitgeverij.

DiSimoni, F. (1978). Token Test for Children (TTFC). Austin, Texas: PRO-ED.

Dodd, B., Holm, A., Hua, Z., \& Crosbie, S. (2003). Phonological development: a normative study of British-English speaking children. Clinical Linguistics and Phonetics, 17, 617-643.

Dollaghan, C. A., Campbell, T. F., Paradise, J. L., Feldman, H. M., Janosky, J. F., Pitcairn, D. N., \& Kurs-Lasky, M. (1999). Maternal education and measures of early speech and language. Journal of Speech, Language and Hearing Research, 42, 1432-1443.

Eslinger, P. J., Flaherty-Craig, C. V., \& Benton, A. L. (2004). Developmental outcomes after early prefrontal cortex damage. Brain and Cognition, 55, 84-103.

Fuster, J. M. (2002). Frontal lobe and cognitive development. Journal of Neurocytology, 31, 375385.

Geurts, H. M., Verté, S., Oosterlaan, J., Roeyers, H., Hartman, C. A., Mulder, E. J., van BerckelaerOnnes, I. A., \& Sergeant, J. A. (2004). Can the Children's Communication Checklist differentiate between children with autism, children with ADHD, and normal controls? Journal of Child Psychology and Psychiatry, 45, 1437-1453.

Gogtay, N., Giedd, J. N., Lusk, L., Hayaski, K. M., Greenstein, D., Vaituzis, A. C., Nugent, T. F. 3rd, Herman, D. H., Clasen, L. S., Toga, A. W., Rapoport, J. L., \& Thompson, P. M. (2004). Dynamic mapping of human cortical development during childhood through early adulthood. Proceedings of the National Academy of the Sciences, 101, 8174-8179.

Hahne, A., Eckstein, K., \& Friederici, A. D. (2004). Brain signatures of syntactic and semantic processes during children's language development. Journal of Cognitive Neuroscience, 16, 13021318.

Hale, S. (1990). A global developmental trend in cognitive processing speed. Child Development, $61,653-663$.

Helland, T., \& Asbjornsen, A. (2004). Digit span in dyslexia: variations according to language comprehension and mathematics skills. Journal of Clinical and Experimental Neuropsychology, 26, $31-42$.

Hoff, E. (2003). The specificity of environmental influence: socioeconomic status affects early vocabulary development via maternal speech. Child Development, 74, 1368-1378.

Holm, O., Greaker, E., \& Stroemberg, A. (2002). Experiences of longing in Norwegian and Swedish 4- and 5- year-old children. Journal of Psychology, 136, 608-612.

Hurks, P. P., Vles, J. S., Hendriksen, J. G., Kalff, A. C., Feron, F. J., Kroes, M., van Zeben, T. M., Steyaert, J., \& Jolles, J. (2006). Semantic category fluency versus initial letter fluency over 60 seconds as a measure of automatic and controlled processing in healthy school aged children. Journal of Clinical and Experimental Neuropsychology, 28, 684-695.

Jackson, A. P. (2003). The effects of family and neighbourhood characteristics on the behavioural and cognitive development of poor black children: a longitudinal study. American Journal of Community Psychology, 32, 175-186.

Johnson, M. H, \& Munakata, Y. (2005). Processes of change in brain and cognitive development. Trends in Cognitive Sciences, 9, 152-158. 
Just, M. A., \& Carpenter, P. A. (1992). A capacity theory of comprehension: individual differences in working memory. Psychological Review, 99, 122-149.

Kail, R. (1991). Developmental change in speed of processing during childhood and adolescence. Psychological Bulletin, 109, 490-501.

Kail, R. (1996). Nature and consequences of developmental change in speed of processing. Swiss Journal of Psychology, 55, 133-138.

Kail, R. (2000). Speed of information processing: Developmental change and links to intelligence. Journal of School Psychology, 38, 51-61.

Kalff, A. C., De Sonneville, L. M., Hurks, P. P., Hendriksen, J. G., Kroes, M., Feron, F. J., Steyeart, J., Van Zeben, T. M., Vles, J. S., \& Jolles, J. (2005). Speed, speed variability, and accuracy of information processing in 5 to 6-year-old children at risk of ADHD. Journal of the International Neuropsychological Society, 11, 173-183.

Kalff, A. C., Kroes, M., Vles, J. S. H., Bosma, H., Feron, F. J. M., Hendriksen, J. G. M., Steyaert, J., van Zeben, T. M. C. B., Crolla, I. F. A. M., \& Jolles, J. (2001a). Factors affecting the relation between parental education as well as occupation and problem behavior in Dutch 5- to 6- yearold children. Social Psychiatry and Psychiatric Epidemiology, 36, 324-331.

Kalff, A. C., Kroes, M., Vles, J. S. H., Hendriksen, J. G. M., Feron, F. J. M., Steyaert, J., van Zeben, T. M. C. B., Jolles, J., \& van Os, J. (2001b). Neighborhood-level and individual-level SES effects on child problem behavior: a multilevel analysis. Journal of Epidemiology and Community Health, 55, 246-250.

Klingberg, T., Vaidya, C. J., Gabrieli, J. D. E., Moseley, M. E., \& Hedehus, M. (1999). Myelination and organization of the frontal white matter in children: a diffusion tensor MRI study. NeuroReport, 10, 2817-2821.

Kroes, M., Kalff, A. C., Kessels, A. G., Steyaert, J., Feron, F. J., van Someren, A. J., Hurks, P. P., Hendriksen, J. G., van Zeben, T. M., Rozendaal, N., Crolla, I. F., Troost, J., Jolles, J., \& Vles, J. S. (2001). Child psychiatric diagnoses in a population of Dutch schoolchildren aged 6 to 8 years. Journal of the American Academy of Child and Adolescent Psychiatry, 40, 1401-1409.

Landry, S. H., Smith, K. E., \& Swank, P. R. (2002). Environmental effects on language development in normal and high-risk child populations. Seminars in Pediatric Neurology, 9, 192-200.

Lezak, M. D., Howieson, D. B., \& Loring, D. W. (2004). Neuropsychological assessment (4th ed.). New York: Oxford University press.

Lorch, E. P., Milich, R., \& Sanchez, R. P. (1998). Story comprehension in children with ADHD. Clinical Child and Family Psychology Review, 1, 163-178.

Luciana, M., Conklin, H. M., Hooper, C. J., \& Yarger, R. S. (2005). The development of nonverbal working memory and executive control processes in adolescents. Child Development, 76, 697712.

Luria, A. R. (1966). Higher cortical functions in man. New York: Basic Books

Luria, A. R. (1980). Higher cortical functions in man. New York: Basic Books.

Mackner, L. M., Black, M. M., \& Starr Jr, R. H. (2003). Cognitive development of children in poverty with failure to thrive: a prospective study through age 6. Journal of Child Psychology and Psychiatry, 44, 743-751.

Marton, K., \& Schwartz, R. G. (2003). Working memory capacity and language processes in children with specific language impairment. Journal of Speech, Language and Hearing Research, 46, 1138-1153.

Mathers, M. E. (2006). Aspects of language in children with ADHD: applying functional analyses to explore language use. Journal of Attention Disorders, 9, 523-533.

McNeil, M. M. \& Prescott, T. E. (1978). Revised Token Test (RTT). Austin, Texas: PRO-ED.

Meijs, C. J. C., Hurks, P. P. M., Wassenberg, R., Feron, F. J. M., \& Jolles, J. (in preparation). The influence of presentation modality on performance on a verbal learning test in healthy children aged 5-16 years.

Montgomery, J. W. (2003). Working memory and comprehension in children with specific language impairment: what we know so far. Journal of Communication Disorders, 36, 221-231. 
Nigg, J. T. (2000). On inhibition/disinhibition in developmental psychopathology: views from cognitive and personality psychology and a working inhibition taxonomy. Psychological Bulletin, 126, 220-246.

Paus, T. (2005). Mapping brain maturation and cognitive development during adolescence. Trends in Cognitive Sciences, 9, 60-67.

Pennington, B. F. \& Ozonoff, S. (1996). Executive functions and developmental disabilities. Journal of Child Psychology, 37, 51-87.

Purvis, K. L., \& Tannock, R. (1997). Language abilities in children with attention deficit hyperactivity disorder, reading disabilities, and normal controls. Journal of Abnormal Child Psychology, 25, 133-144.

Quay, L. C., \& Blaney, R. L. (1992). Verbal communication, nonverbal communication, and private speech in lower and middle socioeconomic status preschool children. Journal of Genetic Psychology, 153, 129-138.

Roulstone, S., Loader, S., Northstone, K., \& Beveridge, M. (2002). The speech and language of children aged 25 months: descriptive data from the Avon Longitudinal Study of Parents and Children. Early Child Development and Care, 172, 259-268.

Shaw, P., Greenstein, D., Lerch, J., Clasen, L., Lenroot, R., Gogtay, N., Evans, A., Rapoport, J., \& Giedd, J. (2006). Intellectual ability and cortical development in children and adolescents. Nature, 440, 676-679.

Steinberg, L. (2005). Cognitive and affective development in adolescence. Trends in Cognitive Sciences, 9, 69-74.

Stuss, D. T. (1992). Biological and psychological development of executive functions. Brain and Cognition, 20, 8-23.

Tirosh, E., \& Cohen, A. (1998). Language deficit with attention-deficit disorder: a prevalent comorbidity. Journal of Child Neurology, 13, 493-497.

Travis, F. (1998). Cortical and cognitive development in 4th, 8th and 12th grade students. The contribution of speed of processing and executive functioning to cognitive development. Biological Psychology, 48, 37-56.

Tse, S. K., Kwon, S. M., Chan, C., \& Li, H. (2002). Sex differences in syntactic development: evidence for Cantonese-speaking preschoolers in Hong Kong. International Journal of Behavioral Development, 26, 509-517.

Van der Elst, W., van Boxtel, M. P., van Breukelen, G. J., \& Jolles, J. (2006). The Letter Digit Substitution Test: normative data for 1,858 healthy participants aged 24-81 from the Maastricht Aging Study (MAAS): influence of age, education, and sex. Journal of Clinical and Experimental Neuropsychology, 28, 998-1009.

Walker, D. R., Thompson, A., Zwaigenbaum, L., Goldberg, J., Bryson, S. E., Mahoney, W. J., Strawbridge, C. P., Szatmari, P. (2004). Specifying PDD-NOS: a comparison of PDD-NOS, Asperger syndrome, and autism. Journal of the American Academy of Child and Adolescent Psychiatry, 43, 172-180.

Wechsler, D. (1974). Wechsler Intelligence Scale for Children - Revised. Manual. San Antonio: The Psychological Corporation. 


\title{
CHAPTER 8
}

\section{Speed of language comprehension is impaired in children and adolescents with ADHD - combined subtype}

\begin{abstract}
Language comprehension contributes to self-control, a function that is disturbed in individuals with Attention Deficit Hyperactivity Disorder - combined subtype (ADHD-C). We studied therefore the ability to comprehend complex sentences in children and adolescents with and without ADHD-C. Fifteen children (aged eight to eleven) and 15 adolescents (aged twelve to sixteen) with ADHD-C were matched for age, sex and parental level of education to 30 control subjects. Language comprehension was measured using the neuropsychological procedure proposed by Luria and an adapted version of the Token Test. Compared with the control group, children and adolescents with ADHD-C performed significantly slower on language comprehension tasks. However, differences in accuracy were limited. No interaction between age and ADHD-C was found. In conclusion, children and adolescents with ADHD-C are slower and less efficient than control subjects with respect to complex sentence comprehension. This finding has strong implications for neuropsychological interventions and the practice of education.
\end{abstract}

Renske Wassenberg, Jos G. M. Hendriksen, Petra P. M. Hurks, Frans J. M. Feron, Johan S. H. Vles \& Jelle Jolles. Submitted for publication. 
Attention Deficit Hyperactivity Disorder (ADHD) is a serious developmental disorder that occurs in 3-5\% of all children (American Psychiatric Association, 1994). ADHD has been related to dysfunctioning brain regions including prefrontal structures, the basal ganglia, and the brain stem (Krain \& Castellanos, 2006). In addition to inattention, impulsivity, and hyperactivity, ADHD is associated with language processing deficits (Mathers, 2006). This is an important area of research because language deficits are known to have negative effects on academic, social, behavioral and cognitive functioning (Bashir \& Scavuzzo, 1992). In addition, language competence is important for the control of impulses and behavior regulation (Lezak, Howieson, \& Loring, 2004; Luria, 1966, 1980) and also impacts one's ability to learn self-control (Andreou, Agapitou, \& Karapetsas, 2005). Impulse control, behavior regulation and self control are all functions known to be affected by ADHD (Barkley, 1997; Biederman, 2005).

The present study focused on comparing the comprehension of complex language in children and adolescents with ADHD to complex language comprehension in normally developing control subjects. A vast amount research has been conducted on the occurrence of ADHD in children with language difficulties and vice versa (e.g. Beitchman et al., 1996; Cohen et al., 2000; Snowling, Bishop, Stothard, Chipchase, \& Kaplan, 2006). One study estimated the prevalence of language difficulties in children with ADHD to be as high as $45 \%$ (Tirosh \& Cohen, 1998). Language difficulties in individuals with ADHD are likely to be persistent, as was illustrated in a study with young adults whereby the results showed that young adults with ADHD are 1.9 times more likely to meet the diagnostic criteria for a DSM-IV language disorder that young adults without ADHD (Biederman et al., 2006). Language functions related to speech and expression that have been found to be deficient in individuals with ADHD include pragmatics (Geurts et al., 2004), grammatical complexity (Mathers, 2005), verbal fluency (Hurks et al., 2004), verbal intelligence (Renz et al., 2003), and reading (Willcutt, Pennington, Olson, Chhabildas, \& Hulslander, 2005).

Language comprehension has also been found to be impaired in children with ADHD. Several studies have focused on story comprehension in children with ADHD (Lorch, Milich, \& Sanchez, 1998; Purvis \& Tannock, 1997; Renz et al., 2003). In these studies, children with ADHD listened to audio taped folk tales and retold them (Purvis \& Tannock, 1997) or looked at wordless picture books and constructed the story from the pictures (Renz et al., 2003). The results of these studies indicated that, in general, children with ADHD are, when compared to control subjects, equally capable of perceiving which story element is important. However, children with ADHD tend to recall less information, lag behind their peers in understanding causal relations, and show deficits in the planning of their narrations. They therefore experience problems with conducting tasks that require more effort, vigilance, and controlled processing. These deficits have generally been explained in terms of a general deficit in executive functioning. Although there are more than 30 definitions of the term 'executive functioning', most researchers agree that it is an umbrella term for various self-regulatory processes that are responsible for purposeful and goal-directed behavior (Anderson, 2002; Lezak et al., 2004). In short, higher-order executive function deficits are thought to be responsible for subtle language problems in individuals with ADHD (Lorch et al., 1998; Mathers, 2006; Purvis \& Tannock, 1997; Renz et al., 2003).

The present study focused on a more fundamental aspect of language comprehension, namely the accuracy and speed of complex sentence comprehension. An example 
of the sentences used in this study is: "Which girl is lightest if Olga is lighter than Sonia but darker than Kate?" We investigated whether children with ADHD experience problems in comprehending such sentences that contain information in which they could only rely in part on context and prior knowledge. As language comprehension is thought to be important for self-control and self-control is deficient in ADHD, we hypothesized that children with ADHD would experience difficulties with respect to understanding complex language as reflected by difficulties in understanding sentences similar to the one above (Andreou et al., 2005; Barkley, 1997; Luria, 1966). We also expected that insight on the nature of language difficulties in children with ADHD would best be obtained by measuring not only the accuracy but also the speed of complex sentence comprehension. We considered measuring speed to be important given that, in real life, we rarely have time to reflect while we communicate (Dick, Wulfeck, Krupa-Kwiatkowski, \& Bates, 2004). This choice was further supported by earlier findings in which children with ADHD were significantly slower than control subjects on the first fifteen seconds of a phonological fluency task (Hurks et al., 2004). We thus contended that children with ADHD may possibly need considerably more time to understand complex sentences as accurately as normally developing children. This kind of finding could have serious implications in situations where complex language needs to be understood, such as the classroom. More time for comprehension would be necessary in situations where verbal and complex instructions are provided.

The second aim of this study was to investigate the possibility of age-related differences in complex sentence comprehension in individuals with ADHD. We choose to investigate this aspect because of recent recommendations in the literature (Kipp, 2005). Research focusing on age differences is important for the determination of whether ADHD is a developmental delay or a permanent disability (Barkley, 1997; Biederman et al., 2006). This is especially interesting in light of the recent research on cognitive development whereby a stage-like improvement over childhood and adolescence with a plateau in development at the age of 15 has been observed in normally developing individuals (Anderson, 2002). In the abovementioned studies on language comprehension in individuals with ADHD, age differences were not taken into account. The studies included mostly young children between the ages of 7 and 12 and thus did not report on adolescents (Purvis \& Tannock, 1997; Renz et al., 2003). Therefore, we extended the age-range studied and divided the participants over an ADHD child group (8-11 years) and an ADHD adolescent group (12-16 years). The performance of these ADHD groups was compared to performance in two age-matched control groups.

In brief, this study investigated: (1) the accuracy and speed of complex sentence comprehension in children and adolescents with ADHD in comparison to complex sentence comprehension in normally developing control participants; and (2) the age-related differences in this capacity. Verbal intelligence, level of short-term memory, and the presence of comorbid dyslexia were controlled for in the analyses of complex language comprehension because of their assumed associations (Andreou et al., 2005; Jacquemot \& Scott, 2006; Renz et al., 2003; Purvis \& Tannock, 1997). In investigating these aspects of language comprehension, we endeavored to not only to increase the theoretical knowledge based on the specific language problems experienced by individuals with ADHD, but also to provide recommendations for the practice of education and development and implementation of language interventions. 


\section{Method}

\section{Procedure}

Children and adolescents aged seven to sixteen who had been diagnosed with ADHD combined subtype (ADHD-C) at the specialized multidisciplinary clinic for Learning Disabilities at the Maastricht University Hospital and who were presently being treated by one of the child neurologists at the hospital were approached to participate in this study. Participants between the ages of seven and eleven were included in the child group and participants between the ages of twelve and sixteen were included in the adolescent group. Exclusion criteria for participation in the study included: (1) general information processing abilities below 80; (2) a lack of Dutch nationality which could manifest in language problems; and (3) a history of brain injury. Prior to the study, the participating children had undergone a comprehensive assessment, at the specialized multidisciplinary clinic for Learning Disabilities that included a neurological examination, an inspection of general health, and the collection of psychological data from multiple information sources in a standardized fashion by senior clinical child neuropsychologists (Goldman, Genel, Bezman, \& Slanetz, 1998). Psychological data included: (1) information about the development and functioning, both at home and at school, of the child by means of a standardized clinical interview with parent(s) (Hendriksen, Feron, \& Vles, 2000). This interview also explored the DSM-IV diagnostic criteria for developmental disorders, including ADHD (APA, 1994); (2) a battery of neuropsychological tests; and (3) several standardized questionnaires completed by parent(s) and teacher(s). The Dutch versions of the following behavioral questionnaires were used in the diagnostic process: the Child Behaviour Checklist (CBCL), the Teacher Report Form (TRF) (Achenbach, 1991) and the Disruptive Behavior Disorders (DBD) rating scale (Oosterlaan, Scheres, Antrop, Roeyers, \& Sergeant, 2000). The CBCL and TRF measure general pathology. Earlier research has demonstrated the usefulness of these measures in detecting children with and without behavior problems (Steingard, Biederman, Doyle, \& Sprich-Buckminster, 1992). The DBD consists of four subscales, which, using the DSM-IV criteria, obtain ratings for inattention, hyperactivity-impulsivity, oppositional defiant disorder and conduct disorder. The final diagnosis of ADHD-C was established by an experienced multidisciplinary team of child neuropsychologists, a child neurologist and a youth health care physician. The diagnosis was based on the above mentioned sources of information in combination with clinical judgment (Francis et al., 2005). All children with ADHD-C met the DSM-IV criteria for this disorder (APA, 1994).

Participants from the ADHD-C group were individually matched for age, sex, and parental level of education to control group participants recruited from a large cognitive development study (Wassenberg et al., submitted). This study took place in elementary and secondary schools in Maastricht and the surrounding area in the southern region of the Netherlands. The parents who approved the participation of their children in the selected grades (kindergarten and second, fourth, sixth, seventh, and eighth grade) completed a questionnaire about sociodemographic issues as well as their child's medical history and milestone development. Only children who had the Dutch nationality and who were in the appropriate grade for age were eligible for participation in the study. Exclusion criteria for children in de control group were diagnosed with ADHD and current use of medication that could influence cognitive functioning, such as antihistamines (prescribed for hay fever), and psycho-stimulants (prescribed for ADHD and Autism Spectrum Disorders, among others). Children with dyslexia were not excluded from the study 
because the estimated prevalence of reading and spelling problems in Dutch elementary education is $8.8 \%$ and the prevalence of dyslexia is $3.6 \%$ (Blomert, 2002). The exclusion of children with dyslexia could result in an overly 'normal' sample, which would, evidently, be a poor reflection of the population. We reasoned that, if children were attending a school for regular education and were in the appropriate grade for their age, they were normally developing, regardless of whether or not they had dyslexia.

Informed consent was obtained from the parents of all participants and also directly from the participants in the adolescent group. Testing was conducted individually. For participants with ADHD-C, the testing took place in a stimulus free room in the hospital. For the control participants, the testing took place at school. The testing was conducted by well-trained graduate students majoring in developmental psychology or neuropsychology. The parents of the participating children were reimbursed for their travel expenses and all of the children that participated were given a small present to thank them for their cooperation. The study was approved by the medical ethical committee at Maastricht University Hospital and the ethical committee at Maastricht University's Department of Psychology.

\section{Participants}

In total, 30 participants with ADHD-C were matched for age, sex and parental level of education to 30 control subjects. Parental level of education was measured on a three point scale ranging from low (elementary education) to high (university education). The participants in both groups came predominantly from families with moderate to high socioeconomic status (Directoraat-Generaal voor de Arbeidsvoorziening, 1989). Age distribution was as follows: $\mathrm{ADHD}$ child: range $=8.8-11.9$ years, mean $=10.6, \mathrm{SD}=.9$; Control child: range $=8.4-11.9$ years, mean $=10.5, \mathrm{SD}=1.0 ; \mathrm{ADHD}$ adolescents: range $=12.1-16.9$ years, mean $=14.0, S D=1.4 ;$ Control adolescents: $12.1-15.1$ years, mean $=13.7, S D=1.0)$. Of the children categorized in the ADHD group, 25 used stimulant medication on a daily basis. We requested that the parents of these children withhold the medication at least for 24 hours prior to the investigation as this would be sufficient time for the medication to washout (Greenhill, 1998). On the day the testing was done, the test administrator inquired as to whether the parents had complied with this request and, indeed, all parents had complied.

Participants with psychiatric comorbidity were included in the study to maintain the range of clinical presentations typical of ADHD. The following comorbid problems were present in the participants with ADHD: dyslexia $(\mathrm{N}=10$, see Table 1$)$, dyscalculia $(\mathrm{N}=$ $1)$, oppositional defiant disorder $(N=2)$, and tic disorder $(N=1)$. There was only one child with dyslexia in the control group. Because of the assumed association between dyslexia and language comprehension (Purvis \& Tannock, 1997), we ensured that the third step analyses were controlled for the presence of dyslexia. Characteristics of the participants are displayed in Table 1. 
Table 1: Characteristics of the participants

\begin{tabular}{lllllll}
\hline & \multicolumn{3}{c}{ Children } & \multicolumn{4}{c}{ Adolescents } \\
\cline { 2 - 7 } $\mathrm{N}$ & \multicolumn{1}{c}{ ADHD } & Controls & p-value & ADHD & controls & p-value \\
\cline { 2 - 7 } Sex: N boys & 15 & 15 & 1 & 15 & 15 & 1 \\
Age: $\mathrm{M}(\mathrm{SD})$ & $10.58(0.94)$ & $10.50(1.00)$ & .831 & $14.02(1.40)$ & $13.73(1.03)$ & .529 \\
LPE: M (SD) & $2.40(0.63)$ & $2.40(0.74)$ & 1 & $2.60(0.51)$ & $2.60(0.51)$ & 1 \\
VIQ: M (SD) & $9.31(2.10)$ & $11.07(3.52)$ & .127 & $9.47(1.60)$ & $10.20(1.86)$ & .256 \\
Mem: M (SD) & $6.80(2.18)$ & $6.53(1.77)$ & .715 & $8.00(1.73)$ & $8.53(2.13)$ & .459 \\
Dyslexia: N & 4 & 1 & .142 & 6 & 0 & .006 \\
\hline
\end{tabular}

Note: $M e m=$ Word learning test (Lezak et al., 2004; Meijs et al., in preparation); LOE = Level of Parental education (Directoraat-Generaal voor de Arbeidsvoorziening, 1989); VIQ = Vocabulary WISC-RN (De Bruyn et al., 1986).

\section{Instruments}

Complex language comprehension was investigated using two instruments. The usefulness of these instruments in demonstrating age-related changes in complex language comprehension in normally developing children has been demonstrated earlier (see Chapter 7). The first instrument was the Assessment Battery for Children - Language (ABC-L), which is part of a more extensive language comprehension battery developed by Luria (1966; 1980) and adapted by Christensen (1993) (see also chapters 6 and 7). Of the 24 items present in the original battery, 11 were administered. Since some of the items in the original battery had been developed to assess patients with brain injuries, we excluded those items that would have been too easy for school age children (ie. 'pointing to objects'). The ABC-L items (shown in Table 2) were read aloud to the child by the experimenter and the experimenter noted the child's answer. Items were repeated as often as requested and the time needed to response was documented. The ABC-L took about ten minutes to administer. Each correct answer was awarded one point so that the maximum possible score was 13 points. The ABC-L proportion correct (ABC-L accuracy) and the mean time per item (ABC-L speed) were used in the analyses. The internal consistency of the ABC-L speed and accuracy scores has been shown to be adequate (Cronbach's alpha speed $=.80$, Cronbach's alpha accuracy $=.73$ [see chapter 7]).

The second measure used for language comprehension was an adapted version of the Token Test (TT-A). The original Token Test assesses verbal comprehension of increasingly complex commands (De Renzi \& Faglioni, 1978) and is generally used to screen for aphasia. The test requires participants to move tokens according to oral commands provided by the experimenter. In total, there are 20 tokens in two shapes (circles and rectangles), two sizes (big and little), and five colors (red, blue, yellow, white, and green). The tokens are laid out horizontally in parallel rows with colors in fixed order per row (Lezak et al., 2004). The adapted version used in this study consisted of: (1) part $\mathrm{V}$ of the original Token Test which involves relational concepts and is considered to be the most difficult part (Lezak et al., 2004); and (2) a nine item newly developed part in which the same type of relational concepts as part $V$ are tested. The difference between the first and the second part of the test is that, in the second part, not only large rectan- 
gles and circles but also small rectangles and circles are used. For example, for the following item of part $\mathrm{V}$ of the original Token Test "Pick up the rectangles, except the yellow one", the instruction was changed to "Pick up the rectangles, except the small yellow one". This adapted part of the TT-A was included to increase the complexity and, in doing so, make the test more suitable for children as well as adolescents (in contrast to the original Token Test for Children which is appropriate for children aged three to twelve [DiSimoni, 1978] and the Revised Token Test which is suitable from age twenty on [McNeil \& Prescott, 1978]). The TT-A consisted of 27 items in total (see Table 2) and was administered similarly to the ABC-L in that the items were read aloud to the child by the experimenter. The child responded by moving the tokens and the experimenter noted whether the response was correct or incorrect. Again, items could be repeated as often as requested and the time needed to response was documented. Internal consistency of the TT-A speed and accuracy scores are adequate (Cronbach's alpha speed $=.92$, Cronbach's alpha accuracy $=.79$ [see chapter 7]).

To make the 90 minute test session as diverse as possible, the TT-A was divided in half (14 items, 13 items). The first half was administered after approximately 20 minutes and the second was administered after approximately an hour. Total administration time of both halves was approximately 15 minutes. Each correct answer was awarded one point for a maximum possible score of 27 points. The TT-A proportion correct (TT-A accuracy) and the mean time per item (TT-A speed) were used in the analyses. Obviously, both instruments were used to test the child's ability to understand complex sentences. The difference between the two tests is related to the response output. In the $A B C-L$, mostly oral answers are required. In the TT-A, motor answers are expected.

Table 2: Percentage correct on the ABC-L and TT-A items in the different groups

\begin{tabular}{|c|c|c|c|c|c|}
\hline \multirow{2}{*}{$\mathrm{Nr}$. } & \multirow{2}{*}{$A B C-L$} & \multicolumn{2}{|c|}{ Child } & \multicolumn{2}{|c|}{ Adolescent } \\
\hline & & AD & $\mathrm{CON}$ & AD & $\mathrm{CON}$ \\
\hline 1. & $\begin{array}{l}\text { Is my father's brother the same person as my brother's } \\
\text { father? }\end{array}$ & 73 & 87 & 67 & 87 \\
\hline 2. & Draw a cross beneath a circle & 100 & 93 & 100 & 100 \\
\hline 3. & Draw a circle to the right of a cross & 80 & 100 & 100 & 100 \\
\hline 4. & $\begin{array}{l}\text { Draw a circle to the right of a cross but to the left of } \\
\text { a triangle }\end{array}$ & 27 & 73 & 47 & 93 \\
\hline 5. & $\begin{array}{l}\text { Which is correct: "Spring comes before summer" or } \\
\text { "Summer comes before spring"? }\end{array}$ & 87 & 93 & 93 & 87 \\
\hline 6. & $\begin{array}{l}\text { Who is shortest if John is taller than Pete? } \\
\text { Which is correct: "A fly is bigger than an elephant" }\end{array}$ & 100 & 93 & 93 & 93 \\
\hline $8 a$. & $\begin{array}{l}\text { or "An elephant is bigger than a fly"? } \\
\text { Which girl is lightest if Olga is lighter than Sonia but }\end{array}$ & 80 & 100 & 100 & 100 \\
\hline & darker than Kate? & 73 & 73 & 87 & 93 \\
\hline $8 b$. & And which girl is darkest? & 67 & 53 & 73 & 87 \\
\hline 9. & Nick was struck by Pete. Who was the victim? & 87 & 73 & 87 & 100 \\
\hline 10. & $\begin{array}{l}\text { I had breakfast after I had walked the dog. What did } \\
\text { I do first? }\end{array}$ & 60 & 80 & 73 & 87 \\
\hline $11 \mathrm{a}$. & $\begin{array}{l}\text { The girl who worked in the zoo came to Margaret's } \\
\text { school to give a presentation. Who gave the presenta- } \\
\text { tion? }\end{array}$ & 53 & 47 & 53 & 67 \\
\hline 11b. & What did Margaret do? & 47 & 40 & 67 & 80 \\
\hline & Total & 72 & 77 & 80 & 90 \\
\hline
\end{tabular}


Table 2 continued:

\begin{tabular}{|c|c|c|c|c|c|}
\hline \multirow[b]{2}{*}{ Nr. } & \multirow[b]{2}{*}{ TT-A } & \multicolumn{2}{|c|}{ Child } & \multicolumn{2}{|c|}{ Adolescent } \\
\hline & & $\mathrm{AD}$ & $\mathrm{CON}$ & $A D$ & $\mathrm{CON}$ \\
\hline 1. & Put the red circle on the green rectangle & 100 & 87 & 93 & 93 \\
\hline 2. & Touch the blue circle with the red rectangle & 27 & 13 & 47 & 60 \\
\hline 3. & Touch, with the blue circle, the red rectangle & 67 & 87 & 80 & 100 \\
\hline 4. & Pick up the blue circle or the red rectangle & 100 & 100 & 100 & 100 \\
\hline 5. & $\begin{array}{l}\text { Place the green rectangle away from the yellow } \\
\text { rectangle }\end{array}$ & 80 & 87 & 93 & 100 \\
\hline 6. & If there is a black circle, pick up the red rectangle & 100 & 87 & 80 & 80 \\
\hline 7. & Pick up the rectangles, except the yellow one & 100 & 100 & 100 & 100 \\
\hline 8. & $\begin{array}{l}\text { When I touch the green circle, you pick up the white } \\
\text { rectangle }\end{array}$ & 93 & 87 & 100 & 93 \\
\hline 9. & Put the green rectangles beside the red circle & 93 & 100 & 93 & 93 \\
\hline $\begin{array}{l}10 . \\
11\end{array}$ & Touch the rectangles, slowly, and the circles, quickly & 33 & 60 & 80 & 93 \\
\hline & the green rectangle & 87 & 93 & 87 & 80 \\
\hline 12. & Except for the green one, touch the circles & 87 & 100 & 100 & 100 \\
\hline 13. & Pick up the red circle -no!- the white rectangle & 93 & 100 & 100 & 93 \\
\hline 14. & $\begin{array}{l}\text { Instead of the white rectangle, pick up the yellow } \\
\text { circle }\end{array}$ & 87 & 100 & 100 & 93 \\
\hline 15. & $\begin{array}{l}\text { Together with the yellow circle, pick up the blue } \\
\text { circle }\end{array}$ & 93 & 100 & 100 & 100 \\
\hline 16. & $\begin{array}{l}\text { After picking up the green rectangle, touch the white } \\
\text { circle }\end{array}$ & 80 & 80 & 87 & 100 \\
\hline 17. & Put the blue circle under the white rectangle & 93 & 93 & 100 & 100 \\
\hline 18. & $\begin{array}{l}\text { Before touching the yellow circle, pick up the red } \\
\text { rectangle }\end{array}$ & 87 & 93 & 87 & 100 \\
\hline 19. & $\begin{array}{l}\text { Touch the little yellow circle with the large green } \\
\text { rectangle }\end{array}$ & 40 & 57 & 53 & 93 \\
\hline 20. & $\begin{array}{l}\text { Put the large green circle on the small white rectan- } \\
\text { gle }\end{array}$ & 80 & 100 & 93 & 80 \\
\hline 21. & $\begin{array}{l}\text { Before touching the small white circle, pick up the } \\
\text { large green rectangle }\end{array}$ & 87 & 93 & 80 & 87 \\
\hline 22. & Pick up the rectangles, except the small blue one & 93 & 93 & 93 & 100 \\
\hline 23. & $\begin{array}{l}\text { Touch, with the large white circle, the small blue } \\
\text { rectangle }\end{array}$ & 80 & 86 & 93 & 93 \\
\hline 24. & $\begin{array}{l}\text { Put the small red rectangle next to the small blue } \\
\text { circle }\end{array}$ & 87 & 93 & 93 & 87 \\
\hline 25. & $\begin{array}{l}\text { After picking up the large red rectangle, pick up the } \\
\text { small yellow circle }\end{array}$ & 67 & 50 & 60 & 80 \\
\hline 26. & $\begin{array}{l}\text { Pick up the large green circle or the small yellow } \\
\text { rectangle }\end{array}$ & 73 & 86 & 93 & 80 \\
\hline 27. & Touch the circles, except the large white one & 93 & 93 & 100 & 80 \\
\hline & (1) & 81 & 87 & 88 & 91 \\
\hline
\end{tabular}

Note: $A D=A D H D ; C O N=$ Control .

To control for the influence of short-term memory on complex language comprehension (Baddeley, 2003; Just \& Carpenter, 1992), we used the first trial of a Word Learning Test (WLT) (Lezak et al., 2004; Van der Elst, van Boxtel, van Breukelen, \& Jolles, 2005). In this test, children are shown 15 unrelated pictures or presented with 15 unrelated words on a laptop computer. Immediately after all pictures or words are presented, children are instructed to name as many as possible. The total number of correctly reproduced words is recorded and then used in the analyses. In our study, the different modalities and versions of the test generated no influence on language comprehension scores and, as a 
result, were not used in the analyses. As can be seen in Table 1, the WLT scores did not differ between the ADHD and control groups. However, age-related improvement on the WLT was found (children: mean $=6.7[S D=1.9]$; adolescents: mean $=8.3[S D=2.0]$ ). This difference was significant $\left(t_{(58)}=3.2, p=.002\right)$. Because of these age differences and the expected influence of short-term memory on complex language comprehension, the WLT raw score (range $=0-15$ ) was included as a covariate in the second step of all analyses.

Verbal intelligence was estimated using the Vocabulary subtest of the Dutch Wechsler Intelligence Scale for Children Revised (WISC-R, De Bruyn et al., 1986; Wechsler, 1974). The WISC-R, rather than the WISC-III, was used because the latter only became available in the Netherlands after the study was initiated. In the Vocabulary subtest (VIQ), children are required to define a number of words as accurately and completely as possible. In our study, the scaled scores, ranging from 1 to 19 (mean =10, SD = 3), were used as the outcome variable. Performance was normal for all groups. There was, however, a statistical trend for significance for the difference in VIQ between the ADHD (mean $=9.4, \mathrm{SD}=1.8)$ and the control group (mean $=10.6, \mathrm{SD}=2.8)\left(t_{(56)}=-1.99, p=\right.$ .052, see also Table 1). This finding is not uncommon (Renz et al., 2003). Because of this statistical trend and the assumed association between general vocabulary and language comprehension, VIQ was included as a covariate in the second step of all analyses.

\section{Statistical analyses}

The statistical package SPSS 11.5 was used for all analyses. Because the ABC-L speed and TT-A speed scores were not normally distributed, their logarithmic transformations were used in the analyses. Accuracy scores on both tests were normally distributed and thus no transformations were made. Specific group differences for accuracy and speed for the ABC-L and the TT-A were analyzed in separate linear regression analyses. The different predictors were entered in three steps: (1) step $1=$ group $(0=$ Control; $1=$ ADHD), age ( 0 = child; 1 = adolescent), the interaction between group and age; (2) step 2 = Predictors of block 1, VIQ (continuous), and WLT (continuous); and (3) step $3=$ Predictors of block 2 and dyslexia ( $0=$ no dyslexia; $1=$ dyslexia). The alpha value was set at .05 for all analyses.

\section{Results}

\section{Descriptives}

The correlations between the ABC-L and TT-A scores were, after correction for age, calculated using Pearson partial correlation coefficients. We found positive and significant correlations between the ABC-L and TT-A accuracy scores $(\rho=.435, p=.001)$ and between the ABC-L and TT-A speed scores $(\rho=.643, p<.001)$. The speed and accuracy scores of the TT-A were found to correlate negatively and significantly $(\rho=-.439, p$ $=.001)$. Similar results were found for the ABC-L speed and accuracy scores $(\rho=-.361$, $p=.006$ ). With respect to the speed-accuracy association across the tests, a small negative correlation was found between ABC-L accuracy and TT-A speed $(\rho=-.411, p=$ .001 ) but no significant correlation was found between ABC-L speed and TT-A accuracy $(\rho=-.252, p=.059)$. This reflects the presence of a modest relationship between the 
speed and the accuracy of complex language comprehension when the effect of age is partialled out.

Differences between the groups: Accuracy of language comprehension

Figures $1 \mathrm{~A}$ and $1 \mathrm{~B}$ show the performance of the four groups on the accuracy of language comprehension per test.

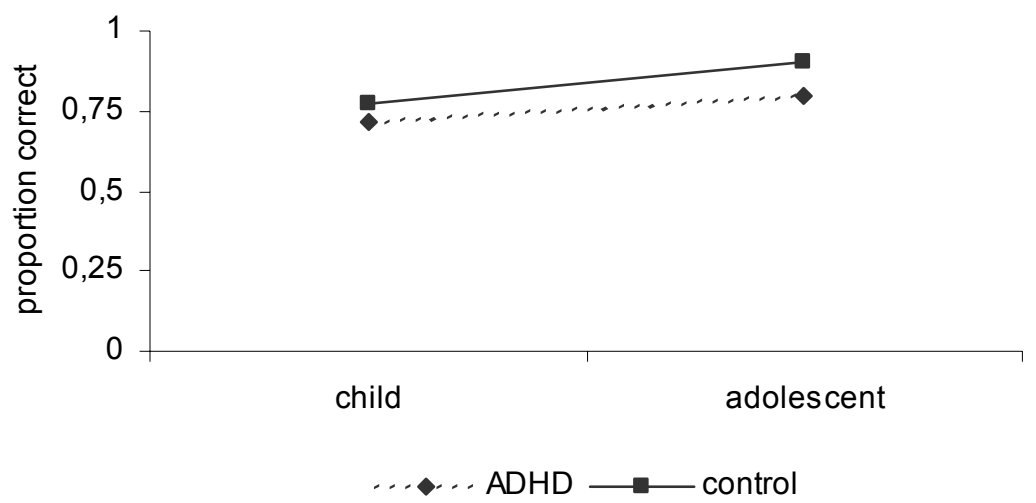

Figure 1A: TT-A accuracy score

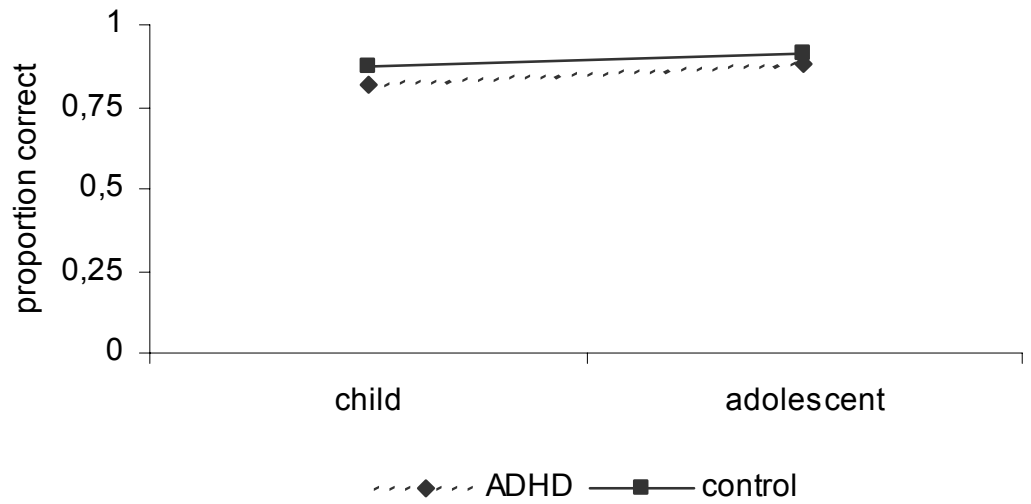

Figure 1B: ABC-L accuracy score

Table 3 displays the results of the linear regression analyses for accuracy of language comprehension. For the TT-A, the first set of predictors resulted in a significant model $\left(F_{(3,52)}=3.69, p=.017\right)$. Diagnosis was the only significantly predictor in this model. This means that participants with ADHD performed significantly worse than participants without ADHD $(p=.050)$. The F value of the model changed significantly when 
the second set of predictors was applied (change: $F_{(2,50)}=3.26, p=.047$, model: $F_{(5,50)}=$ $3.71, p=.006$ ). The estimate of verbal intelligence was the only significant predictor in this model: higher verbal intelligence was associated with higher TT-A accuracy scores $(p=.034)$. In short, ADHD was not significantly associated with TT-A accuracy after controlling for verbal intelligence. The third set of predictors did not significantly change the $F$ value $\left(F_{(1,49)}=.40, p=.529\right)$. Using logistic regression analyses with the same sets of predictors described above, post-hoc analyses per item indicated no significant differences between the ADHD group and control group for any of the TT-A items once the analyses were controlled for verbal intelligence and short-term memory.

Table 3: Linear regression models for accuracy of language comprehension

\begin{tabular}{|c|c|c|c|c|c|c|c|c|c|}
\hline \multirow[b]{2}{*}{ Block } & \multirow[b]{2}{*}{ Effects } & \multicolumn{4}{|c|}{ TT-A } & \multicolumn{4}{|c|}{ ABC-L } \\
\hline & & B & SE & $\beta$ & p-value & B & SE & $\beta$ & $p$-value \\
\hline \multirow[t]{3}{*}{1.} & Interaction & .04 & .05 & .19 & .393 & -.07 & .08 & -.18 & .413 \\
\hline & Group & -.07 & .03 & -.37 & .050 & -.04 & .06 & -.11 & .560 \\
\hline & Age & .04 & .03 & .21 & .252 & .13 & .06 & .40 & .029 \\
\hline \multirow[t]{5}{*}{2.} & Interaction & .02 & .04 & .12 & .576 & -.08 & .08 & -.21 & .305 \\
\hline & Group & -.04 & .03 & -.22 & .240 & .004 & .06 & .01 & .942 \\
\hline & Age & .04 & .03 & .21 & .265 & .10 & .06 & .32 & .077 \\
\hline & VIQ & .01 & .01 & .28 & .034 & .02 & .01 & .32 & .013 \\
\hline & MEM & .01 & .01 & .18 & .194 & .02 & .01 & .28 & .039 \\
\hline \multirow[t]{6}{*}{3.} & Interaction & .03 & .04 & .15 & .510 & -.09 & .08 & -.25 & .244 \\
\hline & Group & -.04 & .03 & -.21 & .274 & -.004 & .06 & -.01 & .951 \\
\hline & Age & .04 & .03 & .20 & .282 & .11 & .06 & .32 & .073 \\
\hline & VIQ & .01 & .01 & .28 & .040 & .02 & .01 & .32 & .011 \\
\hline & MEM & .01 & .01 & .17 & .225 & .02 & .01 & .29 & .032 \\
\hline & Dyslexia & -.02 & .03 & -.09 & .529 & .05 & .06 & .12 & .354 \\
\hline
\end{tabular}

Note: Accuracy is defined as the proportion correct; $B=$ Unstandardized regression coefficient; $S E$ = Standard error; $\beta=$ Standardized regression coefficient; Group = ADHD: 1, control: $0 ;$ Age = child: 0 , adolescent: 1; VIQ = estimate of verbal intelligence, measured with the Vocabulary subtest of the WISC-R (De Bruyn et al., 1986); MEM = Short-term memory, measured with a version of the Word Learn Test (Lezak et al., 2004).

For the ABC-L, the first set of predictors resulted in a significant model $\left(F_{(3,54)}=\right.$ 2.91, $p=.043$ ). Age was the only significant predictor in this model since adolescents performed better than children, regardless of whether or not they had been diagnosed with ADHD $(p=.029)$. The F value of the model changed significantly once the second set of predictors was applied (change: $F_{(2,52)}=5.49, p=.007$, model: $F_{(5,52)}=4.23, p=$ $.003)$. Both verbal intelligence and short-term memory were positively associated with ABC-L accuracy in this model ( $p=.013$ and .039). Additionally, a statistical trend for significance was found for age $(p=.077)$. The third set of predictors did not significantly change the $F$ value $\left(F_{(1,51)}=.87, p=.354\right)$. Using logistic regression analyses with the same sets of predictors described above, post-hoc analyses per item indicated a significant difference between participants with ADHD and controls on one item, namely item 4 (Draw a circle to the right of a cross but to the left of a triangle, OR $=9.17,1.63-51.43, p$ 
$=.012$ ). This difference remained significant after controlling for verbal intelligence and short-term memory.

Differences between the groups: Speed of language comprehension

Figures 1C and 1D present the accuracy scores of language comprehension per test for the four groups. In Table 4, the results of the linear regression analyses for the logarithmic transformation of speed of language comprehension can be found. For the TT-A, the first set of predictors resulted in a significant model $\left(F_{(3,54)}=22.48, p<.001\right)$. Age and diagnosis were both significantly associated with TT-A speed as participants with ADHD performed significantly slower than control participants and children performed significantly slower than adolescents $(p<.001$ and $p=.011)$. There was no significant interaction between diagnosis and age, thereby indicating that the differences between the groups did not change with age. The $\mathrm{F}$ value of the model did not change significantly when the second or third set of predictors were applied (second set: change: $F_{(2,52)}=$ $.02, p=.979$, third set: change: $\left.F_{(1,51)}=.07, p=.798\right)$. Using linear regression analyses with the same sets of predictors described above, post-hoc analyses per item indicated that, for 19 of the 27 TT-A items, participants with ADHD performed significantly slower than control participants (items 1, 6, 7, 9, 10, 12, 13, 14, 15, 17, 18, 19, 20, 21, 22, 23, 24, 26, and 27). These differences remained present after controlling for verbal intelligence and short-term memory.

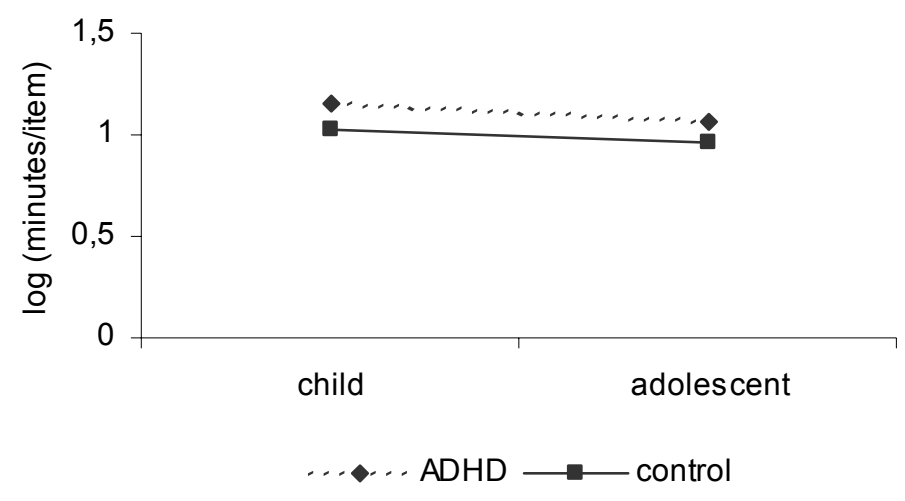

Figure 1C: TT-A speed

Note: Speed is defined as the logarithmic transformation of mean seconds per item over the grades

For the $A B C-L$, the first set of predictors resulted in a significant model $\left(F_{(3,54)}=\right.$ 5.16, $p=.003$ ). Diagnosis was the only significant predictor in this model as exemplified by the fact that participants with ADHD performed significantly slower than control participants $(p=.011)$. The $\mathrm{F}$ value of the model changed significantly after the second set of predictors was applied (second set: change: $F_{(2,52)}=.08, p=.050$ ). Verbal intelligence and diagnosis were significant predictors in this model. Children with higher verbal intelligence scores performed faster on the ABC-L $(p=.017)$ and participants with ADHD performed significantly slower than control participants $(p=.051)$. The third set of predic- 
tors did not significantly change the $F$ value $\left(F_{(1,51)}=.74, p=.394\right)$. Using linear regression analyses with the same sets of predictors described above, post-hoc analyses per item indicated that, on 4 of 13 ABC-L items, participants with ADHD performed significantly slower than control participants (items $4,7,8 a$, and $8 b$ ). These differences remained present after controlling for verbal intelligence and short-term memory.

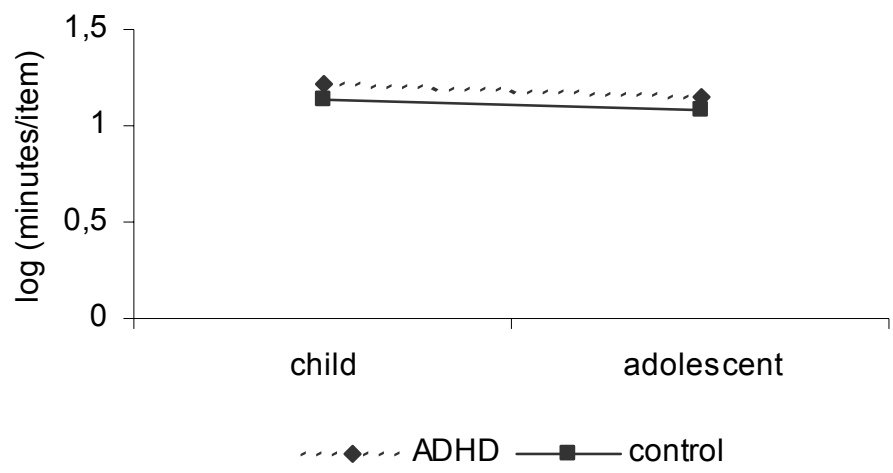

Figure 1D: ABC-L speed

Note: Speed is defined as the logarithmic transformation of mean seconds per item over the grades

Table 4: Linear regression models for speed of language comprehension

\begin{tabular}{|c|c|c|c|c|c|c|c|c|c|}
\hline \multirow[b]{2}{*}{ Block } & \multirow[b]{2}{*}{ Variables } & \multicolumn{4}{|l|}{ TT-A } & \multicolumn{4}{|c|}{ ABC-L } \\
\hline & & B & SE & $\beta$ & $p$ & B & SE & $\beta$ & $p$ \\
\hline \multirow[t]{3}{*}{1.} & Interaction & -.03 & .03 & -.14 & .377 & -.04 & .05 & -.14 & .497 \\
\hline & Group & .13 & .02 & .72 & .000 & .10 & .04 & .45 & .011 \\
\hline & Age & -.06 & .02 & -.33 & .011 & -.05 & .04 & -.22 & .198 \\
\hline \multirow[t]{5}{*}{2.} & Interaction & -.03 & .04 & -.14 & .402 & -.02 & .05 & -.10 & .645 \\
\hline & Group & .13 & .03 & .71 & .000 & .07 & .04 & .34 & .051 \\
\hline & Age & -.06 & .03 & -.34 & .019 & -.05 & .04 & -.24 & .172 \\
\hline & VIQ & -.001 & .01 & -.02 & .837 & -.01 & .01 & -.30 & .017 \\
\hline & MEM & -.0001 & .01 & -.001 & 1.000 & -.003 & .02 & -.06 & .631 \\
\hline \multirow[t]{6}{*}{3.} & Interaction & -.03 & .04 & -.13 & .438 & -.03 & .05 & -.13 & .551 \\
\hline & Group & .13 & .03 & .71 & .000 & .07 & .04 & .32 & .070 \\
\hline & Age & -.06 & .03 & -.34 & .019 & -.05 & .04 & -.24 & .182 \\
\hline & VIQ & -.001 & .01 & -.02 & .826 & -.01 & .01 & -.29 & .020 \\
\hline & MEM & -.0001 & .01 & -.01 & .978 & -.003 & .01 & -.05 & .701 \\
\hline & Dyslexia & -.01 & .03 & -.03 & .798 & .03 & .04 & .11 & .394 \\
\hline
\end{tabular}

Note: Speed is defined as the logarithmic transformation of the mean duration of items in seconds; $B=$ Unstandardized regression coefficient; $S E=$ Standard error; $\beta=$ Standardized regression coefficient; Group = ADHD: 1 , control: $0 ;$ Age = child: 0 , adolescent: $1 ;$ VIQ = estimate of verbal intelligence, measured with the Vocabulary subtest of the WISC-R (De Bruyn et al., 1986); MEM = Shortterm memory, measured with a version of the Word Learn Test (Lezak et al., 2004). 


\section{Discussion}

We studied the ability to process and understand complex sentences in children and adolescents with ADHD relative to control groups matched for age, sex, and parental level of education. We controlled for the following in the analyses: level of verbal intelligence, level of short-term memory, and presence of dyslexia. The primary finding of this study is that, although participants with ADHD appeared to understand the complex sentences as accurately as control participants, they needed considerably more time to provide accurate answers. This difference was statistically significant for both of the complex language batteries applied. This implies that the speed of the complex sentence comprehension is impaired in children and adolescents with ADHD. Because complex language is often used in classroom instructions, this finding has significant implications for the practice of educating children and adolescents with ADHD. These individuals may need more time to process multi-facetted instructions such as "Take out your workbook, open it to page 34 and start working on assignment B". Because of this limitation, children and adolescents with ADHD should be provided with compensation strategies such as additional time and opportunities to ask for repetition. This finding is not only important for teachers. It is also important for the parents of children with ADHD and the professionals that work with these children. Parents, teachers and professionals should bear in mind that, for children and adolescents with ADHD, language is comprehended at a slower rate than usual. The behavior of those who work and live with children and adolescents with ADHD should adjust accordingly.

Speed of language comprehension was found to be impaired in ADHD. This effect was generated by both instruments used in this study. However, the effect was stronger when the TT-A was used $(p<.001)$ than when the ABC-L was used $(p=.051)$. We have considered the possibility that the output modalities of the tasks are related to this difference. The TT-A demands more motor responses than the ABC-L, which demands mostly oral responses (10 of the 13 items). Since motor performance is known to be disturbed in ADHD (Kroes et al., 2002), it is possible that the output modality is the reason for the greater effect found using the TT-A. Perhaps the difficulties children and adolescents experienced in responding quickly to the complex sentences presented in this study were caused by motor problems rather than language problems. However, post-hoc analyses per item indicated a slower speed in the responses of children with ADHD on 4 of the $13 \mathrm{ABC}-\mathrm{L}$ items, of which three were items requiring an oral response. Therefore, we contend that motor problems do not appear to be the only cause of the slower speed of language comprehension found in children with ADHD. This deficiency could possibly be explained in the context of a more general deficit in information processing speed. Several studies comparing cognitive performance of children with and without ADHD found slower response outputs in children with ADHD by means of a number of different paradigms and tasks, such as general motor speed (Carte, Nigg, \& Hinshaw, 1996), response time on a selective inhibition task (Bedard et al., 2003), processing speed on the Coding subtest of the WISC-III (Chhabildas, Pennington, \& Willcutt, 2001), and reaction time on focused and divided attention tasks (Kalff et al., 2005). However, not all studies support this assumption (Chhabildas et al., 2001; Kalff et al., 2003). It would be interesting to investigate the speed of complex sentence comprehension in children with ADHD in a reaction time paradigm, which is assumingly more sensitive to differences and variations in response speed than the more general approach used in this study. Use of this kind of paradigm would likely be able to reveal the extent of the 
speed impairments in the language comprehension of children with ADHD. Evidently, this could have significant implications for clinical and educational practice.

Although some have recommended exercising caution when controlling for IQ because this removes a portion of the variance directly attributable to ADHD (Frazier, Demaree, \& Youngstrom, 2004), we endeavored to investigate whether the complex language comprehension impairments in children with ADHD go beyond general verbal intellectual deficits (Andreou et al., 2005). Therefore, we controlled for an estimate of verbal intelligence in our analyses of language comprehension abilities. Verbal intelligence was estimated by the Vocabulary subtest of the WISC-RN (De Bruyn et al., 1986). We found that controlling for verbal intelligence did indeed remove the TT-A accuracy score deficit found for participants with ADHD but did not fully remove the deficits in speed of language comprehension. This deficit remained largely present. Evidently, this indicates that the complex language comprehension deficits found for the ADHD participants cannot be fully explained by a general deficiency in verbal skills (Andreou et al., 2005).

In an effort to investigate the cognitive developmental perspective of ADHD, our study included the delineation of two groups that were distinguished according to a cut off age of 12 years old. In our earlier, large scale, cross-sectional study of normally developing children, we found continued improvement on the tests used here until the sixth grade for accuracy and the seventh grade for speed of language comprehension (see Chapter 7). We thus assumed that the performance of the adolescent groups in the present study had reached a developmental plateau. Our study found no interaction between ADHD and age-group on either accuracy or speed of the complex language comprehension measures. The language comprehension deficits of participants with ADHD were equally present in both children and adolescents. This finding rejects the notion that temporal cognitive problems in children with ADHD decrease in adolescence. Evidently, our results suggest that $A D H D$ is not a delay in development but rather a permanent disability (Barkley, 1997; Kipp, 2005), at least insofar as language difficulties and early adolescence are concerned. Although longer scale longitudinal research is needed to draw definitive conclusions on this issue, our findings suggest that when no attempts are undertaken to treat the complex language disabilities of children with ADHD, these children may suffer from permanent problems in this area. In other words, our findings emphasize the need to develop specific interventions for complex language comprehension in children and adolescents with ADHD.

The present study endeavored to be the first attempt at studying complex sentence comprehension in children and adolescents with ADHD. Although the sample size was no smaller than those in other language comprehension studies with ADHD participants, the sample size in the different groups was not large enough to generalize the findings to the total population. Similarly, as only children with ADHD combined subtype were included, we cannot simply generalize our findings to the ADHD inattentive subtype. Another potential limitation of our study is related to male-female ratio of the participants. Of the 30 children with ADHD, four were female. A similar ratio was present in the control group due to matching and, because only a small number of female children participated, we were unable to conduct separate analyses for boys and girls. This was unfortunate as separate analyses could be highly relevant in the context of language competence (Bauer, Goldfield, \& Reznick, 2002). Furthermore, we only controlled for short-term memory abilities and not for working memory abilities. This is unfortunate given that 
working memory is thought to be related to complex language comprehension (Baddeley, 2003; Just \& Carpenter, 1992). Working memory deficits are also thought to be among the core features of ADHD (Barkley, 1997) although there is, at this point in time, no consensus on whether these problems are characteristic of the ADHD diagnosis or caused by comorbid language difficulties (Barkley, 1997; Martinussen \& Tannock, 2006; Norrelgen, Lacerda, \& Forssberg, 1999). Future research should consider both types of memory and control for their potential influence on complex language comprehension.

In conclusion, we contend that, in comparison to matched control subjects, children and adolescents with ADHD-C are equally able to understand complex sentences but require more time to process them. This means that the speed of complex sentence comprehension can be added to the list of deficient language functions related to ADHD. We claim that, due to the established association between language competence and learning self-control (Andreou et al., 2005), interventions that specifically address language problems in children and adolescents with ADHD are urgently needed. We further contend that our findings have implications for the practice of education. Children and adolescents with ADHD should be provided with more time to process oral instructions. Furthermore, in clinical practice, more attention should be given to different aspects of language in the diagnostic process of ADHD as this has implications for the behavioral, social, and cognitive functioning of the child and for treatment perspectives (Cohen et al., 2000). We thus recommend including a test of language comprehension speed in the establishment of an ADHD diagnosis in children. 


\section{References}

Achenbach, T. M. (1991). Manual for the Child Behavior Checklist/4-18 and 1991 Profile. Burlington: University of Vermont Department of Psychiatry.

American Psychiatric Association (1994). Diagnostic and statistical manual of mental disorders (4th ed.). Washington DC: American Psychiatric Association.

Anderson, P. (2002). Assessment and development of executive function (EF) during childhood. Child Neuropsychology, 8, 71-82

Andreou, G., Agapitou, P., \& Karapetsas, A. (2005). Verbal skills in children with ADHD. European Journal of Special Needs Education, 20, 231-238.

Baddeley, A. (2003). Working memory and language: an overview. Journal of Communication Disorders, 36, 189-208.

Barkley, R. A. (1997). Behavioral inhibition, sustained attention, and executive functions: constructing a unifying theory of ADHD. Psychological Bulletin, 121, 65-94.

Bashir, A. S., \& Scavuzzo, A. (1992). Children with language disorders: natural history and academic success. Journal of Learning Disabilities, 25, 53-65.

Bauer, D. J., Goldfield, B. A., \& Reznick, J. S. (2002). Alternative approaches to analyzing individual differences in the rate of early vocabulary development. Applied Psycholinguistics, 23, 313336.

Bedard, A. C., Ickowicz, A., Logan, G. D., Hogg-Johnson, S., Schachar, R., \& Tannock, R. (2003). Selective inhibition in children with attention-deficit hyperactivity disorder off and on stimulant medication. Journal of Abnormal Child Psychology, 31, 315-327.

Beitchman, J. H., Brownlie, E. B., Inglis, A., Wild, J., Ferguson, B., Schachter, D., Lancee, W., Wilson, B., \& Mathews, R. (1996). Seven-year follow-up of speech/language impaired and control children: psychiatric outcome. Journal of Child Psychology and Psychiatry, 37, 961-970.

Biederman, J. (2005). Attention-deficit/hyperactivity disorder: a selective overview. Biological Psychiatry, 57, 1215-1220.

Biederman, J., Monuteaux, M. C., Mick, E., Spencer, T., Wilens, T. E., Silva, J. M., Snyder, L. E., \& Faraone, S. V. (2006). Young adult outcome of attention deficit hyperactivity disorder: a controlled 10-year follow-up study. Psychological Medicine, 36, 167-179.

Blomert, L. (2002). Stand van zaken dyslexie. In: Dyslexie; Naar een vergoedingsregeling [State of affairs dyslexia. In: Dyslexia; Towards a reimbursement of expenses]. Amstelveen: College voor Zorgverzekeringen, Rapport 03-144, pp. 28-139.

Carte, E. T., Nigg, J. T., \& Hinshaw, S. P. (1996). Neuropsychological functioning, motor speed, and language processing in boys with and without ADHD. Journal of Abnormal Child Psychology, 24, 481-498.

Casey, B. J., Tottenham, N., Liston, C., \& Durston, S. (2005). Imaging the developing brain: what have we learned about cognitive development? Trends in Cognitive Sciences, 9, 104-110.

Chhabildas, N., Pennington, B. F., \& Willcutt, E. G. (2001). A comparison of the neuropsychological profiles of the DSM-IV subtypes of ADHD. Journal of Abnormal Child Psychology, 29, 529-540.

Christensen, A-L. (1993). Luria's neuropsychological investigation text. Risskov, Denmark: P. J. Schmidts Bogtrykkeri, Vojens.

Cohen, N. J., Vallance, D. D., Barwick, M., Im, N., Menna, R., Horodezky, N. B., Isaacson, L. (2000). The interface between ADHD and language impairment: an examination of language, achievement, and cognitive processing. Journal of Child Psychology and Psychiatry, 41, 353362.

De Bruyn, E.E.J., Van der Steene, G., Van Haasen, P.P., Coetsier, P., Pijl, Y.J., Spoelders-Claes, R., Poortinga, Y.H., Stinissen, J., \& Lutje Spelberg, H.C. (1986). Wechsler Intelligence Scale for Children - Revised (WISC-R). Lisse: Swets \& Zeitlinger.

De Renzi, E., \& Faglioni, P. (1978). Normative data and screening power of a shortened version of the Token Test. Cortex, 14, 41-49.

Dick, F., Wulfeck, B., Krupa-Kwiatkowski, M., \& Bates, E. (2004). The development of complex sentence interpretation in typically developing children compared with children with specific language impairments or early unilateral focal lesions. Developmental Science, 7, 360-377. 
Directoraat-Generaal voor de Arbeidsvoorziening (1989). Handleiding voor de functieanalyse [Function analysis manual]. Den Haag: SDU uitgeverij.

DiSimoni, F. (1978). Token Test for Children (TTFC). Austin, Texas: PRO-ED.

Francis, D. J., Fletcher, J.M., Stuebing, K. K., Lyon, G. R., Shaywitz, B. A., \& Shaywitz, S. E. (2005). Psychometric approaches to identification of LD: IQ and achievement scores are not sufficient. Journal of Learning Disabilities, 38, 98-108.

Frazier, T. W., Demaree, H. A., \& Youngstrom, E. A. (2004). Meta-analysis of intellectual and neuropsychological test performance in attention-deficit/hyperactivity disorder. Neuropsychology, 18, 543-555.

Geurts, H. M., Verté, S., Oosterlaan, J., Roeyers, H., Hartman, C. A., Mulder, E. J., van BerckelaerOnnes, I. A., \& Sergeant, J. A. (2004). Can the Children's Communication Checklist differentiate between children with autism, children with ADHD, and normal controls? Journal of Child Psychology and Psychiatry, 45, 1437-1453.

Goldman, L. S., Genel, M., Bezman, R. J., \& Slanetz, P. J. (1998). Diagnosis and treatment of attention-deficit/hyperactivity disorder in children and adolescents. Council on Scientific Affairs, American Medical Association. Journal of the American Medical Association, 279, 1100-1107.

Greenhill, L. L. (1998). Childhood attention deficit hyperactivity disorder: pharmacological treatments. In: P. E. Nathan \& J. Gorman (Eds.). A guide to treatments that work (pp. 42-64). New York: Oxford University Press.

Hendriksen, J. G. M., Feron, F. J. M., \& Vles, J. S. H. (2000). Klinisch Ontwikkeling Interview [Clinical Development Interview]. Internal publication University Hospital Maastricht, Department of Psychiatry and Neuropsychology.

Hurks, P. P., Hendriksen, J. G., Vles, J. S., Kalff, A. C., Feron, F. J., Kroes, M., van Zeben, T. M., Steyaert, J., \& Jolles, J. (2004). Verbal fluency over time as a measure of automatic and controlled processing in children with ADHD. Brain and Cognition, 55, 535-544.

Jacquemot, C., \& Scott, S. K. (2006). What is the relationship between phonological short-term memory and speech processing? Trends in Cognitive Science, 10, 480-486.

Just, M. A., \& Carpenter, P. A. (1992). A capacity theory of comprehension: individual differences in working memory. Psychological Review, 99, 122-149.

Kalff, A. C., de Sonneville, L. M., Hurks, P. P., Hendriksen, J. G., Kroes, M., Feron, F. J., Steyaert, J., van Zeben, T. M., Vles, J. S., \& Jolles, J. (2003). Low- and high-level controlled processing in executive motor control tasks in 5-6-year-old children at risk of ADHD. Journal of Child Psychology and Psychiatry, 44, 1049-1057.

Kalff, A. C., De Sonneville, L. M., Hurks, P. P., Hendriksen, J. G., Kroes, M., Feron, F. J., Steyaert, J., van Zeben, T. M., Vles, J. S., \& Jolles, J. (2005). Speed, speed variability, and accuracy of information processing in 5 to 6 -year-old children at risk of ADHD. Journal of the International Neuropsychological Society, 11, 173-183.

Kipp, K. (2005). A developmental perspective on the measurement of cognitive deficits in attentiondeficit/hyperactivity disorder. Biological Psychiatry, 57, 1256-1260.

Krain, A. L., \& Castellanos, F. X. (2006). Brain development and ADHD. Clinical Psychology Review, 26, 433-444.

Kroes, M., Kessels, A. G., Kalff, A. C., Feron, F. J., Vissers, Y. L., Jolles, J., \& Vles, J. S. (2002). Quality of movement as predictor of ADHD: results from a prospective population study in 5and 6-year-old children. Developmental Medicine \& Child Neurology, 44, 753-760.

Lezak, M. D., Howieson, D. B., \& Loring, D. W. (2004). Neuropsychological assessment (4th ed.). New York: Oxford University press.

Lorch, E. P., Milich, R., \& Sanchez, R. P. (1998). Story comprehension in children with ADHD. Clinical Child and Family Psychology Review, 1, 163-178.

Luria, A. R. (1966). Higher cortical functions in man. New York: Basic Books

Luria, A. R. (1980). Higher cortical functions in man. New York: Basic Books.

Martinussen, R., \& Tannock, R. (2006). Working memory impairments in children with attentiondeficit hyperactivity disorder with and without comorbid language learning disorders. Journal of Clinical Experimental Neuropsychology, 28, 1073-1094. 
Mathers, M. (2005). Some evidence for distinctive language use by children with Attention Deficit Hyperactivity Disorder. Clinical Linguistics and Phonetics, 19, 215-225.

Mathers, M. E. (2006). Aspects of language in children with ADHD: applying functional analyses to explore language use. Journal of Attention Disorders, 9, 523-533.

McNeil, M. M. \& Prescott, T. E. (1978). Revised Token Test (RTT). Austin, Texas: PRO-ED.

Norrelgen, F., Lacerda, F., \& Forssberg, H. (1999). Speech discrimination and phonological working memory in children with ADHD. Developmental Medicine and Child Neurology, 41, 335-339.

Oosterlaan, J., Scheres, A., Antrop, I., Roeyers, H., \& Sergeant, J. A. (2000). Manual of the Questionnaire for Behaviour problems in Children [Handleiding bij de Vragenlijst voor Gedragsproblemen bij Kinderen]. Amsterdam, Vrije Universiteit.

Purvis, K. L., \& Tannock, R. (1997). Language abilities in children with attention deficit hyperactivity disorder, reading disabilities, and normal controls. Journal of Abnormal Child Psychology, 25, 133-144.

Renz, K., Lorch, E. P., Milich, R., Lemberger, C., Bodner, A., \& Welsh, R. (2003). On-line story representation in boys with attention deficit hyperactivity disorder. Journal of Abnormal Child Psychology, 31, 93-104.

Snowling, M. J., Bishop, D. V. M., Stothard, S. E., Chipcase, B., \& Kaplan, C. (2006). Psychosocial outcomes at 15 years of children with a preschool history of speech-language impairment. Journal of Child Psychology and Psychiatry, 47, 759-765.

Steingard, R. J., Biederman, J., Doyle, A., \& Sprich-Buckminster, S. (1992). Psychiatric comorbidity in attention deficit disorder: Impact on the interpretation of Child Behaviour Checklist results. Journal of the American Academy of Child and Adolescent Psychiatry, 31, 449-454.

Tirosh, E., \& Cohen, A. (1998). Language deficit with attention-deficit disorder: a prevalent comorbidity. Journal of Child Neurology, 13, 493-497.

Van der Elst, W., van Boxtel, M. P., van Breukelen, G. J., \& Jolles, J. (2005). Rey's verbal learning test: normative data for 1855 healthy participants aged 24-81 years and the influence of age, sex, education, and mode of presentation. Journal of the International Neuropsychological Society, 11, 290-302.

Wechsler, D. (1974). Wechsler Intelligence Scale for Children - Revised. Manual. San Antonio: The Psychological Corporation.

Willcutt, E. G., Doyle, A. E., Nigg, J. T., Faraone, S. V., \& Pennington, B. F. (2005). Validity of the executive function theory of attention-deficit/hyperactivity disorder: a meta-analytic review. Biological Psychiatry, 57, 1336-1346. 



\section{CHAPTER 9}

Concluding remarks 
Cognitive child development is a complex process that is influenced by many factors. For example, we know that the age-related differences in cognitive functioning are influenced by inter-individual variables and factors that can be both child and context related. Since cognitive development has strong implications for academic functioning, understanding how normal cognitive development, with all its variability, occurs is imperative. It is also important to know which factors contribute to this development. With this knowledge, we will likely be able to detect cognitive weaknesses earlier and more optimally. We may then be able to reduce these weaknesses using cognitive strengths.

The studies described in this dissertation endeavored to contribute to the current scientific knowledge based on differential cognitive development and the inter-individual variability that is related to this aspect of development. A neuropsychological approach was used and different cognitive functions were studied. Although many cognitive functions can be studied, the complex cognitive functions described in this dissertation were selected because they were considered important for children's daily functioning. These functions included subcomponents of sense of time, complex language comprehension, and selective attention. The relationship between general cognitive and motor development in young children was also studied. To explain variability in cognitive development, the focus was placed on three inter-individual factors, namely attention difficulties, sex, and parental level of education.

The results of several large-scale cross-sectional studies and one longitudinal study were described in this dissertation. Each of these studies focused on a distinct cognitive function and the influence of one or more of the above-mentioned inter-individual differences. With respect to the study samples, the number of participants varied from several tens to several hundreds of children, depending of the study. The age range in the studies conducted was 5 to 16 years. In this final chapter, the general findings of the studies described in this dissertation are summarized and placed in a theoretical context. In addition, practical implications of the findings are discussed.

\section{Differential cognitive development: Extending Peter Anderson's (2002) model}

Recent research using brain imaging methods has shown that certain parts of the human brain, especially parts of the prefrontal cortex, continue to develop into late adolescence or even early adulthood (Alvarez \& Emory, 2006; Casey, Giedd, \& Thomas, 2000; Castellanos et al., 2002; Crone, 2004; Gogtay et al., 2004; Klingberg, Vaidya, Gabrieli, Moseley, \& Hedehus, 1999; Paus, 2005; Shaw et al., 2006; Sowell et al., 2003; Thatcher, 1991). In parallel to this prolonged differentiation and maturation of the prefrontal cortex, complex cognitive functions also continue to develop into adolescence or even early adulthood. These functions include cognitive flexibility, behavioral planning, impulse control, and working memory (V. A. Anderson, Anderson, Northam, Jacobs, \& Catroppa, 2001; Brocki \& Bohlin, 2004; Casey, Tottenham, Liston, \& Durston, 2005; Eslinger, Flaherty-Craig, \& Benton, 2004; Fuster, 2000; Hooper, Luciana, Conklin, \& Yarger, 2004; Luna, Garver, Urban, Lazar, \& Sweeney, 2004; Paus, 2005; Steinberg, 2005). These cognitive processes have been described as being 'executive functions'. Executive functions are thought to be various self-regulatory processes that are responsible for purposeful, goal-directed behavior (Alvarez \& Emory, 2006; Brocki \& Bohlin, 2004; Lehto, Juujarvi, Kooistra, \& Pulkinnen, 2003; Lezak, Howieson, \& Loring, 2004; Odhuba, van den Broek, \& Johns, 2005; Pennington \& Ozonoff, 1996; Zelazo, Craik, \& Booth, 2004). 
From a child neuropsychological perspective, Peter Anderson's (2002) model is especially informative when executive functioning is concerned because it takes the developmental aspect of cognitive functions into account. On the basis of child neuropsychological studies, the model conceptualizes executive functioning as four discrete cognitive domains that operate in an integrative manner. This model was discussed in detail in the Introduction of this dissertation. However, so the reader does not have to refer back to the Introduction, a short description is also included in this chapter (see Figure 1). According to Peter Anderson (2002), performance on the first domain, attentional control, develops mostly during infancy and early childhood and is relatively established by mid-childhood. The other three domains, namely information processing, cognitive flexibility, and goal setting, follow slightly different developmental trajectories. However, these are all relatively mature by the age of 12 but only reach full establishment by midadolescence.

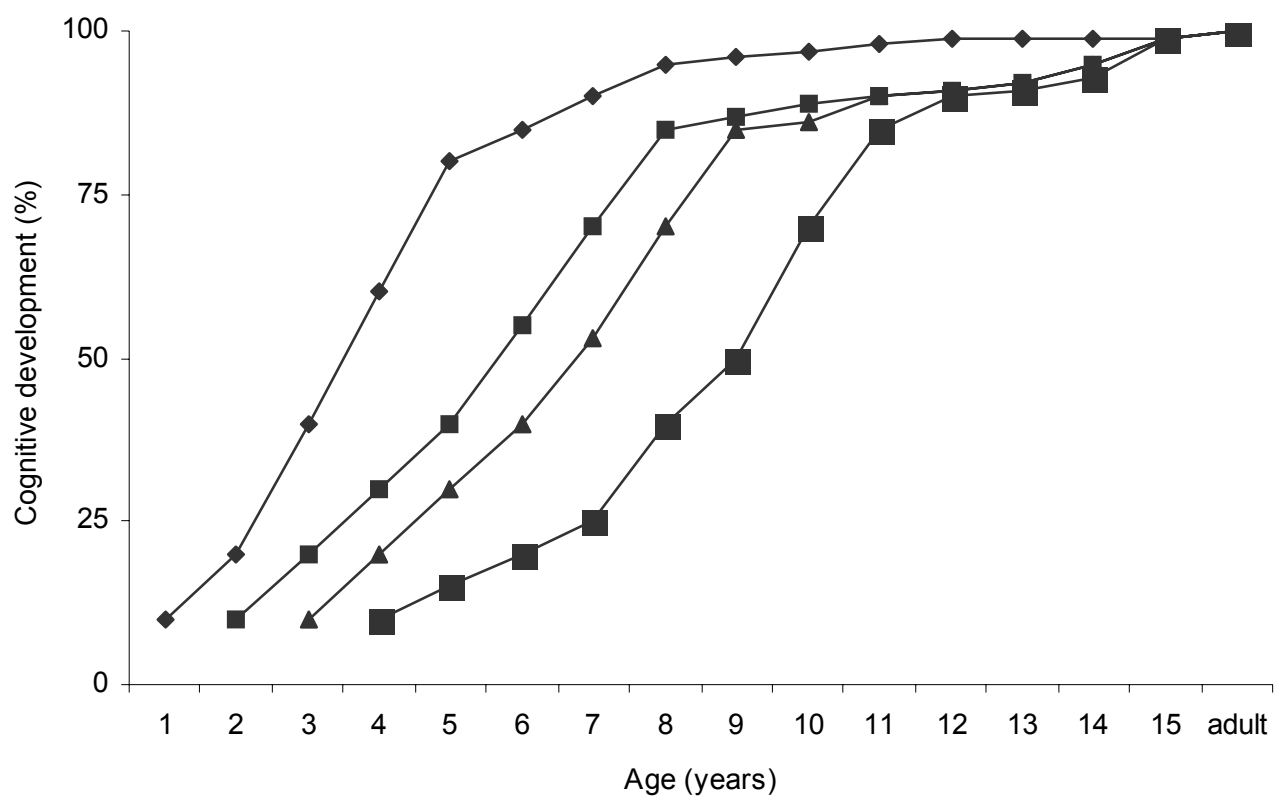

$\multimap$ attentional control

$\multimap$ information processing $\longleftarrow$ cognitive flexibility goal setting

Figure 1: Protracted developmental trajectories of the executive domains Note: By Peter Anderson (2002), Child Neuropsychology, 8, p. 78.

At this point, it is necessary to define a limitation of Peter Anderson's (2002) model of executive functioning. Although the model is very informative with regard to 'pure' cognitive processes, it does not describe cognitive development in a social context. More 
specifically, Anderson's (2002) model of executive functioning does not include the developmental pattern of emotional or affective aspects of cognitive development, such as moral judgment, decision-making, and risk-taking. These are functions that take quite long to develop and are not thought to be fully mature until early adulthood (Ernst et al., 2005; Steinberg, 2005). Thus, Anderson's (2002) statement that cognitive development is relatively complete by the age of 15 is only applicable to cognitive functions that do not have an affective component.

Peter Anderson's (2002) model of executive functioning was used as the theoretical foundation for the studies described in this dissertation. The first aim of the dissertation was to investigate age-related improvement on several cognitive functions that are thought to be important for children's daily functioning. These cognitive functions included sense of time, complex language comprehension, and selective attention. Based on Anderson's (2002) model of executive functioning, the expectation was that development of these cognitive functions would be differential with simple aspects reaching a mature state prior to more abstract aspects.

The results of the studies described in this dissertation were diverse. Some cognitive function subcomponents appeared to have reached full maturity already in the second grade (e.g. the number of inattentive errors made during a selective attention task, chapter 4; knowledge of the duration of daily events on a sense of time task, chapter 5), while other functions did not appear to have reached a plateau in development by the age period studied (processing speed of selective attention, chapter 4). Still other functions continued to develop into secondary school, more specifically into the seventh grade (speed of complex language comprehension, chapter 7). These results emphasize the differential nature of cognitive development and the need to investigate the cognitive development of children beyond elementary school age.

To obtain a comprehensive model of cognitive development, the results of this dissertation were placed in the context of Peter Anderson's (2002) model of executive functioning. Performance of the samples studied was transferred to percentage scores of total cognitive development. The following rationale was used to accomplish this: (1) The age at which no further improvement occurred was considered to be equal to $100 \%$ cognitive development. Thus, a mature state was not necessarily perfect performance on a task. Additionally, the determination of a mature state in performance was not only based on the oldest children studied, but on all age-groups in which a plateau in development was found; and (2) Performance of younger children was transferred to the cognitive development scale (in \%) accordingly. For example, performance on the subcomponent 'duration comparison' of sense of time (described in chapter 5) was poorer in the second grade than in all the other grades and no differences in performance were observed between the other grades. Performance in grades three, four, five, and six was thus considered to have reached a mature state. Mean performance in these grades was $88.6 \%$, whereas performance in second grade was $74.9 \%$. If a score of $88.6 \%$ on the duration comparison items is equal to $100 \%$ cognitive development, then a score of 74.9 $\%$ is equal to $84.5 \%[(74.9 * 100) / 88.6]$. This process was repeated for each of the cognitive functions described in this dissertation. Figure 2 displays these results ${ }^{2}$.

\footnotetext{
${ }^{2}$ Although all age-groups in which no further improvement occurred on a given cognitive function were used as the reference category, the developmental trajectories shown in Figure 2 were essentially the same when only the oldest age category would have been used.
} 

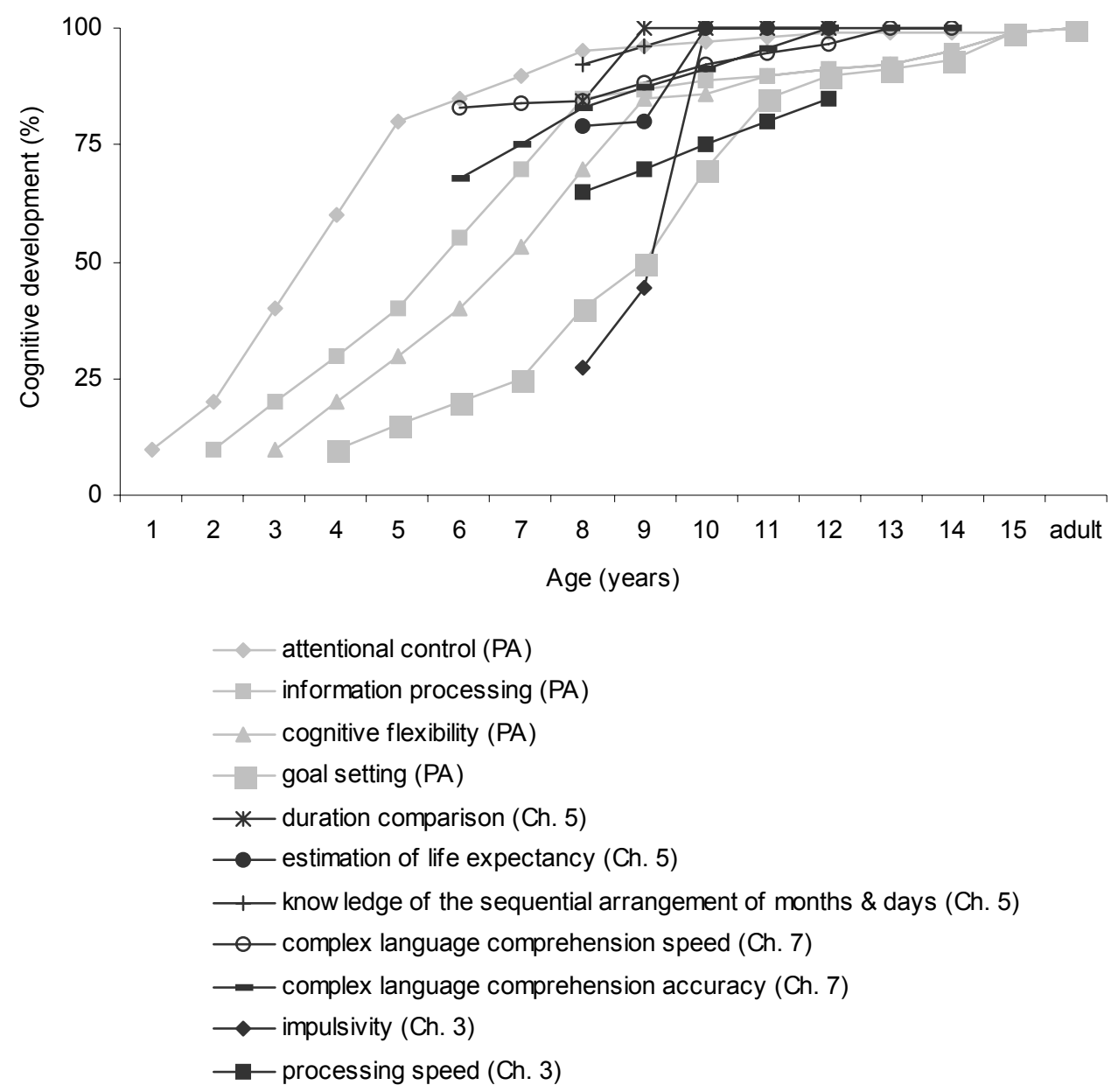

Figure 2: Results of this dissertation included in Peter Anderson's model (2002) Note: $P A=$ domain of executive functioning, by Peter Anderson (2002); Ch. $5=$ Chapter 5 of this dissertation; Ch. 7 = Chapter 7 of this dissertation, Ch. $3=$ Chapter 3 of this dissertation.

The only cognitive function for which the developmental trajectory could not be placed in the model with absolute certainty was processing speed on a selective attention task. This was because complete development may not have been reached in the age period studied. More specifically, linear improvement was observed up to sixth grade and, because our sample did not include children beyond this age, we were unable to determine whether performance would continue to improve beyond this age (chapter 3 ). Therefore, information from the literature was used to transfer performance to a $100 \%$ scale. Kail (1996, 2000), Hale (1990) and Luna and colleagues (2004) reported that processing speed continues to develop until 15 years of age. Performance of the sample 
in chapter 3 was extrapolated until the age of 15 and the hypothesized score at 15 years was considered to be equal to $100 \%$ complete development. The performance of the younger groups was then transferred to a $100 \%$ scale according to the process described earlier.

To enhance clarity, functions that did not show age differences in the age period studied are not included in Figure 2 because performance on these functions would be equal to $100 \%$ cognitive development in all age-groups. These functions were inattention (the number of inattentive errors made during a selective attention task, chapter 4), and knowledge of the duration of daily events on a sense of time task (chapter 5).

In conclusion, we consider the results of this dissertation to be a considerable extension of Anderson's model (2002). We have shown that sense of time, selective attention, and language comprehension follow differential development paths throughout childhood. Performance on subcomponents of selective attention and language comprehension did not reach a mature state until early adolescence. The developmental trajectories of the cognitive functions studied and reported in this dissertation support Peter Anderson's model (2002). The general conclusion that simple aspects of a cognitive function develop earlier than complex aspects has also been explored.

Perhaps the most important conclusion that can be drawn based on the studies reported in this dissertation is that prolonged development does not only occur for functions that serve as the bases for Peter Anderson's (2002) model, namely the 'executive functions' cognitive flexibility, impulse control, and goal setting. Rather, other cognitive processes may be more complex than we initially expected. These cognitive processes include complex language comprehension, sense of time, and subcomponents of selective attention. Thus, this dissertation has served to considerably increase the existing scientific knowledge base on normal cognitive development. This knowledge is important because it enables education and health care professionals to assess children's abilities. For example, our studies demonstrated that children in the sixth, seventh and eighth grade understood, on average, more than $90 \%$ of the complex sentences presented. This indicates that young adolescents who comprehend a lesser amount, for example, $20 \%$ of the sentences, may have a specific deficit in this cognitive process, which likely manifests as difficulties in daily life. Evidently, knowledge on normal development may help us to better understand deviant cognitive development. This may enable us to identify and understand adverse developmental processes earlier and more optimally. In doing so, we will likely be able to initiate the remediation of adverse developmental processes earlier and more effectively. One cognitive function that showed a pronounced prolonged development into adolescence was processing speed. The results with regard to this function are discussed in more detail in the following paragraph.

\section{Differential cognitive development: Processing speed}

Various studies reported in this dissertation indicated that one aspect of the information processing domain, namely speed of processing, is an important factor to consider with respect to cognitive development. Firstly, on a selective attention task, it became apparent that processing speed had not yet reached full maturity by the sixth grade (12 years of age), whereas omission and commission error rates had already stabilized before or in fourth grade (chapter 3). Secondly, on a complex language comprehension task, processing speed continued to develop until the seventh grade (13 years of age), which was a year later than the stabilization of the accuracy component of complex language com- 
prehension (chapter 7). These findings suggest two things. Firstly, it is not the accuracy with which a task is performed but rather the response speed that is most informative and sensitive to developmental differences. Secondly, processing speed is not a task or function specific factor but rather a general cognitive ability that continues to develop into adolescence.

Earlier cognitive studies using reaction time paradigms on various cognitive functions have reached similar conclusions (Hale, 1990, Kail, 1996, 2000; Kuhn, 2006; Luna et al., 2004). According to Kail (1991), age differences in processing speed reflect a general component that changes rapidly during childhood and more slowly during adolescence. In addition, Peter Anderson (2002) described processing speed as one aspect of the executive domain 'information processing', alongside fluency and efficiency of output. In his review of child neuropsychological studies, Anderson concluded that the most striking increments in response speed occur between three and five years of age and between nine and eleven years of age. Further improvement occurs during adolescence, although no large progress is expected after the age of 15 , when a mature state is reached. Explanations that have been provided for the prolonged development of processing speed are neural processes such as myelination and synaptic pruning. Myelination is the insulation of established axonal connections that optimizes the propagation of electrical signals throughout the brain and therefore allows for faster responses (Giedd et al., 1999). Synaptic pruning is the selective elimination of unnecessary neuronal connections that can speed and enhance information processing (Giedd et al., 1999). Both neuronal processes continue to develop into young adulthood (Casey et al., 2000; Casey et al., 2005; Giedd et al., 1999), which may imply that processing speed continues to improve until early adulthood as well. It is possible that studies using a cognitive reaction time paradigm are not sensitive enough to indicate speed improvements after the age of 15. Future research using fMRI paradigms is therefore recommended.

In conclusion, the scientific literature on this matter indicates that processing speed is a cognitive function that continues to develop into adolescence. The studies described in this dissertation confirm this conclusion but also investigated other cognitive functions. For example, prior to our study, the link between complex language comprehension and processing speed had not yet been investigated. Although the age at which a mature level of processing speed is thought to be reached is 15 years of age, this varies between the cognitive functions studied (Kail, 1991). Additionally, recent structural brain studies show potential indications that improvement on processing speed is ongoing (Casey et al., 2000; Casey et al., 2005; Giedd et al., 1999).

The relatively young age at which maturity was reached with respect to speed of complex language comprehension, namely thirteen, could be function-specific. On the other hand, it is also possible that, although the performance of children in the seventh and eighth grades did not differ, speed may improve further in older children. However, our study sample did not include children in later grades. This should be investigated in future research so that a definite age at which maturity in speed of language comprehension is reached can be defined. The same applies to the selective attention paradigm. Performance increased until the sixth grade, but no older children were investigated thus we were unable to determine the age at which maturity is attained.

Processing speed is not only important to consider in normal development, it can also be informative when investigating the development of children with Attention Deficit Hyperactivity Disorder (ADHD). This dissertation includes a study in which the findings 
suggest that processing speed on a complex language comprehension task can reliably distinguish between children and adolescents with and without ADHD. The same study indicated that accuracy could not, independently of age, distinguish between participants with and without ADHD (chapter 8). This result supports previous studies conducted with children with ADHD that demonstrated slower than normal response output on a number of other paradigms and tasks, including general motor speed (Carte, Nigg, \& Hinshaw, 1996), response time on a selective inhibition task (Bedard et al., 2003), processing speed on the Coding subtest of the WISC-III (Chhabildas, Pennington, \& Willcutt, 2001), and reaction time on focused and divided attention tasks (Kalff et al., 2005). In short, there appears to be a general deficit in processing speed in ADHD that is also applicable to the language comprehension. This is a finding that is highly relevant for children's daily lives. In individuals with ADHD, the general processing speed deficit may be related to delayed prefrontal brain maturation (Kipp, 2005), although this has not yet been investigated specifically.

In summary, elementary school children in general, and children with ADHD in particular, process information relatively slow, while accuracy is not affected. More specifically, in elementary school children, processing speed on a selective attention task continued to develop into the sixth grade, while omission and commission errors did not decrease further after the fourth grade (chapter 3). Additionally, we also found that processing speed on a language comprehension task improved until the seventh grade, while accuracy had stabilized in the sixth grade. We can thus conclude that a mature level of accuracy was reached at an earlier age than a mature level of speed. In children with ADHD, accuracy levels of complex language comprehension were not impaired, although considerably more time was needed to complete the required tasks (chapter 8 ). For both normally developing children and for children with ADHD, poor performance, or performance that does not correspond with the potential of the child, can be expected when time demands are placed upon that child. This has serious implications for the practice of education. Providing children with extra time to process instructions or to produce output may improve accuracy of performance considerably. However, response speed is important for many tasks in daily life and should be treated as such. Children must learn to be able to perform accurately under time pressure. Evidently, this highlights the need to develop specific treatment programs that aim to increase processing speed. This kind of training may be especially relevant for children with ADHD as the provision of such a program may help them to put their performance on par with their potential.

This dissertation studied cognitive development using mostly cross-sectional designs and, even though large samples were used ( $N=83$ to 454$)$, the use of crosssectional designs is less desirable than the use of longitudinal designs. Most importantly, inter-individual variability in brain development is thought to be higher than developmental variability and, as such, cross-sectional studies may overestimate age differences in cognition (Durston et al., 2006). Although longitudinal studies have their own disadvantages, such as higher costs, selective attrition and test-retest effects (Salthouse, 2000), they are still considered to generate more sensitive means of measuring development. Evidently, there is a need for longitudinal studies that investigate the cognitive functions described in this dissertation. Nonetheless, the studies described here are of great value with respect to the practice of child neuropsychology because: a) they are the first studies that prolonged development does not only occur for hard-core executive functions but 
also for functions that, at face value, may appear relatively easy; and b) they controlled for the influence of several inter-individual factors on cognitive development, including attention, parental level of education and sex. The results of the analyses with regard to these inter-individual differences are discussed in the following sections.

\section{Inter-individual variability in cognitive development: Attention}

Attention is a higher-order cognitive function that is inherent to all other cognitive and academic processes (Baron, 2004; Cooley \& Morris, 1990; Tannock, 2003). Subdomains of attention that are currently distinguished in clinical practice include selective attention, sustained attention, attention switching, and divided attention (Baron, 2004). Peter Anderson (2002) captures selective attention, sustained attention, and the ability to inhibit prepotent responses in the domain termed 'attentional control'. He also hypothesized that this domain is the first to mature. The intact functioning of this domain is thought to significantly influence the functioning of the other three executive domains $(P$. Anderson, 2002). Therefore, it is important to evaluate a child's basic attention functions when differential cognitive development is concerned. The influence of attention and attention deficits on cognitive development was reported on in several of the studies described in this dissertation. The general conclusion of these studies was that attention is an important moderator of cognitive development. The main results with respect to this matter were threefold.

Firstly, we studied the extent to which the relationship between normal motor and cognitive performance was influenced by attention. This question was addressed in an effort to determine whether motor development and cognitive development are independent or dependent processes (Bushnell \& Boudreau, 1993; Churchland, 1986, 2002; Lehnung et al., 2003; Piaget \& Inhelder, 1966). The results indicated that indeed a relationship between cognition and motor performance can be found in young children. However, the results also showed that relationship disappeared when we controlled for the level of attention using cognitive tests. This indicates that cognitive development and motor development do not influence each other directly. Rather, it is attention that determines both cognitive and motor progress (chapter 2).

Secondly, we concluded that attention, as measured by cognitive tests, in kindergarten and the first grade could, to a large extent, predict academic outcome in the sixth grade (chapter 4). Attention deficits measured by behavioral questionnaires contributed less to the prediction of academic outcome. Both these findings were based on research conducted with a population sample of normally developing children. As such, we concluded that attentional functioning is important in normally developing children and should therefore receive more consideration, both in science and in the practice of education.

Thirdly, we demonstrated that children and adolescents with attention difficulties, and more specifically children with ADHD combined subtype, showed deficits in complex language comprehension, independent of their age. The deficits did not appear to decrease or increase in adolescence as compared to childhood. This means that the problems experienced by children with ADHD are unlikely to resolve on their own and must therefore be targeted by treatment programs that take these deficits into account. This last finding contributes to the conceptualization of ADHD as a chronic condition with all its associated implications (Barkley, 1997; Kipp, 2005). In short, we have shown that both in a clinical sample (chapter 8) and in population samples (chapters 2 and 4), atten- 
tion was found to be an important moderator of cognitive development. This confirms that attention is not a dichotomous variable, in that you either do or do not have 'adequate attention'. Rather, attention is a continuum. Children who do not suffer from ADHD can still have sub-clinical attention deficits that influence their cognitive functioning, as illustrated in Figure 3.

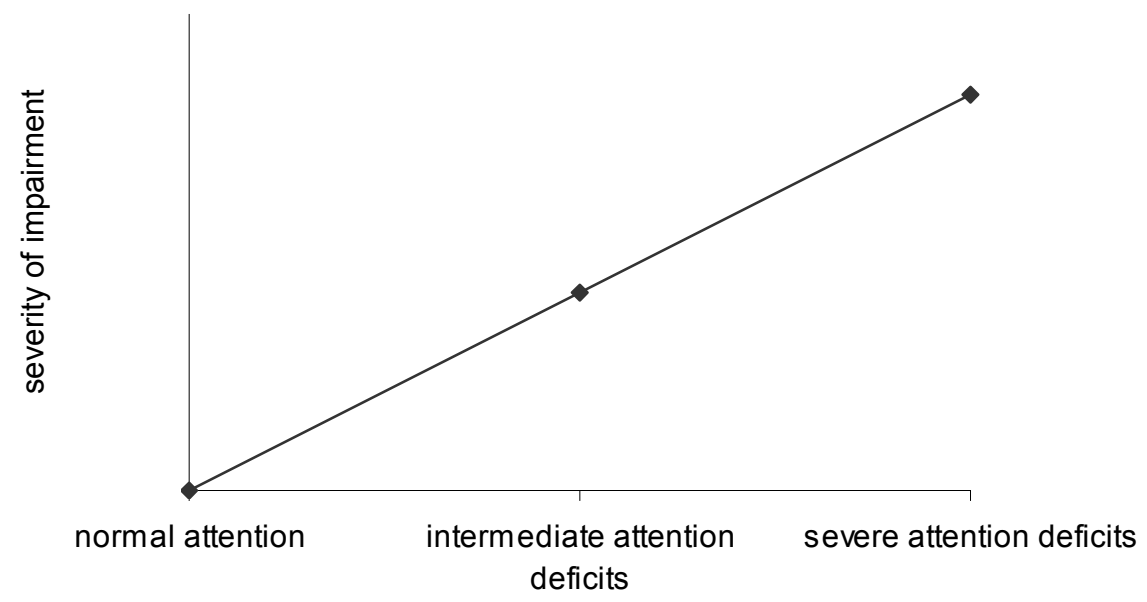

Figure 3: The continuum of attention

In conclusion, attention determines the extent to which children are able to develop and reach their full cognitive potential. Evidently, this contention implies that we cannot easily distinguish between sub-clinical and clinical attention deficits. However, a diagnosis of clinical attention deficits cannot be made if the attention deficits do not severely impair a child's functioning. This is known as the DSM-IV criterion D (Gordon et al., 2006). Although some studies have indicated that medication can be useful for the improvement of attention both in ADHD and in normally developing children (Rapoport \& Inoff-Germain, 2002), the prescription of medication in the absence of a diagnosis is undesirable because of the possible side effects (e.g. sleeping and eating problems) that may ensue (Charach, Figueroa, Chen, Ickowicz, \& Schachar, 2006; Greenhill et al., 2002; Zachor, Roberts, Hodgens, Isaacs, \& Merrick, 2006). Rather, neuropsychological treatment programs that aim to increase attention capacity should be developed (Rueda, Rothbart, McCandliss, Saccomanno, \& Possner, 2005). Similar treatment programs are already in place for attention and working memory and the preliminary results are positive. They indicate improvements even within a short period of time (Klingberg et al., 2005; Klingberg, Forssberg, \& Westerberg, 2002; Penkman, 2004). Attention training programs may be beneficial for children with sub-clinical attention deficits. However, before any definitive conclusions can be drawn, additional research is needed. It is important that we determine whether programs for children with ADHD work best on their own or in combination with medication. In conclusion, regardless of whether an ADHD diagnosis of $A D H D$, attention is indeed a factor that should be considered in all children. 


\section{Inter-individual variability in cognitive development: Parental level of education and sex}

In addition to investigating the effect of attention on cognitive development, other factors were also studied. Although it would have been interesting to study the influence of many inter-individual factors simultaneously, this was, due to practical reasons, not feasible. Therefore, we choose to focus on the influence of two important factors that can potentially generate inter-individual differences in cognitive development. These two factors were parental level of education, as a proxy of socioeconomic status (SES), and sex. The influence of these two factors differed between the cognitive functions studied.

With regard to parental level of education, no influence was found for selective attention (chapter 3 ) or for sense of time (chapter 5). In contrast, it was found that, with respect to the accuracy of language comprehension, children with highly educated parents had an advantage over children that came from a lower or more moderate educational background. Evidently, it appears that the parental level of education had some kind of influence on complex cognitive development. Most studies that focus on this aspect have found that parental level of education is associated with academic performance as well as general level of cognition (Greenberg, Lengua, Coie, \& Pinderhughes, 1999; Huda, Grantham-McGregor, Rahman, \& Tomkins, 1999; Roberts, Bornstein, Slater, \& Barrett, 1999). Explanations for these relationships include genetics, differences in access to material and social resources and differences in one's reactions to stressful conditions (Bradley \& Corwyn, 2002; Turkheimer, Haley, Waldron, D'Onofrio, \& Gottesman, 2003).

In summary, the results of the studies described in this dissertation did not indicate a robust influence of parental education level. This may have been due to the fact that most of the studies reported in this dissertation had a relatively high mean for parental education level. It could be suspected that the influence of parental education level on the cognitive functions will be stronger in studies that include more children from lower socioeconomic backgrounds (Greenberg et al., 1999; Hoff, 2003; Jackson, 2003; Landry, Smith, \& Swank, 2002). Future research on this matter to confirm this expectation is therefore recommended. It is important to note that, in the studies described in this dissertation, involving children from low educated families was difficult. The non-response rate among these families was, in comparison to families with a relatively high level of parental education, much higher. Perhaps the detailed information packages distributed were responsible for this difference. Parents with lower educational backgrounds may have lower verbal capacities and this may have, in turn, inhibited parents' ability to read and complete these packages. However, because researchers are ethically obligated to inform participants and their parents as fully as possible about the intention, content, and implications of the study, it is unlikely that less detailed packages could be provided. Future research could attempt to include more children with lower parental level of education by organizing information sessions at the school or community centers. Here, information packages could be presented verbally and questions could be answered directly.

On the other hand, it is also possible that the relationship found between accuracy of complex language comprehension and parental level of education reflects a specific association in school aged children. Perhaps, highly educated parents use more abstract language in daily communication and thus train their children to formulate their oral responses in this way. In other words, children with highly educated parents may have an advantage over children from backgrounds with a lower level of parental education when it comes to understanding complex language that requires an oral response. In this con- 
text, it is interesting to note that a higher parental level of education is also associated with shared parent-child book reading in young children as this is known to improve language acquisition (Karrass \& Braungart-Rieker, 2005; Raikes et al., 2006). Such relationships are not static. Effective treatment programs that endeavor to improve the language acquisition of low income children by increasing the amount of literacy activities do exist (Weitzman, Roy, Walls, \& Tomlin, 2004). These treatment programs are thought be successful because they provide children with focused language experience that tends to be similar in quality to those normally experienced by children from more educated families (Raikes et al., 2006). The specific nature of the relationship between parental level of education and language use in older children remains unknown and is therefore worthy of further investigation.

With respect to the influence of sex on cognitive development, our expectation was that the relationship between cognitive and motor performance would be more pronounced in boys than in girls (American Psychiatric Association, 1994; Dewey, Kaplan, Crawford, \& Wilson, 2002). This hypothesis was not confirmed. After controlling for attention, it was found that the relationship between general cognitive performance and motor performance was still present in girls but not in boys. In addition, an association between verbal fluency and quantity of motor performance occurred only in boys, while an association between working memory and motor performance occurred only in girls. Thus, the relationship between cognitive and motor performance is of a similar strength for five to six year old boys and girls. However, there is a difference with respect to the specific cognitive functions that are associated with motor performance.

In the studies that investigated cognitive development, girls performed better than boys on the sense of time questionnaire (chapter 5). They also comprehended complex language faster but did not display more accuracy (chapter 7 ). In contrast, no differences between the performance of boys and girls were found on a selective attention task (chapter 3). It is possible that girls have an advantage over boys with respect to verbal tasks and that this may explain the findings reported above. More specifically, the sense of time questionnaire was conducted verbally (chapter 5) and complex language comprehension was also measured using verbal tasks (chapter 7 ). Earlier studies have demonstrated that girls ave an advantage over boys when it comes to verbal ability and that boys have an advantage over girls when it comes to spatial ability (Dodd, Holm, Hua, \& Crosbie, 2003; Holm, Greaker, \& Stromberg, 2002; Lowe, Mayfield, \& Reynolds, 2003; Overman, 2004; Roulstone, Loader, Northstone, \& Beveridge, 2002; Tse, Kwong, Chan, \& Hui, 2002). However, recent views on these advantages tend to be slightly more nuanced than before as the actual performance differences are often small and taskspecific (P. Anderson, 2002; Spelke, 2005). Cognitive differences between males and females are often explained by biological differences, such as sex hormones, or by environmental differences, such as differential rearing practices, educational strategies and performance expectations (Spelke, 2005). In summary, the results of this dissertation seem to correspond with the view that, with respect to verbal aspects of cognitive development, girls do have an advantage over boys.

\section{Conclusions}

Cognitive development is a complex and differential process that continues into adolescence or even early adulthood. It is an important field of study because of the implications research can have on the practice of education. The complete development and 
maturation of the functions described in this dissertation was reached somewhere between the second and the seventh grade. These results correspond with Peter Anderson's (2002) model of executive functioning and extend the model considerably to include other cognitive processes that are relevant for clinical and educational practice. Future research should focus on the emotional, social, and affective aspects of cognitive developments, as an increased improvement on these aspects is expected (e.g. risk taking; Steinberg, 2005). The contextual inter-individual differences in cognitive development are large and, as such, important to consider both in scientific research and in the practice of educational. Most importantly, attention was found to be a moderator of cognitive development, both in normally developing children and in children with ADHD. The results of the studies described in this dissertation emphasize the need for better attention treatment programs that are beneficial for children with sub-clinical and clinical attention deficits. In addition, the need to improve treatment for children with attention difficulties is highlighted, as their problems are heterogeneous and unlikely to resolve on their own. Further, the need for the development of neuropsychological treatment programs that focus on cognitive improvement is stressed. These programs should focus in particular on complex language comprehension. Evidently, what this dissertation has shown is that: a) cognitive functions develop differentially during childhood; and b) cognitive functions are highly influenced by attentional functioning. 


\section{References}

Alvarez, J. A., \& Emory, E. (2006). Executive function and the frontal lobes: a meta-analytic review. Neuropsychology Review, 16, 17-42.

American Psychiatric Association. (1994). Diagnostic and statistical manual of mental disorders (4th ed.). Washington, DC: American Psychiatric Association.

Anderson, P. (2002). Assessment and development of executive function (EF) during childhood. Child Neuropsychology, 8, 71-82.

Anderson, V. A., Anderson, P., Northam, E., Jacobs, R., \& Catroppa, C. (2001). Development of executive functions through late childhood and adolescence in an Australian sample. Developmental Neuropsychology, 20, 385-406.

Barkley, R. A. (1997). Behavioral inhibition, sustained attention, and executive functions: constructing a unifying theory of ADHD. Psychological Bulletin, 121, 65-94.

Baron, I. S. (2004). Neuropsychological evaluation of the child. Oxford: University Press.

Bedard, A. C., Ickowicz, A., Logan, G. D., Hogg-Johnson, S., Schachar, R., \& Tannock, R. (2003). Selective inhibition in children with attention-deficit hyperactivity disorder off and on stimulant medication. Journal of Abnormal Child Psychology, 31, 315-327.

Bradley, R. H., \& Corwyn, R. F. (2002). Socioeconomic status and child development. Annual Review of Psychology, 53, 371-399.

Brocki, K. C., \& Bohlin, G. (2004). Executive functions in children aged 6 to 13: a dimensional and developmental study. Developmental Neuropsychology, 26, 571-593.

Bushnell, E.W., \& Boudreau, J.P. (1993). Motor development and the mind: the potential role of motor abilities as a determinant of aspects of perceptual development. Child Development, 64, 1005-1021.

Carte, E. T., Nigg, J. T., \& Hinshaw, S. P. (1996). Neuropsychological functioning, motor speed, and language processing in boys with and without ADHD. Journal of Abnormal Child Psychology, 24, 481-498.

Casey, B. J., Giedd, J. N., \& Thomas, K. M. (2000). Structural and functional brain development and its relation to cognitive development. Biological Psychology, 54, 241-257.

Casey, B. J., Tottenham, N., Liston, C., \& Durston, S. (2005). Imaging the developing brain: what have we learned about cognitive development? Trends in Cognitive Science, 9, 104-110.

Castellanos, F. X., Lee, P. P., Sharp, W., Jeffries, N. O., Greenstein, D. K., Clasen, L. S., Blumenthal, J. D., James, R. S., Ebens, C. L., Walter, J. M., Zijdenbos, A., Evans, A. C., Giedd, J. N., \& Rapoport, J. L. (2002). Developmental trajectories of brain volume abnormalities in children and adolescents with attention-deficit/hyperactivity disorder. Journal of the American Medical Association, 288, 1740-1748.

Charach, A., Figueroa, M., Chen, S., Ickowicz, A., \& Schachar, R. (2006). Stimulant treatment over 5 years: effects on growth. Journal of the American Academy of Child and Adolescent Psychiatry, 45, 415-421.

Chhabildas, N., Pennington, B. F., \& Willcutt, E. G. (2001). A comparison of the neuropsychological profiles of the DSM-IV subtypes of ADHD. Journal of Abnormal Child Psychology, 29, 529-540.

Churchland, P.S. (1986). Neurophilosophy: toward a unified science of the mind-brain. Boston: MIT Press.

Churchland, P.S. (2002). Brain-wise. Studies in neurophilosophy. Cambridge, Massachusett: MIT Press.

Cooley, E. L., \& Morris, R. D. (1990). Attention in children: A neuropsychologically based model for assessment. Developmental Neuropsychology, 6, 239-274.

Crone, E. (2004). Het brein in ontwikkeling: consequenties voor zelfregulatie [Brain in development: consequences for self regulation]. Neuropraxis, 5, 131-137.

Dewey, D., Kaplan, B. J., Crawford, S. G., \& Wilson, B. N. (2002). Developmental coordination disorder: associated problems in attention, learning, and psychosocial adjustment. Human Movement Science, 21, 905-918.

Dodd, B., Holm, A., Hua, Z., \& Crosbie, S. (2003). Phonological development: a normative study of British English-speaking children. Clinical Linguistics and Phonetics, 17, 617-643. 
Durston, S., Davidson, M. C., Tottenham, N., Galvan, A., Spicer, J., Fossella, J. A., \& Casey, B. J. (2006). A shift from diffuse to focal cortical activity with development. Developmental Science, 9, 1-8.

Ernst, M., Nelson, E. E., Jazbec, S., McClure, E. B., Monk, C. S., Leibenluft, E., Blair, J., \& Pine, D. S. (2005). Amygdala and nucleus accumbens in responses to receipt and omission of gains in adults and adolescents. Neuroimage, 25, 1279-1291.

Eslinger, P. J., Flaherty-Craig, C. V., \& Benton, A. L. (2004). Developmental outcomes after early prefrontal cortex damage. Brain and Cognition, 55, 84-103.

Fuster, J. M. (2000). Executive frontal functions. Experimental Brain Research, 133, 66-70.

Giedd, J. N., Blumenthal, J., Jeffries, N. O., Castellanos, F. X., Liu, H., Zijdenbos, A., Paus, T., Evans, A. C., \& Rapoport, J. L. (1999). Brain development during childhood and adolescence: a longitudinal MRI study. Nature Neuroscience, 2, 861-863.

Gogtay, N., Giedd, J. N., Lusk, L., Hayaski, K. M., Greenstein, D., Vaituzis, A. C., Nugent, T. F. 3rd, Herman, D. H., Clasen, L. S., Toga, A. W., Rapoport, J. L., \& Thompson, P. M. (2004). Dynamic mapping of human cortical development during childhood through early adulthood. Proceedings of the National Academy of the Sciences, 101, 8174-8179.

Gordon, M., Antshel, K., Faraone, S., Barkley, R., Lewandowski, L., Hudziak, J. J., Biederman, J., \& Cunningham, C. (2006). Symptoms versus impairment: the case for respecting DSM-IV's Criterion D. Journal of Attention Disorders, 9, 465-475.

Greenberg, M. T., Lengua, L. J., Coie, J. D., \& Pinderhughes, E. E. (1999). Predicting developmental outcomes at school entry using a multiple-risk model: four American communities. The Conduct Problems Prevention Research Group. Developmental Psychology, 35, 403-417.

Greenhill, L., Beyer, D. H., Finkleson, J., Shaffer, D., Biederman, J., Conners, C. K., Gillberg, C., Huss, M., Jensen, P., Kennedy, J. L., Klein, R., Rapoport, J., Sagvolden, T., Spencer, T., Swanson, J. M., \& Volkow, N. (2002). Guidelines and algorithms for the use of methylphenidate in children with Attention-Deficit/ Hyperactivity Disorder. Journal of Attention Disorders, 6, S89-100.

Hale, S. (1990). A global developmental trend in cognitive processing speed. Child Development, $61,653-663$.

Hoff, E. (2003). The specificity of environmental influence: socioeconomic status affects early vocabulary development via maternal speech. Child Development, 74, 1368-1378.

Holm, O., Greaker, E., \& Stromberg, A. (2002). Experiences of longing in Norwegian and Swedish 4- and 5-year-old children. Journal of Psychology, 136, 608-612.

Hooper, C. J., Luciana, M., Conklin, H. M., \& Yarger, R. S. (2004). Adolescents' performance on the lowa Gambling Task: implications for the development of decision making and ventromedial prefrontal cortex. Developmental Psychology, 40, 1148-1158.

Huda, S. N., Grantham-McGregor, S. M., Rahman, K. M., \& Tomkins, A. (1999). Biochemical hypothyroidism secondary to iodine deficiency is associated with poor school achievement and cognition in Bangladeshi children. Journal of Nutrition, 129, 980-987.

Jackson, A. P. (2003). The effects of family and neighborhood characteristics on the behavioral and cognitive development of poor Black children: a longitudinal study. American Journal of Community Psychology, 32, 175-186.

Kail, R. (1991). Developmental change in speed of processing during childhood and adolescence. Psychological Bulletin, 109, 490-501.

Kail, R. (1996). Nature and consequences of developmental change in speed of processing. Swiss Journal of Psychology, 55, 133-138.

Kail, R. (2000). Speed of information processing: Developmental change and links to intelligence. Journal of School Psychology, 38, 51-61.

Kalff, A. C., De Sonneville, L. M., Hurks, P. P., Hendriksen, J. G., Kroes, M., Feron, F. J., Steyaert, J., Van Zeben, T. M., Vles, J. S., \& Jolles, J. (2005). Speed, speed variability, and accuracy of information processing in 5 to 6 -year-old children at risk of ADHD. Journal of the International Neuropsychological Society, 11, 173-183.

Karrass, J., \& Braungart-Rieker, J. M. (2005). Effects of shared parent-infant book reading on early language acquisition. Applied Developmental Psychology, 26, 133-148. 
Kipp, K. (2005). A developmental perspective on the measurement of cognitive deficits in attentiondeficit/ hyperactivity disorder. Biological Psychiatry, 57, 1256-1260.

Klingberg, T., Fernell, E., Olesen, P. J., Johnson, M., Gustafsson, P., Dahlstrom, K., Gillberg, C. G., Forssberg, H., \& Westerberg, H. (2005). Computerized training of working memory in children with ADHD--a randomized, controlled trial. Journal of the American Academy of Child and Adolescent Psychiatry, 44, 177-186.

Klingberg, T., Forssberg, H., \& Westerberg, H. (2002). Training of working memory in children with ADHD. Journal of Clinical and Experimental Neuropsychology, 24, 781-791.

Klingberg, T., Vaidya, C. J., Gabrieli, J. D., Moseley, M. E., \& Hedehus, M. (1999). Myelination and organization of the frontal white matter in children: a diffusion tensor MRI study. NeuroReport, 10, 2817-2821.

Kuhn, D. (2006). Do cognitive changes accompany developments in the adolescent brain? Perspectives on Psychological Science, 1, 59-67.

Landry, S. H., Smith, K. E., \& Swank, P. R. (2002). Environmental effects on language development in normal and high-risk child populations. Seminars in Pediatric Neurology, 9, 192-200.

Lehnung, M., Leplow, B., Ekroll, V., Herzog, A., Mehdorn, M., \& Ferstl, R. (2003). The role of locomotion in the acquisition and transfer of spatial knowledge in children. Scandinavian Journal of Psychology, 44, 79-86.

Lehto, J. E., Juujarvi, P., Kooistra, L., \& Pulkinnen, L. (2003). Dimensions of executive functioning: Evidence from children. British Journal of Developmental Psychology, 21, 59-80.

Lezak, M. D., Howieson, D. B., \& Loring, D. W. (2004). Neuropsychological assessment (4th ed.). New York: Oxford University press.

Lowe, P. A., Mayfield, J. W., \& Reynolds, C. R. (2003). Gender differences in memory test performance among children and adolescents. Archives of Clinical Neuropsychology, 18, 865-878.

Luna, B., Garver, K. E., Urban, T. A., Lazar, N. A., \& Sweeney, J. A. (2004). Maturation of cognitive processes from late childhood to adulthood. Child Development, 75, 1357-1372.

Odhuba, R. A., van den Broek, M. D., \& Johns, L. C. (2005). Ecological validity of measures of executive functioning. British Journal of Clinical Psychology, 44, 269-278.

Overman, W. H. (2004). Sex differences in early childhood, adolescence, and adulthood on cognitive tasks that rely on orbital prefrontal cortex. Brain and Cognition, 55, 134-147.

Paus, T. (2005). Mapping brain maturation and cognitive development during adolescence. Trends in Cognitive Science, 9, 60-68.

Penkman, L. (2004). Remediation of attention deficits in children: a focus on childhood cancer, traumatic brain injury and attention deficit disorder. Pediatric Rehabilitation, 7, 111-123.

Pennington, B. F., \& Ozonoff, S. (1996). Executive functions and developmental psychopathology. Journal of Child Psychology and Psychiatry, 37, 51-87.

Piaget, J., \& Inhelder, B. (1966). La psychologie de l'enfant [The psychology of the child]. Paris: Presses Universitaires de France.

Raikes, H., Luze, G., Brooks-Gunn, J., Raikes, H. A., Pan, B. A., Tamis-LeMonda, C. S., Constantine, J., Tarullo, . B., \& Rodriguez, E. T. (2006). Mother-child bookreading in low-income families: Correlates and outcomes during the first three years of life. Child Development, 77, 924953.

Rapoport, J. L., \& Inoff-Germain, G. (2002). Responses to methylphenidate in AttentionDeficit/Hyperactivity Disorder and normal children: update 2002. Journal of Attention Disorders, 6, S57-60.

Roberts, E., Bornstein, M. H., Slater, A. M., \& Barrett, J. (1999). Early cognitive development and parental education. Infant and Child Development, 8, 49-62.

Roulstone, S., Loader, S., Northstone, K., \& Beveridge, M. (2002). The speech and language of children aged 25 months: Descriptive data from the Avon Longitudinal Study of Parents and Children. Early Child Development and Care, 172, 259-268.

Rueda, M. R., Rothbart, M. K., McCandliss, B. D., Saccomanno, L., \& Posner, M. I. (2005). Training, maturation, and genetic influences on the development of executive attention. Proceedings of the National Academy of the Sciences, 102, 14931-14936. 
Salthouse, T. A. (2000). Methodological assumptions in cognitive aging research. In: F. I. Craik \& T. A. Salthouse (Eds), The handbook of aging and cognition (2nd ed.). Mahwah, NJ: Lawrence Erlbaum Associates.

Shaw, P., Greenstein, D., Lerch, J., Clasen, L., Lenroot, R., Gogtay, N., Evans, A., Rapoport, J., \& Giedd, J. (2006). Intellectual ability and cortical development in children and adolescents. Nature, 440, 676-679.

Steinberg, L. (2005). Cognitive and affective development in adolescence. Trends in Cognitive Science, 9, 69-74.

Sowell, E. R., Peterson, B. S., Thompson, P. M., Welcome, S. E., Henkenius, A. L., \& Toga, A. W. (2003). Mapping cortical change across the human life span. Nature Neuroscience, 6, 309315.

Spelke, E. S. (2005). Sex differences in intrinsic aptitude for mathematics and science? A critical review. American Psychologist, 60, 950-958.

Tannock, R. (2003). Neuropsychology of attention disorders. In: S. J. Segalowitz. \& I. Rapin. (Eds.), Handbook of neuropsychology (2nd ed., pp. 753-784). Amsterdam: Elsevier Science B.V.

Thatcher, R. W. (1991). Maturation of the human frontal lobes: Physiological evidence for staging. Developmental Neuropsychology, 7, 397-419.

Tse, S. K., Kwong, S. M., Chan, C., \& Hui, L. (2002). Sex differences in syntactic development: evidence from Cantonese-speaking preschoolers in Hong Kong. International Journal of Behavioral Development, 26, 509-517.

Turkheimer, E., Haley, A., Waldron, M., D'Onofrio, B., \& Gottesman, II. (2003). Socioeconomic status modifies heritability of IQ in young children. Psychological Science, 14, 623-628.

Weitzman, C. C., Roy, L., Walls, T., \& Tomlin, R. (2004). More evidence for reach out and read: a home-based study. Pediatrics, 113, 1248-1253.

Zachor, D. A., Roberts, A. W., Hodgens, J. B., Isaacs, J. S., \& Merrick, J. (2006). Effects of longterm psychostimulant medication on growth of children with ADHD. Research in Developmental Disabilities, 27, 162-174.

Zelazo, P. D., Craik, F. I., \& Booth, L. (2004). Executive function across the life span. Acta Psychologica, 115, 167-183. 

SUMMARY 
Cognitive development is a complex process that continues into adolescence and is characterized by variability. The specific pattern by which many cognitive functions develop is not entirely clear nor is the extent to which inter-individual differences influence this development. Knowing how normal cognitive development occurs may enable us to detect cognitive weaknesses earlier and more optimally so that we can reduce these weaknesses using cognitive strengths. Therefore, the central goal of this dissertation was to extend Peter Anderson's (2002) model of executive functioning by, firstly, describing age-related improvement on several complex cognitive functions in children aged five to sixteen, and, secondly, determining the influence of inter-individual differences. The complex cognitive functions studied were chosen because of their importance for children's daily functioning. These functions included subcomponents of sense of time, complex language comprehension, and selective attention. Questions that were addressed were: a) at which age are the different cognitive functions fully matured?; b) does this vary between children with and without attention deficits?; and c) do sex and parental level of education influence cognitive development and, if so, how?. Several large-scale cross-sectional studies and one longitudinal study were conducted to achieve this central goal. With respect to the study samples, the number of participants varied from several tens to several hundreds of children. Additionally, the age range in the studies conducted was five to sixteen years.

Chapter 1 explains the rationale for the studies described in this dissertation. As cognitive development has implications for academic functioning, knowing how normal cognitive development, with all its variability, occurs is imperative. Additionally, it is important to know which factors contribute to this development. The term 'executive functioning' is described, as is the model proposed by Peter Anderson (2002). This model is used as the foundation for the studies reported in this dissertation because it takes the developmental perspective of executive functioning into account. The model conceptualizes executive functioning as four discrete cognitive domains that operate in an integrative manner. One domain, namely attention control, is thought to be completely developed somewhere between the ages of nine and eleven, while the other three domains, namely information processing, cognitive flexibility, and goal setting, are hypothesized to improve approximately until the age of fifteen (Anderson, 2002). Following the description of the model, the influence of three important inter-individual variables, namely attention, parental level of education, and sex, on cognitive development and the uncertainties related to their potential impact are discussed. Chapter 1 is concluded with, firstly, a statement in which the central goal of the dissertation is conveyed and, secondly, an overview of the remaining chapters.

Chapter 2 describes the results of a large-scale cross-sectional study that focused on the relationship between cognitive and motor performance in children attending normal kindergarten. General and more specific relationships between several domains of cognition (e.g. language, visuoperception, construction, attention, and executive functioning) and quality and quantity of motor performance were studied. A sample of 378 children aged five to six attending normal kindergarten was included in the study. Half of these children had no behavior problems, while the remainder was selected for externalizing $(38 \%)$ or internalizing problems $(12 \%)$, as determined by the Child Behavior Checklist 
(CBCL) (Achenbach, 1991). Inter-individual differences in the relationship between motor and cognitive performance, such as sex and attention, were studied as well.

Attention was found to be a strong mediator of the overall relationship between cognitive and motor performance. When the effect of attention was partialled out, positive linear relationships between an estimate of general cognitive performance and total and qualitative aspects of motor performance remained. However, the associations found were rather small and, when only cognitive tasks without a motor component were included in the estimate of cognitive performance, no significant association with motor performance was found. This finding conflicts with the notion that a global relationship between cognitive and motor performance exists. Instead, specific positive associations were found between quantity and quality of motor performance, visual motor integration and working memory, and between quantitative aspects of motor performance and verbal fluency. The strength of the relationship between cognitive and motor performance was similar for boys and girls but differences were found regarding the specific cognitive functions associated with motor performance.

In short, several aspects of complex cognitive and general motor performance in five to six year old children appear to fall on a continuum, ranging from children who perform well on both cognitive and motor tasks, to those who perform at an average level to those who perform poorly on both types of tasks. These findings reveal interesting parallels between normal cognitive and motor development in five to six year old children that cannot be attributed to attentional process.

Chapter 3 examines the developmental pattern of three subcomponents of selective attention. The subcomponents studied were inattention, impulsivity, and processing speed. Performance was expected to be optimal by ten years of age. Inter-individual differences (sex, parental level of education and behavior ratings of attention problems) in the development of selective attention were studied as well. In addition, the level of verbal ability was controlled for in the analyses. Selective attention was measured using the d2 Test of attention (Brickenkamp \& Zillmer, 1998). The sample included 451 Dutch schoolchildren attending the second to the sixth grade of normal elementary school.

The results of this study indicated a differential development of the three aspects of selective attention. The largest age differences were found for processing speed. This function was found to improve until the sixth grade, which was considerably longer than expected. Impulsivity, as measured by the percentage of commission errors, decreased until the fourth grade. Inattention, as measured by the percentage of omission errors, was stable in all grades. These findings are described in the context of Peter Anderson's (2002) model.

With regard to the influence of inter-individual variables on the development of selective attention, no effects were found for sex, parental level of education, or verbal ability. In contrast, attention deficits in daily life, as measured by the score the Attention Problems subscale of the CBCL (Achenbach, 1991), correlated significantly with processing speed and impulsivity according to the $\mathrm{d} 2$ Test. The results clearly indicated that children with more attention problems in daily life performed slower and made more errors due to impulsivity. This confirms the ecological validity of the d2 Test of Attention. These findings are discussed in the context of contradictory findings for children with Attention Deficit Hyperactivity Disorder (ADHD). In conclusion, the results imply that 
selective attention is a differential process that continues to develop until the end of elementary school and perhaps even later.

Chapter 4 presents the results of a longitudinal study that investigated the predictive value of attention in kindergarten and the first grade for academic outcome in the sixth grade. This is an important area of research as children who succeed in school tend to also succeed in other aspects of life (Durlak, 2001). To our knowledge, no similar longterm follow-up studies have been reported. Attention was measured using tests (e.g. selective, sustained, attention span) and behavioral ratings of attention problems. The following domains of academic outcome were investigated: total academic achievement $(N=147)$, language, mathematics, study skills $(N=133)$, and world orientation $(N=$ 117). Inter-individual differences (sex, parental level of education, verbal intelligence, and having repeated a grade or not) were controlled for in the analyses of academic outcome.

The results indicated that the influence of attention on academic outcome was highly significant. Attention test scores explained $29 \%$ of the variance of the total score on a standardized academic test, $26 \%$ of the variance in arithmetic/mathematics, and $25 \%$ of the variance in language. World orientation was the academic domain on which attention measures predicted outcome only minimally.

Performance on attention tests measuring working memory and selective attention correlated best with academic outcome. Behavioral ratings of attention problems were also found to be involved in the prediction of academic outcome, although their predictive value was weaker than that of attention tests. Only higher scores on an ADHD precursor questionnaire significantly predicted lower levels for study skills and mathematics. No general relationship between characteristics or precursors of ADHD in kindergarten and academic outcome in the sixth grade was found. Rather, there appeared to be a more specific association between inattention and some aspects of academic outcome.

In conclusion, the results suggest that attention is strongly related to academic outcome in children attending elementary schools. Additionally, the study shows that both cognitive tests and behavioral ratings of attention problems are important factors to consider when predicting academic outcome of relatively young children. Clearly, the findings of this study may improve our ability to detect, at an earlier age, children at risk for negative academic outcome.

Chapter 5 describes the results of a cross-sectional study that investigated the development of sense of time. A new questionnaire, namely the Children's Time Estimation Questionnaire (CTAQ), was developed for this study. This questionnaire was intended to measure different aspects of sense of time, such as estimation and knowledge of the order of days and months. In addition, the CTAQ aimed to measure sense of time in an ecologically valid way by creating test items that refer to events that are familiar to children. Inter-individual differences in the development of sense of time, namely sex and parental level of education, were studied as well. In addition, level of verbal ability was controlled for in the analysis. The CTAQ was completed by 248 adults to determine the matured level of responses for each item. Following this, 454 children attending the second through the sixth grade of normal elementary school completed the test.

Five aspects of sense of time could be distinguished using the CTAQ. These factors were termed a) duration comparisons (concerning which of two time units takes longer, 
e.g. an afternoon or a week); b) events with a clear time component (concerning the duration of events discussed in daily life, e.g. the time a control visit to the dentists takes); c) events without a clear time component (concerning the duration of events that are probably not regularly discussed, e.g. the time it takes to drink a glass of lemonade); d) life expectancy (concerning how long dogs and humans live); and e) sequential arrangement of months and days (concerning knowledge of the order of days and months). The ability to estimate life expectancy and to arrange months and days sequentially developed later than the other three factors. While the other three factors were fully developed by the second or third grade, the ability to estimate life expectancy and arrange months and days reached full maturity only in the fourth grade. This indicates that sense of time develops differentially in school children.

This study confirmed our hypothesis that concrete aspects of sense of time reach maturity at an earlier age than more abstract aspects. With respect to the influence of inter-individual variables on the development of sense of time, girls performed better than boys on three of the factors. No influence of parental level of education on any aspect of sense of time was found, which could possibly be explained by the fact that only a small number of children with a low parental education level were included in the study. Children with an enhanced verbal ability performed better on three aspects of sense of time. This may suggest that general ability develops parallel to aspects of sense of time. In conclusion, we contend that the CTAQ appears to be a promising instrument for the measurement of sense of time since it can be administered, in a short period of time, to groups and individuals alike.

Chapter 6 presents the results of a cross-sectional study that investigated school aged children's ability to comprehend complex sentences. The aim of this study was to determine whether the ability to comprehend complex sentences is fully developed by the end of elementary school. A total of 83 children were categorized in one of three age-groups, namely children attending kindergarten or the first grade, children enrolled in the second or third grade, and children attending the fourth, fifth or sixth grade. Language comprehension was measured according to the neuropsychological procedure proposed by Luria (1966, 1980; see also Christensen, 1993). An example of the sentences studied is: "Who is fairest if Olga is fairer than Kate, but darker than Sonia?" Children who answered $85 \%$ or more of the complex sentences correctly were considered to have mastered this function. Levels of short-term and working memory were controlled in the evaluation of language comprehension.

The results indicated that comprehension of simple instructions was mastered in the youngest age-group (e.g. "Which is correct: 'spring comes before summer' or 'summer comes before spring'?"), whereas some logical grammatical structures were only mastered in the second or third grade (e.g. "I had breakfast after I had walked the dog. What did I do first?"). Other logical grammatical structures were too difficult to comprehend; even for the oldest children (e.g. "Is my father's brother the same person as my brother's father?"). Short-term memory and working memory were found to be related to language comprehension but did not account for the age differences found.

In conclusion, we contend that complex language comprehension develops differentially. The most complex logical grammatical structures were not mastered by the end of elementary school, which indicates that children in secondary school may be less able to deal with multifaceted questions and tasks than we normally expect. 
Chapter 7 describes a study that can be considered a continuation of the study on complex language comprehension described in chapter 6 . This chapter reports the results of a much larger cross-sectional study in which the ability to comprehend complex language was investigated in 361 children attending kindergarten through to the eighth grade. Language comprehension was measured using both the neuropsychological procedure proposed by Luria and an adapted version of the Token Test (Lezak, Howieson, \& Loring, 2004). Inter-individual differences (sex and parental level of education) in the development of complex language comprehension were studied as well. In addition, level of verbal ability and short-term memory were controlled for in the analyses.

Perfect language comprehension was not reached in the age period studied. The findings indicated that the most complex sentences were not comprehended by all eighth graders meaning that the complex sentences were too difficult for 14 year old adolescents. Accuracy of language comprehension continued to develop until the sixth grade, whereas the speed of language comprehension continued to improve up until the seventh grade. We thus conclude that complex language comprehension in children is not fully developed until early adolescence. This finding corresponds with the study reported in chapter 6 . We further contend that, with respect to measuring developmental differences, the speed of complex language comprehension appears to be more sensitive than accuracy.

With regard to the influence of inter-individual variables on the development of complex language comprehension, we found that girls performed faster than boys on one of the tasks. No influence of sex was found for the accuracy of language comprehension. In other words, boys and girls were equally able to understand complex sentences but girls were faster when it came to providing the correct answer. We also found that children with a high parental education level had an advantage over children from low or moderate educational backgrounds with respect to accuracy on one of the tasks. Children with a larger memory span comprehended the complex sentences faster, but not more accurately, than children with a smaller memory span. In conclusion, we contend that complex language comprehension is a higher-order cognitive function that continues to develop until early adolescence.

Chapter 8 can be seen as a continuation of our investigation regarding the influence of inter-individual differences on the development of complex language comprehension. This chapter examines the influence of attention on this function by comparing the performance of children and adolescents with and without ADHD combined subtype (ADHDC). We expected complex language comprehension to be disturbed in individuals with ADHD-C because language is related to self-control and self-control has been found to be disturbed in individuals with ADHD-C (Andreou, Agapitou, \& Karapetsas, 2005; Barkley, 1997). The second aim of the study was to investigate the possibility of agerelated differences in complex sentence comprehension in individuals with ADHD-C, to determine whether this function in ADHD is reflective of a developmental delay or a permanent disability (Biederman et al., 2006).

Children aged eleven or younger $(\mathrm{N}=15)$ and adolescents aged twelve or older $(\mathrm{N}=$ 15) with ADHD-C were matched to normally developing control children for age, sex, and parental level of education. In addition, levels of short-term memory, verbal ability and comorbid dyslexia were controlled for in the analysis. Accuracy and speed of language comprehension were investigated using the same instruments described in chapter 7. 
The results indicated that, when compared to control subjects, children and adolescents with ADHD-C performed significantly slower on the language comprehension tasks. Accuracy was only modestly affected by the presence of ADHD-C. There was no interaction between age and ADHD-C. Clearly, these results imply that the comprehension of complex sentences in both children and adolescents with ADHD-C is characterized by a decrease in speed and efficiency. This finding is important for the teachers, parents, and professionals that interact with children diagnosed with ADHD-C, regardless of the child's age. Those that deal with children bear in mind that children and adolescents with ADHD-Ccomprehend language at a slower rate and should thus adapt their behavior accordingly.

Chapter 9 combines the findings of the experimental studies described in this dissertation by discussing the results of the studies on a more theoretical level. As expected, the pattern that emerged from the studies is that cognitive development occurs differentially in terms of function during childhood. Large developmental differences were found for various cognitive functions and subcomponents of these functions. Complete development was attained somewhere between the second and the seventh grade, dependent on the function. The theoretical implications of these findings are discussed in the context of their contribution to the executive functioning model proposed by Peter Anderson (2002). The developmental trajectories found in this dissertation were added to Peter Anderson's model so that an orderly pattern of the various functions could be derived.

With respect to the inter-individual differences in cognitive development, attention was found to be an important moderator of cognitive development. This implies that attentional functioning in normally developing children should receive more consideration from both scientists and professionals working in education. In addition, the results of the studies described in this dissertation emphasize the need to develop better treatment for children with attention difficulties, as their problems are heterogeneous and unlikely to resolve on their own. Treatment programs should focus on improving specific aspects of cognition, e.g. complex language comprehension.

The other inter-individual differences considered here, namely sex and parental level of education, showed a less consistent influence on the cognitive functions studied. With respect to the influence of sex, we found that girls performed better than boys on verbal tasks. With respect to the parental level of education, we found that children from highly educated families tended to have an advantage over other children on some of the functions studied. In conclusion, as a whole, the studies described in this dissertation indicate that cognitive development continues into early adolescence and is influenced by interindividual factors. 


\section{References}

Achenbach, T. M. (1991). Manual for the Child Behavior Checklist/4-18 and 1991 Profile. Burlington: University of Vermont Department of Psychiatry.

Anderson, P. (2002). Assessment and development of executive function (EF) during childhood. Child Neuropsychology, 8, 71-82

Andreou, G., Agapitou, P., \& Karapetsas, A. (2005). Verbal skills in children with ADHD. European Journal of Special Needs Education, 20, 231-238.

Barkley, R. A. (1997). Behavioral inhibition, sustained attention, and executive functions: constructing a unifying theory of ADHD. Psychological Bulletin, 121, 65-94.

Biederman, J., Monuteaux, M. C., Mick, E., Spencer, T., Wilens, T. E., Silva, J. M., Snyder, L. E., \& Faraone, S. V. (2006). Young adult outcome of attention deficit hyperactivity disorder: a controlled 10-year follow-up study. Psychological Medicine, 36, 167-179.

Brickenkamp, R., \& Zillmer, E. (1998). The d2 Test of attention. First US Edition. Göttingen: Hogrefe \& Huber Publishers.

Christensen, A-L. (1993). Luria's neuropsychological investigation text. Risskov, Denmark: P. J. Schmidts Bogtrykkeri, Vojens.

Durlak, J. (2001). School problems in children. In: M. C. Roberts (Ed.), Handbook of clinical child psychology (3rd ed.). New York: John Wiley \& Sons, Inc.

Lezak, M. D., Howieson, D. B., \& Loring, D. W. (2004). Neuropsychological assessment (4th ed.). New York: Oxford University press.

Luria, A. R. (1966). Higher cortical functions in man. New York: Basic Books

Luria, A. R. (1980). Higher cortical functions in man. New York: Basic Books. 
SAMENVATTING 
Cognitieve ontwikkeling is een complex proces dat gekarakteriseerd wordt door variabiliteit en doorgaat tot in de adolescentie. Met name complexe cognitieve functies, ook wel executieve functies genoemd, hebben de laatste tijd veel aandacht gekregen in de literatuur. Het specifieke patroon van ontwikkeling van veel cognitieve functies is echter nog niet duidelijk en ook de invloed van interindividuele verschillen, zoals geslacht, op deze ontwikkeling is nog onbekend. Het is belangrijk om te weten hoe de normale cognitieve ontwikkeling verloopt, omdat op deze manier cognitieve zwaktes beter en vroeger in de ontwikkeling ontdekt kunnen worden. Het doel van dit proefschrift was dan ook om het model van Peter Anderson (2002) over executief functioneren uit te breiden door de leeftijdsverschillen op enkele complexe cognitieve functies te beschrijven. Deze complexe cognitieve functies, die belangrijk zijn voor het dagelijks functioneren, werden onderzocht in kinderen tussen de vijf en zestien jaar. Daarnaast werd de invloed van verschillende interindividuele verschillen op de ontwikkeling van de complexe functies bestudeerd. De volgende complexe cognitieve functies werden onderzocht: tijdsbesef, complex taalbegrip en selectieve aandacht. De volgende vragen werden getoetst in dit proefschrift: 1) Wat is de leeftijd waarop de verschillende complexe cognitieve functies volledig ontwikkeld zijn?, 2) Varieert dit tussen kinderen met en zonder aandachtsproblemen?, en 3) Is er een invloed van geslacht en opleidingsniveau van de ouders op de ontwikkeling van deze complexe cogntieve functies? Om deze vragen te beantwoorden werden verschillende grootschalige crosssectionele en één longitudinale studie uitgevoerd. Elke studie omvatte tientallen tot honderden kinderen in de leeftijd van 5 tot 16 jaar.

Hoofdstuk 1 legt de beweegredenen uit van het onderzoek dat beschreven staat in dit proefschrift. Het is belangrijk om te weten hoe de cognitieve ontwikkeling verloopt omdat dit aanzienlijke implicaties heeft voor andere domeinen van ontwikkeling, zoals schools presteren. Daarnaast kan afwijkende ontwikkeling beter begrepen worden als er meer kennis is over de normale ontwikkeling. Hierbij is het van belang om oog te hebben voor de variabiliteit in cognitieve ontwikkeling. In hoofdstuk 1 wordt de term 'executief functioneren' uitgelegd aan de hand van het model van Peter Anderson (2002). Dit model beschrijft executief functioneren vanuit een ontwikkelingsperspectief en wordt daarom gebruikt als het uitgangspunt van het onderzoek dat beschreven wordt in dit proefschrift. Het model beschrijft executief functioneren als vier aparte cognitieve domeinen die integraal samenwerken. Eén domein, aandachtscontrole, zou al op negen tot elfjarige leeftijd volledig ontwikkeld zijn. De andere drie domeinen zouden zich ontwikkelen tot de leeftijd van vijftien jaar (Anderson, 2002).

Daarnaast wordt in hoofdstuk 1 de invloed van drie interindividuele verschillen op cognitieve ontwikkeling beschreven, namelijk aandacht, opleidingsniveau van de ouders en geslacht, en welke onduidelijkheden hierover bestaan. Hoofdstuk 1 eindigt met de algemene doelstelling van dit proefschrift en een overzicht van de experimentele hoofdstukken.

Hoofdstuk 2 beschrijft de resultaten van een grootschalige cross-sectionele studie naar de relatie tussen cognitieve en motorische prestaties bij kleuters. Zowel de globale relatie tussen deze twee ontwikkelingsgebieden als de specifieke relaties tussen domeinen van cognitie (bijvoorbeeld taal, visuele perceptie en constructie, aandacht en executief functioneren) en domeinen van motoriek (kwaliteit en kwantiteit) werden bestudeerd. De 
studie was gebaseerd op een steekproef van 378 kinderen van vijf en zes jaar die groep 2 van het reguliere basisonderwijs bezochten. De helft van deze kinderen had geen gedragsproblemen, de andere helft werd geselecteerd op de aanwezigheid van externaliserende gedragsproblemen (naar buiten gericht gedrag, 38\%) of internaliserende gedragsproblemen (naar binnen gericht gedrag, 12\%). Deze indeling van gedragsproblemen werd gebaseerd op de door ouders ingevulde gedragsvragenlijst Child Behavior Checklist (CBCL) (Achenbach, 1991). Interindividuele verschillen in de relatie tussen cognitie en motoriek werden bestudeerd in de vorm van geslachtsverschillen en de aanof afwezigheid van aandachtsproblemen.

Aandacht bleek een belangrijke factor te zijn in de algemene relatie tussen cognitie en motoriek. Als er gecontroleerd werd voor het effect van aandacht bleek er een postieve relatie te zijn tussen algemene cognitieve prestaties en algemene motorische vaardigheden. Ook was er een relatie tussen algemene cognitieve prestaties en de kwalitatieve aspecten van motoriek. Echter, deze relaties waren vrij zwak. Indien alleen cognitieve taken zonder een motorische component werden meegenomen in de maat voor algemene cognitieve prestaties werd er geen relatie gevonden met motoriek. Dit betekent dat er geen globale relatie is tussen cognitieve en motorische prestaties bij kleuters. In plaats daarvan werden specifieke relaties gevonden tussen kwantiteit en kwaliteit van motoriek en bepaalde cognitieve maten, namelijk visueel motorische integratie en werkgeheugen. Ook was er een specifieke relatie tussen kwantitatieve aspecten van motoriek en verbale vloeiendheid. De relatie tussen cognitie en motoriek was even sterk bij jongens als bij meisjes, maar er werden wel geslachtsverschillen gevonden in de specifieke cognitieve functies die gerelateerd waren aan motoriek.

Al met al betekent dit dat bepaalde aspecten van cognitie en motoriek bij kleuters op een continuüm liggen. Dit continuüm loopt van kinderen die laag scoren op beide ontwikkelingsdomeinen via kinderen die gemiddeld scoren voor zowel cognitie als motoriek naar kinderen die hoog scoren op beide domeinen. Deze gegevens laten dus zien dat er interessante parallellen in de ontwikkeling van cognitie en motoriek zijn bij kleuters. Deze parallellen kunnen niet verklaard worden door aandachtsprocessen.

Hoofdstuk 3 onderzoekt het ontwikkelingspatroon van drie subcomponenten van selectieve aandacht. Deze subcomponenten zijn onoplettendheid, impulsiviteit en verwerkingssnelheid. De verwachting, gebaseerd op eerder onderzoek, was dat de prestatie op deze subcomponenten optimaal zou zijn op de leeftijd van 10 jaar. Interindividuele verschillen in de ontwikkeling van selectieve aandacht werden bestudeerd in de vorm van geslachtsverschillen, verschillen in opleidingsniveau van de ouders en de aanwezigheid van aandachtsproblemen in het dagelijks leven (gemeten met de CBCL). Selectieve aandacht werd gemeten met de d2 Aandachtstest (Brickenkamp \& Zillmer, 1998). Er werden 451 proefpersonen geïncludeerd in de studie, namelijk kinderen uit groep 4 tot en met groep 8 van het reguliere basisonderwijs.

De resultaten van de studie lieten zien dat er een differentieel ontwikkelingspatroon is voor de drie subcomponenten van selectieve aandacht. De grootste leeftijdsverschillen werden gevonden bij verwerkingssnelheid: deze functie ontwikkelde door tot in groep 8, wat veel langer was dan verwacht. Impulsiviteit, gemeten met het percentage fouten, verminderde tot in groep 4. Onoplettendheid, gemeten met het percentage weglatingen, was stabiel in alle groepen. Deze bevindingen worden in hoofdstuk 3 beschreven in de context van het model van Peter Anderson (2002). 
Met betrekking tot de invloed van interindividuele verschillen op de ontwikkeling van selectieve aandacht werden geen effecten gevonden van geslacht, opleidingsniveau van de ouders en woordenschat. Wel werd een relatie aangetoond tussen verwerkingssnelheid, impulsiviteit en aandachtsproblemen in het dagelijkse leven. De resultaten lieten duidelijk zien dat kinderen met meer aandachtsproblemen in het dagelijkse leven trager werkten op de d2 Aandachtstest en meer impulsieve fouten maakten. De bevindingen worden bediscussieerd in de context van tegengestelde resultaten in kinderen met ADHD. Al met al heeft deze studie laten zien dat selectieve aandacht een differentieel proces is, waarvan bepaalde aspecten ten minste door ontwikkelen tot het einde van de basisschool.

Hoofdstuk 4 presenteert de resultaten van een longitudinale studie naar de voorspellende waarde van aandacht gemeten in groep 2 en 3 voor de schoolprestaties in groep 8. Dit is een belangrijk onderwerp, omdat kinderen die goed presteren op school het vaak ook goed doen in andere levensgebieden (Durlak, 2001). Naar ons beste weten is dit de eerste studie die, over een dergelijk lange periode, het effect van aandacht op schoolprestaties bestudeerd heeft. Aandacht werd gemeten met cognitieve taken (onder andere op het gebied van selectieve en volgehouden aandacht) en met gedragsvragenlijsten. Schoolprestaties werden gemeten met de Cito-eindtoets. De Cito-eindtoets richt zich op de volgende didactische gebieden: totale prestatie $(N=147)$, taal, rekenen en informatieverwerking $(N=133)$ en wereldoriëntatie $(N=117)$. De analyses werden gecontroleerd voor de invloed van interindividuele verschillen zoals geslacht, opleidingsniveau van de ouders, woordenschat en doublures.

De resultaten lieten zien dat de invloed van aandacht op schoolprestaties aanzienlijk is: cognitieve aandachtstaken die in groep 2 afgenomen werden verklaarden $29 \%$ van de variantie in totale schoolprestaties in groep $8,26 \%$ van de variantie in rekenen en $25 \%$ van de variantie in taal. Wereldoriëntatie kon het minst goed voorspeld worden met aandachtsvariabelen. Prestatie op twee cognitieve aandachtstaken hing het beste samen met schoolprestaties, namelijk een werkgeheugentaak en een taak naar selectieve aandacht. Scores op gedragsvragenlijsten waren ook betrokken bij de voorspelling van schoolprestaties, maar niet zo sterk als de prestatie op cognitieve aandachtstests. Alleen een hogere score voor onoplettendheid op een vragenlijst voor voorlopers van ADHD in groep 2 voorspelde lagere scores voor informatieverwerking en rekenen in groep 8.

Concluderend lieten de resultaten van deze studie zien dat aandacht sterk gerelateerd is aan schoolprestaties bij kinderen op het reguliere basisonderwijs. Zowel cognitieve aandachtstests als gedragsvragenlijsten naar aandachtsfunctioneren dragen bij aan de voorspelling van schoolprestaties aan het einde van de basisschool. Deze resultaten hebben directe implicaties voor het op jonge leeftijd opsporen van kinderen met een risico op lage schoolprestaties.

Hoofdstuk 5 beschrijft de resultaten van een cross-sectionele studie naar de ontwikkeling van tijdsbesef. Hiervoor werd een vragenlijst ontwikkeld, de Vragenlijst Tijdsbesef bij Kinderen (VTK). Deze vragenlijst had als doel verschillende aspecten van tijdsbesef te meten, zoals schatting van tijdsduur en kennis van de volgorde van dagen en maanden. De VTK beoogde tijdsbesef op een ecologisch valide manier te meten door vragen te gebruiken die refereren naar gebeurtenissen die bekend zijn voor kinderen. Deze aanpak zou beter aansluiten bij de belevingswereld van het kind dan de traditioneel gebruik- 
te computertaken voor tijdsbesef. Interindividuele verschillen in de ontwikkeling van tijdsbesef werden onderzocht in de vorm van geslachtsverschillen en verschillen in opleidingsniveau van de ouders. De VTK werd ingevuld door 248 volwassenen om de antwoordsleutel voor de vragen vast te stellen. Vervolgens deden 454 kinderen uit groep 2 tot en met 8 van het reguliere basisonderwijs mee aan het onderzoek.

Vijf verschillende aspecten van tijdsbesef konden gemeten worden met de VTK. Deze factoren kregen de volgende namen: vergelijking van tijdseenheden (vragen die nagaan welk van twee tijdseenheden langer duurt, zoals een middag of een week), schatting van gebeurtenissen met een duidelijke tijdscomponent (vragen over gebeurtenissen waarvan de duur regelmatig besproken wordt in het dagelijkse leven, zoals een controlebezoekje aan de tandarts), schatting van gebeurtenissen zonder een duidelijke tijdscomponent (vragen over gebeurtenissen waarvan de duur niet snel besproken zal worden in het dagelijkse leven, zoals het drinken van een glas limonade), schatting van levensverwachting (vragen over de gemiddelde levensduur van mensen en honden) en sequentiële ordening van maanden en dagen (vragen over de kennis van de volgorde van maanden en dagen). Het schatten van de levensverwachting en de kennis om maanden en dagen te ordenen ontwikkelde het langste door, namelijk tot in groep 6. De prestatie op de andere drie aspecten was volledig ontwikkeld in groep 4 of 5 . Dit betekent dat tijdsbesef zich differentieel ontwikkeld in schoolkinderen.

De hypothese dat concrete aspecten van tijdsbesef eerder volledig ontwikkeld zouden zijn dan meer abstracte aspecten werd bevestigd. Interindividuele verschillen in tijdsbesef konden niet worden aangetoond voor opleidingsniveau van de ouders, wat mogelijk verklaard kan worden door het relatief lage aantal kinderen met laagopgeleide ouders. Wel was er een verschil tussen jongens en meisjes op drie aspecten van tijdsbesef. Meisjes presteerden hierop beter dan jongens. Concluderend kunnen we stellen dat de VTK een instrument met potentie is om tijdsbesef te meten in groepen of tijdens individueel onderzoek.

Hoofdstuk 6 presenteert de resultaten van een cross-sectionele studie naar complex taalbegrip in schoolkinderen. Het doel van deze studie was te onderzoeken of grammaticaal complexe zinnen begrepen worden door kinderen aan het einde van de basisschool. In totaal deden 83 kinderen met hoogopgeleide ouders mee aan het onderzoek. Deze kinderen werden verdeeld over drie leeftijdsgroepen aan de hand van hun groep op school, namelijk kinderen uit groep 2 en 3, kinderen uit groep 4 en 5 en kinderen uit groep 6, 7 en 8. Complex taalbegrip werd gemeten met de neuropsychologische aanpak van Luria (1966, 1980; zie ook Christensen, 1993). Een voorbeeld van de gebruikte zinnen is: 'Wie is het blondst als Anja blonder is dan Saskia maar donkerder dan Katja?'. Het taalbegrip van kinderen die $85 \%$ of meer van de complexe zinnen goed beantwoordden werd als volledig ontwikkeld beschouwd. De analyses werden gecontroleerd voor het niveau van korte termijn geheugen en werkgeheugen.

De resultaten gaven aan dat sommige zinnen al in de jongste leeftijdsgroep beheerst werden (bijvoorbeeld 'Pak deze pen, leg hem op de vensterbank en geef mij het potlood dat daar ligt'). Sommige logisch grammaticale structuren werden pas beheerst in de middelste leeftijdsgroep (bijvoorbeeld 'Wie is het kleinst als Jan langer is dan Piet?'). Weer andere complexe zinnen waren te moeilijk om goed te begrijpen, zelfs voor de oudste kinderen (bijvoorbeeld 'Is de vader van mijn broer dezelfde persoon als de broer van mijn vader?'). Hoewel het niveau van korte termijn geheugen en werkgeheugen 
gerelateerd was aan de mate van zinsbegrip, werden de leeftijdsverschillen hier niet door veroorzaakt.

Concluderend heeft deze studie laten zien dat complex taalbegrip zich differentieel ontwikkelt. De meest complexe logische grammaticale structuren worden niet beheerst aan het einde van de basisschool. Dit betekent dat kinderen op het voortgezet onderwijs meer moeite kunnen hebben met het begrip van veelvoudige vragen en taken dan gedacht.

Hoofdstuk 7 gaat verder met het onderzoek naar complex taalbegrip dat in hoofdstuk 6 beschreven werd. Dit hoofdstuk beschrijft de resultaten van een veel groter crosssectioneel onderzoek waarin het begrip van complexe zinnen onderzocht werd in 361 kinderen uit groep 2, 4, 6 en 8 van het reguliere basisonderwijs en klas 1 en 2 van het regulier voortgezet onderwijs. Taalbegrip werd weer gemeten met de neuropsychologische aanpak van Luria en daarnaast met een aangepaste versie van de Tokentest (Lezak, Howieson, \& Loring, 2004). Interindividuele verschillen in de ontwikkeling van complex taalbegrip werden ook onderzocht, namelijk geslachtsverschillen en de invloed van het opleidingsniveau van de ouders. Daarnaast werd er gecontroleerd voor woordenschat en korte termijn geheugen in de analyses.

Niet alle kinderen in de tweede klas van het voortgezet onderwijs begrepen de meest complexe zinnen: zij antwoorden $87 \%-94 \%$ van de zinnen correct. Dat wil zeggen dat sommige zinnen te moeilijk waren voor veel 14 -jarigen. De nauwkeurigheid van het complex taalbegrip verbeterde tot in groep 8 , terwijl de snelheid waarmee de complexe zinnen begrepen werden verbeterde tot in de brugklas. Er kan dus geconcludeerd worden dat complex taalbegrip van kinderen pas volledig ontwikkeld is in de vroege adolescentie, wat aansluit bij de bevindingen van hoofdstuk 6 . Verder lijkt het erop dat snelheid van complex taalbegrip gevoeliger is om ontwikkelingsverschillen aan te tonen dan nauwkeurigheid.

Met betrekking tot de invloed van interindividuele verschillen in de ontwikkeling van complex taalbegrip werd het volgende gevonden: meisjes presteerden sneller dan, maar even nauwkeurig als jongens op een van de gebruikte taken. Het opleidingsniveau van de ouders correleerde positief met de nauwkeurigheid op een van de twee taken: kinderen met hoog opgeleide ouders presteerden nauwkeuriger dan kinderen met laag tot gemiddeld opgeleide ouders. Ook het niveau van korte termijn geheugen was geassocieerd met complex taalbegrip: kinderen met een grotere geheugenspanne begrepen de complexe zinnen sneller, maar niet nauwkeuriger dan kinderen met een kleinere geheugenspanne.

Hoofdstuk 8 gaat verder met het onderzoek naar interindividuele verschillen in de ontwikkeling van complex taalbegrip. Dit hoofdstuk gaat over de invloed van aandacht op complex taalbegrip, door de prestatie van kinderen en adolescenten met een Aandachtstekortstoornis met Hyperactiviteit van het gecombineerde type (ADHD-C) te vergelijken met die van normaal ontwikkelende kinderen. De verwachting was dat complex taalbegrip verstoord zou zijn in ADHD-C, omdat taal gerelateerd is aan zelfcontrole, en zelfcontrole afwijkend is in ADHD-C (Andreou, Agapitou, \& Karapetsas, 2005; Barkley, 1997). De tweede doelstelling van de studie was de leeftijdsverschillen in complex taalbegrip in ADHD-C te onderzoeken (Biederman et al., 2006). 
Er deden 15 kinderen van elf jaar of jonger en 15 adolescenten van twaalf jaar of ouder met ADHD-C mee aan de studie. Deze kinderen werden één op één gematched aan zich normaal ontwikkelende kinderen, waarbij werd gelet op leeftijd, geslacht en opleidingsniveau van de ouders. Voor het niveau van korte termijn geheugen en woordenschat werd gecontroleerd in de analyses. De nauwkeurigheid en snelheid van taalbegrip werden onderzocht met dezelfde maten als in hoofdstuk 7 .

De resultaten geven aan dat kinderen en adolescenten met ADHD-C significant langzamer presteerden op de taken voor complex taalbegrip dan kinderen in de controlegroep. Nauwkeurigheid was echter nauwelijks lager dan in de controlegroep. Er was geen interactie tussen leeftijd en ADHD-C, wat aangeeft dat het snelheidsprobleem van complex taalbegrip niet afhankelijk is van leeftijd. Deze bevinding is belangrijk voor ouders, leerkrachten, en gezondheidszorgspecialisten die omgaan met kinderen met ADHD-C. Zij zouden er alert op moeten zijn dat taalbegrip van kinderen met ADHD-C op een trager tempo verloopt dan normaal en hiermee rekening moeten houden.

Hoofdstuk 9 combineert de bevindingen van de experimentele studies die beschreven zijn in dit proefschrift en bediscussieert deze op theoretisch vlak. Zoals verwacht hebben de studies een patroon van differentiële cognitieve ontwikkeling over de kindertijd laten zien. Er werden grote ontwikkelingsverschillen gevonden met betrekking tot de verschillende bestudeerde cognitieve functies en hun subcomponenten. Volledige ontwikkeling van deze functies werd ergens tussen groep 4 van het basisonderwijs en de eerste klas van het voortgezet onderwijs bereikt, afhankelijk van de specifieke functie. De theoretische implicaties van deze bevindingen worden in hoofdstuk 9 besproken in relatie tot het model van Peter Anderson (2002) over executief functioneren. De ontwikkelingspatronen die gevonden werden in dit proefschrift worden in het model van Anderson geplaatst, zodat een compleet overzicht te zien is.

Met betrekking tot de interindividuele verschillen in cognitieve ontwikkeling werd gevonden dat aandacht een belangrijke factor is. Dit impliceert dat het functioneren van de aandacht en concentratie van normaal ontwikkelende kinderen meer belangstelling zou moeten krijgen van wetenschappers en onderwijskundig personeel. Daarnaast benadrukken de resultaten van de studies die in dit proefschrift beschreven worden ook de noodzaak voor het ontwikkelen van betere behandelingsmogelijkheden voor kinderen met aandachtsstoornissen. Deze behandeling zou zich moeten richten op het verbeteren van specifieke aspecten van cognitie, zoals complex taalbegrip.

De andere interindividuele verschillen die in dit proefschrift werden onderzocht, namelijk geslacht en opleidingsniveau van de ouders, toonden een minder consistente invloed op de cognitieve ontwikkeling. Als er een invloed van geslacht werd gevonden, dan presteerden meisjes beter dan jongens. Dit effect werd vooral gevonden op taken met een talige component. Kinderen uit hoog opgeleide gezinnen leken beter te presteren dan kinderen met lage of gemiddeld opgeleide ouders op enkele van de cognitieve functies die hier bestudeerd werden. Al met al heeft het onderzoek dat in dit proefschrift wordt beschreven aangetoond dat cognitieve ontwikkeling doorgaat tot in de vroege adolescentie en dat hierin specifieke interindividuele verschillen bestaan. 


\section{Referenties}

Achenbach, T. M. (1991). Manual for the Child Behavior Checklist/4-18 and 1991 Profile. Burlington: University of Vermont Department of Psychiatry.

Anderson, P. (2002). Assessment and development of executive function (EF) during childhood. Child Neuropsychology, 8, 71-82

Andreou, G., Agapitou, P., \& Karapetsas, A. (2005). Verbal skills in children with ADHD. European Journal of Special Needs Education, 20, 231-238.

Barkley, R. A. (1997). Behavioral inhibition, sustained attention, and executive functions: constructing a unifying theory of ADHD. Psychological Bulletin, 121, 65-94.

Biederman, J., Monuteaux, M. C., Mick, E., Spencer, T., Wilens, T. E., Silva, J. M., Snyder, L. E., \& Faraone, S. V. (2006). Young adult outcome of attention deficit hyperactivity disorder: a controlled 10-year follow-up study. Psychological Medicine, 36, 167-179.

Brickenkamp, R., \& Zillmer, E. (1998). The d2 Test of attention. First US Edition. Göttingen: Hogrefe \& Huber Publishers.

Christensen, A-L. (1993). Luria's neuropsychological investigation text. Risskov, Denmark: P. J. Schmidts Bogtrykkeri, Vojens.

Durlak, J. (2001). School problems in children. In: M. C. Roberts (Ed.), Handbook of clinical child psychology (3rd ed.). New York: John Wiley \& Sons, Inc.

Lezak, M. D., Howieson, D. B., \& Loring, D. W. (2004). Neuropsychological assessment (4th ed.). New York: Oxford University press.

Luria, A. R. (1966). Higher cortical functions in man. New York: Basic Books

Luria, A. R. (1980). Higher cortical functions in man. New York: Basic Books. 
DANKWOORD 


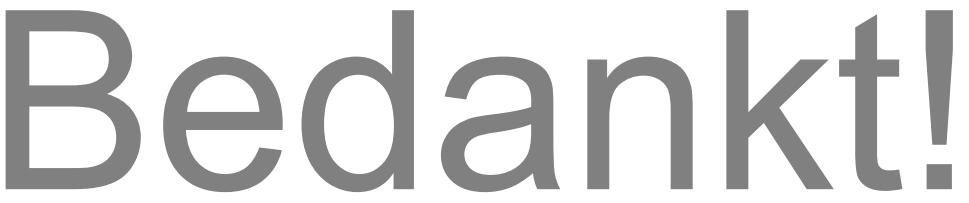




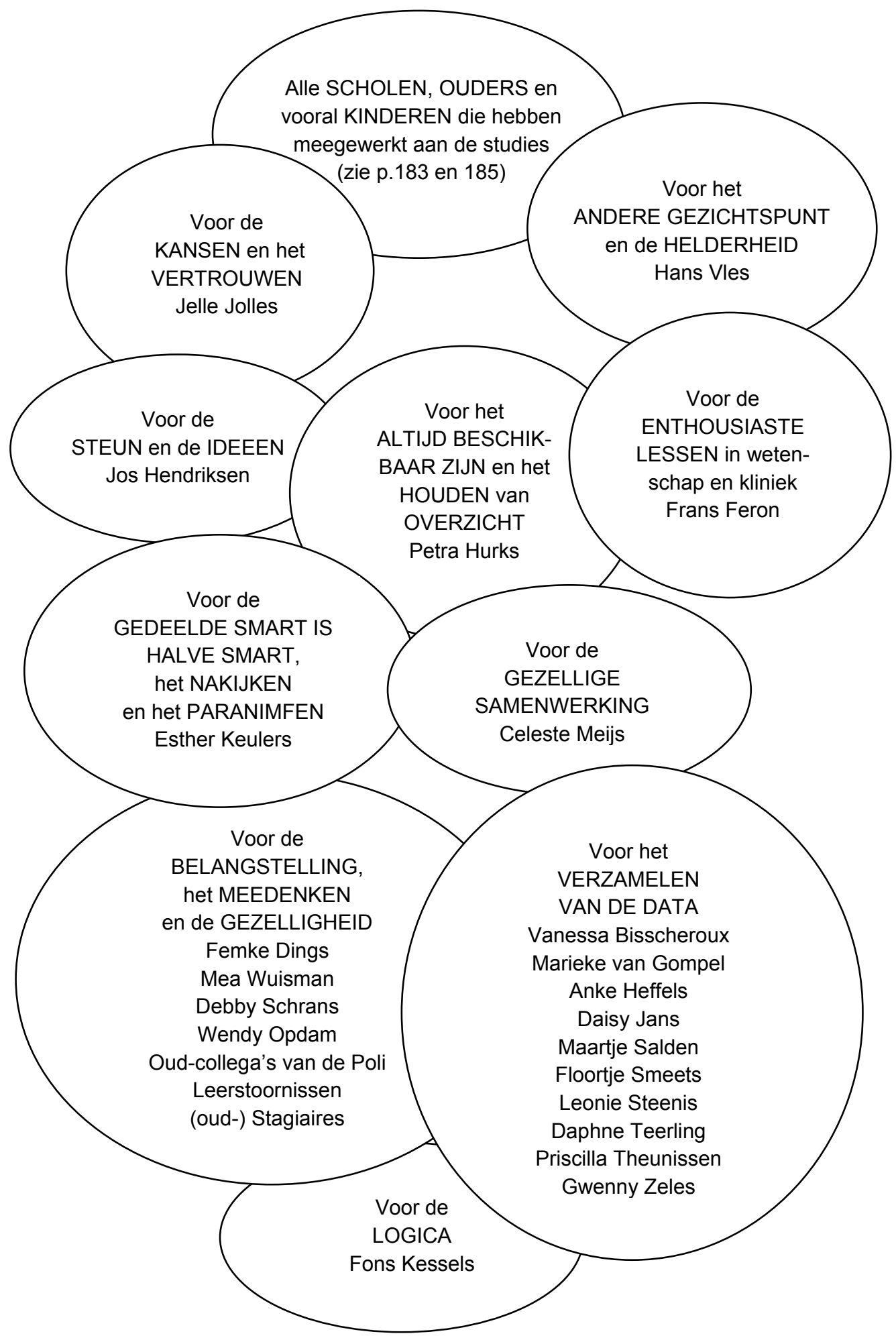




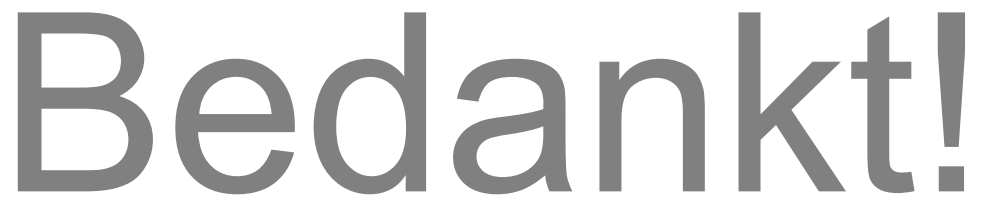




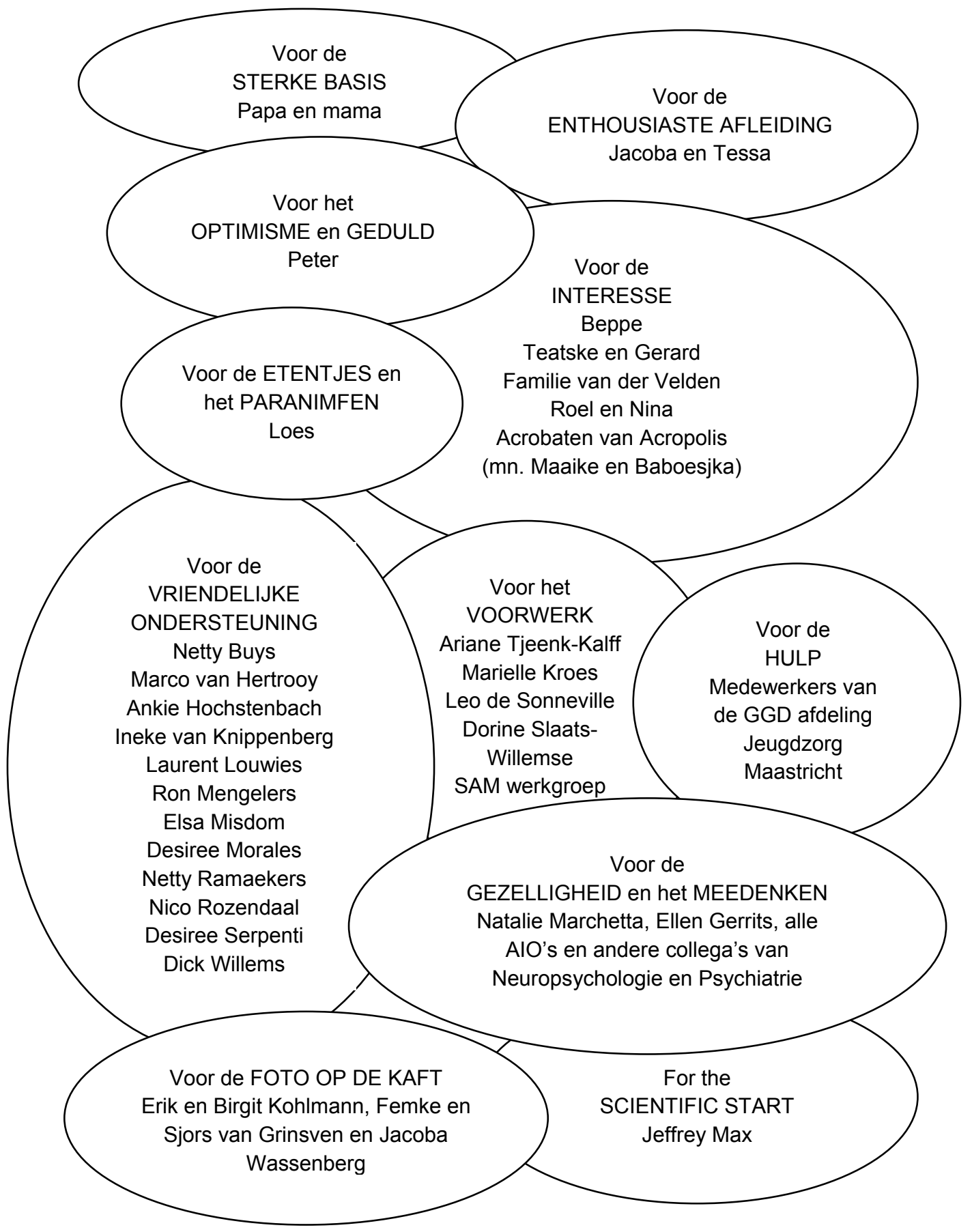




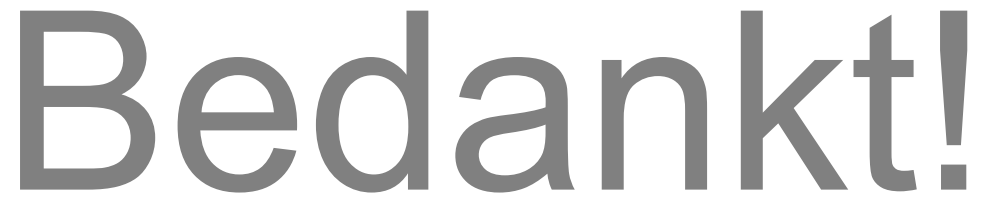




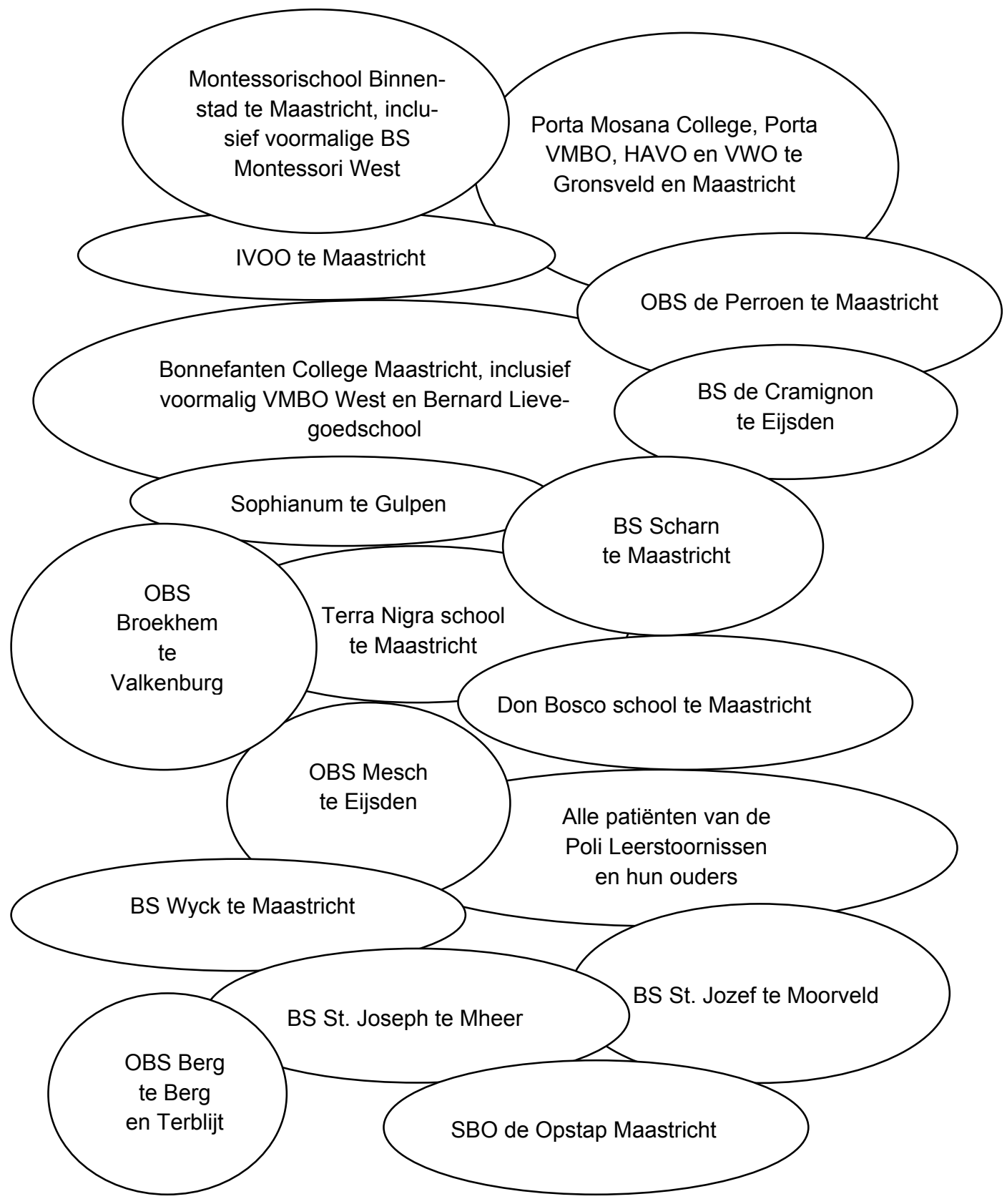




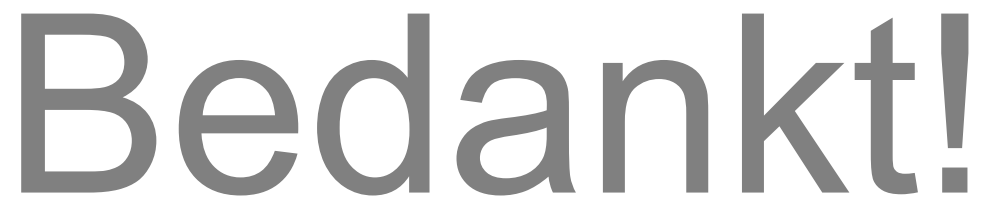




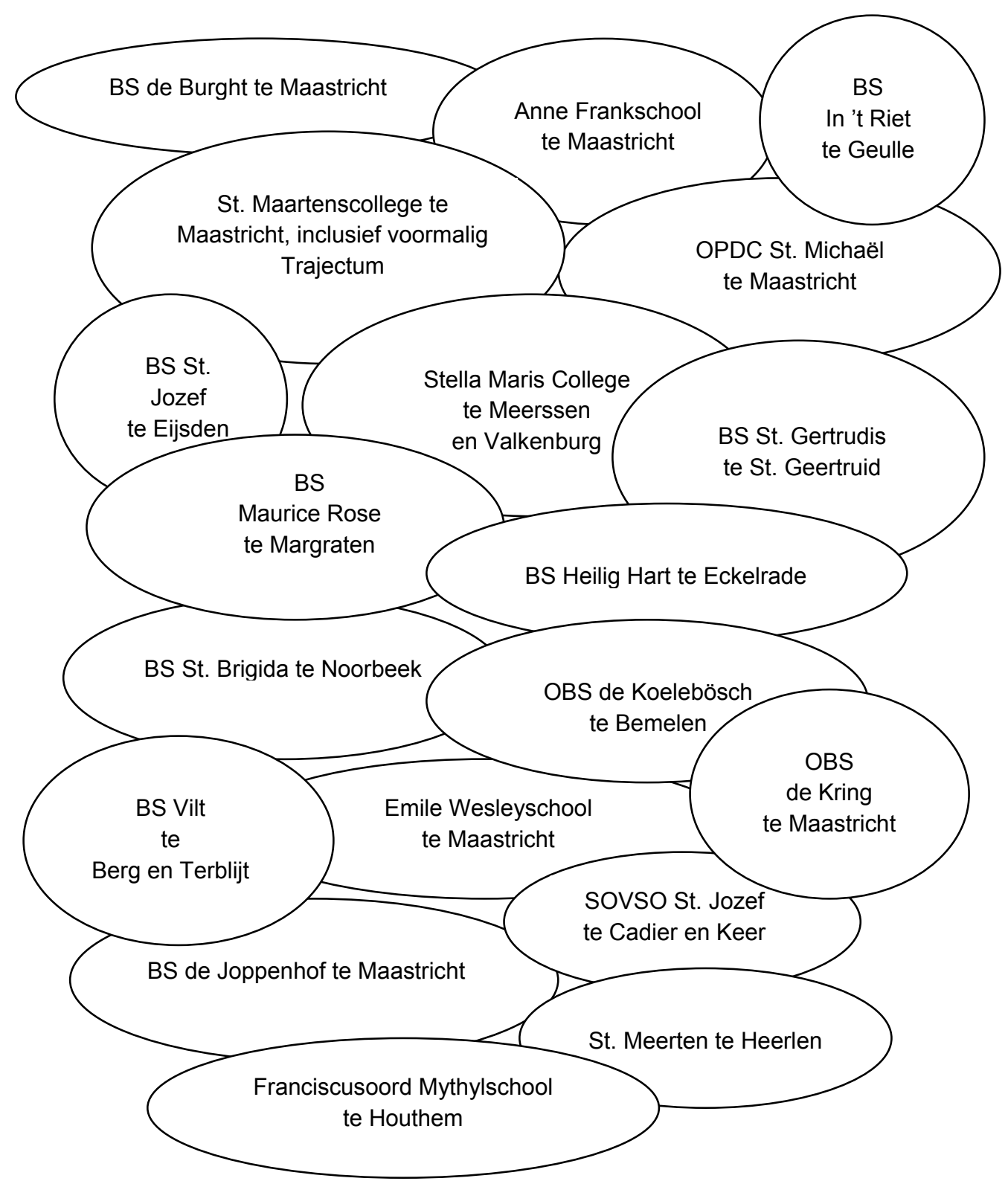





\section{CURRICULUM VITAE}

Renske Wassenberg werd op 19 november 1979 geboren te Veghel. Na het behalen van haar VWO diploma aan het Kruisheren Kollege te Uden ging zij in 1998 Psychologie studeren aan de Universiteit Maastricht met als afstudeerrichting biologische psychologie en als keuzevak neuropsychologie. Na een wetenschappelijke stage aan de Universiteit van San Diego (UCSD) in de Verenigde Staten van Amerika en een klinische stage in kinderrevalidatiecentrum Franciscusoord te Houthem, behaalde zij in september 2002 cum laude haar diploma. In oktober 2002 werd zij als psychodiagnostisch werker aangesteld bij de Poli Leerstoornissen van het Academisch Ziekenhuis Maastricht. Deze aanstelling ging over in een promotietraject en in januari 2004 werd haar contract overgenomen door de Universiteit Maastricht, vakgroep Psychiatrie en Neuropsychologie. $\mathrm{Na}$ het afronden van haar onderzoek, dat beschreven staat in dit proefschrift, begon zij op 1 januari 2007 met de opleiding tot gezondheidszorgpsycholoog op de afdeling Psychiatrie en Neuropsychologie van het Academisch Ziekenhuis Maastricht. 



\section{PUBLICATIONS}

Wassenberg, R., Max, J. E., Koele, S. L., \& Firme, K. (2004). Classifying psychiatric disorders after traumatic brain injury and orthopaedic injury in children: adequacy of KSADS versus CBCL. Brain Injury, 18, 377-390.

Wassenberg, R., Max, J. E., Lindgren, S. D., \& Schatz, A. (2004). Sustained attention in children and adolescents after traumatic brain injury: relation to severity of injury, adaptive functioning, ADHD and social background. Brain Injury, 18, 751-764.

Wassenberg, R., Feron, F. J., Kessels, A. G., Hendriksen, J. G., Kalff, A. C., Kroes, M., Hurks, P. P., Beeren, M., Jolles, J., \& Vles, J. S. (2005). Relation between cognitive and motor performance in 5- to 6-year-old children: results from a large-scale cross-sectional study. Child Development, 76, 1092-1103. [Chapter 2 of this dissertation]

Keulers, E. H. H., Hendriksen, J. G. M., Feron, F. J. M., Wassenberg, R., WuismanFrerker, M. G. F., Jolles, J., \& Vles, J. S. H. (2007). Methylphenidate improves reading performance in children with attention deficit hyperactivity disorder and comorbid dyslexia: An unblinded clinical trial. European Journal of Paediatric Neurology, 11, 21-28.

Wassenberg, R., Hendriksen, J. G. M., Hurks, P. P. M., Feron, F. J. M., Keulers, E. H. H., Vles, J. S. H., \& Jolles, J. Development of inattention, impulsivity, and processing speed as measured by the d2 Test: Results of a large cross-sectional study in children aged 7-13. Child Neuropsychology, in press. [Chapter 3 of this dissertation]

Hendriksen, J. G. M., Keulers, E. H. H., Feron, F. J. M., Wassenberg, R., Jolles, J., \& Vles, J. S. H. Subtypes of learning disabilities: neuropsychological and behavioural functioning of 495 children referred for multidisciplinary assessment. European Child and Adolescent Psychiatry, in press.

Keulers, E. H. H., Hendriksen, J. G. M., Feron, F. J. M., Wassenberg, R., Boschma, L., Dings, F., Jolles, J., \& Vles, J. S. H. Non-verbale leerstoornissen: spectrum of één syndroom? Submitted for publication.

Wassenberg, R., Hendriksen, J. G. M., Hurks, P. P. M., Feron, F. J. M., Keulers, E. H. H., Vles, J. S. H., \& Jolles, J. Development of different aspects of sense of time: Results of a cross-sectional study. Submitted for publication. [Chapter 5 of this dissertation]

Wassenberg, R., Hendriksen, J. G. M., Hurks, P. P. M., Feron, F. J. M., Vles, J. S. H., \& Jolles, J. Comprehension of complex sentences in children and adolescents with ADHD. Submitted for publication. [Chapter 8 of this dissertation]

Wassenberg, R., Hurks, P. P. M., Hendriksen, J. G. M., Feron, F. J. M., Kessels, A. G. H., Vles, J. S. H., \& Jolles, J. Attention in kindergarten and the first grade predicts academic outcome in the sixth grade. Submitted for publication. [Chapter 4 of this dissertation] 
Wassenberg, R., Hurks, P. P. M., Hendriksen, J. G. M., Feron, F. J. M., Meijs, C. J. C., Vles, J. S. H., \& Jolles, J. Age-related improvement in complex language comprehension: Results of a cross-sectional study with 361 children aged 5 to 15 . Submitted for publication. [Chapter 7 of this dissertation]

Wassenberg, R., Hurks, P. P. M., Hendriksen, J. G. M., Kalff, A. C., Slaats-Willemse, D. I. E., Feron, F. J. M., Vles, J. S. H., \& Jolles, J. Comprehension of logical grammatical structures in school aged children. Submitted for publication. [Chapter 6 of this dissertation] 

